


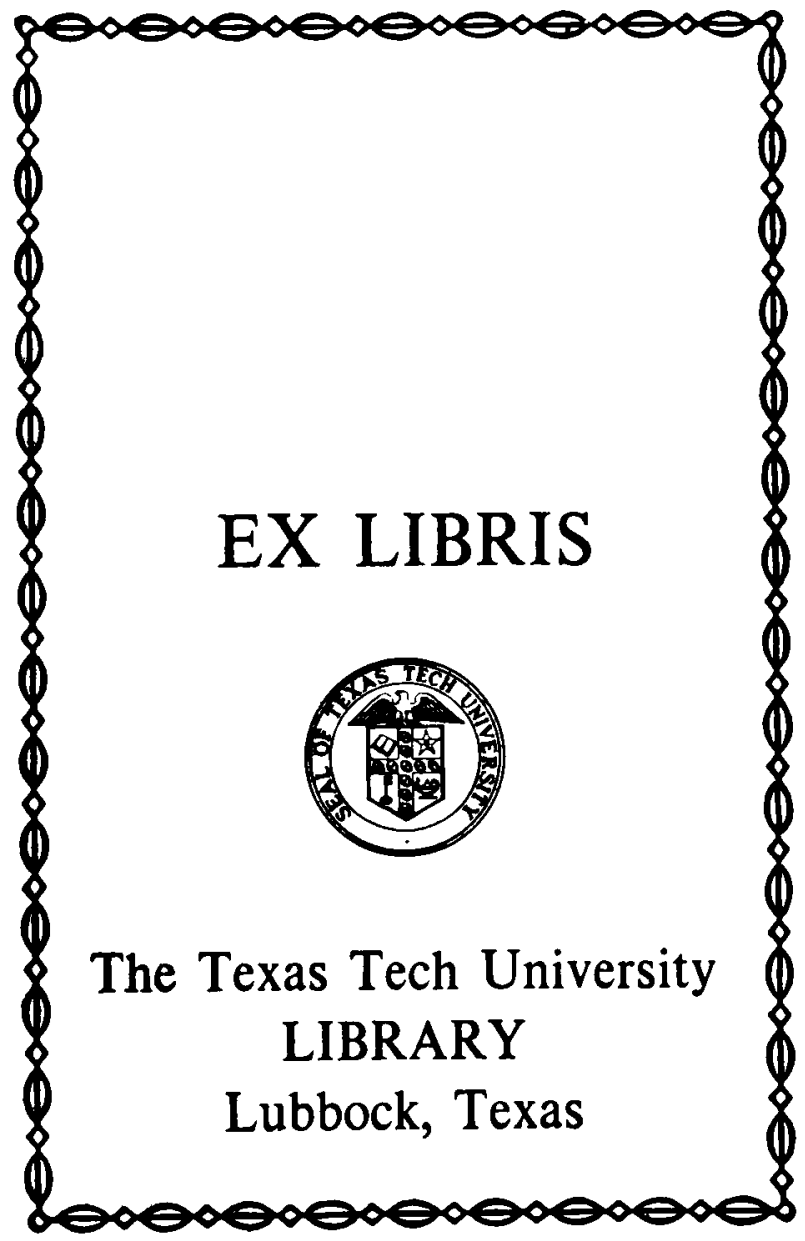






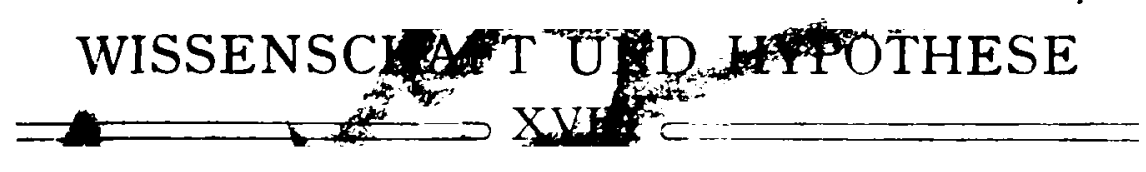

\section{PROBLFME DER}

\section{SOZIALPHILOSOPHIE}

VON

ROBERT MICHELS

ฉृ

LEIPZIG UND BERLIN

DRUCK UND VERLAG VON B. G. TEUBNER

I 9 I 4 
COPYRIGHT I9I3 BY B. G. TEUBNER IN LEIPZIG 
MEINEM LIEBEN SCHWIEGERVATER THEODOR LINDNER DEM GESCHICHTSPHILOSOPHEN 



\section{VORWORT}

In diesem Bande habe ich versucht, einige Fragen zu erörtern, die im Mittelpunkt der Sozialphilosophie stehen.

Ich bin der erste zu erklären, daB ich keines der hier angeschnittenen Probleme erschöpft habe. Zu erschöpfender Behandlung hätte ich jedem einzelnen von ihnen einige Bände widmen müssen. Das lag nicht in meiner Absicht. Diese ist weit bescheidener. Mir kam es lediglich darauf an, zu zeigen, daß trotz der wahren Bibliothek von Folianten, die von gelehrter wie von ungelehrter Hand über die von mir hier behandelten Fragen geschrieben wurden, immer noch Probleme vorliegen. Ich bilde mir ein, neben manchem Bekannteren, das ich gab, eine Reihe von sachlich neuen Streiflichtern geworfen zu haben. Nicht mehr und nicht weniger. Es ist Sache meiner Leser und meiner Kritiker, zu entscheiden, ob und inwieweit diese Einbildung der Wahrheit entspricht.

Turin Sommer r9i3. 


\section{INHALT}

Seite Vorwort . . . . . . . . . . . . . . . . . V

Erstes Kapitel: Zum Problem der Kooperation. . . . I Zweites " Zum Problem der Eugenetik. . . . . . 44 Drittes " Zum Problem: Solidarität und Kastenwesen • • • • • • • • • 53

Viertes " Zum Problem des Fortschritts... . . 63

Fünftes " Zum Problem der Messung der Sittlichkeit 85

Sechstes " Zum Problem der Koketterie . . . . 94

Siebentes " Zum Problem der Behandlung des Proletariats in der Wissenschaft .98

Achtes " Zum Problem der zeitlichen Widerstands. fähigkeit des Adels . . . . 132

Neuntes " Zum Problem der internationalen Bourgeoisie. . . . . . 158

Zehntes " Zum Problem: Wirtschaft und Politik . I88 Namenverzeichnis . . . . . . . . . . . . . . 205 


\section{Erstes Kapitel. \\ Zum Problem der Kooperation.}

Um die dem Homo oeconomicus immanente Tendenz zur Kooperation zu begreifen, ist es unerläßlicheVorbedingung, das Wesen der generellen Aspiration des Menschen in der isolierten Ökonomie erfaßt zu haben. Das Fundament der Ökonomie besteht in den leiblichen oder aus der Leiblichkeit abgeleiteten Bedürfnissen des Menschen. Dem Körper, d. h. der physischen Existenz des Individuums, ist eine Reihe von Notwendigkeiten zu eigen, die nach Befriedigung verlangen. Nur die klare Erkenntnis von demWesen dieser Bedürfnisse vermag dem Menschen die Möglichkeit an die Hand zu geben, sein Leben vernünftig zu regeln und einzurichten. Deshalb kann man sagen, daß sich die Bedürfnisse des Menschen zur Volkswirtschaft wie die Gesundheit des Menschen zur Heilkundeverhalten; wie die Aufgabe desArztes in der möglichsten Erhaltung des Lebens, so besteht die Aufgabe der $\mathrm{Na}$ tionalökonomie als der Lehre von der Produktion in der möglichsten Befriedigung der menschheitlichen Bedürfnisse. Denn der Mensch arbeitet nicht so sehr zum Zweck der Gütererzeugung, sondern er wird vornehmlich deshalb zur Arbeit angetrieben und läßt sie über sich ergehen - denn die Arbeit verliert ihren initialen Schmerzcharakter nie vollständig! -, weil er nur durch sie einem noch intensiveren Schmerzgefühl, das durch das Unbefriedigtlassen seiner Bedürfnisse entstehen müßte, wobei es wenig darauf ankommt, ob diese Bedürfnisse realer oder imaginärer Natur sind, ob sie sich auf sein ökonomisch-soziales Wohlergehen beziehen oder sein 
geistiges und moralisches Sein betreffen, zu entgehen hofft. Das ganze Tun und Lassen des Homo oeconomicus läBt sich messen an dem Kriterium, das in der Frage eingeschlossen liegt: wie kann mit dem geringstmöglichen Kraftaufwand, oder anders ausgedrückt der geringstmöglichen Summe von Unlustgefühlen, der größtmögliche Nutzen erzielt werden?

Indes diejenigen menschlichen Bedürfnisse, welche in der nationalökonomischen Wissenschaft mit einem vielleicht nicht immer klaren und einwandfreien Terminus Kollektivbedürfnisse benannt werden, können von dem Einzelindividuum nur mit Hilfe einer Summe von unerhörten Mühen und Anstrengungen befriedigt werden. Ihre Befriedigung erfordert also die Übereinkunft, Zustimmung und gegenseitige Hilfeleistung einer Reihe von Gliedern der Gesellschaft. Wir dürfen deshalb behaupten, daß das Prinzip der Kooperation aus dem Gesetz des geringsten Kraftaufwands entstanden ist.

$\mathrm{Zu}$ Beginn der modernen Ära waren alle sozialen Beziehungen von starrem kooperativistischen Geiste beseelt. Das mittelalterliche Städtewesen wie der Inhalt des Staatswesens im 16. und 17. Jahrhundert baute sich auf dem Prinzip einer koerzitiven Kooperation auf. Die zu Zünften zusammengeschlossenen Handwerke auf der einen, die Stiftungen und Einrichtungen der katholischen Kirche auf der anderen Seite stellen nur verschiedene Formen ein und desselben kooperativen Grundgedankens dar. Das ganze wirtschaftliche und soziale Leben war durch Tausende von Satzungen geregelt, geordnet, mit scharfen Grenzen umgeben, kontrolliert und gehütet, so daß es dem oberflächlichen Beobachter wohl scheinen mochte, als ob alle jene der Laune unterworfenen Triebfedern des heutigen Wirtschaftslebens damals - und zwar ganz besonders zu den Zeiten des Höhepunkts jener Entwicklung, im Zeitalter Colberts - dem hohen Willen der Staatsgewalt untertan gewesen seien. Schien es ihr doch mit Hilfe der sogenannten merkantilistischen Methode gelungen 
zu sein - man gestatte uns diesen Vergleich —, jene beiden Straßenjungen, die mit ihren nicht vorherzusehenden und unvorhergesehenen Dummenjungenstreichen der modernen Volkswirtschaft soviel Kopfzerbrechen verursachen, nämlich die beiden Faktoren "Angebot" und „Nachfrage“, im Zaume zu halten. Allerdings trug die Kooperation in jenem Zeitraum ausgesprochen obligatorischen Charakter. Nur für die fernen Kolonien, in welchen der noch nicht zu Besitzstand gewordene Boden sich der gebundenen Ökonomie des Mutterlandes entzog, vermochte der freie Impuls der genossenschaftlichen Tätigkeit unserer Tage bisweilen vorgeahnt zu werden. So regte es zum Beispiel Vauban an, daß die Untertanen des Roi Soleil in Kanada genossenschaftliche Unterstützungsvereine zum gemeinschaftlichen Einkauf und Transport von Baumaterialien und anderen Rohstoffen, ,pour voiturer les pierres et les matériaux “, gründen sollten. ${ }^{1}$ )

Als aber zugleich mit der politischen Freiheit und dem Anbruch einer sich auf die Grundprinzipien der Demokratie berufenden Ära sich auch die ökonomische Freiheit, die Gewerbefreiheit, durchsetzte, da fanden die mittelalterlichen und absolutistischen Formen der Kooperation ihren Untergang, um einer sozialen Ordnung Platz zu machen. Diese wies mehr als einen Berührungspunkt mit der uns von Ciccotti beschriebenen Wirtschaft des römischen Altertums auf, da sie die beiden anscheinend einander entgegengesetzten Prinzipien der Statolatrie und des Individualismus, beide in gleich hoher Potenz, in sich vereinigte; die Statolatrie bezüglich des öffentlichen Rechtes, soweit die Altion und die Verteidigung des Staates in Kraft trat; den Individualismus, in seiner Absolutheit aufgefaßt und in Wirksamkeit gesetzt auf dem Gebiete des Privatrechtes, indem nunmehr der Staat die Aufgaben der Gütererzeugung der nicht nur spontanen,

I) Ferdinand Dreyfus, „Vauban Economiste“. Paris 1872. Ancienne Maison Quantin, p. 47. 
sondern vom Ganzen völlig losgelösten und isolierten Tätig. keit des Individuums oder der Familie überließ, ohne je in irgendwelcher Weise in diese Sphäre einzudringen oder sie außer in unvermeidlichen Fällen, wenn es sich nämlich um die Unternehmung und Sicherstellung einer gemeinsamen Handlung zur Erzielung eines offensichtlich gemeinsamenVorteils handelte, auch nur einzuschränken. ${ }^{1}$ )

Hand in Hand mit dieser demokratischen Entwicklung und vielfach sie bedingend, bisweilen allerdings auch ihr vorauseilend, ging die Entwicklung in der Wirtschaft selbst. Die Revolutionierung in der Technik der Produktion, die wir dem Erfindungsgenie einzelner verdanken, verursachte eine Revolution in der Produktion selbst und folglich in den Beziehungen zwischen Mensch und Mensch. Die feudalen patriarchalischen und idyllischen Verhältnisse fielen jäher Zerstörung anheim. Die wirtschaftlichen und gesellschaftlichen Bande, die den Menschen an seine ererbten Vorgesetzten knüpften, zerrissen in Fetzen. Die rostzerfressenen Ketten der alten Kooperation barsten, und als einziges Bindeglied, welches die große Umwandlung aller Gewohnheiten und sozialen Verhältnisse überlebte, blieb das nackte und trockene persönliche Interesse der auf sich selbst gestellten Erwerbs. menschen übrig. Die enge Berufsvereinigung des Mittelalters, die Gilde, diese primitive Form der Kooperation, verfiel nach und nach vollkommener Auflösung. Sie beruhte auf einer Zweiteilung, die weit davon entfernt war, rein ökonomischen Charakter zu tragen und zwei scharf abgegrenzte ökonomische Kategorien Produzenten zu schaffen, sondern vielmehr überwiegend praktisch-technischen Erfordernissen der Produktion sowie den Bedürfnissen der Arbeitsteilung nach Maßgabe der Altersgrade entsprach. In der Gilde standen sich die derselben gewerblichen Organisation angehörigen Klas-

I) Cfr. Ettore Ciccotti, „Tratti caratteristici dell' Economis antica“. Biblioteca di Storia Economica, Milano 1905. Vol. II, p. XIX. 
sen, die Meister und Gesellen, in vollkommener Kameradschaftlichkeit, etwa wie der, welche heute die Avantageure und jüngeren Offiziere ein und desselben Offizierkorps mit ihren Stabsoffizieren verbindet, weil die einen heute befehlen und die anderen morgen befehlen werden, gegenüber. Nun wurden die Gesellen zu Lohnarbeitern und verloren, zugleich mit der allmählichen Verdrängung der Kleinindustrie durch die Großindustrie und der Einführung kostspieliger, mit Dampf und später mit Elektrizität betriebener Maschinen, welche die Arbeit in immer wachsendem Maße von den Besitzern dieser Werkzeuge abhängig machte, mehr und mehr auch den letzten Rest von Hoffnung, sich mit der Zeit zur Würde eines Unternehmers aufzuschwingen und aus Arbeitnehmern in Arbeitgeber verwandeln zu können. ${ }^{1}$ ) Den Thron der verjagten Kooperation jedoch bestieg, die Brust geschwellt von spekulativer Kühnheit, aber auch von unbändigem Egoismus, der oft selbst die Form berechnendster Grausamkeit annahm, die private Initiative.

Diese neuen wirtschaftlichen und sozialen Bedingungen riefen zunächst einen ungeheuren Aufschwung der wirtschaftlichen Produktion, die sich endlich aus der Engigkeit des ihr aufgezwungenen Schutzes der Kollektivität befreit sah, hervor und hatten die nunmehr ungehemmte Ausbreitung jenes Komplexes wirtschaftlicher und intellektueller Güter, den wir europäische Zivilisation nennen, über alle Meere und alle Kontinente zurunmittelbaren Folge. Da die maschinelle Technik aber ein Anwachsen der Produktion bis zur Überproduktion, die ein nicht unbeträchtliches Sinken des Konsums zur Begleiterscheinung hatte ${ }^{2}$, mit sich brachte, wurde sie auch

1) Diese Tendenz übt auch heute noch ihre Wirkung aus. Man vergleiche hierüber mein Buch: „Saggi economici sulle Classi Popolari Moderne". Palermo I9I3. Sandron, p. 9i ff.

2) Louis Blanc, "Organisation du Travail“. $4^{\circ}$ édition considérablement augmentée, précédée d'une introduction et suivie d'un compte-rendu de la maison Leclaire. Paris 1845. Cauville Frères, p. 61. 
zur Urheberin einer langen Reihe traurigster Folgeerscheinungen, die besonders die Riesenphalanx jener Erwerbsmenschen trafen, die, um sich in dem angebrochenen zügellosen und unbarmherzigen Konkurrenzkampf aller gegen alle, in den sie sich hineingerissen sahen und der als das charakteristischste Kennzeichen der ersten Periode der jungen kapitalistischen Ära angesehen werden darf, zu behaupten, keine anderen wirtschaftlichen Waffen zu ihrer Verfügung hatten als die Kraft ihrer Arme. So entstand denn jenes äußerste Elend der handarbeitenden Klassen, welches der Geschichte jener Jahre die Signatur gibt und von dem uns die Nationalökonomen aller Schulen und aller sich zum Weltkapitalismus entwickelnden Länder mit überzeugender Beredsamkeit zu berichten wissen. ${ }^{1}$ ) Die Abschaffung der alten Gilden mit ihren, wenn auch schwerfälligen, Schutzbestimmungen wurde auf diese Weise zurSchädigung derInteressen derselben, welche sich für die Abschaffung mit soviel Eifer ins Zeug gelegt hatten.

I) Anbei einige der wichtigsten Bücher, welche dieses Thema behandeln. Über die Entwicklung in England: J. Ch. L. Sim.onde de Sismondi, ,Nouveaux Principes d'Economie politique ou de la Richesse dans ses Rapports avec la Population". Paris I819, $2^{\circ}$ edit. I827. Delaunay, vol. II, libre VII; und „Études sur les Sciences sociales". 3 vol., Paris I836-38. - Friedrich Engels, "Lage der arbeitenden Klassen in England". London I845. - Karl Marx, „Das Kapital“. Vol. I, I. Aufl., 1867. - Alexandre Auguste Ledru-Rollin, „De la Décadence de l'Angleterre“. Vol. II, Paris I 850. Escudier Frères. - H. M. Hyndman, "The Historical Basis of Socialism". London I883. Kegan Paul, Trench and Co., p. 362. Über die Entwicklung in England und Frankreich: Eugène Buret, "De la Misère des Classes laborieuses en Angleterre et en France". $2^{\circ}$ edit,, Bruxelles 1845 . Über die Entwicklung in Frankreich allein: Louis René Villermé, ,Tableau de l'État physique et moral des Ouvriers employés dans les Manufactures de Coton, de Laine et de Soie“. 2 vol., Paris 1838. - N. Villia u mé, „Nouveau Traité d'Économie politique“. Paris I866, p. 64 ss. - Tallon, „La Vie morale des Ouvriers“. - Boyer, "De l'État des Ouvriers et de son Amélioration par l'Organisation du Travail“. $2^{\circ}$ edit. I84I. Charles Fourier, "De l'Anarchie industrielle et scientifique". Paris 
DerArbeiter, isoliert,von niemandem beschützt,ein widerstandsloses Spielzeug aller soeben durch die uferlose Gewerbefreiheit losgelassenen wirtschaftlichen Leidenschaften, wurde zum Opfer der technischen Fortschritte der Produktionswerkzeuge. Jeder neuen Erfindung wohnte die Tendenz inne, den Marktpreis derWare Arbeitskraft unmittelbar zum Sinken zu bringen und eine weitere Zahl Arbeitender zu Arbeitslosen zu machen. So war es denn verständlich, daB damals in der Arbeiterschaft der schreckliche, von derVerzweiflung eingegebene Gedanke Platz greifen konnte, daß es, da der sogenannte freie Arbeitsvertrag sie dem Hungertod entgegenführe, immer noch besser für sie sei, leibliches Eigentum der Unternehmer zu werden. Denn nur wenn sie Sklaven seien, würden sich die Unternehmer verpflichtet sehen, in allen Wechselfällen des Lebens für ihren Unterhalt Sorge zu tragen, während sie als freie Menschen keinerlei Recht auf Hilfe hätten, weder seitens des Staates noch seitens der Industrie. ${ }^{1}$ ) Auf die Jugendzeit

1847. Librairie Phalanstérienne (s. p. I $8 \mathrm{ff}$. den Satz: "Voilà les fruits des systèmes d'industrialisme, bons pour enrichir la finance, le haut commerce, la grande propriété, et ne laisser au peuple que la faim et la nudité pour prix d'un travail de forçat, exercé souvent dans des ateliers où il est enfermé 18 heures par jour"). - Adolphe Jérôme Blanqui, „Les Classes ouvrières en France pendant l'Année 1848". Paris 1849 . Firmin Didot (Petits Traités publiées par l'Académie des Sciences morales et politiques). - Pierre Armand Dufau, „Essai sur la Science de la Misère sociale“. Paris 1857. Über die Entwicklung in Amerika: Robert Hunter, "Poverty". New York 1906. The Macmillan Company. - Austin Lewis, "The Rise of the American Proletarian". Chicago 1907. Charles H. Kerr and Co. - Ferner vergleiche man, für die neuere Zeit, die wertvolle ökonomisch-psychologische Monographie von Werner Som bart, „Das Proletariat". Bilder und Studien. Frankfurt a. M. 1906. Rütten und Löning.

I) „Mieux eût valu pour lui (le salariat) un complet esclavage; car le maître au moins nourrit, loge, vêtit son esclave, le soigne dans ses maladies, à cause de l'intérêt qu'il a de le conserver; mais celui qui n'appartient à personne, on s'en sert pendant qu'il y a 
der kapitalistischen Gesellschaftsordnung trifft die einmal von Camillo Supino gemachte Bemerkung zu, daß das Privateigentum die Ungleichheit zwischen den Menschen immer weiter fördert und deshalb die Angehörigen der nichts besitzenden Klassen zu Unfreien macht. ${ }^{1}$ )

Die wissenschaftliche Erkenntnis von der Existenz des von dem extremen Individualismus in der Wirtschaft herrüh. renden Elends der niederen Bevölkerungsklassen mußte natürlich uneigennützige Forscher, die es wie zu allen Zeiten auch in jener Wirtschaftsepoche gab, mit Macht zu sorgfältigen Untersuchungen über die Sachlage antreiben, um die geeignetsten Mittel und Wege ausfindig zu machen, den wirtschaftlich schwachen Teil der Erwerbsmenschen gegen den wirtschaftlich starken Teil zu schützen. In Frankreich setzte der Sozialphilosoph Saint Simon die ganze Schärfe seiner Kritik daran, die Völker auf die mangelhafte Organisation in ihrer Industrie und ihrerWissenschaft aufmerksam zu machen und glaubte für die Unordnung in der Ökonomie mit der Verkündung eines neuen sozialen Prinzips der Reorganisation ein wirksames Heilmittel gefunden zu haben. ${ }^{2}$ ) Der Sozialist Louis Blanc, dessen Lehren auf der Beobachtung fußten, daß die große Mehrzahl der Erwerbsmenschen in dem steten Kampf der kapitalistischen Konkurrenz um das tägliche Brot wegen ihrer wirtschaftlichen Armut schwach und hilflos zugrunde gingen, schlug, mitten in den Wirren der achtund-

quelque profit à en tirer, puis on le laisse la" (Félicité de La. mennais, „Le Livre du Peuple“. Paris I866. Bureaux de la Publication Bibliothèque Nationale, p. 17).

1) Camillo Supino, „Principii di Economia politica“. $2^{2}$ edizione, Napoli 1905. L. Pierro, p. 162.

2) Henri de Saint Simon, "Lettres d'un Habitant de Genève à ses Contemporains". Genève 1803 , und „Du Système industriel“, Paris I82I; sowie Abel Transon, "Saint Simon“, in „Recueil de Prédications. Religion Saint-Simonienne". Vol. I, p. 514. Paris 1832. Aux Bureaux du Globe. 
vierziger Jahre, die Bildung großer vom Staate fundierter Arbeits- und Produktivgenossenschaften für die Arbeiter vor, die er ateliers sociaux genannt haben wollte und von deren Erziehung zum Solidaritätsgefühl und rationellem System bewußter Zusammenarbeit er erwartete, daß sie allmählich die Konkurrenz der Privatbetriebe aus dem Felde schlagen und sie aufsaugen könnten. ${ }^{1}$ ) Der Katholik Lamennais bekämpfte mit dem feurigen Enthusiasmus eines Apostels die schädliche Einteilung der Gesellschaft in Klassen, weil, wie er ausrief, la Providence maudit les possessions solitaires, qui irritent sans cesse la convoitise et ne la satisfont jamais, und vermeinte, als Gegengewicht gegen den brutalen Egoismus der Einzelindividuen vermöge nur die Ausbreitung einer Gesellschaftslehre, der gemäB alle echten Christen durch Bande enger sozialer und ökonomischer Solidarität verbunden und verwandt seien, praktisch wirksam zu sein. ${ }^{2}$ )

In England erstand Robert Owen mit seinem genialen - wenn auch nicht originalen - Gedanken, die Arbeiter in Konsortien zu vereinigen, in denen die Konsozierten alle für das Leben nötigen Gegenstände gemeinsam produzieren und gemeinsam konsumieren könnten. ${ }^{3}$ ) Die berühmt gewordenen Equitable Pioneers von Rochdale erklärten, dazu veranlaßt durch die elenden Löhne, die ihnen als Fabrikarbeiter im Unternehmerdienst gezahlt wurden, als Konsumenten den Zwischenhändlern entschlossen den Krieg, und machten sich, mit bewundernswertem Verständnis für die praktischen Erfordernisse des Unternehmers und ungewöhnlicher rechneri-

I) Louis Blanc, ,Organisation du Travail“. Paris 1839 , und „Pages d'Histoire de la Révolution de Février 1848“. Bruxelles 1850. Soc. Typ. Belge, p. 331.

2) Félicité de Lamennais, "Le Livre du Peuple“, l. c. und „Paroles d'un Croyant", 1833. Neuausgabe der Bibliothèque Nationale, $186 \mathrm{r}$.

3) Robert Owen, ,Report to the Committee of the House of Commons on the Poor Law". London 1817 . 
scher Begabung, viribus unitis an die Errichtung eines Ladengeschäftes, um sich - auf direktem Wege, vom Produzenten, - die zum Leben notwendigsten Waren preiswerter zu verschaffen.1) Um die gleiche Zeit fanden sich immer wieder von neuem mutige Scharen Utopisten in allen Lebensaltern, die aus Europa auswanderten und die Urwälder Amerikas aufsuchten, in der Absicht, dort einen Boden zu gewinnen, auf dem sie ihre soziale Theorie durch die experimentelle Methode auf ihre Richtigkeit hin prüfen könnten, und zu diesem $Z$ wecke dort kleine kommunistische Gemeinden gründeten, mit denen sie den greifbaren Nachweis für die unschätzbaren Vorteile dieser neuen Gesellschaftsordnung zu erbringen hofften, und die dazu bestimmt waren, der allgemeinen Wiedergeburt des Menschengeschlechts als Vorbild zu dienen. ${ }^{2}$ )

Währenddessen feuerten die Deutschen Friedrich Engels und Karl Marx mit dem schicksalsschweren Rufe: „Proletarier aller Länder, vereinigt euch!“ die Arbeiterbataillone auf dem politischen Plan zur organisierten Klassenrevolte an. ${ }^{3}$ )

Gewiß, alle diese Versuche gingen von verschiedenartigen Gesichtspunkten aus und wurden zum Teil von auseinandergehenden Absichten geleitet, aber sie hatten doch alle zwei Leitgedanken von weittragendster Bedeutung gemeinsam: erstens die klare Einsicht in die Ohnmacht des Homo oeconomicus in der Isoliertheit, zumal insoweit er ohne Besitz-

I) George Jacob Holyoake, "History of Cooperation in Rochdale", 1858 . In alle Sprachen übersetzt und vielfach neu aufgelegt.

2) Etienne Cabet, „Voyages en Icarie“. Paris I 842. Wir erinnern hier auch an das interessante kommunistische Experiment in Italien (1887-88), welches in dem folgenden Werke beschrieben wird: Giovanni Rossi (Cardias), „Utopie und Experiment“. Zürich 1897. Sanftleben.

3) Karl Marx und Friedrich Engels, „Das kommunistische Manifest". Brüssel 1847. 6. deutsche Auflage Berlin 190r. Verl. Vorwärts. 
rechte an den Produktionsmitteln ist, sowie zweitens, als logische Folge des ersten Motivs, die Erkenntnis von der Notwendigkeit, in das soziale und ökonomische Leben der Menschen das Prinzip der Kooperation wiedereinzuführen.1] In der Tat sehen wir alsbald gerade in denjenigen Millionen umfassenden Volksklassen, die durch die Lösung der alten kooperativen Bande zu Spielbällen des Schicksals geworden waren, den anscheinend altfränkisch gewordenen Gedanken der Kooperation, den der aus der Revolution der Produktionstechnik geborene junge kapitalistischeSiegfried für immer beiseite geschoben $\mathrm{zu}$ haben geglaubt hatte, allüberall wieder lebendig werden. In diesem Sinne kann man behaupten, daß die Kooperation als berechtigtes und dringend notwendiges Mittel derVerteidigung der Kollektivität gegen die Usurpation des ökonomischen Ichs einiger wenigen in die Schranken trat. Denn die Kooperation ist in letztem Grade identisch mit der fundamentalen Bejahung der Rechte der sozialen Körper gegenüber den Anmaßungen eines falsch verstandenen Freiheitsbegriffes, welcher den Armen und Elenden zuruft: "Jeder muß für sich allein fertig werden!“ Diese Bejahung findet aber eine weitere Stütze und ihre Vollendung in der Erkenntnis, daß, um die Rechte der Kollektivität wirksam wahrnehmen zu können, erst die soziale Emanation des Gesetzes vom geringsten Kraftaufwand in Kraft treten muß: nämlich die organisatorisch angewandte Solidarität der Interessentengruppen.

Nun entsteht für uns die Frage: Welches ist das hriterium, auf Grund dessen die Menschen die kooperierenden

I) Eine Andeutung über die gleichzeitig, in den verschiedensten Kreisen des achtundvierziger Frankreich, entstehende spontane Bewegung, den durch die kapitalistische Konkurrenz bedrohten ärmeren Volksklassen auf dem Wege der Organisation dieser Klassen zu helfen, finden wir bei P.-J. Proudhon, "Propagande antisocialiste“, in der Sammlung: Mélanges, Articles de journaux, 1848-1892. Paris I869. Lacroix, Verboeckhoven et Co., p. 140. 
Gruppen bilden? In der Gesellschaft walten die größten Antagonismen und Kontraste ob und bestehen nebeneinander. Es liegt deshalb auf der Hand, daß die Quelle jedweder Kooperation nur in der Gemeinsamkeit eines Komplexes wesentlicher Interessen liegen kann, die, wenn sie einerseits ihrer Natur nach eine große Zahl Erwerbsmenschen zum $\mathrm{Zu}$ sammenschluß zu veranlassen vermögen, sie andererseits von einer anderen Gruppe trennen. Dem Schoße der sozialen Disharmonien entspringen alle politischen, sozialen und ökonomischen Einrichtungen, die mit Hilfe der Assoziation freier Kräfte die Befriedigung der gemeinsamen Bedürfnisse der einen kooperierenden Gruppe entgegen den Bestrebungen anderer, ebenfalls um das Banner derKooperation gescharten Gruppe zum Ziele haben.

Wir bemerkten bereits, dab die wirtschaftliche Entwicklung immer mehr zu einem mit gewaltigem Aufwand an Kapital betriebenen Großindustrialismus überleitet. Dieser Entwicklung entsprechend muß das hauptsächlichste Kriterium der Bildung und Definition der einzelnen Gesellschaftsklassen in den verschiedenen Antworten auf folgende drängende Frage liegen: Welches ist die Rolle, die die betreffende zu definierende Gruppe im Mechanismus der Produktion spielt? Oder kann man, da gerade ob des immer stärker hervortretenden Übergewichtes der industriellen Riesenbetriebe im Wirtschaftsleben sich immer mehr die große Trennung des unter dem Szepter der kapitalistischen Gesellschaftsordnung lebenden Menschengeschlechts nach dem Verhältnis, in dem die einzelnen Erwerbsmenschen zu den technischen Mitteln der Produktion stehen, unserer Beobachtung aufdrängt, diese Frage auf die anscheinend einfachere und bescheidenere Frage reduzieren: In welchem Verhältnis steht der zu definierende Wirtschaftskreis zu dem Besitz der Produktionsmittel? Das ist das Kriterium, auf Grund dessen eine wettverbreitete Schule in der Nationalökonomie, die sich auf Karl Marx beruft, es für zweckmäßig und zugleich wissen- 
schaftlich zulässig gehalten hat, die Gesamtheit der Homines oeconomici in zwei einzige große Kategorien einzuteilen: die Besitzer der Produktionsmittel und die von diesen Produktionsmitteln abhängigen Lohnarbeiter. ${ }^{1}$ )

Der Reichtum des mittellosen Erwerbsmenschen wird durch die Lohnhöhe bestimmt, die er durch den Eintausch seiner Arbeitskraft, der einzigen Ware, die er besitzt, erhält. Das stärkste Bedürfnis des Lohnarbeiters muß also demnach, sobald nur sein Verstand genügend geschärft ist, um die Notwendigkeit zu erkennen, seine Lebensbedingungen zu bessern, in dem heißen Wunsch bestehen, eine Erhöhung seines Lohnes zu erlangen. Allein der Lohnarbeiter, der seine Wünsche dem Unternehmer gegenüber isoliert geltend macht, ist zunächst nur ein Petulant; er ist nie Herr der Situation und seine Forderungen wiegen leicht wie Federn; er ist eine soziale Null, die sich nicht unangenehm bemerklich machen darf, bei Strafe, von seinem Herrn entlassen und durch eine andere Null ersetzt zu werden.

Auf die Erkenntnis dieser Tatsache gestützt, haben die Arbeiter als Produzenten jene Form der Kooperation ins Leben gerufen, die in England unter dem Namen der Trade Union und in Italien unter dem Namen der Lega di Resistenza, Bezeichnungen, von denen die eine mehr den industriellen und die andere mehr den Kampfescharakter dieser Arbeiterorganisation andeutet, bekannt ist. Aus generationen-

I) $\mathrm{DaB}$ diese soziale Unterscheidung nicht alleiniges Verdienst der Marxschen Schule ist, ersehen wir u. a. aus einigen Worten von Charles Fourier (1850): „Le Capital et le Travail! voilà le plus bralant, le plus irritant des dualismes qui divisent les esprits dans les circonstances révolutionnaires où nous nous trouvons. Ce dualisme prend aujourd'hui un caractère de gucrre sociale, comme le dualisme de l'esprit et de la matière, du spirituel et du temporel a engendré autrefois des guerres religieuses; comme l'antagonisme de la liberté et du pouvoir a causé nos révolutions politiques". (Charles Fourier, „Accord des Principes. Travail des Écoles sociétaires“. Paris 1850. Librairie Phalanstérienne. p. 100.) 
langer Erfahrung wohl wissend, wie selten natürliche $U_{r}$ sachen in Kraft treten, die auf spontanem Wege zu Lohnerhöhungen führen, wie z. B. der Import der Massen Goldbarren aus Kalifornien und Australien in den fünfziger Jahren des vorigen Jahrhunderts, der zeitlich mit einem großen Steigen der Löhne zusammenfiel ${ }^{1}$ ), haben die Arbeiter ihre Bünde gegen die Unternehmer, in deren Betrieben sie arbeiten, mit dem offenen Ziel gegründet, mittelst direkter wie indirekter Pression auf die Veränderung des Arbeitsvertrages zu ihren Gunsten hinzuwirken. Zur Bildung dieser Verbände haben die ungeheure Volksvermehrung sowie die durch die Einführung des neuen Produktionsmittels bedingte tagtägliche Zusammenarbeit kompakter Massen in der Fabrik und die dadurch erworbene Fähigkeit zur technischen Kooperation der Arbeiter im Mechanismus der industriellen Produktion, Qualitäten, die auch im Leben der Arbeiter außerhalb der Fabrik nach beendigter Arbeit weiter wirken mußten, in sehr wesentlichem Maße beigetragen, da sie für die Entstehung auf der Basis der Solidarität ruhender Organisationen erst den Mutterboden abgaben.

Der von den Gewerkschaften gegen die Privatunternehmer entfesselte Kampf wird auf die verschiedensten Arten und Methoden geführt. Wir können uns hier leider mit ihrer Analyse nicht beschäftigen ${ }^{2}$ ), sie weisen aber sämtlich

I) Charles Gide, „Economie sociale“. Paris I905. Librairie de la Société du Recueil Général des Lois et Arrêts, Larose et Tenin, directeurs, p. 80-8I.

2) Eine begabte holländische Dichterin und Sozialschriftstellerin, Henriette Roland Holst-van der Schalk, hat einen ganzen dicken Band allein einer Untergattung des Streiks, dem Generalstreik („Generalstreik und Sozialdemokratie“, 2. Auf., Dresden I 906, Kaden), gewidmet und diese Untergattung je nach ihren Zielen, den Ursachen und den Begleiterscheinungen mit großem philologischem Verständnis weiter in viele Arten und Unterarten geteilt, wie Linné seine Tiere nach ihren Zähnen und Klauen eingeteilt und klassifiziert hat. Sie unterscheidet allein fünf Kardinalarten des Generalstreiks: „General- 
die Tendenz auf, durch engen Zusammenhalt dem Privatkapital den größtmöglichen Anteil an der Distribution der produzierten Güter, beziehungsweise an dem kapitalistischen Unternehmergewinn strittig zu machen.

Dem gleichen Gegensatz der Arbeit zum Kapital verdankt auch ein hoher Prozentsatz der Vereine, die heute als Produktivgenossenschaften bezeichnet werden, ihr Dasein. Diese Kooperationsform, die die Anfertigung und den Verkauf von Waren durch die Arbeiter selbst ohne Hilfe des Privatunternehmers betreibt, ist häufig nur eine auf das Gebiet der Produktion übertragene Gewerkschaft. Nicht selten ist die Entstehung der Produktivgenossenschaften sogar direkt auf Streiks zurückzuführen: die Lohnarbeiter, ermüdet und angewidert durch die zu lange Auseinandersetzung mit ihren Unternehmern, schreiten dazu, gemeinsam ein eigenes geschäftliches Unternehmen zu gründen und auf diese Weise den Beweis zu erbringen, daß sie fähig sind, auch außerhalb des Rahmens privatkapitalistischer Produktion - auf eigene Faust - zu produzieren.

Auch die weitverbreitete Form der Arbeiterkooperation, die wir als Konsumgenossenschaft kennen, hat mit der sozialen Kampfesorganisation der Arbeiterschaft engen genetischen Nexus. Ihre Entstehung entspringt dem Wunsche des Arbeiters, die Kaufkraft seines Lohnes zu steigern. HeiBblütige Freunde dieser Genossenschaftsform, deren es zurzeit viele gibt, gehen sogar so weit, den Nutzen des Konsumvereins sachlich dem Nutzen der Gewerkschaft gleichzustellen, da es dasselbe sei, ob die Arbeiter als Produzen-

streik, Generalisierter Sympathiestreik, Ökonomisch-sozialer Generalstreik, Ökonomischer Streik mit politischer Bedeutung und Politischer Massenstreik". Man vgl. auch das über dasselbe Thema, wenn auch nicht mit der gleichen politischen Färbung, so doch dem gleichen philologischen Geschick geschriebene Buch einer anderen Frau, Els beth Georgi, ,Theorie und Praxis der Generalstreiks in der modernen Arbeiterbewegung“. Jena 1908. Gustav Fischer. 
ten mehr Lohn oder als Konsumenten mehr Kaufkraft erhalten. ${ }^{1}$ ) Richtig ist jedenfalls, daß der Konsumverein, da er die Tendenz verfolgt, seinen Mitgliedern die Anschaffung guter Waren zu möglichst billigen Preisen zu vermitteln und deshalb seine Einkäufe entweder direkt bei den Grossisten oder den Großindustriellen macht oder sogar innerhalb der Grenzen des Möglichen zur Gründung eigener, ihm als Konsumverein angegliederter und zugehöriger Produktionsbetriebe schreitet, auch als Kampfesorganisation der Arbeiterkonsumenten gegen das private Unternehmertum, als Konsumentengewerkschaft, betrachtet werden kann.

Alle diese verschiedenen Formen der Kooperation haben zwar in der Praxis durchaus nicht den Beweis für den ihnen von ihren Anhängern zugesprochenen absoluten und allgemeinen Wert zu erbringen vermocht. Ihre bisherige Geschichte hat jedenfalls so viel gezeigt, daß es ihnen an innerer Kraft mangelt, den allgemeinen Gang der Wirtschaft in nennenswerter Weise zu beeinflussen ${ }^{2}$ ) und daß der Errichtung eines neuen Konsumvereins in der Regel keine größere Bedeutung zugesprochen werden kann als der Eröffnung irgendeines anderen Kramladens. Aber diese kooperativen Formen besitzen, wenn auch also vielleicht abgesehen davon, daß sie zur progressiven Dekadenz der Mittelschichten der Gesellschaft beitragen - keinen großen wirtschaftsdynamischen, so doch einen sehr beträchtlichen wirtschaftsphilosophischen Wert in pädagogischer und didaktischer Hinsicht. In der Tat: die Produktivgenossenschaften eliminieren theoretisch den kapitalistischen Unternehmer und sind dadurch ein Beweis für die Entbehrlichkeit

I) Vgl. z. B. Franz Staudinger, "Gewerkschaft und Genossenschaft", in den Sozialist. Monatsheften, XII (XIV), Heft 25.

2) Vgl. über die nicht immer erfreuliche Geschichte der italien. Produktivgenossenschaften den lehrreichen Artikel von Lamberto Paoletti, „Un Cimitero di Cooperative“. Giornale degli Economisti. Anno XVI, sett. I905. 
der sozialen Funktion der Privatunternehmer; sie bekämpfen, wenn auch mehr verbal als ökonomisch, den privaten Großbetrieb ${ }^{1}$ ); die Konsumgenossenschaften, die in letzter Instanz dem Kapitalismus in höchsteigener Person auf den Leib zu rücken beabsichtigen, krümmen diesem zwar kein Haar, aber sie untergraben statt seiner, nolentes volentes, die Stellung der proletaroïden kleinen Kaufleute und Vermittler zwischen dem Produzenten und dem Konsumenten; die Kreditgenossenschaften machen den Bankier unnötig; die Baugenossenschaften, deren wir ein glänzendes Beispiel in Reggio Emilia, wo ein Genossenschaftskonsortium sogar eine Eisenbahnlinie gebaut und sie dann später auch in eigene Verwaltung übernommen hat, besitzen, ersetzen den Bauunternehmer und Privatvermieter.

$\mathrm{Da}$ aber die beiden mächtigsten Kardinalformen der Arbeiterbewegung, die Kooperation der Produzenten und die Kooperation der Konsumenten, nicht genügende Umgestaltungskrait besitzen, üm dâs immanente Ziel des modernen Proletariats, die Befreiung aus der Herrschaft der Kapitalinhaber, zu erreichen, ist eine weitere synthetische Form der Arbeiterkooperation entstanden in der politischen Abart des Sozialismus: die - im weitesten Wortsinne zu verstehende - Partei.

Wir können also vier Hauptformen der Arbeiterkooperation unterscheiden: die ökonomische Kooperation der proletarischen Produzenten oder Arbeits- und Produktivgenossenschaften; die ök on om ische Kooperation der

I) Der Entwicklung der Produktivvereine werden durch ihr Wesen als Arbeitervereine selbst gewisse Grenzen gezogen. Mit Recht bemerkt einmal Kautsky, daß je ausgedehnter und kapitalreicher ein Unternehmen ist, desto schwerer es in ein Arbeitergeschäft umzuwandeln ist, während es leicht in ein solches verwandelt werden kann, wenn nur geringe Mittel technischer und administrativer Natur erforderlich sind (Karl Kautsky, „Konsumvereine und Arbeiterbewegung". Wien 1897. Brand, p. 6).

Michels: Probleme der Sozialphilosophie 
proletarischen Konsumenten oder Konsumvereine; die soziale Kooperation der Lohnarbeiter oder die Gewerk. schaft; die politische Kooperation der sog. revolutio. nären Proletarier oder die Arbeiterpartei. ${ }^{1}$ )

Mit letzterem Terminus streifen wir die bewuBt oder un. 'bewußt jeder Organisation der Arbeiterklasse eigentümliche Tendenz zum Sozialismus. Da die Besitzer der Produktions. mittel als solche auch die Herren der Produktion und als solche wiederum die Herren der Gesamtgesellschaft sind, so sieht sich das Proletariat genötigt, mit ihm nicht gehörigen Arbeitsmitteln zu arbeiten und ist deshalb zu einer Un. terordnung in der Wirtschaft und der Gesellschaft gezwungen, die mehr der Form als der Substanz nach von jenen Versuchen, dem Eigentumsrecht seinen allzu absolutistisch. tyrannischen Stachel zu nehmen, die uns als Tarifverträge, Einigungsämter u. a. mehr bekannt sind, gemildert wird. Infolgedessen kann das moderne Proletariat nicht nur in keiner Weise ein Interesse an der Aufrechterhaltung in aeternum

I) In seinem interessanten Bande "Sozialpolitik" (Leipzig 19II, Teubner) erklärt sich Freih. Otto von $Z$ wiedineck-Südenhorst mit diesem meinem Schema einverstanden. Er hält es für „gut herausge. arbeitet", fügt dem aber hinzu, daß mein Begriff der ökonomischen $\mathrm{K}_{0}$. operation der proletarischen Konsumenten (Konsumvereine) noch nicht vollständig sei, da die Arbeiter ,die wich tige ökonomische Funktion des Boykotts außerbalb der Form der Konsumvereine durchführen"(p. 180). Diesem Versuch des Karlsruher Volkswirtschaftslehrers, die Boykottan. ten als eine neue Rubrik der Arbeiter-Konsumenten-Organisationen einzuführen, möchten wir entgegenhalten, daß der Boykott nicht eigentlich unter den Begriff der Kooperation fällt, wie wir ihn in diesen Seiten zu fassen trachteten. Der „Kooperation“ der Boykottanten feblt jedes juristische oder kontraktuale Band: Sie sind nicht in Vereinen zusammengeschlossen. Ihre Tätigkeit ist eine rein persönliche, isolierte. Insoweit sie sich $z u$ der von ihnen angewandten Maßregel gezwungen fühlen, ist es lediglich ein moralischer Zwang, der sie als Mitglieder einer anderen Form der Kooperation (Gewerkschaft, Genossenschaft, Partei) dazu veranlaBt. Die kooperative Form des Boy. kotts ist stets ein Derivat. 
des Besitzrechtes Privater an den Arbeits- und Tauschmitteln haben, sondern sieht sich im Gegenteil durch sein eigenstes Lebensinteresse auf den Weg getrieben, der zur Elimination eines derartigen Rechtes führt. Alle Tage von dem Gespenst der Arbeitslosigkeit bedroht, dazu abhängig nicht nur von den höheren Gewalten der Wirtschaftskrisen, sondern auch von den Launen, den Antipathien und den Nervenkrisen der Unternehmer und ihrer Stellvertreter ${ }^{1}$ ), wie der Proletarier

I) In meinem auf dem I. Internat. Kongreß zur Bekämpfung der Arbeitslosigkeit (Mailand 1903) gehaltenen Referat über die Bekämpfung der Arbeitslosigkeit durch die freien Gewerkschaften Deutschlands ("I Sindacati Tedeschi e la Lotta contro la Disoccupazione.“ Milano 1903. L'Umanitaria, 60 pag.) habe ich, auf historisches und statistisches Material gestützt, versucht, die Erscheinung zu beleuch. ten, daB unter den zahlreichen Ursachen der Arbeitslosigkeit auch der schlechte Wille einzelner Unternehmer oder Unternehmergruppen einigen Arbeitern oder Arbeitergruppen gegenüber, die sich aus organisatorischen oder politischen Gründen unliebsam gemacht haben, gerechnet werden muß; daß daher der Arbeitsmangel, den die Unternehmer vorschützen und als Vorwand benützen um Arbeiterentlassungen vorzunehmen, häufig nur eine Repressalie gegen die moderne Arbeiterbewegung ist; daß endlich, auch wo die Entlassung aus rein ökonomischen Motiven vorgenommen wird, der Unternehmer als die zu Entlassenden häufig mit Vorliebe gerade die ihrer Gewerkschaft am meisten ergebenen Arbeiter, die, welche er für die gefährlichsten und zu Störungen im Betrieb (Streik) gegebenenfalls am meisten geneigten hält, auswählt, sodab man alles in allem sagen kann, daß die Arbeitslosigkeit auch von der Willkür der Unternehmer abhängt (p. Io u. 2I). Meines Wissens war ich der erste, der auf diese Nebenquelle der Arbeitslosigkeit hingewiesen hat. Übrigens haben sich zwei genaue Kenner des uns hier beschäftigenden Problems, die Professoren Carl Oldenberg (,Über Arbeitsversicherung und Arbeitsnachweis" in Schmollers Jahrbuch für Gesetzgebung, vol. XXXI, fasc. I, p. 289) und Walter Troeltsch („Das Problem der Arbeitslosigkeit", Kaisergeburtstagsrede, Marburg 1907. Elwert, p. 27), freilich ohne auf ihn des näheren einzugehen, auf diesen meinen Gedanken bezogen, und der Spezialist Dr. Gustav Brüggerhoff hat sich in seiner lesenswerten Monographie „Das Unterstützungswesen bei den deutschen freien Gewerkschaften" (Jena 1908, Gustav Fischer), obgleich er, gleich den beiden vorerwähnten Schriftstellern, das Gesamt- 
ist, kann es niemanden wundernehmen, daß in seiner Seele der legitime Wunsch erwacht, zu einer der heutigen von Grund aus verschiedengearteten Wirtschaftsordnung zu gelangen, in der die Warenproduktion und die Arbeitstech. nik in einer Weise geregelt ist, daß jede Möglichkeit wirtschaftlicher Herrschaft des einen über den anderen a priori ausgeschlossen sein würde.

Es kann nicht unsere Aufgabe sein, an dieser Stelle zu prüfen, ob und, wenn $\mathrm{j}$ a, bis zu welchem Grade jener Ideen. komplex und seine Folgerungen, den wir unter dem Namen Sozialismus zusammenfassen, berechtigt und, falls berechtigh, ausführbar ist, wenn es auch keinem $Z$ weifel unterliegt, daB die Zahl der Gelehrten, die Gaetano Mosca Recht geben ${ }^{\text {), }}$ wenn er der Arbeiterschaft die Möglichkeit, jemals an ihr Ziel der Gründung einer großen Gesellschaft der Gleichen zu gelangen, bestreitet, in stetem Wachsen begriffen ist, weil sich mit dem Wachstum des politischen Erfahrungstoffes immer mehr die Beobachtung aufdrängt, daß die Tendenz zur Bildung-ven Oligarchien in dieser Klasse sich in genau derselben Gradstärke und mit genau der gleichen Wucht be. merkbar macht wie in allen übrigen Klassen der Gesellschaft.') Aber nicht darüber wollen wir hier reden.

Uns kam es lediglich darauf an, mit kurzen Strichen auf einen Umstand hingewiesen zu haben, der in den heftigen Diskussionen, zu denen die sozialen Probleme Anlaß geben, nur zu häufig vergessen wird, darauf nämlich, daß die hohen

problem unter wesentlich anderen Gesichtspunkten betrachtet als ich, veranlaßt gesehen, auszusprechen, daß die Arbeitslosigkeit in der Tat bisweilen mit eigenwilliger Entlassung der Arbeiter identisch sei und $\mathrm{da} B$ ich seines Dafürhaltens nach mit meinem Hinweis im ganzen recht habe (p. 77). Bocca.

I) Gaetano Mosca, ,Elementi di Scienza politica“. Roma I 896.

2) Dieses Thema ist von mir eingehend in meinem Werke: „Zur Soziologie des Parteiwesens in der modernen Demokratie" (Leipzig I9I I, Klinkhardt) erörtert worden. 
und idealen Endziele des Sozialismus, wie sie von den Anhängern dieser Weltanschauung genannt werden, keineswegs etwa - gleich so und so vielen Dei ex machina des alten griechischen Theaters oder Minerven aus dem Haupte Jovis - den Köpfen geistreich-paradoxaler Philosophen oder elender Aufwiegler und Marktschreier entsprungen sind, sondern daß sie ihre Entstehung ganz vorzugsweise der speziellen ökonomischen Stellung des Proletariats im kapitalistischen ProduktionsprozeB verdanken, also als natürliche und autochthone Frucht dieses gegebenen Milieus zu betrachten sind. $\left.{ }^{1}\right)$ Der Sozialismus ist die ideologische Emanation eines bestimmten in unserer heutigen Gesellschaft vorhandenen ökonomischen Ursachenkomplexes.

Wir haben bereits bemerkt, daß es nur natürlich war, daß die Kooperation gerade von denjenigen Klassen der Gesellschaft wieder rehabilitiert und zur Würde eines ge- sellschaftsbildenden Prinzips erhoben wurde, welche Gefahr liefen, unter dem Druck der unumschränkten Herrschaft des Kapitals, die durch das freie Schalten und Walten der entfesselten blinden Kräfte der modernen Volkswirtschaft entstanden war, zusammenzubrechen. Für die Arbeiterschaft war die Kooperation das einzige Mittel, um dem ihr verderblichen Isoliertsein ihrer einzelnen Komponenten zu entgehen. Aber der kampflustige Geist unter den jung organisierten Arbeitermassen und die nicht seltenen Siege, die sie in ihren ersten Zusammenstößen mit dem Kapital davontrugen, auf

I) Vgl. auch $\mathrm{Karl} \mathrm{Ka} \mathrm{utsky,} \mathrm{,Klasseninteresse,} \mathrm{Sonderinteresse,}$ Gemeininteresse", in der neuen Zeit, Anno XXI, vol. II, sowie Ar"uro Labriola, „Sul Momento attuale della Scienza economica“, öffentliche Antrittsvorlesung eines über Nationalökonomie an der $\mathrm{Kgl}$. Universität Neapel gehaltenen Kollegs, erschienen in den Pagine Libere. Anno I, fasc. I (I906). - Über den ökonomischen Nexus ¿wischen der Lebenslage der heutigen Arbeiterschaft und ihrer antipatriotischen Ideologie s. die klaren Bemerkungen von Werner "Sombart, „Das Proletariat", loco cit. (pag. Ioff.) sowie meine Schrift: „Patriotismus und Ethik“. Leipzig 1906. Dietrich (p. 32). 
der einen, sowie der unter den isoliert gebliebenen Unternehmern herrschende Zustand ständiger Konkurrenz, der sie häufig genug bis zur gegenseitigen Erschöpfung - einem „Weißbluten“ - führte, auf der andern Seite, mußte all. mählich auch jene Klasse, die ein halbes Jahrhundert lang mit so imponierender Zähigkeit das Banner der Isolierung als Wirtschaftsprinzip hochgehalten und die Kooperation mit so viel individualistischer Dreistigkeit verhöhnt hatte, auf die Vorteile der Solidarität gleicher wirtschaftlicher Größen hinweisen und sie veranlassen, dem ihnen von der Arbeiterklasse gegebenen Beispiel zu folgen. Heute ist das Prinzip der Kooperation, das ursprünglich zweifelsohne ein überwiegend proletarisches Phänomen war, auch in alle Gebiete der bürgerlichen Tätigkeit eingedrungen.

Das bezeugt die langsame, aber konsequente Verwand. lung des privaten Kapitals in gesellschaftliches oder unpersönliches Kapital - der Besitzer eines Betriebs zieht sich zurück, um das Terrain einer Aktien- oder anonymen Gesellschaft frei $\mathrm{zu}$ lassen, wodurch eine neue Besitzes- und Produktionsform entsteht, die den Arbeiterproduzenten und den Mechanismus der Produktion selbst völlig vom Kapital. inhaber scheidet und so die Trennung der Besitzer der Pro. duktionsmittel von der Produktion endgültig besiegelt, wo. durch sich diese Gesellschaften als die Form einer von Kapitalsbesitzern gebildeten aber unter der technischen Leitung angestellter besoldeter Beamten stehende ökonomisch-auto. matische Kooperation darstellen. ${ }^{1}$ )

I) Hierzu ist freilich zu bemerken, $d a ß$ die Überführung von Privatgeschäften in Aktiengesellschaften häufig nur eine Finte des Besitzers ist, um dem Geschäft neues Kapital zuzuführen, ohne daß die realen Besitzesverhältnisse wesentlich tangiert werden. Der Privat. unternehmer verschwindet in solchen Fällen durch Zurückziehung seines Namens vor der breiten Öffentlichkeit freilich von der Bildfläche, bleibt aber als Hauptbesitzer der Aktien (deren Mehrzahl sich in seinen Händen befindet) fast unumschränkter Herr über die er. weiterte "Aktiengesellschaft". 
Das bezeugt ferner die Entstehung mächtiger Unternehmerverbände, in Frankreich charakteristisch als défense patronale bezeichnet, Arbeitgebergewerkschaften, welche es als ihren Daseinszweck ansehen, den Forderungen der Arbeiter einen Damm entgegenzusetzen und gegebenenfalls dem Streik der Arbeitnehmer mit der Aussperrung (lock-out, serrata) der Arbeitgeber begegnen zu können - Organisationen, die, um die Schlagfertigkeit ihrer Kadres zu sichern und ihnen den Charakter wohldisziplinierter und mit militärischer Solidarität erfüllter Organismen zu geben, nicht zögern, selbst der individuellen Bewegungsfreiheit ihrer Vereinsmitglieder Schranken zu setzen, indem sie sie bei eventuellen Austrittserklärungen nicht nur zur strikten Einhaltung einer sechsmonatlichen Kündigungsfrist anhalten, sondern auch, um jede Desertion vor dem Feinde zu verhüten, in Zeiten des Konfliktes mit der Arbeiterschaft überhaupt keine Austrittserklärungen annehmen und bisweilen zu diesem $Z$ wecke sogar von ihren Mitgliedern die Hinterlegung fester Summen, die im Falle der Desertion eingezogen werden dürfen, fordern. ${ }^{1}$ )

Das bezeugt - zuletzt, aber nicht zum wenigsten - die Erstehung der Trusts, Kartelle und industriellen Corners, wirtschaftliche Formen, die zwar ursprünglich aus Amerika eingewandert sind, sich aber im Umsehen in Europa völlig akklimatisiert haben. Sie stellen machtvolle Versuche des Kapitals dar, der durch den steten Antagonismus der allgemeinen Konkurrenz, die zur Folge hat, dab die kapitalistischen Produzenten die Kenntnis des Marktes und den Überblick über den Absatz verlieren, verursachten wirtschaftlichen Anarchie ein Ende zu bereiten und durch eine Art neuer Kooperation, welche sich, falls es nämlich zu einer Fusion der Einzelunternehmungen unter einheitlicher Leitung kommt,

1) Heinrich Herkner, „Die Arbeiterfrage“. 5. Aufl. Berlin r908. J. Guttentag, p. 226. 
bis zu einer kapitalistischen Produktiv- und Verkaufsgenossenschaft entwickeln kann, selbst den Markt zu beherr. schen. Der Trust und seine Verwandten können als spezifisch agressiven Charakter tragende und von je nachdem mehr oder weniger stark ausgeprägtem Genossenschaftsgeist beseelte Unternehmergewerkschaften einzelner Industriezweige angesehen werden. Sie haben fast immer die immanente doppelte Tendenz, sowohl den Konsumenten als auch der in den betreffenden Branchen beschäftigten Arbeiterschaft Schach zu bieten. Bisweilen kommt es allerdings auch vor, daß der Trust auf einer Verschwörung des Kapitals mit der Arbeiterorganisation zum Schaden der Konsumenteninteressen allein beruht. Durch die Vereinigung ehemals autonomer Betriebe entsteht eine wirtschaftliche Neubildung, die an Stelle der unsystematisch waltenden Kräfte im Wirtschafts. leben nach und nach ein enges Netz von Bestimmungen, Ab. machungen, Regelungen, Verträgen und Maßregeln zur nötjgenfalls zwangsweisen Aufrechterhaltung der Solidarität webt, um innerhalb der Grenzen der Möglichkeit die Nachfrage zur Unterwerfung zu bringen. Die erste Masche des Netzes pflegt in der Regel in einer Verständigung über den Minimalpreis beim Verkauf der Waren zu bestehen; dem pflegt dann eine Ausmachung über das Maximum der herzustellenden Waren, über das man sich gegenseitig verpflichtet, nicht herauszugehen, zu folgen; bei weiterer Entwicklung schreitet man zur Verteilung des Marktes unter die Beteiligten für den Warenverkauf; nicht selten wird dem Ganzen schlieblich durch die Errichtung von Kommissionen zur Kontrolle der Mitglieder und von Zentralstellen zum gemeinsamen Warenabsatz die Krone aufgesetzt. Auf diese Weise ist der Trust auf bestem Wege, uns das System der modernen Öko. nomie in ihrer vollkommensten Form zu zeigen. Er gibt uns das Bild einer bis zur Vollendung getriebenen wirtschaftlichen Organisation, die in ihrem kräftigen Schoß die typischen Keime der kapitalistischen Ökonomie: die Konzen- 
tration, die Spezialisation und die Kombination, zur höchsten Entfaltung bringt. ${ }^{1}$ ) Das verhindert nicht, daB dieser perfektionierte Kapitalismus gleichzeitig auch mit sozialistischen Elementen geschwängert ist. Das Trustwesen scheint in der Tat den lebendigen Beweis für die Möglichkeit einer kooperativen Organisation der gesellschaftlichen Produktion unter Ausschluß der freien Konkurrenz zu liefern. Paul Lafargue hat den Trust als den Entwurf zu einer unter der Hegemonie einer Oligarchie von Kapitalmagnaten stehenden nationalen Organisation der Erzeugung und des Tausches der Güter bezeichnet. ${ }^{2}$ ) Jedenfalls ist dem Trust ein rätselhafter Dualismus zu eigen. Er vereinigt in sich die Realisierung der größtmöglichen wirtschaftlichen Potenzialität gewisser Gruppen von Kapitalisten, die um so gewaltiger ist, als sich das Trustphänomen mit Vorliebe gerade in der Produktion der notwendigsten Güter, wie Kohle, Petroleum, Seife, Eisen, Fleisch, Eisenbahnen, offenbart, während es zugleich mit Recht als negation of the principles upon which the claim of individual ownership of capital is based ${ }^{9}$ ) bezeichnet werden kann, u. a. auch, weil es die verschiedensten Unternehmungen für gute wie schlechte Geschäftszeiten solidarisiert. So ist diese kapitalistische Form der Kooperation, von logischer Warte aus gesehen, die notwendige Folgeerscheinung einer erfreulichen Reaktion auf das System der freien Konkurrenz, welches die Produzenten dazu antrieb, eine größere $Z a h l$ von Gütern zu erzeugen, als sie der Magen des Marktes vertragen konnte, also einen beständigen Überschuß des Angebots über die Nachfrage herzu-

I) Werner Sombart, „Die deutsche Volkswirtschaft im Neunzehnten Jahrhundert". Berlin 1903, Bondi, p. 371 .

2) Paul Lafargue, "Les Trusts Américains, leur Action économique, sociale et politique". Paris 1903. Giard et Brière, p. I 21.

3) Austin Lewis, "The Rise of the American Proletarian", l. c., p. I 24. 
stellen $^{1}$ ) und auf diese Weise den Ausbruch häufiger und verderblicher Produktionskrisen heraufzubeschwören. Allerdings muß dem hinzugefügt werden, daß, so gewaltig die Macht dieser den Namen Trust tragenden „vorbildlichen Kooperationsform", die in Amerika nicht davor zurückscheut, selbst dem Staat den Fehdehandschuh ins Gesicht zu werfen, auch ist, die in ihr vorhandene Überfülle angelegten Kapitals, das nicht unbenutzt liegen bleiben kann, sowie die der Produktion als solcher inhärente Ausdehnungstendenz sie doch bisher daran verhindert haben, ihr sozusagen theoretisches Ziel, die Produktion dem Konsum anzupassen, zu erreichen. ${ }^{2}$ )

Eines scheint uns also festzustehn: das Prinzip der Kooperation wird heute allgemein gewürdigt und angewandt. Es tritt mit solcher Stärke auf, daß man nicht mit Unrecht hat behaupten können, daß, falls man alle nicht nur individualistischen und persönlichen Charakter tragenden Erscheinungen des Wirtschaftslebens als außerhalb der Ökonomie stehend betrachten wollte, man die gesamte Ökonomie als unökonomisch bezeichnen müßte, da die gesamte Volkswirtschaft der Gegenwart assoziativer Natur sei. ${ }^{3}$ ) Dem Prinzip der Kooperation huldigen gegenwärtig alle Klassen und Unterklassen. Auch die Mittelschichten unserer Gesellschaft, welche heute einen hartnäckigen und langwierigen Kampf teils um ihre Existenz selbst, teils um ihre soziale Bedeutung und Autorität durchzufechten haben, sind zur

I) Als solches wird der Trust auch in einer von dem Holländer F. M. Wibout auf dem internationalen Sozialistenkongreß zu Paris 1900 eingebrachten und einstimmig angenommenen Resolution aufgefaßt; vgl. „Les Congrès Socialistes Internationaux. Ordres du jour et Résolutions, publiés par le Bureau Socialiste International de Bruxelles". Gand 1902. Volksdrukkerij, p. 104.

2) Vgl. Camillo Supino, „Le Crisi economiche“. Milano 1907. Hoepli, p. I 43 .

3) Arturo Labriola, „L'Economico e l'Extra-Economico", in den Pagine Libere. Anno II, Nr. 23. 
Kooperation zurückgekehrt und klammern sich an dieses Prinzip gleich als an den letzten Anker ihrer Hoffnung an. In allen Ländern sind die kleinen Landeigentümer eifrig am Werke, eine bunte Reihe von Gesellschaften zu gemeinsamem Einkauf von Chemikalien, Agrarmaschinen usw. zu gründen und sich mit Versicherungskassen und Leihinstituten aufrecht zu erhalten, da sie nur auf diese Weise der Konkurrenz der mit modernerer Technik arbeitenden landwirtschaftlichen Großbetriebe Herr zu werden vermögen. Mehr noch. Im Mittelstand, in der Industrie und im Handwerk ist in dem Bestreben, sich gegenüber der Großindustrie zu behaupten, der Drang nach Zusammenschluß so mächtig, daß vielfach sogar wieder zu mittelalterlichen Mitteln Zuflucht genommen wird. In Deutschland, und mit noch größerem Erfolge in Österreich, versuchen die Handwerker nicht nur, mit Hilfe von Abmachungen über den Verkauf ihrer Erzeugnisse und die Höhe der in den einzelnen $Z$ weigen zu zahlenden Löhne den Markt und die Arbeiterschaft zu meistern, sondern auch, mit Hilfe des Staates die Konkurrenz künstlich einzuschränken, indem sie die Schaffung obligatorischer Prüfungen befürworten, die zum Titel „Meister" berechtigen und ohne welche kein Handwerker die behördliche Genehmigung zur Niederlassung, d. h. zur freien Ausübung seines Berufes erhält. $\left.{ }^{1}\right)$ Schon heute hat man durchgesetzt, den Meistertitel, der gar dem Doktortitel der gelehrten Berufe, deren Angehörige ja auch durch die Prüfung erst den Beweis dafür erbringen müßten, daß sie fähig seien, sie auszuüben, entsprechen soll, mit großen praktischen Prärogativen auszustatten ${ }^{2}$ ). So ist das wichtige Recht der Haltung von Lehr-

I) Vgl. insbesondere die am 27 . Februar 1908 im Reichstag gehaltenen Reden der Abgeordneten Ad. Albrecht (Sozd.) und Gustav Malkewitz (Kons.) - Protokoll der Reichstagsverhandl. p. $3432 \mathrm{ff}$. und $34+2 \mathrm{ff}$.

2) So z. B. die Argumentation der Abg. Karl Rieseber: (Mittelstandsvereinigung, von Beruf Bäckermeister) und Gustav Malkewitz (kons.). - Protokoll p. $3+32$ und $34+8$. 
lingen an ihn gebunden, wobei der Kreis der hierzu Berechtigten dadurch noch weiter eingeschränkt wird, daß man von ihnen auch noch ein Minimum von 23 Lebensjahren und von 5 Jahren persönlicher Ausübung des Handwerks verlangt ${ }^{1}$ ), durch welche Kette von Gesetzesbestimmungen allerdings die selbständige Niederlassung für nicht geprüfte Meister wesentlich erschwert werden wird. ${ }^{2}$ ) Was von den Handwerkern nichtsdestoweniger nur als „Abschlagszahlung“ auf dem Wege zu der von ihnen gehegten Idee der Zwangskooperation betrachtet wird.

Wer die Entwicklung der Kooperation bis auf den heutigen Tag in allen ihren Formen betrachtet, wird also nicht leugnen können, daß dem Kriterium, das der marxistischen Schule zur Klassifizierung der Gesellschaftsklassen dient, ein wissenschaftlicher, wenn auch mehr instinktiver Wert nicht abzustreiten ist. Aber es will uns doch scheinen, als ob die Anwendung dieses Kriteriums sowohl in der Theorie wie in der Praxis auf große Schwierigkeiten stoße und bei einseitiger oder oberflächlicher Handhabung zu absolut irrigen Resultaten führe. Es unterliegt keinem Zweifel: die Marxisten, die, von wahlopportunistischem Eifer getrieben, selbst die hohen Angestellten des Kapitals, wie etwa den Direktor eines modernen Riesenbetriebs, beispielsweise der Kruppwerke, nur weil er nicht Besitzer der Produktionsmittel ist, mit denen er arbeitet, der Rubrik der „Lohnarbeiter“ oder „Proletarier“ zuzählen - und um derartige kleine Posten, die einen jährlichen „Lohn" bis zu 40000 Mark abwerfen, bewerben sich, nebenbei gesagt, bisweilen preußische Minister -, begehen den gleichen groben Irrtum, dem jener bescheidene arme Pferdebahnkutscher anheimfiel, von dem uns mit feinem

I) S. die Vorlage in den Drucksachen des Reichstags Nr. 350.

2) Das wurde selbst von dem nationalliberalen Abg. Hans Linck zugegeben (Protokoll p. 3438). 
Humor Edmondo De Amicis zu berichten weiB ${ }^{1}$ ), und der in seiner Eigenschaft als privatrechtlicher Besitzer eines erbärmlichen Fleckchens Erde an den Ufern des Tanaro, das zwar alle Augenblicke durch Überschwemmung unter Wasser verschwand und seinem Eigentümer noch nicht einen roten Heller eingebracht hatte, auf dem er aber eine große Buche angepflanzt hatte, welche den Anblick eines Mastes auf untergegangenem Schiff gewährte und aus deren Holzertrag er im Laufe der Jahre einige siebzig Lire herausschlagen zu können hoffte, sich nicht für einen Lohnarbeiter, sondern für einen selbständigen kleinen Besitzer und deshalb für logisch verflichtet hielt, den expropriationsdurstigen Sozialismus mit allen Mitteln zu bekämpfen.

Denn obschon der Mensch im allgemeinen, von höherer Gewalt getrieben, vornehmlich der Erreichung der ihm durch seine sozialen und wirtschaftlichen Interessen gesteckten Ziele und, demgemäß, den Zielen, die der sozialen Klasse, der er durch Geburt oder durch seine wirtschaftliche Stellung angehört, gesteckt sind, zustrebt, so wäre es doch falsch, den materialistischen Faktor in der Ideenbildung zu überschätzen. Man kann zunächst in unserer Wissenschaft nicht oft genug daran erinnern, ein wie kompliziertes Ding es ist, das wir als „ökonomisches Interesse“ bezeichnen. Das Wirtschaftsleben kennt klare Unterschiede und Grenzen nur ausnahmsweise. Zwischen dem Typus „Proletarier“ und dem Typus „Bourgeois“ fristet immer noch eine überaus zahlreiche Kategorie wirtschaftlicher Existenzen, die gleichzeitig oder abwechselnd eine ganze Reihe von Charakteristiken, die wir als der wirtschaftlichen Stellung des Proletariers oder der des Bourgeois angehörig zu betrachten gewohnt sind, zur Schau tragen, ihr Leben. Man kann den Sozialwissenschaftlern den Vorwurf nicht ersparen, daß sie sich mit diesen

1) Edmondo De Amicis, „La Carrozza di tutti“. Mfilano I 896. Treves, p. 344-345. 
mittleren Typen unserer Gesellschaft, der ganzen großen Schar derjenigen Homines oeconomici, die zwei so sehr verschiedene und so sehr zueinander im Widerspruch stehende soziale Funktionen erfüllen müssen, daß man von ihnen sagen kann, daß sie, wie der Conte Ugolino in Dantes Hölle zwischen Himmel und Erde in der Luft schweben, da sie, obgleich mit beiden durch mehr oder weniger enge Interessengemeinschaft verbunden, keiner Klasse ganz angehören, nicht eingehend genug beschäftigt haben.

Der Mezzadro (Halbpachtbauer) aus der Emilia oder der kleine selbständige Landwirt aus dem Biellese nehmen in der Ökonomie eine eigentümliche Stellung ein. Diese sehen sich nämlich in der Periode derWeinernte gezwungen, einen oder mehrere Tagelöhner zur Mithilfe heranzuziehen, während ihnen im übrigen Teil des Jahres das ihnen gehörige Stückchen Land nicht genügt, um aus seinem Ertrag die zum Leben nötige Rente herauszuwirtschaften, so daß sie, um noch einige hundert Lire zum Familienbudget hinzuzugewinnen, ihre Kinder in der Saison der Reisernte ${ }^{1}$ ) oder des Jätens der Reisfelder in die risaje des Novarese schicken

I) Giovanni Lorenzoni teilt uns mit (,I Lavoratori delle Risaie. Inchiesta sulle Condizioni del lavoro." Milano 1904. Ed. Ufficio del Lavoro. Vol. I, p. 34), daß zur Rcissaison in der Poebene selbst die Frauen der Halbpachtbauern von den Hügeln des Biellese herabsteigen. - Francesco L. Pullè, auf dem „I Congresso Nazionale dei Lavoratori della Terra", Bologna rgor (s. Resoconto stenografico, Bologna I902, Azzoguidi, p. 22) weiß uns über die ökonomisch neutrale Lage der selbständigen kleinen Bauern der Hochlombardei (Provinz Como) folgendes zu berichten: „Qui è la famiglia individuata che si scinde: la donna, $i$ vecchi, i bambini restano a casa e rappresentano la condizione di proprietari coltivatori; invece il marito e i figli sopra i dodici anni sono per otto mesi nelle condizioni di operai fuori di paese e solo per quattro nelle condizioni di proprietari in casa. Quindi non ci si presenta una figura di piccolo proprietario che si possa scompagnare dall' altra figura del contadino e dell' operaio; essi combinano il doppio aspetto di lavoratori della terra e dell' industria." 
müssen. Sie sind zugleich Arbeitgeber und Arbeitnehmer, je nach den Jahreszeiten. Und wie viele kleine Hausbesitzer gibt es nicht, die aus zwingenden Gründen nicht in den eigenen Häusern wohnen und so in eigener Person teils die Interessen der Hausbesitzer, teils die der Mieter wahrzunehmen haben! Und wie viele Angehörige der freien Berufe sind nicht gleichzeitig Grundbesitzer. Und wie viel Lohnarbeiter leben nicht außer von dem Verkauf ihrer Ware Arbeitskraft von der kleinen Rente eines nicht eigenhändig bebauten Stückchen Landes oder von den Prozenten einiger kleiner Ersparnisse oder einer kleinen Erbschaft: Ausgebeutete, insofern ihnen täglich ein Teil des Wertes ihrer Arbeitsleistung - der sog. Mehrwert - vom Lohne subtrahiert wird, durch dessen Summe der Unternehmergewinn entsteht, und selbst Ausbeuter, insofern auch sie ihren Lebensunterhalt zum Teil mit Hilfe von ,arbeitslosem Einkommen“ bestreiten.

Auf eine weitere Schwierigkeit stößt man auch bei der Klassifizierung von Schichten, die zwar zur Zeit der statistischen Aufnahme eine eindeutige Stellung im Wirtschaftsleben einnehmen, deren Stellung aber nur eine so zeitweilige ist, daß sie psychologisch nicht mit ihr verwachsen und infolgedessen auch die Interessen ihrer Klasse, die für sie nur ein Durchgangsstadium ist, nicht mit genügender Energie vertreten können, um das Bedürfnis der Kooperation zu empfinden, ein Bedürfnis, zu dem die nötige Voraussetzung Klassenbewußtsein ist. Hierher gehören weite Bestandteile der Landarbeiterschaft Südwest- und Mitteldeutschlands, deren tüchtigste Elemente, begünstigt durch die in jenen Landesteilen herrschende Erbsitte, die eine weitgehende Parzellierung des Landes zuläßt und deshalb auch dem Zwergkapitalisten den Ankauf eines Häuschens und eines Fleckchen Landes zum Bau von Kartoffeln, Gemüse oder anderen Handelspflanzen ermöglicht, jederzeit auf der sozialen Stufenleiter in einen nicht hohen, aber doch höheren Stand hinauf- 
steigen können. $\left.{ }^{1}\right)$ Auch das landwirtschaftliche Gesinde ist zum Teil mit seinem Berufe nicht eng verwachsen, weil Knechte und Mägde den Dienst häufig nur als ein Mittel betrachten, einige technische Kenntnisse zu erwerben und kleine Ersparnisse anzulegen, auf Grund deren dann binnen kürzerer oder längerer Frist zur Dienstaufgabe wegen Heirat und zu wenigstens relativer Selbständigmachung geschritten wird.

In allen diesen äußerst verzwickten sozialen Beziehungen hängt die endgültige Stellungnahme des Wirtschaftsmenschen in den sozialen und politischen Kämpfen der Gegenwart und sein AnschluB an eine bestimmte Kooperationsform entweder von dem wirtschaftlichen Überwiegen der einen oder der anderen der von ihm erfüllten antinomischen Funktionen im einzelnen $a b$ - hat man im philologisch scharfsinnigen Deutschland doch sogar eine Unterscheidung zwischen, ,grundbesitzenden Tagelöhnern" und "gelegentlich tagelöhnernden Grundbesitzern" konstruieren wollen - teils aber wird sie auch von dem ganz individuellen Gefühl der Betreffenden bestimmt (d.h. von der Antwort auf die Frage: als was fühle ich mich mehr?, also von einem Appell an das wissenschaftlich unkontrollierbare Gefühlsleben des einzelnen), und bleibt folglich in vielen Fällen in suspenso.

Endlich ist in diesen Zusammenhängen auch der Antrieb der reinen Idee, dieser häufig so entschiedenen Gegnerin der reinen Ökonomie, bestimmend, da sie sehr wohl die Menschen veranlassen kann, einen ihren wirtschaftlichen Interessen entgegengesetzten Weg einzuschlagen. Es ist in unser aller Gedächtnis, daß es Mitglieder der höchsten Aristokratie und Latifundienbesitzer gegeben hat und noch gibt, die ihre Kräfte und ihren Geist in den Dienst der sozialen Revolu-

I) Vgl. hierüber auch den interessanten Aufsatz von Arthur Schulz: "Die landwirtschaftlichen Arbeiter", in den Sozial. Monatsheften, vol. XII (XIV), Heft 25 , in welchem die einzelnen differenzierten Verhältnisse der deutschen Handarbeiter einer glänzenden Analyse unterzogen werden. 
tion gestellt und sich als überzeugte Anhänger der Notwendigkeit einer allgemeinen Enteignung des Bodens und seiner Überführung in den Besitz der Kollektivität erklärt haben, während andererseits Hunderttausende von Instleuten und Landarbeitern existieren, die mit ihrem Schicksal durchaus zufrieden sind, und die zum Teil aus Furcht und Fatalismus, zum Teil aus angeborener geistiger Stumpfheit, zum Teil aber auch aus intensivem Dankbarkeitsgefühl und treuer Ergebenheit zur Person ihres angestammten Grundherrn jedes Gesetz für eine Ungerechtigkeit halten würden, das ihrem Herrn die freieVerfügung über seinen Besitz irgendwie schmälern würde.

Die Geschichte Amerikas gibt uns ein geradezu klassisches Beispiel für die gelegentliche Übermacht des ideellen über den ökonomischen Faktor. Im Bürgerkrieg von I 86 I bis 1865 konnten die Südstaaten ganze Regimenter aus schwarzen Sklaven bilden, welche im Kampfe gegen dieWeißen der Nordstaaten, die gekommen waren, um sie ihrer Befreiung entgegenzuführen und die Ketten ihrer Sklaverei zu sprengen, den Heldentod starben. Noch heute gewahren wir, wie oft der elendeste Tagelöhner, der auf den Rittergütern des groBen grundbesitzenden Adels in Preußen arbeitet, in den Wahlen seine Stimme für seinen Baron abgibt, damit dieser dasselbe feudale Regime am Ruder erhalte, das sich vorzugsweise auf mehr oder weniger gesetzliche Koalitions- und Streikverbote der Landarbeiter stützt, während die Kollegen des Landarbeiters in der Stadt, die Industriearbeiter, sich schon über ein halbes Jahrhundert lang aller diesbezüglichen staatsbürgerlichen Freiheiten erfreuen. Das ökonomische Bewußtsein der einzelnen Klassen hängt also nicht ausschließlich vom ökonomischen Faktor ab, auch abgesehen davon, daß die Menschen erst dann wirtschaftlich denken lernen, wenn der Verstand ihre Regungen bereits stark beherrscht und ihre Willensrichtung zu beeinflussen vermag. Zur Entstehung des gesamten Komplexes menschlicher Handlungen 
und Meinungen wirken neben dem ökonomischen Movens notwendigerweise auch andere Koëffizienten mit, wie das historische Movens der Tradition und der spezifische Entwicklungsgrad der philosophischen und abstrakten Gefühlsregungen, der in den einzelnen Ländern oder Bevölkerungsteilen anzutreffen ist. Es kann ein ausgesprochen kapitalistischer Stand ökonomischer Entwicklung vorliegen, ohne $\mathrm{da} B$ in den Arbeitermassen ein entsprechendes ökonomisches Klassenbewußtsein vorhanden $z u$ sein braucht, wie in den Vereinigten Staaten von Nordamerika - die das Maximum an kapitalistischem Industrialismus enthalten -, und man kann andererseits ein hochentwickeltes Klassenbewußtsein in der Arbeiterschaft eines Staates antreffen, der, ökonomisch betrachtet, einen geringeren Entwicklungsstand aufweist und sich auf einem viel niedrigeren industriellen Niveau befindet, wie Frankreich - welches das Maximum an revolutionärem Sozialismus enthält. Diese Tatsachenreihe ist nicht etwa, wie einige glauben möchten, aus der Annahme zu erklären, daß das in den Proletariervierteln der Arbeiterstädte Frankreichs so tief wurzelnde Gefühl moralischer und intellektueller Rebellion gegen die bestehenden Zustände in Amerika ob der höheren Lebenshaltung der dortigen arbeitenden Klassen nicht habe aufkommen können. Denn gerade in Amerika lebt neben einigen aristokratischen Arbeiterschichten ein Lumpenproletariat, das nicht nur absolut, sondern auch relativ weit zahlreicher ist als das Lumpenproletariat in der französischen Republik; noch existiert dort eine, wenn auch noch so anämische, soziale Gesetzgebung, welche imstande wäre, den Arbeitern in die ihnen im sozialen und ökonomischen Leben geschlagenen Wunden wenigstens einigen Balsam zu gießen.

So sehen wir auch, daß, obgleich die politische Kooperation, mit anderen Worten, die Partei, historisch-genetisch zunächst ebenfalls als die Resultante ökonomischer und sozialer Bedürfnisse oder Klasseninteressen zu betrachten ist, 
sie in Wirklichkeit aus einer zusammengewürfelten Menge ohne das einigende Band bestimmter technischer Qualitäten und ohne Homogeneität der ökonomischen Interessen besteht und also auf einer Zusammenarbeit von den disparatesten Klassen angehörigen Männern beruht. Es darf als wissenschaftliches Verdienst der jungen sog. syndakalistischen Schule der Sozialisten angesehen werden, daß sie den Gedankenfehler einer Gleichsetzung von politischer Partei und ökonomischer $\mathrm{Kl}$ asse nachgewiesen und durch eine sorgfältige Analyse der sozialen Zusammensetzung der einzelnen Parteikörper den Beweis dafür geliefert hat, daß, wenn die Partei auch häufig ihre Entstehung einer Klasseneinheit verdankt, sie doch in ihrer politischen Wirklichkeit ein überwiegend ideologisches Gebilde ist, da das Movens, welches die einzelnen Staatsbürger zum Beitritt zu einer politischen Partei 'veranlaßt, in der Zustimmung zu einem Programm, d. h. zu einem bestimmten Gedankenkomplex zu suchen ist, die von den wirtschaftlichen Verhältnissen dessen, der sich zu ihm bekennt, unabhängig sein kann, wenn auch diese wirtschaftlichen Verhältnisse deshalb nicht aufhören werden, das Verhalten der Parteimitglieder unbewußt weiter zu beeinflussen.

In den politischen Parteien selbst befinden sich das ökonomische und das ideologische Element in beständigem Kampfe miteinander. Es besteht keine einzige politische Partei in Europa, die nicht auf die eine oder andere Weise als Vertreterin ökonomischer Interessen angesehen werden könnte und die nicht als der politische Ausdruck bestimmter Gesellschaftsklassen zu betrachten wäre. Aber andererseits gibt es auch nicht eine, die nicht gleichzeitig auch von gewissen abstrakten und außerhalb der rein ökonomischen Interessensphäre liegenden Grundideen geleitet wird. In diesem Dualismus hat bald die eine, bald die andere Seele die Oberhand. Jedermann weiß, daß es politische Parteirichtungen gibt, die ganz überwiegend wirtschaftlichen Stempel tragen, wie der Bund der Landwirte in Deutschland, der die 
großen und mittleren Grundbesitzer umfaßt und dessen Pro. gramm fast einzig in dem Ausdruck des festen Willens besteht, die Preise der Agrarprodukte auf dem Markte hochzuhalten, zur Erreichung welchen $Z$ weckes er vorzugsweise eine Politik der Schutzzölle treibt und sich auf sie stützt.") Andererseits kennen wir auch Parteien, in denen zwar eben. falls ökonomische Grundtendenzen lebendig sind, die aber doch überwiegend ideologisches Gepräge tragen, wie die nationalistischen Parteien in Österreich, die angeblich die völkischen Interessen aller Italiener, aller Kroaten usw. ohne Unterschied der Klassen und des Berufs vertreten, oder die Zentrumspartei im Deutschen Reich, welche alle Bürger katholischen Glaubens, die eine von christlichem Geiste geleitete Politik gewährleistet sehen wollen, $\mathrm{umfaBt}^{2}$ ) oder die republikanischen Parteien in Spanien und Italien, die alle

I) „Die konservative Agrarpolitik ist natürlich in erster Linie Interessenpolitik der Großgrundbesitzer: hoher Getreidepreis, Vieh. preis, Zuckerprämien, Spiritussteuerrückzahlung, Grundrente ... Er sagt zum Bauer: Du verkaufst $z$ war weniger als ich, aber da dn auch das Wenige gern preiswert verkaufst, so ist $z$ wischen uns kein Unterschied." (Friedrich Naumann: „Demokratie und Kaiser. tum". 3. Aufl. Berlin-Schöneberg 1904. Hilfe, p. 98-99.)

2) Die geistigen Häupter des Zentrums denken gar nicht daran, die bestehende große Trennung der Produzenten von den Konsumenten oder den eklatanten Interessengegensatz zwischen Kapital und Arbeit auch nur im entferntesten zu leugnen (vgl. die Schrift des Ökonomisten der Partei, Prof. Franz Hitze: „Die Arbeiter. frage“. 4. Auflage München-Gladbach 1905, p. 6 ff.), aber sie glatben, daß die in der Gesellschaft obwaltenden, an sich unvermeid. lichen Antagonismen mit Hilfe des ethischen Begriffes der geistigen Gefühlsgemeinschaft im Katholizismus von ihrer Gehässigkeit befreit werden können, denn „es gibt eben ohne Religion, Sittlichkeit und Recht keine absoluten Begriffe von nützlich und zweckmäßig, welche als sicherer, von allen anerkannter Maßstab angewendet werden könnten" (vgl. die Schrift des Mainzer Bischofs und Reichstags* abgeordneten Wilhelm Emil Freiherrnv. Ketteler, "Die Zentrumsfraktion auf dem ersten deutschen Reichstag “. Mainz I 872, p. 7). 
"Elemente in sich zu vereinigen trachten, welche die Staats"form der Republik der Staatsform der Monarchie vorziehen. Alle diese Parteien abstrahieren, wenigstens in der Theorie, vollkommen von den Interessengegensätzen der sozialen Klassen, deren Existenz sie entweder leugnen oder die sie zu "„harmonisieren" vorgeben. Drittens kennen wir auch noch politische Parteien, in denen die beiden Elemente sich die Wage halten, wie die Partei der Nationalliberalen in Deutschland, ursprünglich eine ausgesprochene Intellektuellenpartei mit scharf patriotischem, selbst ins Nationalistische schillerndem Charakter, die aber in ihrer praktischen Politik so energisch die Interessen der jungen, ausdehnungseifrigen und :weltmachtslüsternen deutschen Industriekreise vertritt, daß sie trotz ihrer schwerwiegenden Kulturkampfvergangenheit und ihres noch heute zugespitzt protestantischen, antikatholischen Wesens auch die reichen Industrieherren katholischer Konfession, denen das Zentrum zu sehr Kaplanspartei - ideologische Partei - und zu arbeiterfreundlich ist, d. h. ihre industriellen Herreninteressen in nicht genügender Weise zum Ausdruck bringt, zu ihren Mitgliedern zählt. Bei dieser Gelegenheit mag auch eine Gruppe der Anarchisten Erwähnung finden, die sich mit ihrer Propaganda zwar ausgesprochenermaßen nur an eine einzige soziale Klasse, das Proletariat, wendet, dabei aber alle ihre Kraft aufbietet, ihm nicht so sehr den ideologischen Überbau seiner speziellen wirtschaftlichen Bedingungen klarzumachen, als es vielmehr über allgemein menschliche Generalbegriffe, die mit jenen in keinem notwendigen oder doch nur einem mehr akzidentiell gearteten Konnex stehen, zu belehren und sich auf diese Weise als eine echt ideologische Sekte darstellt, deren einziges Ziel, einem geistreichen Wort Edouard Berths zufolge, darin besteht, aus den Gewerkschaften eine Art metaphysischer und antiautoritärer Klubs zu machen. ${ }^{1}$ )

I) Edouard Berth, "Les nouveaux Aspects du Socialisme“. Paris 1908. Marcel Rivière, p. 6. 
Es sei uns gestattet, aus den angedeuteten Entwick. lungstendenzen und Tatsachenbeständen einige Schlüsse zu ziehen.

Das Zeitalter des reinen Individualismus auf ökonomischem Gebiet darf heute als definitiv abgeschlossen betrachtet werden. Ein Gedanke, wie er im Strafgesetzbuch der Napo. leonischen Ära Gestalt gewonnen hatte, in dem jede Koalition, der Arbeiter sowohl als der Unternehmer, als eine Verletzung der individuellen Freiheit der Staatsbürger mit strengen Strafen bedroht wurde, ist heute kaum noch nachdenkbar.

Wir haben gesehen, daß der Homo oeconomicus heute schlechterdings nur noch als Bestandteil eines Aggregats existiert, und daß nach und nach alle Klassen der Gesell. schaft sich dem Prinzip der Kooperation unterordnen. Dieses Prinzip beherrscht heute selbst die Gedanken und Träume der Sozialrevolutionäre, die, wie Arturo Labriola, Erklärungen abgeben, daß die soziale Revolution nur dem Autoritarismus im Organisationsgedanken, nicht aber dem in diesem Gedanken vorhandenen assoziativen Element und dem vom Kapitalismus geschaffenen wirtschaftlichen Verantwortlichkeitsgefühl den Todesstoß versetzen werde ${ }^{1}$ ), oder mit Francesco Saverio Merlino sagen, daß sie sich die Gesellschaft der Zukunft nur als ein kombiniertes System konsumgenossenschaftlicher und produktivgenossenschaftlicher Gruppierungen vorzustellen vermöchten. ${ }^{2}$ ) Aber es hat sich uns doch andererseits die Beobachtung aufgedrängt, daß die Kooperation aus zwei genau trennbaren und sehr verschiedenartigen Elementen zusammengesetzt ist. Wenn wir den Begriff der Kooperation in seiner Quintessenz, Korrelativität und Kausalität

I) Arturo Labriola, „Sull' Azione politica del Partito Socialista“. Relazione al IX Congresso Naz. del Part. Soc. Ital. (Roma 1906). Frascati I 908. Stabilimento Tip. Ital., p. II.

2) Francesco Saverio Merlino, "L' Individualismo nell' Anarchismo“. Roma 1895. Tip. dell' Asino, p. 56. 
genau analysieren, kann es uns nämlich nicht entgehen, daß seine Merkmale sich um ein Positivum und ein Negativum gruppieren lassen: Den gemeinsamen Besitz einer Summe von 'ökonomischen, sozialen und intellektuellen Interessen, welche die Kooperierenden zusammenschließen, sowie das Vorhandensein eines den Komponenten einer jeden Gruppe von ihnen gemeinsamen Antagonismus gegenüber einer anderen Gruppe von Kooperierenden. Mit anderenWorten: DieVoraussetzung der Kooperation ist der Gegensatz, der Kampf. Ein ewiger Janus Bifrons, ist die Kooperation zwar ihrem Wesen nach darauf gerichtet, der Solidarität der Menschheit zuzustreben (teleologischer Kooperativismus), verdankt ihre Entstehung und ihr Wachstum jedoch vorzugsweise der Negation der Solidarität der Menschheit, indem sie sich nur durch die $Z$ wistigkeiten und Interessenungleichheiten der verschiedenen Gruppen sozialer Aggregate lebensfähig erbält (praktischer Kooperativismus).

Dieser Tendenz zur Uneinheit kann sich auch die Arbeiterkooperation als Ganzes genommen, trotz aller Versuche sie zu taktischer und prinzipieller Einheit zu erziehen, nicht entschlagen.

Die vier Haupttypen der Kooperation der Arbeiterschaft, von denen wir im Laufe dieses Kapitels gesprochen haben, sind weit davon entfernt, sich gegenseitig so zu ergänzen und zu durchdringen, daß man von ihnen sagen könnte, sie seien nur verschiedene Ausdrücke für ein und dieselbe Funktion. Wir können vielmehr die Beobachtung machen, daß ihre Einheit sich außer der Gemeinsamkeit einer gewissen Anzahl sehr nebelhaft erfaßter und allgemein gehaltener Aspirationen, auf eine sich auf einen mehr oder weniger hohen Prozentsatz der Mitglieder erstreckende Personalunion beschränkt, da viele gleichzeitig an zwei oder mehreren Formen der Arbeiterkooperation beteiligt sind. Generalisierend kann man wohl sagen, daß besonders die Kooperation der proletarischen Konsumenten sich vollständig von jeder im 
gesellschaftlichen und politischen Interesse ihrer Klasse liegenden kooperativen Aktion fernhält. Da sie finanziell überwiegend auf bourgeoise Kundschaft angewiesen ist, besonders wenn sie nicht nur an die großenteils dem Arbeiter. stand angehörigen eigenen Mitglieder (deutsches System), sondern unterschiedslos an das allgemeine Publikum ver. kauft (italien is ches System), und deshalb von berechtigter Sorge erfüllt ist, diese Kundschaft zu erhalten, ist in ihr natürlicherweise wenig Verständnis für die Notwendigkeit eines engen Zusammenhangs zwischen den verschiedenen Metho. den des Klassenkampfes zu finden, während sie andererseits, in ihrer Eigenschaft als kaufmännische Unternehmung, die als solche allen Bedingungen der Kapitalwirtschaft unterworfen und allen Gefahren und Wechselfällen der Konkurrenz ausgesetzt ist und sich gegen diese möglichst zu schützen hat, leicht dazu getrieben wird, auch wenn sie sich noch so sehr darum bemüht, in den ihr angegliederten eigenen Produktivbetrieben vorbildliche Arbeiterverhältnisse zu schaffen, in einen Gegensatz zur sozialen Kooperation der Lohnarbeiter, der Gewerkschaftsbewegung, zu geraten und der Forderung der höheren Löhne oder der Anerkennung von tariflich festgesetzten Minimallöhnen nicht stattzugeben.

Die Varietät und Spezialisierung der Bedürfnisse im Wirtschaftsleben, Ursache und Wirkung der Heterogenität der sozialen Struktur, macht nicht vor der Kooperation halt. Selbst den ordnungsgemäß innerhalb eines bestimmten kooperativen Kaders kooperierenden Elementen werden in ihren Vereinen innere Kämpfe sozialer und ökonomischer Natur nicht erspart. Innerhalb der Arbeiterklasse findet sich generell ein oft latenter, oft akuter Gegensatz zwischen Beschäftigten und Arbeitslosen, Streikenden und Streikbrechern vor. ${ }^{1}$ ) In den

I) Wollen wir von den Verschiedenheiten in ihrem moralischen und psychologischen Empfinden absehen, so können wir die Behauptung aufstellen, daß der organisierte Arbeiter mit dem besser entlohnten und der Streikbrecher mit dem schlechter entlohnten Teil 
vier Wänden der politischen Kooperation, in den politischen Parteien des organisierten Proletariats, macht sich häufig das Vorhandensein zweier einander feindlich gesinnter sozialer Gruppen bemerkbar; da haben wir, je nach der Art ihrer sozialen Zusammensetzung,Kämpfe zwischen Stadt- und Landarbeitern, Lohnarbeitern und Bauern, Arbeitern und Beamten, qualifizierten und unqualifizierten Arbeitern. ${ }^{1}$ ) Noch bemerkenswerter ist der bereits angedeutete Antagonismus zwischen den Mitgliedern der Konsumvereine, in denen bisweilen zwischen den Arbeiteraktionären und den angestellten Lohnarbeitern,zumal den in den denKonsumvereinen gehörigen Produktionsbetrieben tätigen Arbeitern, die zwar fast durchgängig gleichzeitig Mitglieder des Vereins sind, bei denen aber doch der Charakter der Lohnarbeit über den der Mitarbeit überwiegt, wahre Klassenkämpfe Platz greifen, da sie sich einer Kollektivität von Individuen gegenüber zu verteidigen haben, die zwar an sich Lohnarbeiter sind wie sie selber, innerhalb der Konsumgenossenschaft aber die Funktion des Arbeitgebers in einem kapitalistischen Betrieb ausüben. Diese interessanten Gegensätze im Rahmen der Kooperationsmikrokosmen selbst, die ein eingehenderes Studium verdienten, als

der Arbeiterschaft identisch ist. (Vgl. auch mein Buch: „Zur Soziologie des Parteiwesens", 1. c., p. $278 \mathrm{ff}$.)

I) „C'est dans une situation privilégiée analogue que se trouvent parfois les ouvriers qualifiés lorsqu'ils ne forment qu'un contingent relativement restreint du personnel ouvrier d'une grande entreprise composée pour le reste d'ouvriers , non qualifiés'. L'augmentation du salaire des ouvriers spécialistes au détriment de celui payé aux ouvriers de fabrique ordinaires est une mancuvre capitaliste fréquemment employée. Pour les ouvriers plus favorisis, il est alors possible que la limite maxima indiquée ci-dessus soit dépassée vers le haut, pourvu du moins que le montant total des salaires dans l'entreprise reste au dessous de la limite maxima tracée par la productivité de l'entreprise dans son entier." Christiaan Cornelissen, "Théorie du Salaire et du Travail salarié". Paris 1908. V. Giard et E. Brière, p. 640. 
ihnen von wissenschaftlicher Seite heute zuteil wird, und die im Verlauf ihrer Entwicklung häufig den Beweis für die Er. scheinung liefern, daß die organisierten Arbeiter, die ein so feines Gefühl für die Ausbeutung zu haben pflegen, der sie selbst unterliegen, desselben Gefühles häufig völlig bar sind, so. bald es sich um in ihren Diensten befindliche Genossen handelt, für deren Ausbeutung sie keine Augen haben, sind im letzten Grunde nur der natürliche Ausdruck des Interessengegensatzes zwischen dem Arbeiter als Produzent und dem Arbeiter als Konsument und als Unternehmer.

Es ist schlechterdings nicht zu leugnen, daß die Kooperation, wenngleich mit solidarischen Zielen ins Leben getreten, dem, der sie im höheren Sinne erfaßt und von der Liebe des Theoretikers zu ihr erfüllt ist, ein trauriges Schauspiel darbietet. Ein Schauspiel heftiger Kämpfe nach außen wie nach innen, die der unendlichen Differenziation der Interessen und dem Vorhandensein unzähliger ökonomischer Schattierungen in unserem Gesellschaftskörper entsprechen. Es ist deshalb wohl verständlich, wenn es auch unter den Männern der Wissenschaft nicht an solchen fehlt, die angesichts der schier unentwirrbaren Häufung gesellschaftlicher Zwistigkeiten von pessimistischer Müdigkeit befallen werden und diese Müdigkeit in die theoretische Formel zusammenfassen, das Wort Kooperation sei nur ein Euphemismus, hinter dem sich der häßliche Egoismus kleiner Gruppen der Wirtschaftsmenschen verberge, und sie sei unfähig, sich jemals zur Vertreterin der Gesamtinteressen auszuwachsen. Aber es will uns doch scheinen, als ob die oft gehörte These, die in stolzem Wagemut das Vorhandensein absolut kollektiverInteressen schlankweg überhaupt leugnet und selbst die Notwendigkeit einer juristischen Ordnung, welche die Beziehungen zwischen den persönlichen Interessen der Mitglieder der menschlichen Gesellschaft regelt, verwirft, keinen Sinn hat, da es wissenschaftlich nicht angängig ist, zu be- 
haupten, daß es kein Band der Solidarität gebe, das sich um alle Individuen, welcher Klasse sie immer angehören mögen, schlinge, wie z. B. das Band der Solidarität, das alle, Arme wie Reiche, zwingt, sich einträchtiglich zur Bekämpfung der Infektionskrankheiten zusammenzuschließen. Es ist ein anderes, die Solidarität der sozialen Klassen im ProzeB der wirtschaftlichen Produktion und also auch in der Politik zu leugnen, ein anderes, die rein menschliche Solidarität der einzelnen Mitglieder der Gesellschaft untereinander leugnen zu wollen. Aber wenn auch die Kooperation in absehbarer Zeit unseres Erachtens auf dem ökonomischen und sozialen Gebiet niemals die Ausdehnungsfähigkeit erreichen wird, alle Kreise der Gesellschaft zu einer einzigen großen Interessengemeinschaft zu vereinigen, so gibt es doch einen Boden, auf dem die Kooperation unbekümmert um alle Verschiedenheiten gesellschaftlicher, nationaler und konfessioneller Natur zu gedeihen vermag. Dieser Boden ist die Wissenschaft. Der Gott der Wissenschaft ist kein Janus Bifrons. Die wissenschaftliche Kooperation, in deren Phalanx ich selbst in meiner Eigenschaft eines Mitgliedes des Lehrkörpers dieser erlauchten italienischen Universität als bescheidener Soldat von jenseits der Alpen als ein lebender Beweis für die Richtigkeit meiner These gelten kann $^{1}$ ), stellt zweifellos die reinste und vornehmste Form der Kooperation dar. Theoretisch außerhalb der Tageskämpfe stehend, denen die übrigen Formen der Kooperation ihre Entstehung verdanken, und über jedes Vorurteil erhaben, weil, wie Achille Loria mit markigem Wort gesagt hat, die politischen Parteien zwar Pflichten gegenüber derWissenschaft haben mögen, die Wissenschaft aber niemals Pflichten gegenüber den politischen

1) Der Grundstock dieses Kapitels besteht in der öffentlichen Antrittsvorlesung (Prolusione), welche schreiber dieses am I. Dezember 1908 zu einem Kolleg über Nationalökonomie an der Kgl. Universität Turin gehalten hat. 
Parteien haben $\operatorname{kann}^{1}$ ), empfindet die Wissenschaft, die ihrem innersten Wesen nach international ist, gegen keine einzige der Gesellschaftsklassen interessierten $\mathrm{Hab}$, da ihr einziger. und unteilbarer Zweck in der ernsten und strengen, aber vorurteilsfreien und gerechten Suche nach der Wahrheit besteht.

\section{Zweites Kapitel. \\ Zum Problem der Eugenetik.}

Unter den neuen Wissenschaften, die mit ihren antiken Namen das Herz der gebildeten Menge je nachdem erfreuen oder erschrecken, ist der Eugenismus die allerneueste. Im August I 912 hat sogar in London ein KongreB stattgefunden, zu dem große Gelehrte aus allen Teilen der bekannten Welt geeilt sind und an welchem die besten Kreise der eng. lischen Aristokratie und der englischen Gelehrtenwelt teilnahmen.

Was wollten diese Männer? Was war der Zweck des mit echt englischer Grandiosität veranstalteten Meetings? Die neue Disziplin, das ist unsere ganz offene Antwort auf die gestellte Frage, will nichts durchaus neues, noch ist sie an sich ein neuer Zweig der Wissenschaft. Sie will nur, was alle guten und gescheiten Menschen schon seit vielen tausend Jahren wollen: die physische, psychische und intellektuelle Besserung des Menschengeschlechtes der Zukunft, die Hervorbringung gutgeborener, daß heißt gutgezeugter Menschenkinder. Zur Erreichung dieses Zweckes ruft sie eine Reihe von Wissenschaften zur Hilfe. Von be-

I) Achille Loria, „La Scienza economica ed i Problemi sociali del nostro Tempo", öffentliche Antrittsvorlesung zu einem Kolleg äber Nationalökonomie an der Kgl. Universität Turin 1903, abgedruckt in seinem Werke: "Verso la Giustizia sociale“. $2^{\mathrm{a}}$ ediz., Milano-Roma-Napoli 1908, Soc. Edit. Libr., p. 26 I. 
reits bestehenden Wissenschaften, unter denen, wie auch die Zusammensetzung des genannten Kongresses, in welchem der Sohn des großen Darwin den Vorsitz führte, bewies, zwei die Hauptrolle spielten: die Anthropologie und die Nationalökonomie; die eine, um die naturwissenschaftliche, die andere, um die wirtschaftstechnische Basis des gestellten Problems zu prüfen. Der Eugenismus oder die Eugenetik ist also nicht so sehr ein neuer Wissenszweig als vielmehr, um im Bilde zu bleiben, ein neuer Versuch, bestehende $Z$ weige zu besserem und rascherem Wachstum zu verbinden, oder doch sie methodisch zu den gleichen Zielen in die gleiche Direktion zu bringen.

Es ist selbstverständlich, daß die Eugenetik sich zunächst mit dem Studium des Hauptsubjektes in der menschlichen Gesellschaft beschäftigen muß. Dieses kann nur das Proletariat, oder, um auch die kleinen Agrarstaaten Süd- und Nordeuropas zu berücksichtigen, das „Volk“ sein. Nicht nur wegen der numerischen ziffernmäßig feststellbaren Größe dieses Bevölkerungselementes. Auch wegen der traurigen biologischen Lage, in welcher es sich befindet. Diese geht klar hervor für den, welcher sich die Mühe gibt, die physischen, demographischen und mentalen Charaktere der die sog. „oberen“ und die sog. „unteren“ Klassen der Gesellschaft ausmachenden Individuen untereinander zu vergleichen. Es stehen dazu bekanntlich mehrere Methoden zu unserer Verfügung. Es sei nur auf einige der vorzüglichsten hingewiesen, welche die genauesten Resultate geliefert haben: Der Vergleich kann zwischen armen und reichen Kindern ein und derselben Schule auf Grund der Berufsstatistik der Eltern angestellt, also die Verschiedenheit zwischen beiden Gruppen bei Gleichheit des Alters, des Milieus und der Tätigkeit nachgewiesen und festgestellt werden. Oder auch der Vergleich findet zwischen verschiedenen Berufsgruppen Erwachsener statt. Endlich, noch umfassender, es werden ganze Stadtteile, die nur von Reichen oder nur 
(bzw. überwiegend) von Armen bewohnt werden, miteinander verglichen. Alle derartigen Untersuchungen stimmen darin überein, daß ihr Endergebnis in der untrüglichen Feststellung der Minderwertigkeit der handarbeitenden Volksschichten gipfelt. In der Tat stehen diese hinter den reichen sowohl an Körpergröße wie an Schädelweite, an meß. barer Sensibilität, an Widerstandsfähigkeit gegenüber der Müdigkeit usw. zurück. Mehr noch: sie sind physisch mit einer weit höheren Anzahl von Anomalien behaftet, ihre Töchter entwickeln sich langsamer, die Menstruation tritt bei ihnen später ein usw. Sie sind anthropologisch gesprochen minderwertig. Hier steht die neue Wissenschaftssynthese, die wir als Eugenetik bezeichnen - und wir können diese Dinge hier nur andeuten - nun vor der letzten Frage, die wir sogar nicht anstehen, als die grundlegende Frage der gesamten Wissenschaft zu bezeichnen, nämlich vor der, ob die unleugbare Inferiorität der unteren Volksklassen auf granitenem anthropologischem Boden beruht und die Klassenabstufung also nur als ihre Folge erscheint, oder ob vielmehr die untergeordnete „Rasse“ nicht nur eine Folgeerscheinung wirtschaftlicher Bedingungen ist, mit anderen Worten, ob die minderwertige Anthropologie der nichtbesitzenden Klassen aus den Lohn- und Lebensverhältnissen abzuleiten und mit ihnen zu beseitigen sei. Freilich läßt sich diese Frage auch weniger absolut stellen. Dann würde die Fragestellung mit denWorten beginnen müssen: In wie weit ...?

Der Eugenismus besteht in einem Abwägen zweier Größen und einem Bestimmen des minderen Übels. Die Freunde des Militarismus haben diesen ebenfalls als durchaus im eugenetischen Interesse liegend in Anspruch nehmen wollen. Sie betrachten ihn als ein Element der Menschenveredelung nicht nur im moralischen, sondern auch im physischen Sinne. Sie weisen auf die die Körperkräfte und gesunde Energie des Rekruten stählende militärische Zucht, auf das Leben in frischer Luft und in der "Natur" hin und versichern stolz, 
der junge Mann verlasse den Militärdienst weit mehr gestählt und auf seinen Beruf als Erzeuger eines besseren, tüchtigeren Menschengeschlechtes physisch weit besser vorbereitet als er ihn einige Jahre zuvor angetreten habe. In diesen Argu- * menten liegt jenes Körnchen Wahrheit verborgen, das allen menschlichen Aussagen, insoweit sie nicht Insassen des Irrenhauses entstammen, innewohnt. Aber dieses Körnchen Wahrheit liegt doch hier unter sehr vielen groben Körnern Unwahrheit. Zunächst ist schon die These von der moralischen Kraft des Militarismus anfechtbar. Zugegeben, daß teils infolge des künstlich gepflegten Ehrbegriffes, teils infolge der gesellschaftlichen Auslese der mittlere Berufsmilitär an Ehrenhaftigkeit den durchschnittlichen Advokaten und Kaufmann eher übertrifft, so ist doch andererseits die ver:rohende Wirkung eines einzig der Menschenmordung geweihten Berufszweiges zumal auf die ohnehin schon mit sehr primitiven Auffassungen über den Wert des Menschenlebens zur Armee kommenden Bauernburschen unverkennbar. Was die Behauptung anbelangt, daß die Dienstzeit einem Kräftigungsproze $\beta$ der männlichen Jugend gleichkäme, so ist zunächst zu bemerken, daß ja nur die bereits ausgewählte Elite körperlich Starker in Frage kommt, so daß sich jeder Vergleich zwischen der Mortalität im Heere und der Mortalität der Bevölkerung oder auch nur des gleichaltrigen Teiles der männlichen Zivilbevölkerung von vornherein von selbst verbietet. Unverkennbar ist natürlich, daß das Militärleben trotz aller Strapazen, im Frieden wenigstens, gesünder ist als das Leben in einer Anilinfabrik. Aber andererseits ist auch nicht zu vergessen, daß das Soldatenleben, wie jedes andere gedrängte Zusammenleben junger Menschen, sittlich und gesundheitlich Gefahren in Hülle und Fülle bringt, die das Zivilleben in dem Maße nicht kennt. Alles in allem betrachtet, erscheint es mehr als $z$ weifelhaft, ob die stehenden Heere der Neuzeit wirklich der Idee der Eugenetik in Friedenszeiten gute Dienste leisten. Vom Kriege dabei ganz zu schweigen. 
Unter die glücklicheren Partien einer neueren Schrift Gold. scheids sind unseres Erachtens die Betrachtungen zu rech. nen, die der Verfasser in einem Kapitel über das "Naturrech", den historischen Rechtsgedanken und das Entwicklungsrecht zusammenfaßt. Goldscheid stimmt mit der historischen Rechts. schule darin überein, daß das Recht keine normativen Begriffe kennt, die für alle Zeiten die gleiche Gültigkeit aufweisen, sondern daß das Recht dem organischen Werden der Gesellschaft unterliegt und deshalb Schwankungen und Veränderungen seiner Struktur aufweist. Aber er glaubt doch, den Normbegriff, der allein dem Recht einen ethischen Halt verleihe, nicht ganz aufgeben zu dürfen, und schlägt deshalb folgende Lösung der viel umstrittenen Frage vor: $\mathrm{DaB}$ das Recht zu jeder Zeit als das Produkt abstrakter Konstruktion betrachtet werden müsse, wenn es sich auch, wenigstens insofern die positive Gesetzgebung in Frage komme (was $z u$ bedenken sei), im Laufe der Zeit verändere. Diese Synthese nennt er Entwicklungsrecht. ${ }^{1}$ )

Wie ist in einem bestimmten Fall, fragt sich der Verfasser weiter, zu entscheiden, was das Recht ist? Wenn sich zwei verschiedenartige Persönlichkeiten um ein bestimmtes Gut streiten, so ist weder das Naturrecht, noch das auf Gewalt beruhende und ein Resultat von Stärkeverhältnissen darstellende sog. historische Recht imstande, die gerechte Ent. scheidung zu bringen. Diese Entscheidung müsse hingegen dem Entwicklungsrecht leicht fallen. Dieses werde stets ohne Schwierigkeit die Entscheidung darnach fällen können, ob „der im Überfluß schwimmende Snob oder das darbende Genie" einen größeren Anspruch auf ein bestimmtes $O b$. jekt habe. $\left.{ }^{2}\right)$ Jedoch möchten wir uns mit dieser Theorie nicht ohne weiteres zufrieden geben. In der Tat: wie stellt sich

I) Rudolf Goldscheid, Entwicklungswertheorie, Entwick. lungsökonomie, Menschenökonomie. Eine Programmschrift, Leiprig I 908. Werner Klinkhardt, $21 \delta \mathrm{pp}$.

2) p. 164 . 
die Rechtsfrage, wenn nicht der im Überfluß schwimmende :Snob dem darbenden Genie, sondern dem darbenden Snob - die Analyse unserer Gesellschaftsschichten weist auch die Existenz dieses Typus auf - das im Überfluß schwimmende Genie gegenübersteht? Das Genie besitzt unzweifelhaft kraft seiner psychischen Außergewöhnlichkeit und, könnte man hinzufügen, kraft der Fäden, die es doch wohl mit der Pathologie verbinden, ein seiner größeren Differenziertheit entsprechendes Plus von Bedürfnissen, und also auch von Naturrechten, Menschenrechten für sich; wenn auch nicht rein formaler, so doch, um des Verfassers eigene Sprache zu reden, evolutionistischer Rechte. Gewiß sagt auch Goldscheid, der evolutionistisch Fortgeschrittene dürfte vom evolutionistisch minder Fortgeschrittenen Opfer verlangen. Nur fordert er, daß sich dieses Verlangen auf solche Opfer beschränke, die im Interesse der rapidesten und solidesten Steigerungen des sozial evolutionistischen Mehrwerts notwendig seien, also keine Entbehrungen heische, die jenen oder die Gesellschaft in höherem Maße schädigen, als sie diesen in seiner Entfaltung fördern. Das ist aber wiederum, will uns scheinen, ein sehr schwankendes und unbestimmbares Kriterium, über dessen Inhalt uns weder formelles noch gewordenes Recht AufschluB gibt. Die Ungerechtigkeit der Natur setzt der Gerechtigkeit im Recht enge Schranken und verurteilt angewandte Gerechtigkeit, das Rechttun, zu lebenslänglichem Relativismus. Auch Goldscheids epigenetischer Gerechtigkeitsbegriff, der zweifellos eine höhere Entwicklung des Rechtskriteriums bedeutet, wird in Einzelfällen ohnmächtig sein, die ihm gestellten Aufgaben zu lösen. Dagegen ist er uns als Direktive, als Willensrichtung, als Tendenz vom höchsten Werte. Er ist uns sittliche Norm und richterlicher Maßstab zugleich.

Der Hauptwert der Programmschrift Goldscheids, die in Ton und Stimmung prophetenhaft ist, ohne deshalb gekünsteltem Pathos zu verfallen, liegt für uns aber überhaupt auf 
ethischem Gebiete. Habe ich Goldscheid richtig verstanden, so legt er den Hauptnachdruck seiner Theorie auf eine neve und höhere Wertung des Menschentums in der Soziologie oder sagen wir ganz einfach in der Wissenschaft. Wogegen er sich mit aller ihm zu Gebote stehenden Macht wendet, - und diese Macht ist in Anbetracht seiner Kenntnisse auf den verschiedensten Wissensgebieten nicht gering - das ist die niedrige Einschätzung, die in der modernen Wissenschaft von Darwin und von Marx bis Nietzsche dem Menschen als solchem zuteil wird. Der Mensch ist kein überflüssiges Gut, - das ist wohl, wenn man seine Ausfuhrungen auf die kürzeste Formel bringen will, die Quintessenz der Weltanschauung, der Goldscheid einen nicht unbeträchtlichen Teil seiner Schrift widmet. Von dieser These aus erkennt Goldscheid auch die Möglichkeit einer Übervölkerung nicht an, kann sie nicht anerkennen. Bei alledem wertet Goldscheid vielleicht nicht immer in genügender Weise die Wichtigkeit des ökonomischen Koeffizienten der Geschichte, wie sich überhaupt mit ihm über Begriff, Wesen, Spannkraft der Ökonomie (wie er sie formuliert) streiten läßt. Vielleicht überwiegt bei ihm manchmal das teleologische Element, sein glühender Optimismus, der ihn auch dann mit fortreißt, wenn dem Pathos ernste Probleme den Weg verlegen müßten. So in der Frage der Entwicklung, die sich Goldscheid offenbar nur nach aufwärts gerichtet vorstellen kann.

Im ganzen wird die Vorsorge für die Zukunft des Menschengeschlechtes indes mehr negative als positiveWege gehen müssen. Es wird ihr mehr obliegen, zu verhindern, daß die Rasse bewußt verschlechtert wird als zu erzwingen, daß sie besser werde. Um an zwei Beispielen die Sache zu erläutern: die Eugenetik wird nicht dahin trachten dürfen, Menschen zu züchten, wie man Kaninchen züchtet, etwa blonden Männern die Ehe nur mit schwarzhaarigen Mädchen zu gewähren, andererseits aber überall da helfend gesetzgeberisch eingreifen können, wo es gilt, untauglichen Menschen die Zev- 
gung ebenso untauglicher Kinder unmöglich zu machen. Man mag über die Sterilisierungsversuche schwerer Verbrecher, wie sie in einigen Staaten der Nordamerikanischen Union unternommen worden sind, noch kein endgültiges Urteil fällen; soviel aber darf doch wohl schon heute mit voller Bestimmtheit ausgesprochen werden, dab sich die Justizpflege hierbei auf dem richtigem Wege befindet und einer eugenetischen Auffassung des „Weltgetriebes" sehr wertvolle Fingerzeige zu geben im Begriffe steht.

Allerdings ist die Lösung aller dieser Fragen mit Wenn und Aber gespickt und Vorschnelligkeit bedeutet in diesen Zusammenhängen oft Unmenschlichkeit, ja, Verletzung des elementarsten Gedankens der Gerechtigkeit. Ich habe an anderer Stelle ${ }^{1}$ ) ausführlicher darzulegen versucht, daß die sogenannte Notzucht, wenn nicht schwere geschlechtliche Reizung des Mannes seitens des Weibes, so doch zum mindesten schwere Feigheit, mehr noch, fast stets auch eine moralische Schuld des Weibes selbst voraussetzt. Alte deutsche Juristen, wie Carpzovius, haben als Kriterium für die Tatbestimmung der Notzucht die absolut negative Beantwortung der drei Fragen angegeben: War das fallende Weib unmittelbar vor dem Geschlechtsakt mit der Begehung dieses einverstanden? War sie es während desselben? War sie es nachträglich, nachdem derselbe mit inr ausgeübt worden, beziehungsweise beim zweiten Gange? ${ }^{2}$ ) Es ist ohne weiteres klar, daß bei einer derartig strengen Fassung achtzig von hundert der Notzuchtsfälle nicht als solche angesehen werden dürfen. Die Verantwortlichkeit der Frau, ja selbst ihre Mitschuld ist in vielen Fällen unmöglich zu bestreiten. An-

I) Robert Michels, „Die Grenzen der Geschlechtsmoral. Prolegomena. Gedanken und Untersuchungen". München-Leipzig i911, Frauenverlag, 2. Aufl., p. $84 \mathrm{ff}$.

2) „Benedicti Carpzovii Praticae Novae Imperialis Saroniae Rerum Criminalium." Pars I, Francofurte ad Moenum MCXXLVIII, p. 2 I 8. 
deres kommt dazu, um die Fälle der Notzucht noch weiter zu verringern, z. B.: Suggestion und falsche Phantasterei kleiner Mädchen, die zu törichten, aber gefährlichen Anklagen führen kann. Kurz, der Richter kann gerade bei Notzuchts. prozessen mit der Verhängung schwerer und entehrender Strafen nicht vorsichtig genug zu Werke gehen.

Indes alles das hat natürlich wieder seine Grenze. Es gibt unzählige Fälle, in denen die große Geistes- oder Willensschwäche des Weibes nur der Skrupellosigkeit des Man. nes Vorschub leistet. Und wenn auch der Notzuchtparagraph hier nicht am Platz sein mag, so ist doch ein anderer genügender strafrechtlicher Schutz dringend nötig. Die „Verführung unter Zusage der Ehe", die z. B. das österreichische Strafgesetz kennt, ist allerdings so schwer zu beweisen, daß zumeist selbst in wohlberechtigten Fällen diese Strafbestimmung nicht anrufbar ist. Und doch sind gerade vom Standpunkt des Eugenismus die Folgen solch halbgewollter, halberzwungener, jedenfalls unverantwortlicher Zeugungsakte doppelt beklagenswert. Bei zweifellos klarersichtlich liegenden Fällen aber, da wo der Zweck mit Waffengewalt und unter auch nur wörtlicher Bedrohung von Leib und Leben vonstatten ging, ist keine Gnade angebracht. Hier handelt es sich darum, die Menschheit vor Bestien zu schützen und hier geht die Pflicht des Gesetzgebers sogar weit über den Schutz der gegenwärtig lebenden Menschheit hinweg in die Zukunft. Es muß ihm darauf ankommen, nicht nur die Frauen von heute vor der Existenz, sondern auch die Frauen der Zukunft nach Möglichkeit vor der Entstehung solcher Männer zu schützen, welche für ihre Person die ganze Kulturentwicklung vom reißenden, seine Wünsche und Begierden rücksichtslos verfolgenden Tier zum Zivilisierten, der gerade den Geschlechtsverkehr als nur auf der Basis der Gleichartigkeit und Gegenseitigkeit sittlich möglich erkannt hat (obgleich auch da noch viel zu sagen wäre!), rückgängig gemacht haben. Die Verhinderung des berufsmäBigen Notzüch- 
tigers an der Kindererzeugung bei möglichster Konservierung und Respektierung seiner geschlechtlichen immanenten Rechte, durch die Sterilisierung, ist deshalb als erfreuliche, in der Richtung auf die Ziele der Eugenetik liegende Anregung zu begrüßen. Es erhellt ohne weiteres, daß was hier von der Ausschaltung der Sexualverbrecher aus der Reihe der das Geschlecht der Zukunft Zeugenden gesagt worden ist, mutatis mutandis et reservatis reservandis auch von vielen anderen Spezies von Verbrechern, ebenso wie, wennschon hier aus wohl begreiflichen ethischen Gründen vorsichtiger vorgegangen werden muß, von mit schweren, erblichen Krankheiten Belasteten wiederholt werden müßte. Auch der schwere, berufsmäßige Alkoholiker dürfte, ohne daß die Individualisten ein Recht hätten, von der Vergewaltigung der heiligsten Menschenrechte zu parlieren, mit gutem Gewissen aus der Reihe der zukunftsbildenden Geschlechtsmenschen gestrichen werden.

Keine nietzscheanische Kunstproduktion von Übermenschen, sondern eine anthropologische Besserung der Rasse durch Eliminierung gänzlich untauglicher wie sittlich minderwertiger Elemente aus der geschlechtlichen Zirkulation und, worauf wir vielleicht noch größeren Wert legen möchten, das Einsetzen einer die ökonomischen und sozialen Verhältnisse des Menschen bessernden Reformarbeit. Darin scheint uns, in Stichworten angegeben, die Aufgabe des Eugenismus zu bestehen.

\section{Drittes Kapitel.}

\section{Zum Problem: Solidarität und Kastenwesen.}

Die Solidarität ist der direkte Ausfluß der Klassenantagonismen. Diese stehen zu jener im gleichen Verhältnis wie die Ursachen zur Wirkung. Wenn in einem Lande die Solidarität der Klassen vielleicht einen höheren Grad er- 
reicht hat als in den meisten übrigen Ländern, so ist die Erklärung für die Tatsache darin zu suchen, daß in ihm eben die Gegensätze ökonomischer, sozialer, intellektueller, konfessioneller und traditioneller Natur zu bedeutenderer Höhe gestiegen sind als in der Mehrzahl der übrigen Län. der. Darum bin ich auch sehr weit davon entfernt, gleich dem Baron Raffaele Garofalo auf dem Internationalen SoziologenkongreB in Bern 1909 , die Gewerkschaften und die Streiks als Störungen, ja als handgreifliche Negationen des Geistes der Solidarität zu bezeichnen ${ }^{1}$ ), sondern erblicke in ihnen umgekehrt eine der wenigen heute möglichen Arten praktischer Anwendung der Solidarität. Gewiß ist selbst die begrenzte, aus dem gemeinsamen $\mathrm{HaB}$ gegen einen ge. meinsamen Gegner geborene Solidarität mit Dornen be. deckt. Oft fehlt ihr selbst einer ihrer wesentlichsten logischen Koeffizienten: die Freiwilligkeit und Unmittelbarkeit, wie denn z. B. die Arbeiter die starke Tendenz haben, der So. lidarität einen koerzitiven Sinn zu geben, indem sie ihre Genossen gern zum Eintritt in die Gewerkschaften sowie, in noch höherem Maße, zur Kohäsion in den Arbeitsausstellungen zwingen. Indes, auch wenn wir von der koerzitiven Solidaritat absehen und uns auf die Untersuchung der spontanen Solida. rität beschränken, sehen wir doch in der Solidarität zwei Elemente vorhanden und sich die Wage halten: Opferfreudig. keit und Eigennutz. Der Begriff des Nutzens ist von der praktischen Solidarität nicht $\mathrm{zu}$ trennen. Also sind Altruismus und Egoismus gleich notwendige Ingredienzien der angewandten Solidarität. Nicht Sympathie und Gerechtigkeitsgefühl allein geben die Basis zu der Vereinigung und $\mathrm{Zv}$ sammenarbeit. Wir vermögen mit Squillace und anderen nicht völlig darin übereinzustimmen, daß Gefühle wie der Haß Hin-

I) Annales de l'Institut Internationale de Sociologie. Tome XII: "La Solidarité Sociale dans le Temps et dans l'Espace." Paris 1910. Giard et Brière, p. 62. 
dernisse für soziale Bindung darstellen. ${ }^{1}$ ) Ich möchte sagen: es kommt hier auf das Objekt an. Gewi $B$ wird der Hassende mit dem Gehaßten nicht zusammenarbeiten. Er wird aber, von diesem $\mathrm{Ha \beta}$ getrieben, mach Personen suchen und sich mit ihnen zusammenfinden, welche die gleichen Objekte mit ihrem $\mathrm{HaB}$ verfolgen. Ich möchte den $\mathrm{HaB}$ insofern als die bedeutendste Triebfeder der Solidarität bezeichnen.

Die Himmelsblume der Solidarität wächst und gedeiht bloß auf dem vulkanischen Boden der Interessengegensätze. Eine allgemeine Solidarität der Gesellschaft - die Solidarität in ihrer reinsten Form - besteht nur gewissen elementaren Naturereignissen gegenüber - gegen die Epidemien, die Erdbeben und eventuelle Einfälle barbarischerVolksstämme $\left.{ }^{2}\right)$-, ohnehin auch dort nicht ihren Charakter der Abwehr verleugnend. Bei Betrachtung des Phänomens der Solidarität auf dem ökonomischen und sozialen Gebiete ist unter diesem Terminus ohne weiteres eine partielle Solidarität $z u$ verstehen. Die Solidarität des Menschengeschlechts ist, gleich der Interessengemeinschaft der Gesellschaftsklassen, eine Utopie, weil sie die Lösung teils noch ungelöster, teils überhaupt unlösbarer wesentlicher Probleme voraussetzt. Heute kann die Solidarität, oder was wir so nennen, nur als Folgeerscheinung eines fehlerhaften Equilibriums betrachtet werden. Zur Bildung eines Solidaritätskreises ist a priori die Existenz scharfer Gegensätze erforderlich; man ist nur solidarisch gegen jemand. Die Solidarität, dieser unentbehrliche Kern jeder Kooperation, birgt also ein überwiegend negatives Element in sich.

Die Einzelindividuen werden durch das Schmerzgefühl vereinigt, welches sie veranlabt, gegen sie drückende Leiden zu reagieren. Die Sonderinteressen, Unglück wie Wohl-

1) Fausto Squillace, "Dizionario di Sociologia“ (2. Aufi.). Palermo 1911. Sandron, p. 275.

2) Vgl. p. 43. 
ergehen, üben auf die Menschheit eine lediglich trennende Wirkung aus. Intellektuelle Verschiedenheit und wirtschaft. liche Ungleichheit machen die Individuen gegeneinander gleichgültig oder feindlich. Nur derSchmerz, imVerein mit dem Verständnis für die Gemeinsamkeit bestimmter Bedürfnisse, vermag in ihnen ein Gefühl für die Notwendigkeit gegenseitiger Hilfe zu erwecken. Die Gemeinsamkeit nicht gesättigter Interessen ist die Mutter sozialer Solidarität. Es besteht also ein nahes Verhältnis zwischen den sozialen Antagonismen und der partiellen Solidarität: die Intensität der Solidarität wächst oder sinkt je nach dem Wachsen oder Sinken der Antago. nismen. In einem Milieu, in dem keine Antagonismen vor. handen wären, würde auch die Solidarität sich nicht entfalten können.

Auf diese Prämissen gestützt möchten wir eine These aufstellen, deren Richtigkeit wir im folgenden beweisen wer. den: Obgleich das rein humanitäre und individuelle Gefühl der Solidarität in Deutschland vielleicht weniger entwickelt ist als in anderen Ländern, wie z. B. in Italien - was dar. zustellen freilich aus dem Rahmen unserer Aufgabe herausfallt -, so gibt es doch andererseits vielleicht kein Land, in welchem die partielle Solidarität einen so hohen Grad erreicht hat, als Deutschland.

Um das zu beweisen, brauchen wir nur die Größe der Anta. gonismen anzudeuten, welche die verschiedenen Interessensphären in jedem Lande unterscheiden. $\mathrm{Zu}$ diesem Behufe darf wohl in erster Linie daran erinnert werden, wieviel das moderne Deutschland noch von dem alten Kastendeutschland bewahrt hat. Die Quintessenz des Kastensystems besteht besonders in einer sehr starken, aber sehr eng begrenzten Solidarität. Die Solidarität verbundet nur Gleiche und derselben Kaste Angehörige. Es ist das Charakteristikum der Kaste, daß sie für alle ihr nicht angehörigen Elemente nur Gefühle der Geringschätzung oder doch der Interesselosig. keit besitzt. Darum bewahrt sie trotz aller persönlichen Zwistig. 
keiten, trotzdem Ehrgeiz, Eigenliebe und Charakterverschiedenheiten auch ihre eigenen Komponenten voneinander scheiden und trennen, ihre geschlossene Einheit gegen jedweden, der ihr als Ganzem, d. h. ihren kollektiven Interessen zu nahe tritt. Daher dasVorhandensein jenes sog.Korpsgeistes, welcher die deutsche Gesellschaft je nach dem Grade des Wohlstandes, den Berufen, der sozialen Herkunft, der Religion usw. in tausend kleine Kreise einteilt und untereinteilt, und welcher die Mehrzahl der deutschen Kleinstädte für denjenigen, welchem geistige Freiheit und Menschenwürde lieb ist, so unbewohnbar macht. Aus der gleichen Quelle ist auch jener beklagenswerte Mangel an Toleranz, welcher das soziale und politische Leben Deutschlands charakterisiert, entsprungen, dem zufolge es genügt, Sozialist zu sein, um von den herrschenden Klassen und dem Staat wie ein Aussätziger behandelt und nicht nur aus den Salons der sogenannten guten Gesellschaft, sondern auch von den Lehrstühlen der Universitäten und selbst dem bescheidenen Amt eines Landbriefträgers ausgeschlossen zu werden, und dem zufolge andererseits das Wort Bourgeois in einzelnen sozialistischen Arbeiterkreisen einen wahren Horror auslöst. Aber dieser Korpsgeist bringt andererseits eine ganze Reihe von auf Kastensolidarität begründeten Einrichtungen hervor, welche ausgezeichnet funktionierende Organisationen ins Leben gerufen haben, wie z. B. die studentischen Korps und, auf wirtschaftlichem Gebiet, eine große Anzahl von Instituten, Unterstützungskassen für Studenten, Söhne und Töchter altadeliger Familien usw. Bisweilen erinnert der in ihnen herrschende Geist der Engigkeit und Heimlichkeit in den gegenseitigen Hilfeleistungen ihrer Nitglieder an die Freimaurerschaft oder auch an gewisse Formen der süditalienischen Camorra.

Der Kastengeist ist durch den Industrialismus, oder besser gesagt durch die Faktoren der modernen Wirtschaft noch stärker, wenn auch mehr in die Breite, entwickelt worden. Wenn der siegreiche Kapitalismus einerseits ohne Zweifel 
durch die riesengroßen Differenzen, welche er in der Ver. teilung der Güter hervorgebracht hat, einen wahren Abgrund zwischen den beiden wesentlichsten Gesellschaftsklassen ge. schaffen und dadurch die bereits vorher bestehenden Kon. traste noch vertieft und vergrößert hat, so ist er andererseits gerade deshalb zu einer Musterschule der Solidarität ge. worden. Besonders die Arbeitermassen sind durch den Ka. pitalismus vorzüglich in der Solidarität geschult worden. Sie leiden heute unter denselben Übeln, sie hegen heute die. selben Wünsche und Hoffnungen; sie sind außerdem auch durch den großindustriellen Produktionsmechanismus in gi. gantischen Werkstätten zu gemeinsamer Arbeit vereinigt und durch die dadurch bedingte ständige technische Zusammen. arbeit und den psychologischen Kontakt untereinander leicht organisierbar geworden. ${ }^{1}$ ) So sind die Arbeitermassen des industriellen Deutschlands sozusagen dazu prädestiniert, die Avantgarde der mächtigen Solidaritätsarmee dieses Landes zu bilden. Aber diese Prädestination hat ihren Ursprung nicht nur in den technischen Verhältnissen der modernen Industrie; sie entspringt zugleich auch aus dem deutschen Nationalcharakter, aus jenem Geist des Zusammenschlusses und der Disziplin, aus jenem Bedürfnis nach Führung, wel. che auch von Georges Blondel in seinen Studien über Deutsch. land hervorgehoben werden ${ }^{2}$ ), aus jener Neigung zur Syste. matisierung, welche, einem anderen ausländischen Sach. kenner, William Harbutt Dawson, zufolge, den Schlüssel zo allen deutscherseits auf den verschiedensten Gebieten er. fochtenen Siegen biete ${ }^{3}$ ) und welche einen Landsmann des letzteren, B. H. Thwaite, zu dem Ausspruch veranlaßte, der wesentlichste Unterschied zwischen Deutschland und Eng.

1) Vgl. p. I4.

2) Georges Blondel, „L'Essor économique de l'Empire Alle. mand". Paris 1898, p. 31 .

3) William Harbutt Dawson, "The German Workman. A Study of national Efficiency". London I 906, King, p. VIII. 
land sei ebenderselbe, welcher zwischen dem Kosmos und dem Chaos, zwischen dem Verantwortlichkeitsgefühl und der Unverantwortlichkeit besteht. ${ }^{1}$ )

Die Kaste im älteren, strengeren Sinne des Wortes ist ausgestorben. Durch geschriebenes Gesetz voneinander gesonderte Gesellschaftsschichten existieren nicht mehr. Selbst in Indien ist die Kaste in diesem Sinne durch das Gesetz abgeschafft. Die moderne Demokratie hat, auch in der Mehrzahl der überwiegend aristokratisch regierten Länder, alle Schranken, die eine geschlechtliche Vermischung verschiedenen Kreisen angehöriger Menschen sowie das Aufsteigen von einem dieser Kreise in einen anderen verhinderten, eliminiert. Das von Rechts wegen. Die Sitte hat diese Entwicklung, welche zur Zerstörung der alten Kasten geführt aat, zum großen Teile mitgemacht. Die moderne Geldwirtschaft stellt sich als ein fürchterlicher Hexenkessel dar. Alle schranken der alten Ordnung wurden niedergebrochen und ür eine Zeitlang der soziale Austausch zwischen den Klasien beschleunigt. Trotzdem ist die Kaste auch heute nicht töllig getilgt. Teils hat sie auch in der Demokratie und trotz tes Zustandes der Schutzlosigkeit, in welcher sie vom Ge:etz gelassen worden ist, die Stürme der Zeit überdauert, eils sind ihr aus der geordneten Arbeitsteilung, in welcher schon Friedrich Albert Lange den Keim der Kastenbildung srblickte ${ }^{2}$, neue Lebenselemente entstanden. Letztere dürfen reilich bei der großen Leichtigkeit, mit welcher insbesondere Jie moderne Arbeiterbevölkerung vielfach von einem Beruf zum anderen überzugehen und innerhalb kurzer Zeitspanne sine große Anzahl von verschiedenen Gelderwerbsarten zu :ersuchen pflegt $^{3}$ ), nicht überschätzt werden.

I) B. H. Thwaite, "The Rise of Germany 1870-1905“. Lonlon 1906, King, p. 23.

2) Fr. A. Lange, „Die Arbeiterfrage, ihre Bedeutung in Geenwart und Zukunft". 3. Aufl. Winterthur 1875, Bleuler, p. 55.

3) Vgl. Werner Sombart, „Das Proletariat. Bilder und Stu- 
In den oberen Ständen indes ist der Mangel an Kasten. geist nur scheinbar. Vielfach möchte man den Satz auf. stellen: auf der Straße Gleichheit, im Salon Ungleichheit Der italienische Aristokrat verkehrt in der Volksversamm. lung, im Café, im Bureau, auf dem Sportplatz, mit den An. gehörigen der anderen Stände ohne jede ostensible Distanzierung. Aber über die Schwelle seines Hauses und insbe. sondere die des Salotto seiner Frau läßt er doch nur solche Personen treten, die der gleichen gesellschaftlichen Sphäre angehören wie er selbst.

Bei der Analyse der Entstehung und Erhaltung der Kaste verdient die Lebensführung der Frau besondere Beobachtung. In fast allen Kulturstaaten ist die Erziehung der Frau enger, mehr an das Haus gebunden, als die des Mannes. Das Mädchen hat infolgedessen weit weniger Gelegenheit, seinen Blick zu weiten, es bleibt viel tiefer in den Lebensgewohnheiten der Familie und des Menschenkreises, den diese Lebensgewohnheiten umfassen, stecken als der Mann, den die freiere Lebensführung mit sehr verschiedenen Kreisen in Kontakt bringt Das Gesagte bezieht sich zumal auf das Schulwesen. Überall, zumal in der Schweiz, Österreich, Deutschland und Italien, aber auch, obgleich in geringerem Maße, in Frankreich und Eng. land (in welchen Ländern einige exklusive Schulen bestehen), verleben die jungen Leute die Schulzeit in von zahlreichen Knaben ihres Alters, die, wennschon natürlich nicht aus allen Klassen, so doch aus allen Schattierungen einer großen Klasse stammen, besuchten großen, innerhalb der angedeuteten Grenzen von demokratischem, kameradschaftlichem Geiste getragenen Schulen: Gymnasium, Universität. Gewiß macht sich auch dort die immanente Anziehungskraft homogener Ele-

dien“. Frankfurt a. M. I906, Rütten u. Loening, p. 64 ff. Für gelernte Arbeiter jedoch scheint sich diese Beobachtung nicht zu bewahrheiten. (Vgl. Marie Bernays, „Berufswahl und Berufsschicksal des modernen Industriearbeiters". Archiv für Sozialwiss. u. Sozialpol., Bd. 36, Heft 3, p. 890 ff.) 
mente geltend, aber die Auswahl des Verkehrs geht doch keineswegs allein nach Kastenkriterien vor sich. Auch wirkt die erwähnte demokratisch-kameradschaftliche Atmosphäre häufig doch auf eine Fusion der in ihr lebenden Elemente. Nicht so bei den jungen Mädchen. Sie werden entweder nur zu Hause unterrichtet oder besuchen doch, zumal was die höheren Kreise der Bourgeoisie und des Adels, und unter ihnen wieder zumal die katholischen, betrifft, Anstalten, die auf einen weit weniger zahlreichen Kreis von Schülerinnen reflektieren und deshalb bewuBt oder unbewuBt, absichtlich oder unabsichtlich, nur von einem bestimmten Ausschnitt ein und derselben sozialen Klasse besucht werden: Pensionate, Klöster. Die gesellschaftliche Abgeschlossenheit und Einseitigkeit des Verkehrs, das Untersichsein ganz bestimmten Kreisen angehöriger junger Mädchen ist die Regel höherer weiblicher Erziehung. So atmen die Mädchen mit vollen Lungen Kastenluft in sich ein und, einmal verheiratet, suchen sie auch den Umgang ihres Mannes nach Möglichkeit nach Kastenrücksichten zu bestimmen. Ihre Ansichten sind enger als die ihrer Männer, weil das Milieu, in dem sie ihre Entwicklungsjahre verbrachten, enger war als das ihrer Männer, als sie noch junge Leute waren. So wird die Frau in der Regel zur stärksten Basis für die Fortdauer des Kastenbewußtseins in der Familie.

Das sicherste Kriterium für die Existenz gesellschaftlicher Kasten besteht in der starken Anziehungskraft gesellschaftlich homogener Teile und der ebenso starken Abstoßungskraft gesellschaftlich heterogener Teile, wie sie bisweilen beim Vergleich der Ziffern der Nuptialität zum Ausdruck kommt. Dieser gibt freilich Ergebnisse, die jeden in Erstaunen setzen, der nicht mehr als oberflächliche Kenntnisse auf diesem $\mathrm{Ge}$ biete besitzt. Wenn wir zum Beispiel unser Augenmerk auf einen Vergleich der Heiraten zwischen Juden und Geburtsaristokraten in den einzelnen Ländern richten, werden wir gewahr, daß die Leichtigkeit der Verheiratung zwischen Mit- 
gliedern der beiden Gruppen keineswegs der Leichtigkeit der sonstigen gesellschaftlichen Beziehungen und der Grad. stärke der in den einzelnen Ländern vorhandenen demo. kratischen Einrichtungen oder auch nur Anschauungen entspricht, sondern, anscheinend ganz unlogisch, die entgegengesetzte Tendenz verfolgt. Die Attraktion zwischen Juden und "Ariern", wenigstens insoweit sie in den Eheziffern zum Ausdruck kommt, nimmt mit zunehmender Abgeschlossenheit der alten christlichen Gesellschaft zu. In keinem Lande der Welt sind die Juden im Besitz so geringer Rechte als in RuBland. Keine Kaste der Welt ist in ihrem gesellschaft. lichen Verhalten den Juden gegenüber so zurückhaltend und abweisend wie der preußische Adel. Andererseits spielen die Juden in keinem Lande der Welt eine so mächtige Rolle als in Italien, dessen Regierungsspitze sowohl wie Hauptstadt im Jubiläumsjahr der nationalen Einheit durch Juden vertreten war, wo die ausgesucht feinsten Umgangs. formen alle Kreise der Gesellschaft verbindet und der Antisemitismus nicht einmal dem Namen nach besteht. Demungeachtet sind im russischen und, noch mehr, im preußischen Adel die Heiraten mit Jüdinnen äußerst häufig, im italienischen hingegen äußerst selten. Die abgeschlossene russische und preußische Aristokratie besäße, an diesem Kriterium gemessen, also einen geringeren Grad Kastencharakter als die leutselige und allgemein menschlich empfindende Aristokratie Italiens. Die Erklärung für diese an sich seltsame Erscheinung liegt vornehmlich in der Geschichte des Judentums selbst. In Italien ist die Emanzipation des Judentums politisch längst restlos vollzogen. Eine Zurücksetzung der Juden findet in keiner Weise mehr statt. Wenn dort deshalb die Juden auch in der Ehe fast durchweg unter sich bleiben, so entspricht das eben lediglich der Tatsache, daß der italienische Jude, um Karriere $z u$ machen, weder der Taufe noch der Heirat mit einer den obersten Ständen des Volkes an. gehörigen Christin bedarf. Nicht so in Preußen: hier gilt der 
Jude nur in der Verkleidung, in der Assimilation oder wenn man will, in der Dissimulation. Hier ist das gräfliche Ehebett meist die einzige Passage zur Eröffnung des Feldes gesellschaftlicher Ambition. Darum macht in Preußen die reiche Jüdin Jagd auf den Titulierten; in Italien, wo sie auch als Frau eines Juden Kriegsministerin werden kann, läßt sie ihren natürlichen Gefühlen freien Lauf und heiratet einen Vetter aus der Familie. Auf diese Weise erhellt, dab Kaste und immer relativ zu nehmende Blutreinheit nicht zusammenfallen, vorausgesetzt natürlich, daß keine ausgesprochenen Eheverbote obwalten. Das Bestehen einer Kaste in der Demokratie, d. h. in einer Gesellschaftsordnung ohne gesetzliche Schranken, ist ein Inzentivum; durch es werden Aspirationen entzündet, welche zur Blutmischung führen. Darum wird eine Aristokratie nur in der unverfälscht aristokratischen Herrschaftssform oder in der reinen Demokratie rein bleiben können. In den $Z$ wischenformen wird sie stets starken Legierungsprozessen unterliegen. Sie wird Kaste bleiben können, aber nicht Rasse.

\section{Viertes Kapitel. \\ Zum Problem des Fortschritts.}

Die Idee des Fortschritts impliziert zwei verschiedene aber unentbehrliche Elemente. Erstens, eine Gedankenarbeit, bestehend in einem Vergleich zwischen zwei oder mehreren Entwicklungsstadien des zu untersuchenden Gegenstandes. Zweitens einen empirisch gewonnenen MaBstab als Werkzeug zur Ausführung jenes Vergleiches. Dieser Maßstab ist der dem Vergleichenden eigene, teils aus der Tradition, teils aus der Empirie seines Lebens gewonnene Komplex von Überzeugungen, seine „Weltanschauung“.

Das Urteil, das aus dem Vergleich abgeleitet wird und das entweder auf die These des Fortschrittes oder des Rück- 
schrittes oder auch des Stillstandes lautet, involviert mithin ein Werturteil. Der Begriff Fortschritt aber erheischt, daB der Vergleichende das letztere Stadium der verglichenen Entwicklungsepochen für wertvoller hält als das zeitlich weiter zurückliegende. Denn Fortschritt heißt, wie bereits etymologisch ersichtlich, Besserung. Er läßt sich graphisch als aufsteigende Linie beschreiben.

Aus diesen präliminären Feststellungen seiner begrifflichen Elemente erhellt, daß der Begriff Fortschritt selbst nebelhaft und nur mit größter Vorsicht zu gebrauchen ist. Der Fortschritt ist ein relativer Begriff, daß heißt abhängig von der urteilenden Person, und folglich subjektiv. Die bekanntesten Formen des sozialen Lebens, die sich im Munde aller befinden, wie die Revolution, die Evolution, die Reaktion, die Glaubensfreiheit, die Gebundenheit, die Aristokra. tie, die Demokratie, werden je nach dem Anschauungskom. plex des einzelnen als auf der Linie des Fortschritts oder auf der des Rückschritts liegend gewertet.

Die Meinungsverschiedenheit im Urteil darüber, ob ein konkretes Geschehnis oder eine konkrete Entwicklung einen Fortschritt oder einen Rückschritt für die Menschheit bedeutet, wird zum Teil durch die Tatsache erklärt, daß jede Veränderung der Zustände einer Fraktion der Menschheit Nutzen, einer andern hingegen Schaden bringt. Es gibt keinen Fortschritt, der nicht ganze Grundklassen oder doch Unterklassen geschädigt oder gar beseitigt hätte. Das gilt von der Erfindung der Druckerei wie von der Äbschaffung der Inquisition. Der Fortschritt ist nie ein solcher für alle. Ein indisches Sprichwort sagt: Des Einen Haus brennt und der Andere wärmt sich daran. So ist auch der Fortschritt. Sein Weg ist mit Leichen gepflastert. Die moderne Zivilisation und die menschliche Psyche sind so komplexe Abstraktionen, daß der Begriff des Fortschrittes notwendigerweise ebenfalls den Stempel der Komplexität tragen muß. Der Fortschritt ist seiner Natur nach aus so viel verschiedenartigen Elementen 
t: zusammengesetzt und von so verschiedenartigen Wirkungen begleitet, daß in der Praxis kaum auf einem Gebiete ein Fortschritt möglich ist, ohne daß er auf anderem Gebiete nachteilige, rückschrittliche Folgen nach sich zöge. Fast jeder Fortschritt in einer Richtung bedingt einen Rückschritt. oder zum mindesten einen Stillstand in_einer andern. Dieser Norm ist sogar die Natur selbst dienstbar. Der Fortschritt scheint dem gleichen restriktiven Gesetz zu unterliegen wie die Individualität. Das Genie, d. h. ein Mensch mit seltenen, weit über den Durchschnitt seiner Mitmenschen herausragenden Eigenschaften, stellt sozusagen eine Inkarnation des intellektuellen Fortschritts der Menscheit dar. Nicht mit Unrecht hat man deshalb das Genie Wegweiser der Mensch"heit genannt. Aber das Vorhandensein genialer Potenzen in einem Menschen setzt empirisch, ja man wäre versucht hinzuzusetzen naturlogisch die Konexistenz ebenso auffälliger Lücken und Fehler in ihrem Inhaber voraus. Das Plus "läBt auf ein Minus schließen. Eines ist nicht ohne das andere nachweisbar. Lombroso hat die Behauptung verfochten, daß das Genie eine Art nervöser Anomalie dar"stelle, eine Gattung der Nevrose, einen engen Verwandten der Geisteskrankheiten. Er hat es zum Stichwort gemacht: Genie und Irrsinn. ${ }^{1}$ ) Und der beste seiner deutschen "Schüler hält es für ausgemachte Sache, daß ,große Tiefe der Begabung, die ihren Gegenstand vollkommen erfaßt und durchdringt, mit einseitiger Fähigkeit Hand in Hand geht, das heißt tiefe Begabung ist meist einseitig“".") Ohne uns im :übrigen bedingungslos unter das Banner Lombrosos stellen zu können, scheint uns mit dieser Feststellung ein wertvoller :Anhaltspunkt für das Problem des Fortschritts überhaupt geKap. 2.

1) Cesare Lombroso, "Genio e Pazzia“. Deutsch bei Reclam.

2) Hans Kurella, "Die Intellektuellen und die Gesellschaft". Beitrag zur Naturgeschichte begabter Familien. Wiesbaden 1912. Bergmann, p. 16. 
wonnen zu sein. In der Psychologie des Mannes von Genie existieren nebeneinander, und durcheinander bedingt, hypertrophisch entwickelte und hypertrophisch zurückgebliebene, d. h. unter dem respektiven Niveau des Durchschnittsmenschen zurückgebliebene Seiten, mit anderen Worten große Fähigkeiten und große Mängel. Die Schwächen der gro. Ben Männer, die oft an Lächerlichkeiten streifen und die auch von der der Ursachen unkundigen Menge mit leichter Mühe wahrgenommen werden, sind nur die Korrelate der großen Eigenschaften, die sie auszeichnen und durch die sie ihre Umgebung überragen. Die großen Schriftsteller und Dichter sind meist sehr mäßige Rechner, und das selbst dann, wenn sie ausgezeichnete Berechner sind. Die großen Künstler, unübertrefflich in ihrer Auffassung des Erhabenen, sind fast immer von kindlicher Unbeholfenheit und seltsamem Un. vermögen zu logischem Denken und gegenüber den Geisteswissenschaften und stehen auch mit der angewandten Kunst des Lebens zumeist auf gespanntem Fuß. Keiner stellt besser als sie den Fortschritt der Menschheit in ihren feinsten Verästelungen der Sinne und des Instinktes dar. Indes der Fortschritt, den sie verkörpern, ist einseitig. Neben ihm klaft ein Defizit. Der Revers ihrer Überlegenheit ist unzertrennlich von dem Avers ihrer Unterlegenheit.

$\mathrm{Zu}$ Beginn des vorigen Jahrhunderts hat ein italienischer Gelehrter, Giuseppe Pecchio, eine Abhandlung darüber geschrieben, daß die wissenschaftliche und literarische Produktion den allgemeinen Gesetzen der Gütererzeugung folge und daß die Entwicklung von Handel und Industrie stets eine Ausbreitung der Bildung und eine Zunahme in der Anfertigung und im Verkauf von Büchern nach sich ziehe. Aber gleichzeitig erklärte er sich außerstande, in dieses System der Beziehungen zwischen ökonomischem Fortschritt und Kulturfortschritt auch die Entstehung und Erzeugung von Genies unterzubringen und zu begründen, woher es komme, daß häufig gerade Zeitalter politischen Stillstandes und po- 
litischer Tyrannei sowie wirtschaftlicher Krise große Dichter

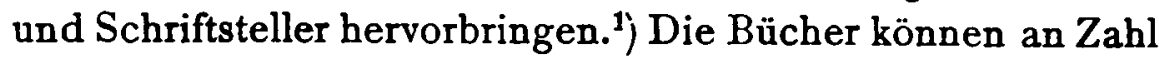
und Lesern zunehmen, an durchschnittlichem Wert hingegen abnehmen. Ranke hat sich geweigert zuzugeben, daB ein materieller Fortschritt in der Philosophie seit Aristoteles nachweisbar sei, während die Masse der philosophischen Dissertationen und ihre Form sicher fortgeschritten sei. ${ }^{9}$ ) Heute sind wir Augenzeugen einer ungemein schnellen Ausbreitung des Wissensstoffes. Das Volksschulwesen steht auf einer ehedem ungeahnten Höhe und macht eine Periode fast ununterbrochenen Fortschritts durch. Ihm reiht sich zudem das Volkshochschulwesen an. In allen Ländern ist die Zahl der des Lesens und Schreibens Unkundigen in schneller Abnahme begriffen, in vielen bereits bis auf den Nullpunkt gesunken. Dagegen ist die Produktion des Genies heute, verglichen mit dem Cinquecento und dem Seicento, in allen Ländern gering. Der Extension des geistigen Fortschritts steht die mangelnde Intensität gegenüber. In Italien haben die Dante und Petrarca den D'Annunzio, in Frankreich die Molière den Rostand, in Deutschland die Goethe den Sudermann, in England die Shakespeare den Bernard Shaw Platz gemacht. Nur die Völker jüngerer Kultur haben offenbar eine wachsende Produktion von Genies, wie Rußland Tolstoj und Norwegen Ibsen, zu verzeichnen, wenn schon auch diese beiden Größen bei ihrem Tode keine ihnen ebenbürtigen Nachfolger in ihrem Volke hinterlassen haben.

Bisweilen ist_der Fortschritt lediglich der Reflex eines Rückschritts. In demselben Maße, in welchem die Menschheft

1) Giuseppe Pecchio, „Dissertazione sino a qual punto le Produzioni scientifiche e letterarie seguano le Le ry economiche della Produzione in generale". Torino I852. Ausg. der Biblioteca dei Comuni Italiani.

2) Leopold von Ranke, "Über die Epochen der Neueren Geschichte". Vorträge, herausgeg. als Anhang zur Weltgescbichte. Leipzig 1895. Duncker u. Humblot, 23. Lief., p. 533. 
immer mehr der physischen Degeneration anheimfällt, in welchem die Gestalt des Durchschnittsmenschen niedriger, seine Sehkraft und sein Gehör schwächer wird, in welchem Kahlköpfigkeit und vorschnelles Ergrauen zunehmen, sich der Rachitismus verbreitet und die Zahl der jungen Män. ner, die vom Militärarzt für untauglich, die Strapazen des Soldatenlebens ohne ernste Gefahr für ihr Leben aushalten zu können, erklärt werden, wächst, kurz in dem gleichen Maße in welchem der Mensch sich von der primitiven aber urwüchsigen und kräftigen Animalität entfernt und in allen Ländern der Welt an physischer Potenz einbüßt, geht die Mortalität im ganzen zurück. Mehr noch: das ZusammenflieBen der ländlichen Elemente aus der Umgegend in der Stadt, ein demographisches Phänomen, das wir unter dem Namen Urbanismus kennen, und welches für weiteste Menschenmassen eine Verlegung der Lebensführung von der frischen klaren Landluft in die staub- und miasmenerfüllte Atmosphäre ekler Fabrikräume zur Folge hat, hat am Ende dieTen. denz zur Verlängerung des menschlichen Durchschnittslebens noch bestärkt. Die Zahl der Krankheiten, insbesondere der professionellen Krankheiten, hat zwar zugenommen, die Lebensdauer aber ebenfalls. Die Statistik bestätigt fast durchweg, daß die Mortalität in den industriellen Bezirken schneller abnimmt als in den agrarischen ${ }^{1}$ ), und diese Konstatierung würde an Prägnanz noch gewinnen, wenn nicht die Zahl der Landbewohner, von der Güte der dortigen Ärzte und Hospitäler angezogen, ihre schweren Krankheiten in die Stadt trüge und infolgedessen die städtischen Sterbeziffern anschwellen machte. Eine geistreiche italienische Gelehrtin, Gina Lombroso Ferrero, hat ein Buch geschrieben, dem sie den Titel I Vantaggi della Degenerazione, die Vorteile der Degeneration gegeben hat. In ihm hat sie mit Hilfe biologi-

I) Napoleone Colajanni, „Manuale di Demografia“. Napoli 1909. Pierro, p. $575 \mathrm{ff}$. 
scher und statistischer Mittel den Nachweis zu führen versucht, dab mit den Gefahren, welche das Leben des Menschen umgeben, die Widerstandsfähigkeit und Anpassungsfähigheit desselben in geometrischem Maßstabe wachsen, die gesundheitsschädlichen Berufsarten und die physisch degeneriertesten Volksmassen die längste Lebensdauer erreichten. $\left.{ }^{1}\right)$ Unbestreitbar ist jedenfalls, daß mit der offenbaren Verschlechterung der allgemeinen physiologischen Charakteristiken des Menschen ein ebenso offenbarer Fortschritt in den biologischen, an der mittleren Lebensdauer gemessenen Bedingungen Hand in Hand geht. Diese Tatsache ist natürlich zum Teil den verbesserten wirtschaftlichen Lebensgrundlagen und der in vieler Hinsicht großartigen modernen hygienischen Prophylaxe zu verdanken, kann zum andern Teil aber doch auch als Resultante der erhöhten, vielleicht gerade durch die vermehrten Feinde entstandenen Immunität des Menschen selbst betrachtet werden. ${ }^{2}$ )

Das Studium der Geschichte zeigt uns den Fortschritt nicht als konstante gerade Linie. Die Zerstörung der alten gräkoromanischen Zivilisation durch die Barbaren aus dem Norden hat den politischen, intellektuellen und wirtschaftlichen Fortschritt auf fast allen Gebieten über acht Jahrhunderte lang unterbunden. Die schier endlos währende Periode des Mittelalters ist, wenn wir von der Musik und der Baukunst absehen, bloß ein Interregnum zwischen zwei Perioden

I) V'gl. Gina Lombroso, „I Vantaggi della Degenerazione“. Torino 1904. Bocca, p. $396 \mathrm{ff}$.

2) Mit Recht verweist auch eine andere Biologin, Oda Lerda Olberg, die Kulturschmäher auf die einfache Tatsache, da $\beta$ die Menschheit noch niemals so gewaltige Kraftproben ausgehalten habe, als gerade in der heutigen verhältnismäßig hochentwickelten $\mathrm{Kul}$ tur. Im primitiven Tierzustande ist das Zugrundegehen die Regel. Der Urmensch wurde $z$ war nicht nervös, aber er starb fast immer eines gewaltsamen Todes oder wurde durch eine Epidemie hingerafft. (Oda Olberg, „Das Weib und der Intellektualismus". Berlin 1902. Edelheim, p. X.) 
des Fortschritts. Die Renaissance erst, die an das Altertum anknüpft, legt durch diese Anknüpfung die Basis zu neuen Er. folgen menschlicher Tätigkeit. Auch von da an ist die Entwicklung aber weder allgemein noch gradlinig. Nicht allgemein, weil es, worauf Lindner uns mit Recht aufmerksam macht, historisch niemals eine einheitliche Menschheit gegeben hat ${ }^{1}$, also auch der Fortschritt der Einheitlichkeit entbehren muBte, da drei Viertel der Welt von vornherein von jeder Berührung mit dem Abendland ausgeschlossen war. Nicht geradlinig, weil auch innerhalb jedes Kulturkreises häufig rückläufige Bewegungen einsetzten. Der Fortschritt der Demokratie ist nach dem Sturze Napoleons um ein halbes Jahrhundert zurückgeworfen worden. Selbst heute noch hat der Gehalt an äußerer und insbesondere innerer Freiheit der Menschheit noch längst nicht in allen Ländern das Niveau von 1780 oder auch nur I 81 3 wieder erreicht. Nach dem Zerfalle des Napoleonischen Imperium wurde in Spanien die Inquisition wieder eingeführt. ${ }^{2}$ ) Auch national trat eine lange, harte Wartezeit ein. Das Weltreich des Korsen besaß zwar keine eigentlich nationale, sondern vielmehr, wie ich anderswo ausgeführt habe, eine dynastisch-internationale Basis. ${ }^{3}$ ) Indes fällt doch gerade in diese Ära, von Napoleon teils wissentlich, teils unwissentlich provoziert, eine Vertiefung des Nationalbewußtseins fast aller mittel-, süd- und nordeuropäischen Völker. Der Wiener Kongreß indes opferte gleichzeitig Deutschland, Italien, Polen, Norwegen, Irland und Belgien.

Selbst die glorreichsten Taten des Menschengeschlechtes

I) Theodor Lindner, "Geschichtsphilosophie“. 3. Aufl. Stuttgart I9I2. Cotta, p. 2 II.

2) Vgl. darüber den interessanten ersten Band der "Mémoires" des Don Juan van Halen, Conde de Peracampos (Französ. Ausg. Paris I821).

3) S. meinen Artikel, „Zur historischen Analyse des Patriotismus". Archiv f. Sozialwiss. und Sozialpol., Bd. 36, Heft 2, p. 394 f. 
stellen keinen Fortschritt schlechthin dar. Die Sklaverei ist in Nordamerika abgeschafft worden, nicht aber die Mißhandlungen und die Verachtung, denen die Neger ausgesetzt sind. Vor dem Sezessionskrieg waren die Neger persönlich von ihren Herren abhängig, wurden aber im ganzen gut behandelt, heute sind sie freie Menschen und werden von den Weißen wie Vogelfreie gelyncht.

Die Idee internationalerVerständigung hat als solche heute einen höheren Grad erreicht als je zuvor. Die bürgerlichen $\mathrm{Pa}$ zifisten und die sozialistischen und anarchistischen Antimilitaristen stimmen in der Voraussicht überein, daß, wie das neunzehnte Jahrhundert das Jahrhundert der Nationalitäten gewesen sei, das zwanzigste Jahrhundert das des Internationalismus sein werde und daß heute das einzige Mittel, die internationalen Aspirationen des modernen Menschen zunichte zu machen, nur noch darin bestehen könne, die Maschinen zu zerstören, die Dynamos und Lokomotiven aus der Welt zu schaffen, die Buchdruckereien zu vernichten, die Schulen zu schließen und die Gelehrten in ihre Laboratorien einzusperren. $\left.{ }^{1}\right)$ Tatsächlich hat es niemals eine so große Zahl offizieller und offiziöser internationaler Vereine, Institute, Ämter und Kongresse gegeben als heute. Von der Post bis zum Tierschutz, von der Arbeiterschutzgesetzregelung bis zum Studium des Alkohols ist alles in den Bereich internationaler Erwägung und Regelung getreten. In der Arbeiterbewegung, der natürlichen Quelle internationaler Gefühlsregungen, halten die Sozialdemokraten alle drei Jahre lange internationale Tagungen ab, zu denen die Genossen aus allen Ecken und Enden derWelt zur Beratung zusammentreffen, ist jede Arbeiterkategorie, die Maurer, die Buchdrucker, die Bergarbeiter usw. in internationale Föderationen gegliedert und internationalen Sekretariaten unterstellt. Wenn wir hingegen von der

I) Vgl. Alfred H. Fried, "Handbuch der Friedensbewegung“. 2. Auf. Leipzig I9II, Vol. I, p. X; und Gustave Hervé, "L'Internationalisme“. Paris 1910. Giard et Brière, p. VII u. 177. 
des Fortschritts. Die Renaissance erst, die an das Altertum anknüpft, legt durch diese Anknüpfung die Basis zu neuen $\mathrm{E}_{\mathrm{r}}$. folgen menschlicher Tätigkeit. Auch von da an ist die Entwicklung aber weder allgemein noch gradlinig. Nicht allgemein, weil es, worauf Lindner uns mit Recht aufmerksam macht, historisch niemals eine einheitliche Menschheit gegeben hat"), also auch der Fortschritt der Einheitlichkeit entbehren muBte, da drei Viertel der Welt von vornherein von jeder Berührung mit dem Abendland ausgeschlossen war. Nicht geradlinig, weil auch innerhalb jedes Kulturkreises häufig rückläufige Bewegungen einsetzten. Der Fortschritt der Demokratie ist nach dem Sturze Napoleons um ein halbes Jahrhundert zurückgeworfen worden. Selbst heute noch hat der Gehalt an äußerer und insbesondere innerer Freiheit der Menschheit noch längst nicht in allen Ländern das Niveau von 1789 oder auch nur 181 3 wieder erreicht. Nach dem Zerfalle des Napoleonischen Imperium wurde in Spanien die Inquisition wieder eingeführt. ${ }^{2}$ ) Auch national trat eine lange, harte Wartezeit ein. Das Weltreich des Korsen besaß zwar keine eigentlich nationale, sondern vielmehr, wie ich anderswo ausgeführt habe, eine dynastisch-internationale Basis. $\left.{ }^{9}\right)$ Indes fällt doch gerade in diese Ära, von Napoleon teils wissentlich, teils unwissentlich provoziert, eine Vertiefung des Nationalbewußtseins fast aller mittel-, süd- und nordeuropäischen Völker. Der Wiener Kongreß indes opferte gleichzeitig Deutschland, Italien, Polen, Norwegen, Irland und Belgien.

Selbst die glorreichsten Taten des Menschengeschlechtes

I) Theodor Lindner, „Geschichtsphilosophie". 3. Aufl. Stuttgart 19I2. Cotta, p. 2 I I.

2) Vgl. darüber den interessanten ersten Band der „Mémoires" des Don Juan van Halen, Conde de Peracampos (Französ. Ausg. Paris $182 \mathrm{I}$ ).

3) S. meinen Artikel, „Zur historischen Analyse des Patriotismus". Archiv f. Sozialwiss. und Sozialpol., Bd. 36, Heft 2, p. $394 \mathrm{ff}$ 
stellen keinen Fortschritt schlechthin dar. Die Sklaverei ist " in Nordamerika abgeschafft worden, nicht aber die Mißhandlungen und die Verachtung, denen die Neger ausgesetzt sind. Vor dem Sezessionskrieg waren die Neger persönlich : von ihren Herren abhängig, wurden aber im ganzen gut behandelt, heute sind sie freie Menschen und werden von den Weißen wie Vogelfreie gelyncht.

Die Idee internationalerVerständigung hat als solche heute einen höheren Grad erreicht als je zuvor. Die bürgerlichen $\mathrm{Pa}$ zifisten und die sozialistischen und anarchistischen Antimilitaristen stimmen in der Voraussicht überein, daß, wie das neunzehnte Jahrhundert das Jahrhundert der Nationalitäten gewesen sei, das zwanzigste Jahrhundert das des Internationalismus sein werde und daß heute das einzige Mittel, die internationalen Aspirationen des modernen Menschen zunichte zu machen, nur noch darin bestehen könne, die Maschinen zu zerstören, die Dynamos und Lokomotiven aus der Welt zu schaffen, die Buchdruckereien zu vernichten, die Schulen zu schließen und die Gelehrten in ihre Laboratorien einzusperren. ${ }^{1)}$ Tatsächlich hat es niemals eine so große Zahl offizieller und offiziöser internationaler Vereine, Institute, Ämter und Kongresse gegeben als heute. Von der Post bis zum Tierschutz, von der Arbeiterschutzgesetzregelung bis zum Studium des Alkohols ist alles in den Bereich internationaler Erwägung und Regelung getreten. In der Arbeiterbewegung, der natürlichen Quelle internationaler Gefühlsregungen, halten die Sozialdemokraten alle drei Jahre lange internationale Tagungen $a b, z u$ denen die Genossen aus allen Ecken und Enden der Welt zur Beratung zusammentreffen, ist jede Arbeiterkategorie, die Maurer, die Buchdrucker, die Bergarbeiter usw. in internationale Föderationen gegliedert und internationalen Sekretariaten unterstellt. Wenn wir hingegen von der

I) Vgl. Alfred H. Fried, "Handbuch der Friedensbewegung". 2. Aufl. Leipzig IqII, Vol. I, p. X; und Gustave Hervé, „L'Internationalisme". Paris 1910. Giard et Brière, p. VIII u. 177. 
Form absehen und dem Inhalt der Form näher treten, gewahren wir mühelos eine der geschilderten schnurstracks $z u$ widerlaufende Tendenz. An Extension ist der Internatio. nalismus des modernen Proletariats zweifellos gewachsen, aber dieses Wachstum hat sich auf Kosten der Intensităt und der Tiefe der Gefühle vollzogen. Ein Vergleich der Zeitungen der alten Internationalen Marxens und Bakunins mit denen der einzelnen sozialistischen Parteien der Gegenwart genügt, um das absolute Schwinden der internationalen Idee in den Kreisen der klassenbewußten Arbeiter zu konstatieren. In allen Parlamenten Europas haben die Vertreter des internationalen Proletariats öffentlich und in rührender Übereinstimmung erklärt, das Vaterland, d.h. den kapitalistischen Staat, einschließlich der von diesem anderen Völkern entrissenen heterogenen Gebietsteile, bis zum letzten Bluts. tropfen verteidigen zu wollen. Die sozialistische Brüderlichkeit aller Menschenantlitz tragenden Lohnsklaven ist zum Thema für begabte Redner der Maifeier herabgesunken. Dabei lassen sich beide Tendenzen auf die gleiche Grundquelle zurück. führen: den modernen Kapitalismus, welcher den Markt und die Anlage von Kapital sozusagen internationalisiert hat und infolgedessen einerseits die verschiedenen Arbeiterkategorien zwingt, sich behufs Austausches der gegenseitigen Erfahrungen und Wünsche sowie zur Besprechung eventuell zu un. ternehmender gemeinsamer Aktionen in möglichst häufige Verbindung miteinander zu setzen, andererseits hingegen die Abhängigkeit der einzelnen nationalen Arbeiterschaften vom Wohl und Wehe der nationalen Industrie und ihres natürlichen Schutzherrn, des nationalen Staates, verschärft. Dem Kapitalismus, welcher gleichzeitig durch die starken proletarischen Wanderungen, deren Ursache er ist und die ihren Ausgangspunkt stets in ökonomisch ärmeren (Italien, Slavien). ihren Zielpunkt aber in ökonomisch bessergestellten Ländern (Amerika, Frankreich, Deutschland) haben, zwischen den einzelnen Proletariaten eine Art von Konkurrenz hervorruft 
und dadurch in ihrer Psyche alles das leicht weckt, was in ihnen an nationalen Vorurteilen und Antipathien gegen die wenn auch klassengenössischen Ausländer schlummerte. ${ }^{1}$ ) Wir stehen da vor einer doppelten Erscheinung. Die äußeren Bande des Internationalismus sind im Begriff tagtāglich stärker und zahlreicher zu werden, was vom internationalen Gesichtspunkt einen Gewinn, vom nationalistischen einen Verlust bedeutet, die Bande internationaler Gesinnung hingegen lockern sich immer mehr, was wieder die Nationalisten als Fortschritt, die Internationalisten als Rückschritt betrachten.

Auch die Hoffnungen derer, die in der erhöhten Schnelligkeit und Präzision der technischen Verkehrseinrichtungen eine Garantie für eine allmähliche seelische Annäherung der Völker und die Verbreitung brüderlicher Gefühle erblickten, dürften heute als getäuscht bezeichnet werden. Es ist für den vorurteilslosen Beobachter kein Zweifel möglich: wir leben gerade jetzt in einer Zeit hochgespanntester nationaler Erregung, einer Erregung, deren dynamische Gewalt aus der Tatsache ersichtlich ist, dab sie selbst bisher so ruhig und in nationalen Dingen so sachlich denkende Völker ergriffen hat wie beispielsweise die Italiener. Wer möchte bestreiten, daß die Gefühle menschlicher Solidarität unter den verschiedenen Nationen keineswegs mit der zunehmenden Leichtigkeit und Bequemlichkeit des Ortswechsels und des Sich - gegenseitig - Kennenlernens zugenommen hat? Eher schon könnte man behaupten, daß zwischen den Mitteln, die Entfernungen abzukürzen oder gar zu überwinden, und den Versuchen, die in den Köpfen der nationalen Kollektivitäten selbst noch bestehenden Barrieren niederzureißen, ein erhebliches Mißverhältnis obwaltet. Erstere Arbeit hat

1) Die nationalen, fremdenfeindlichen Tendenzen der modernen Arbeiter sind in gutes, wenn auch etwas krasses Licht gesetzt worden von Giuseppe Prato, „Il Protezionismo Operajo". Torino 1910. Sten (auch in franz. Ausg., bei Rivière in Paris, 1912). 
sich als viel leichter erwiesen als letztere. Man reist heute in siebzehn Stunden von Paris nach Berlin, in dreiunddreiBig Stunden von Wien nach Rom, während man noch vor sieb. zig Jahren zu einer solchen Reise zwölf bezw. einundzwanzig Tage brauchte. Der seelische Kontrast zwischen Paris und Berlin, Wien und Rom ist deshalb nicht geringer geworden. Die Technik hat alle natürlichen Grenzen mit spielender Leichtigkeit überschreitbar gestaltet, aber die durch die nationalen Gegensätze gezogenen Grenzen in der Psyche des Volkes sind in der alten Starrheit verblieben.

Einer der vornehmsten Gedanken ist unverkennbar der Gedanke des Friedens. Der Friede bedeutet einen wirklichen Fortschritt. Denn er involviert einen weiten Schritt vorwärts in der Richtung auf die Zivilisation in ihrer Eigenschaft als Bändigerin der noch im Menschen vorhandenen wilden tierischen Triebe der Beutelust, der Zerstörung und des Mordes. Er bedeutet eine Ersparnis an kostbaren Menschenleben und einen Verzicht darauf, sich bei Streitfällen des sogenannt höheren Rechtes der Gewalt zu bedienen, welche eine schlechte Richterin ist im Tribunal völkischer Gerechtigkeit. Er setzt überdies auch dem der allgemeinen Wehrpflicht inhärenten Zustand ein Ende, in dem Hunderttausende von Menschen ihr und ihrer, in einem andernen Staate geborener Mitmenschen Leben um einer ihnen unbekannten, gleichgültigen oder gar widrigen und ihren moralischen oder wirtschaftlichen Interessen schädlichen Sache wegen oder auch zur Sühne nicht von ihnen begangener Schuld aufs Spiel zu setzen gezwungen sind. Indes, wenn schon der Friede an sich ein Gut von unberechenbarer Größe ist und seine Erreichung deshalb einen Fortschritt kat' exochèn bedeutet, so wird der Friede unter anderen Gesichtspunkten betrachtet doch wieder zu einem Hindernis für den Fortschritt, zumal ethischer Art.

Der Krieg ist unvernünftig, aber nicht unsittlich, wenigstens nicht schlechtweg. Der Krieg kann ungerecht sein, aber 
er ist es nicht an sich. Er kann sogar eine Mission der Gerechtigkeit erfüllen. Ethisch wäre dem Kriege das Urteil nur dann gefällt, wenn bewiesen werden könnte, daß es niemals gerechte, d. h. einer gerechten Sache dienende Kriege gibt, gegeben hat oder doch geben könnte. Die Idee des Friedens ist an sich ebenfalls von der der Sittlichkeit losgelöst. Sie erhält erst Wert, wenn der Frieden mit Ideen der Sittlichkeit durchsetzt ist, auf sittlicher Basis ruht. Ein Friede ohne internationale Gerechtigkeit aber ist eine sittliche Gefahr, da er in den Massen das Gefühl für die Notwendigkeit der Durchsetzung des Rechtes ertötet.

Wenn der Wille der Pazifisten Tatsache und auf allgemeinen sakrosankten BeschluB der Friede vertragsweise zum unverbrüchlichen Prinzip des Völkerlebens erhoben würde, so könnte das nur auf der Basis der gegenseitigen Anerkennung und Garantieübernahme des gegenwärtigen Besitzstandes aller Staaten geschehen. Die Pax Aeterna als Überbau des Status quo. Hiermit würde für den natürlichen Fortschritt und zum Teil auch für die natürliche Entwicklung der Völker eine traurige Lage geschaffen. Der Friedenspakt würde die Sanktionierung aller nationalen und ethnischen, von der Geschichte begangenen Verunrechtungen bedeuten und Fortschritt mit Immobilismus verwechseln, jede Genugtuung, jede nationale Aspiration a priori ausschließen und die Herrscherrechte derjenigen Völker und Staaten, die in dem geschichtlichen Moment, in welchem die Pazifisten ihre Ideen zum Durchschlag gebracht und zu den die Diplomatie der einzelnen Regierungen bestimmenden gemacht hätten, die Welt beherrschten, in alle Ewigkeit fixieren. Die Staaten, denen es heute noch nicht gelungen ist, alle ihnen durch die Rasse, die Sprache oder den Willen zugehörenden Volkselemente in ihren Grenzen $z u$ fassen, die Völker, die einen Staat bilden oder wieder bilden möchten, aber ihren Wunsch durch widrige Umstände noch nicht zur Wirklichkeit umzuprägen vermochten, würden auf diese Weise 
um ihr heiligstes Recht, das Selbstbestimmungsrecht, betrogen werden. Der Friede würde hundert Völker aufopfern, hundert Probleme ungelöst lassen. Zufall würde vor Recht gehen und Unrecht zu Recht werden.1) Um dem Frieden das Gepräge einer Erscheinung authentischen Fortschrittes zu verleihen, bedarf es daher nicht Gegenseitig. keitsversicherungen der heute bestehenden Staaten und der Gründung obligatorischer Schiedsgerichte, um die zwischen den Staaten entstehenden Zwistigkeiten de iure condito im Keime zu ersticken, noch ist es zu diesem Behufe nötig, Abrüstungsversuche zu unternehmen. Um den Frieden auf ethische Basis zu stellen, ist die Annahme eines Jus condendum Vorbedingung. Dieses Jus condendum würde die Feststellung der nationalen Homogeneitäten im Auge haben und sich in praxi als das Resultat eines allgemeinen Referendums darstellen müssen, welches, mit ernstem Willen unternommen und durchgeführt und, von energischen Schutzvorrichtungen, die jede direkte oder indirekte Fälschung seiner Ergebnisse von vornherein ausschließen, begleitet, in allen national strittigen und umstrittenen Gebieten zur Anwendung kommen und den kollektiven Neigungen und Vor* lieben der Bewohner jener Gebiete freien Lauf lassen müßte. Ein solches Optieren auf Grund einer Reihe allen Beeinflussungen der einzelnen Regierungen entzogener Volksabstimmungen würde zwar die Existenz manchen Staatengebildes in ernste Gefahr bringen. Ja, es gäbe kaum einen Staat, der aus dieser Maßregel nicht in geänderter Form hervorginge, sintemalen es keinen Staat gibt, der mit einer Nation zusammenfiele, und der nicht außer dem Volke, das ihm Namen und Geist gibt, auch noch Bruchstücke

I) Hätten die Pazifisten vor Jahresfrist Europa ihren Willen aufgezwungen, so würden heute noch die Griechen und Serben unter türkischem Druck seufzen. Hundert andere Völker würden vergeb. lich der Verwirklichung ihres nationalen Gedankens harren, würde der Lieblingswunsch der Pazifisten heute erfüllt werden. 
anderer, mehr oder weniger heterogener Rassen in sich schlösse, noch ward je ein Staat gesehen, unter dessen Bürgern es keine Irredenten gegeben hätte. Indes, ohne die hier erwähnte Revision der politischen Landkarte, würde der ewige Frieden ein Instrument völkischer Bedrückung und Unterdrückung werden.

Der ethnische Fortschritt im Sinne von internationaler, auf dem Prinzip der Gerechtigkeit, und somit auf Unabhängigkeit und Selbständigkeit der einzelnen Nationen untereinander aufgebauter Verständigung stößt überdies auf Hindernisse, die in der Psychologie aller die Erde bevölkernden Stämme selbst liegen. Jedes Volk folgt in seiner Geschichte bewußt oder unbewubt dem geheimen Gesetz der Transgression, d.h. der Übertretung der ihm ethnisch und durch den Volkswillen gezogenen Grenzen. Jedes Volk ist bestrebt, über fremde Völker zu herrschen. Jeder Befreiungskrieg, dazu unternommen, außerhalb der Landesgrenzen befindliche, unter fremdem Joche schmachten de Brüder zu befreien, endet, bei glücklichem Ausgang des Unternehmens, mit der Annexion auch dem besiegten Feinde ethnisch und linguistisch gehöriger Gebietsteile. Noch jedes lorbeerumwundene Heer hat sich in ein Werkzeug der nationalen Unterdrückung verwandelt. An typischen Beispielen dafür ist die moderne Geschichte überreich. Das Bedürfnis nationaler Expansion zerreiBt alle Bande der Logik und der Ethik. Nur schwache und unfreie Völker sind gerecht und träumen von internationaler Bruderliebe. Die starken oder stark gewordenen schwachen Völker sind ihrer Natur nach schlechte Nachbarn und harte Herren. Die Fortschritte, die sie machen, vollziehen sich fast immer auf Kosten ihrer Nebenvölker. Ja, sie vermögen sich nationales Wohlergehen und vaterländischen Ruhm nicht einmal mehr gedanklich ohne, wenn auch nicht immer militärische, so doch stets ökonomische und diplomatische Schlappen der übrigen Vaterländer vorzustellen. 
Die erste Voraussetzung zur Bestimmung des Fortschritts ist also die Analyse. Es ist eine unerläßliche Arbeit, den Fortschritt in die ihn bildenden Substanzen zu zerlegen. Der einzige unzweideutig feststellbare Fortschritt ist der Fortschritt in der Technik. Er ist wahrhaft unerhört. GewiB ish, wie die Katastrophe der Titanic beweist, kein Wunder der Technik wunderbar genug, um den bösen Gewalten der Natur Trotz bieten zu können. Die Natur ist in ihren Grundelementen unüberwindbar. Aber wenn man die Technik der Güterproduktion und der Lokomotion von vor hundert Jahren mit unserer heutigen vergleicht, dann wird man an dem Vorhandensein eines gewaltigen Fortschritts auf diesem Gebiete nicht mehr gut zweifeln können.

In der Nationalökonomie hat ein Fortschritt in der Ausbreitung dieser Wissenschaft, nicht aber bezüglich der Achtung vor ihr in den Massen stattgefunden. In den vierziger bis siebziger Jahren des vorigen Jahrhunderts war die Summe volkswirtschaftlichen Verständnisses und volkswirtschaftlicher Kenntnisse in den europäischen Parlamenten unzweifelhaft größer als in den gleichen Körperschaften von 1870 bis auf unsere Tage. ${ }^{1}$ ) Wissenschaftlich freilich hat sich die Nationalökonomie weiterentwickelt. Es gibt vielleicht heute mehr große Nationalökonomen als ehedem, wenn auch nicht als Erfinder neuer Systeme, nicht als Wirtschaftsphilosophen, so doch als Wissende. Die Nationalökonomie hat sich inzwischen durch neue, ihr von den Nachbardisziplinen, insbesondere der Statistik, zugeführte Erkenntnisse bereichert.

Auch die Frage nach dem Fortschritt in derVolkswirtschaft muß in zwei Teile zerlegt werden, den eigentlich ökonomischen, auf die Gütererzeugung gerichteten, und den sozialen, mehr die Menschen ins Auge fassenden. Beide fallen nicht immer zusammen, sondern klaffen oft auseinander. Es kann sozialen Fort-

I) Maffeo Pantaleoni, „Una Visione Cinematografica del Progresso della Scienza Economica“ in Pantaleoni: „Scritti Vari di Economia". Roma 1912. Vol. III. Castellani. 
schritt bei wirtschaftlichem Rückschritt geben, und es kann wirtschaftlicher Fortschritt stattfinden, der sozialen Schaden anrichtet. Letztere These läßt sich an einem typischen Beispiel aus der Geschichte erhärten. Die Einführung des neuen technischen Instruments, der Maschine, in den industriellen Wirschaftsbetrieb ist vielleicht das hervorstechendste Ereignis in der Geschichte der Gewerbe; Marx hat sie gelegentlich sogar als eine wahrhaftige Revolution bezeichnet. Die Folge dieser Neuerung bestand in einem unermeßlichen technischen Fortschritt der gesamten Produktion: ihr Verfahren wurde vereinfacht, ihre Schnelligkeit verdoppelt, ihre Warenmassen an Zahl verhundertfacht. Sie erzielte eine bedeutende Ersparnis an Kraft und menschlicher Arbeit. Aber sozial genommen löste dieser unermeßliche Fortschritt auf dem Gebiete der Gütererzeugung eine Ära von Härten und Drangsalen aller Arten aus. Die Begleiterscheinungen des ersten Auftretens der Maschine sind bekannt: erschreckender Verfall des Handwerks, intensive Landflucht, Umsichgreifen der Arbeitslosigkeit wachsender Stadtarbeitermassen, Zunahme der Sterblichkeit und der Prostitution. Das war die Zeit, in welcher die Theorie von der Verelendung entstand, entstehen mußte, die man später Karl Marx zugeschrieben hat, welche aber, wie ich anderwärts bewiesen habe ${ }^{1}$ ), ein Gemeingut fast aller Volkswirte der ersten Hälfte des vorigen Jahrhunderts, welcher Schule sie angehören mochten, war. Wer immer in jener Epoche die Verhältnisse, wie sie sich in England, dem wirtschaftlich fortgeschrittensten Lande, entwickelt hatten, in Augenschein nahm, fand in dem gelobten Lande, in welchem sich das Wunder des maschinellen Betriebes am schnellsten vollzogen hatte, so entsetzliche Zustände, daß er ihm mit Schauder den Rücken wandte. Simonde de Sismondi, der große französische Volkswirt, wurde nach seiner

r) Roberto Michels, „Saggi Economici sulle Classi Popolari", l. c., P. I3I. 
Studienreise durch England aus einem Saulus ein Paulus. Vorher war er ein eifriger Befürworter der völligen Gewerbefreiheit und ungezügelten Konkurrenz gewesen, von nun an erblickte er das einzige Heil gegen den disaströsen Fortschritt in der Bevormundung der Arbeit durch den Staat, im Staatssozialismus. Ledru Rollin ging noch weiter, indem er die vielgepriesenen sozialen Verhältnisse Englands als schnellster und unentrinnbarster Dekadenz entgegengehend erklärte. Fourier seinerseits schrieb die bitteren Worte nieder, daB es dem Volk in den sogenannt zurückgebliebenen Ländern besser gehe als in den sogenannt fortgeschrittenen; der Spanier habe, falls es ihm einfalle, Arbeit zu begehren, die Möglichkeit, welche zu finden, während selbst der arbeitswilligste französische, englische und katalonische Arbeiter oft vergebens sich nach solcher umsähen. Diese These hatte die ganze Jugendzeit des Kapitalismus hindurch ihre fast unbestreitbare Gültigkeit. Erst die dank dem neuen technischen Instrument ermöglichte Vervielfältigung und Verbilligung vieler Gebrauchsgegenstände des täglichen Lebens und die gesunde nationale und, trotz aller protektionistischen Versuche, internationale Konkurrenz in der Industrie mit ihren preisdrückenden Einflüssen, zumal aber der selbsttätige, auf der Basis des Gedankens der Klassensolidarität erwachte organisierte Widerstand des Proletariats gegen die jämmerliche Lage, in welche der Übermut des neuen Halbgottes es geworfen, haben den Dualismus des Fortschritts allmählich abgeschwächt. Heute kann man sagen, daß sich die Lebensverhältnisse der Arbeiterschaft gerade dort am wesentlichsten gehoben haben, wo der Industrialismus seine tiefsten Wurzeln geschlagen hat. Immerhin ist diese Regel noch nicht ohne Ausnahme. London, immer noch die Königin kapitalistischer Produktion, weist auch heute noch, auch bei Wahrung der Proportionen, ein weit gewaltigeres Lumpenproletariat auf als die ärmste Kleinstadt auf dem Balkan, in welche der Kapitalismus noch nicht seinen Einzug gehalten hat. 
Über die Realität des wirtschaftlichen Fortschritts entscheidet die Zukunft.

Die aufsteigende Linie der Entwicklung Deutschlands ist durch den Industrialismus hervorgerufen, dessen erstaunlicher Aufschwung die Nachbarvölker in Sorge versetzt und die alten Alleinbeherrscher des Weltmarktes, die Engländer, in die Rolle von Konkurrenten zurückgedrängt hat. Indes hat die keimende industrielle Hegemonie Deutschlands ihre Kontrasignatur im Phänomen des Urbanismus und einer teilweisen Entvölkerung des Landes (der „Leutenot“) und beruht überdies auf einer gebrechlichen Basis: dem Export der Industrieerzeugnisse und dem Import von Agrarprodukten. Letzterer macht das Land immer mehr vom Auslande abhängig und könnte ihm im Falle von Zollkriegen und militärischen Auseinandersetzungen verhängnisvoll werden; ersterer wird in dem Augenblick zu existieren aufhören, in welchem die Völker, die sich der aus Deutschland exportierten Waren bedienen, die Lehren der deutschen Meisterin verstanden haben und beginnen werden, die importierten Gegenstände nachzumachen und in deren Qualität zu erreichen. Eingeholt und überboten zu werden ist das Los aller vom Warenexport lebenden Länder. Ein derartiges Schicksal bedeutet aber für sie, zumal wenn die ihnen notwendigsten Güter nur mittelst Tausch mit den von ihnen erzeugten Manufakturwaren beschaffbar waren, Krise und Niedergang. ${ }^{1}$ ) Auf diese Weise wäre die Annahme nicht ausgeschlossen, daß eine der markantesten und großartigsten Wirtschaftsentwicklungen, welche die neuere Geschichte kennt, nur das Präludium zu einer Symphonie der Hölle ist. In solchem Falle wäre der Fortschritt trügerisch und vorübergehend,

1) Vgl. die pessimistischen Erörterungen über dieses Thema bei Karl Oldenberg, „Deutschland als Industriestaat“. Göttingen I 897 , p. $39 \mathrm{ff}$, denen sich auch Gustav schmoller ("Die Zukunft der deutschen Bevölkerung und die heutigen Wanderungen übers Meer", Woche I, Nr. 39) anschloß. 
einem Irrlicht vergleichbar, das im Wanderer wohl intensive Lustgefühle auszulösen vermag, ihn aber dem Verderben zuführt.

Die Duplizität des Fortschritts wird auch am Beispiel der politischen Partei klar. Insbesondere wenn die politische Partei auf ideologischer Basis ruht und gesellschaftsumgestaltende $Z$ wecke verfolgt. Da sehen wir Parteien finanziell reich werden, ihre Kassen füllen, an Mitgliedern wachsen, Wahltriumphe feiern, kurz Fortschritte auf Fortschritte häufen. Gleichzeitig aber verliert die Partei mit dem Heranwachsen und Überhandnehmen eines selbständigen, sie immer mehr als Selbstzweck betrachtenden Führertums ihre Physiognomie, wird den Zielen entfremdet, zu deren Errejchung sie entstanden, läßt sich von der sogenannten Eroberung der politischen Macht hypnotisieren und befindet sich, trotz ihrer glänzenden Organisation, dem Staate gegenüber, mit dem sie sich an Kraft und Weite des Gefüges nicht messen kann, im Zustande der Ohnmacht, ohne Saft und Kraft zu energischen Massenaktionen, welche die bereits erreichten Fortschritte ja wieder in Frage stellen könnten. ${ }^{1}$ ) Dabei handelt es sich hier um reelle, leicht meßbare Fortschritte und fast ebenso leicht, wenn auch nicht auf rechnerische Weise, wahrnehmbaren Rückgang.

Der Fortschritt kann auch Folge eines Übels sein. Das Gelingen eines kollektiven Gewaltaktes, wie z. B. ein siegreicher Krieg, wird stets von der Tendenz der Sieger gefolgt, ihren Tatendrang auch auf andere, dem Gewaltakt selbst fernliegende Gebiete zu übertragen. Dem Gelingen wohnt infolgedessen ein energischer Impuls zum Fortschritt inne. Aber die Geschichte beweist uns, daß eine derartige Entwicklung nie ohne eine beträchtliche Schwächung der moralischen Potenzen vor sich geht und auch den ästhetischen

I) Vgl. mein Werk, „Zur Soziologie des Parteiwesens", l. c., p. 359 . 
Faktoren im Volksleben häufig namhaften Schaden zufügt. Es ist bekannt, wie die lange Reihe siegreicher Kriege Napoleons III. einen Aufschwung des französischen Handels und Wandels, der Arbeiterfürsorge und der Bautätigkeit, aber auch ein Überhandnehmen des Leichtsinns in der Lebensführung sowie eine Veroberflächlichung in der Kunst zur Folge hatte. Nach 1870 hatte das militärisch siegreiche Deutschland einen unerhörten Aufschwung seiner Technik, seiner Industrie, seiner Volkswirtschaft zu verzeichnen gehabt, seine Kunst und seine Literatur dagegen, kurz sein ästhetischer Geschmack hat dreiBig Jahre lang schlimmer denn je daniedergelegen und gleichzeitig ist auch die Psyche des deutschen Volkes einiger ihrer kulturell wertvollsten und liebenswürdigsten Eigenschaften verlustig gegangen, während sie sich andere nützliche, aber ethisch indifferente oder weniger lobenswerte Eigenschaften erwarb. ${ }^{1}$ )

Perioden gewaltigen ökonomischen Fortschritts üben in der Regel zwei sehr verschiedene Wirkungen auf die öffentliche Moral aus. Einerseits heben sie durch die besseren Lebensbedingungen, welche sie, sei es auch nur nach vielen Klassenkämpfen, auch den ärmeren Volksschichten gewähren, die dadurch an dem allgemeinen Segen teilnehmen, die Moral, soweit sie gesetzlich festgelegt ist. Die statistisch nachweisbaren Verbrechen nehmen ab, und, sofern sie nicht abnehmen, verfeinern sie sich: an die Stelle der Bluttaten treten raffinierte Betrügereien. Andererseits blähen sie das Selbstbe-

I) Diese Erkenntnis kommt neverdings in mancherlei Schichten deutscher Gelehrter zum Ausdruck; vgl. beispielsweise Walther Schücking, „Die Organisation der Welt". Leipzig 1909, Kröner, p. $77 \mathrm{ff}$; und Martin Rade, "Mehr Idealismus in der P'olitik !“. Jena I9II, Diederichs. Besonders stark ist die Einseitigkeit des Fortschritts in der Entwicklung Deutschlands auch von modernen Franzosen beobachtet worden. Vgl. Fernand Bac, "Vieille Allemagne“. Paris 1906; Marcel Prévost, "Monsieur et Madame Moloch". Paris 1906, Lemerre. 
wußtsein der besitzenden Klassen und der Regierungen auf, das sich in den Beziehungen mit dem Ausland in chauvinistischer Form und einem allgemeinen Niedergang der Nächstenliebe, soweit sie anderssprachliche und andersrassige Völker betrifft, äußert.

Die politische, geistige und künstlerische Geschichte der Völker besteht in einer schier unübersehbaren Reihenfolge kleiner Fortschritte und kleiner Rückschritte, aneinandergereiht ohne jede Harmonie und Methode und ohne andere Gesetzmäßigkeit als jene launenhafte Tendenz, die Vico als die corsi e ricorsi der Geschichte bezeichnete. Der Grundcharakter des Fortschritts ist seine Unvollständigkeit, sein sprunghaftes, fragmentarisches, widerspruchvolles Wesen. Der Fortschritt umfaßt niemals zugleich alle $Z$ weige der menschlichen Tätigkeit, oft ist seine Wirksamkeit in einer Richtung günstig, in der anderen ungünstig. Bisweilen ist der Fortschritt in der Erzeugung von Quantitätswerten mit Schäden für die Erzeugung von Qualitätswerten verbunden oder umgekehrt. Häufig ist der Fortschritt auf einem Gebiet durch den Rückgang auf einem anderen geradezu bedingt. Die Ereignisse der menschlichen Geschichte in ihrem ewigen Hin und Her, Auf und Nieder sind untereinander nicht vergleichbar und auch ihre Resultate sind schwer feststellbar. Fortschritt ist nicht einmal in ihrem Rhythmus zu erweisen. Höchstens einige Konkomitanzen und Periodizitäten vermag er aufzuweisen. So ist denn mit dem Begriff des Fortschritts wissenschaftlich nichts anzufangen. Diesen unklaren und schwammigen Begriff aber in die Vulgärsprache übertragen, den Zeitungen aufdrängen und ins Volk hineintragen wird Ursache zu gröBter Seichtigkeit und Begriffsverwirrung. Es wäre am Platze, das Wort Der Fortschritt zum mindesten mit dem bestimmten Artikel und als Absolutum aus der Terminologie der Gelehrten zu bannen und höchstens die Rede von definierbaren, umgrenzbaren Fortschritten auf ebenso definierbaren und umgrenzbaren Gebieten zuzulassen. Wie 
alle hochtönenden, aber leeren oder übervollen Worte muß auch das Wort Fortschritt, um wissenschaftlich brauchbar zu werden, in die Kur des Relativismus genommen werden. Die Soziologie darf ihm nur dann Aufnahme gewähren, wenn auf folgende Gewissensfragen gebührende Antwort erteilt werden kann: Fortschritt worin? Fortschritt unter welchem Gesichtswinkel betrachtet? Fortschritt unter welchen Prämissen?

\section{Fünftes Kapitel.}

\section{Zum Problem der Messung der Sittlichkeit.}

Von allen Spezies des Fortschritts ist der Fortschritt auf dem Gebiete der Moral am schwersten faßbar. Den Grad an Moral, den ein Volk besitzt, festzustellen, fehlt uns jedes Mittel. Besondere ökonomische Formen und Einrichtungen gebären notwendigerweise besondere Formen der Vergehen und Verbrechen. Selbst der Begriff der Strafbarkeit einer bestimmten Handlung und ihre juristische Normierung unterliegen bis zu einem gewissen Grade den jedesmaligen wirtschaftlichen Notwendigkeiten eines gegebenen Komplexes sozialer und ökonomischer Konstitutionen und Institutionen. Die Siț̀lichkeit, die Moral läßt sich schwer mit Zahlen messen. Das wird am deutlichsten bei Untersuchung der Geschlechtsmoral. Wie ist in der Tat der Fortschritt oder Rückschritt eines Volkes bezüglich der Geschlechtsmoral festzustellen? Es hält schwer, für das, was wir als geschlechtliche Sittlichkeit bezeichnen, einen untrüglichen, wissenschaftlich brauchbaren Maßstab zu finden.

Besonders vielfach hat man einen Index für das Wachstum oder die Abnahme der in einem Volke vorhandenen geschlechtlichen Muralbegriffe, in der Abnahme oder Zunahme der sich in diesem Volke vorfindenden Ziffernhöhe der un- 
ehelichen Geburten erblicken wollen. ${ }^{1}$ ) Um die Richtigkeit dieser Auffassung zu prüfen, müssen wir uns zunächst die Frage ätiologisch stellen. Etwa folgendermaßen: Welches sind die Koeffizienten, als deren Resultante die Abnahme oder Zunahme der unehelichen Geburtenziffern zu betrachten ist?

Zunächt ist daran zu erinnern, daß die Zahl der unehelichen Geburten, wie sie aus den Statistiken hervorgeht, keineswegs mit der Zahl der unehelichen Geburten, nach natürlichem, d. h. nicht nach nur juristischem Maße gemessen, zusammenfällt, sondern nur einen Teil dieser umfaBt. Wie wir das an anderer Stelle ausgeführt haben ${ }^{2}$ ): Das Gesetz kennt nur starre Normen und schließt vor allen Zwischenstufen die Augen. Das Gesetz weist in sexueller Hinsicht nur zwei Gruppen auf: Kontrollmädchen, d.h. Mädchen, deren Unsittlichkeit kontrolliert und abgestempelt worden ist, und anständige Frauen. Was der ersten Kategorie nicht angehört, fällt ohne weiteres in die zweite. Beide sind wie durch einen Abgrund getrennt, über den der eifrige Schutzmann allerdings von Zeit zu Zeit einen Steg findet, indem er einzelne Individuen aus der zweiten in die erste Kategorie überführt, nicht aber ohne dabei häufig traurigen Mißverständnissen oder merkwürdigen Begriffsverwirrungen anheimzufallen.

Die Statistik verfährt wie das Gesetz. Das wird am deutlichsten ersichtlich aus der statistischen Behandlung der Geburten. Nach dem Gesetz gilt jedes in gültiger Ehe erzeugte Kind als ein eheliches. Auch wenn der Erzeuger dieses Kindes ein ungültiger, ein außerehelicher Mann ist. Selbst wenn dieser Tatbestand von allen beteiligten Seiten - Ehefrau, Ehemann, Ehebrecher - zugegeben wird. Ein derartiges

I) z. B. Prosper Baron de Haulleville, „L'Avenir des Peuples Catholiques“. Turin 1877, Romano, p. 234.

2) Vgl. mein Werk, "Die Grenzen der Geschlechtsmoral“, 1. c., p. $56 \mathrm{ff}$. 
Eingeständnis ändert juristisch nichts an der Ehelichkeit der Geburt. Die Statistik kennt lediglich „eheliche Geburten“ und „uneheliche Geburten“ und registriert sie. Die weitere groBe Rubrik: „uneheliche Geburten in der Ehe“ kennt und registriert sie nicht. Es mag ohne weiteres zugegeben werden, daß dies weder ihres Amtes sein kann, noch daß es sichere Mittel und Werkzeuge, genügende Kriterien, gibt, auf Grund deren diese dritte Rubrik Existenzberechtigung erhalten könnte. Die Vaterschaft ist ein Mysterium und entzieht sich wissenschaftlicher Feststellung. Aber deshalb bleibt die statistische Einteilung der Geburten in eheliche und uneheliche nicht weniger irreleitend. Es ist aus diesem Grunde immer eine mißliche Sache, die moralische Superiorität eines Landes über ein anderes an der Hand einer in dem ersteren von beiden statistisch festgestellten geringeren Zahl illegitimer Geburten konstruieren zu wollen. Kann doch die große Unbekannte der unehelichen Geburten in der Ehe, die von der Statistik den ehelichen Geburten zugezählt wird, sogar dergestalt sein, daß das tatsächliche Verhältnis zwischen den ehelichen und den unehelichen Geburten das in der Statistik gefundene Verhältnis wieder umkehrt.

Die hohen Ziffern unehelicher Kinder, an sich zweifellos ein Übel, sind zunächst verschieden zu beurteilen, je nachdem in den einzelnen Ländern die Erforschung der Vaterschaft gesetzlich verboten oder gesetzlich gestattet ist. Im letzteren Falle versteht es sich von selbst: das Mädchen, das weiß, daß ihm im Bedarfsfalle der Staat für sich und ihr Kind genügend Schutz gewährt, um nicht im Elend umzukommen, indem er ihm dafür einsteht, daB sein Partner zu den durch die gemeinsame Schuld entstehenden Kosten mit herangezogen wird, wird leichter, weil ruhigeren Herzens, Liebeshändel eingehen als das Mädchen, das sich genau dessen bewußt sein muß, daß es die Folgen seines Falles ganz allein zu tragen hat. Insofern schnellt, wie wir das an den Zahlen der unehelichen Kinder in Österreich seit 
den seligen Zeiten Maria Theresiens zur Genüge sehen können, die Fürsorge für die uneheliche Mutter und die gesetzliche Regelung der Alimentation der Bastarde die uneheliche Natalität herauf. ${ }^{1}$ ) Kann man deshalb sagen, dab die Unzucht in solchen Ländern Fortschritte mache?

Im übrigen hängt die Höhe der Ziffer an unehelichen Geburten, die ein Land aufweist, mehr als vom Stärkegrad der „Moralität" von der Stellung ab, welche die Frau im gesellschaftlichen Leben jenes Landes einnimmt, und, was wieder davon herrührt, von den Methoden, denen die Erziehung der weiblichen Jugend unterworfen ist. Wo das junge Mädchen beständiger Aufsicht und unausgesetzter Kontrolle unterliegt, zu Hause wie außer dem Hause stets unter dem wachsamen Auge der Mutter oder sonstiger weiblichen Verwandten steht, kurz wo sie keine Bewegungsfreiheit genießt, wird die illegitime Natalität sich nicht über eine sehr niedrige Ziffer erheben können. Desgleichen dort, wo jeder sexuelle Fehltritt das Leben des Mädchens der Rachsucht jedwedes um die Familienehre besorgten und ob des unmoralischen Verhaltens erzürnten Bruders oder gar Vetters aussetzt. So ist es erklärlich, daß in den Ländern des südlichen Europa die Tugend des jungen Mädchens in allen Volksklassen eine absolute ist, und die unehelichen Geburten auf ein Minimum reduziert und, wo sie dennoch vorkommen, von ganz

I) In der ersten Hälfte des vorigen Jahrhunderts (1841) verhielt sich in den Ländern der österreichischen Monarchie die Zahl der unehelichen zur Zahl der ebelichen Geburten im italienischen Venetien wie I zu 39, in Österreich nieder der Enns (deutsch) wie I zu 2. (C. J. A. Mittermaier, „Italienische Zustände“. Heidelberg 1844, Mohr, p. 167.) Diese Zahlen sind freilich nicht allein dem Einfluß der Theresianischen Gesetzgebung zuzuschreiben, sondern hängen jedenfalls, wie ich das an anderer Stelle ausgeführt habe (Robert Michels, „Demographisch-statistische Studien zur Entwicklungsgeschichte Italiens", in Schmollers Jahrbuch für Gesetzgebung, XXXII 2, p. I05 ff.), auch mit Verschiedenheiten sozialer und ethnischer Natur zusammen. 
anderen Gründen, die mit der Geschlechtsmoral nicht das geringste zu tun haben (nur kirchliche, nicht staatliche Ehe), abhängig sind. Eine größere Bewegungsfreiheit und erweiterte Tätigkeitssphäre, wie sie gerade als ein Kennzeichen der moralisch und intellektuell fortgeschrittenen Länder anzusehen ist, in denen das Weib nicht mehr als ewig Minderjährige, sondern als für ihr Tun und Lassen verantwortliche vollmenschliche Persönlichkeit betrachtet wird, ist die Anzahl unehelicher Geburten in der Regel höber. Der Kontakt mit dem Leben muß bei der Beschaffenheit unserer Physis der Sexualmoral gefährlich werden. Das einzig wirksame Mittel, das Vorkommen unehelicher Natalität zu verhindern, ist immer noch das Gefängnis oder das Gynäzeum. Es kann deshalb ohne große Übertreibung die Behauptung aufgestellt werden, daB die Sexualmoral, soweit sie an der Höhe der Zahl unehelicher Geburten gemessen wird, im umgekehrten Verhältnis zu dem Grad des in den einzelnen Ländern herrschenden Gefühles für Frauenwürde steht. Da die Freiheit, welche die Frau genieBt, eben fast stets der natürliche Ausflub der Achtung und des Vertrauens ist, die man ihr entgegenbringt, und ihrer völligen Menschwerdung erst die Wege ebnet, so kann man sagen, daß Kultur und ein gewisser Grad von sexueller Ungebundenheit hier zusammenfallen.

Es wäre eine interessante Aufgabe, das Verhältnis von Geschlechtsmoral und Sozialismus bzw. moderner Arbeiterbewegung einmal einer eingehenden Prüfung zu unterziehen. An Material für eine derartige Untersuchung würde es, wenigstens für einzelne Distrikte des agrarischen Italien, wo die Landarbeiterschaft nicht nur, soweit sie im Besitze des Wahlrechts ist, sozialistisch wählt, sondern wirklich auch, psychologisch gesprochen, sozialistisch fühlt, nicht fehlen. Für einige ganz besonders sozialistische Gegenden des Mantovano liegen uns Statistiken der Staatsanwaltschaft aus dem Jahre 1896 vor, die uns zahlenmäßig auf ein ganz ungeheures 
Anwachsen der unehelichen Geburten - manchenorts sogar bis zu gleicher Höhe mit den ehelichen - hinweisen. Sozialistischerseits wird dieses Faktum bereitwilligst anerkannt, und in der gemeinsamen Schrift eines der hervorragendsten Praktiker und eines der hervorragendsten Theoretiker der sozialistischen Bewegung (revisionistischer Richtung) in Italien für das Merkmal eines „Kulturfortschritts“ erklärt, nämlich als Anzeichen von dem endlichen Durchbruch eines freieren Geistes, insbesondere einer weitherzigeren Auffassung des Geschlechtslebens durch die Befreiung von dem Aberglauben an die sittliche Notwendigkeit der offiziellen Ehe. $\left.{ }^{1}\right)$ Dagegen haben dieselben Sozialisten die Folgen der freien Liebe selbst stets auf das eifrigste bekämpft und, nach dem Zeugnis von Ärzten, in manchen ehemals von Prostitution, Fruchtabtreibung und Kindesmord außergewöhnlich heimgesuchten Gegenden, wie im Bolognese, diese Verbrechen mittelst unermüdlicher Propaganda so gut wie völlig getilgt. ${ }^{2}$ )

Wir leugnen nicht, daß die Zunahme der unehelichen Geburten unter Umständen auf eine Zersetzung der sittlichen Begriffe in einem Volke schließen läßt. Wir behaupten aber, daß diese Umstände in den seltensten Fällen eintreten. Zumeist ist die Zunahme der unehelichen Geburtenziffer das unmittelbare Ergebnis einer stattgehabten Verschlechterung der Lebensbedingungen der ärmeren Bevölkerungsklassen. Verschlechterungen solcher Art pflegen das mittlere Heiratsalter der diesen Klassen angehörigen Männer und Frauen hinaufzusetzen: die Unsicherheit der Existenz hat zur Folge, daß die Heiraten aufgeschoben, vielfach selbst aufgehoben werden. An die Stelle der unmöglich gewordenen

I) Ivanoe Bonomi e Carlo Vezzani, „Il Movimento Proletario nel Mantovano". Milano I901, Ed. Critica Sociale, p. 19.

2) Nach dem Ms. des Referats von Argentina Altobelli Bonetti, der bekannten Organisatorin der Reisarbeiterinnen, auf dem Internationalen Frauenkongreß, Berlin, Juni 1904. 
ehelichen Geschlechtsverbindungen tritt aber, und muB in Anbetracht der Heftigkeit, mit welcher der Geschlechtstrieb sich in jungen Jahren geltend macht, das „Verhältnis“ und, infolgedessen, die Zunahme in der Produktion der unehelichen Kinder treten. Die Geburtenstatistik zeigt uns in der Tat, daß bei langwährenden Geschäftsstockungen und Wirtschaftskrisen mit der Arbeitslosigkeit die Rate der unehelichen Geburten eine Tendenz zum Steigen aufweist. Woran zu ersehen ist, daß der ökonomische Faktor in diesen $\mathrm{Zu}$ sammenhängen ein gewichtiges Wörtchen mitspricht.

Das gleiche läßt sich, wenn auch in stark vermindertem Maße, von der Gesetzgebung wiederholen. Vom Mittelalter bis in die neueste Zeit war die EheschlieBung kein unantastbares, individuelles Recht, sondern dem Einspruch von Staat, Stadt oder Grundherrn streng unterworfen. In Bayern diesseits des Rheins durfte seit 1868 die Verehelichung eines Mannes nur unter bestimmten Bedingungen vor sich gehen, unter denen sich die Bedingung, daß der Mann mindestens in den letzten drei Jahren keine öffentliche Armenunterstützung mehr bezogen hatte, befand. $\left.{ }^{1}\right)$ Diese und dergleichen Ehehindernisse, welche die Ärmsten der Armen treffen, mehr wirken natürlich in der Richtung auf eine Vermehrung außerehelicher Geschlechtsbefriedigung und ihrer Folgen.

Indes die Verminderung der Ziffern der unehelichen Geburten kann sogar Indicium unzweifelhaft feststehender Zunahme der Unmoral in einem Volke sein. Mit diesen Worten spielen wir nicht auf die Anwendung zeugungsverhindernder Mittel in der sog. freien Liebe an, da wir in dem Gebrauch von Gummiartikeln und anderen Nitteln zum gleichen Zweck an sich keine unmoralischen, sondern höchstens unästhetische Handlungen, die selbst bisweilen $-\mathrm{ja}$, bei außerehelichen Liebesverhältnissen sogar immer - zur Not-

1) Utber diesen Punkt vgl. Johannes Conrad, „GrundriB zum Studium der politischen Ökonomie". Teil II. Jena 1898, Fischer, p. $10 \mathrm{I}$. 
wendigkeit eines sittlichen Gebotes, nämlich des Verantwortlichkeitsgefühles der Gesellschaft gegenüber werden können, zu erblicken vermögen. Wir reden vielmehr von der Ausbreitung der Praktiken, die dazu dienen eine bereits stattgefundene Befruchtung wieder aus der Welt zu schaffen. Die Ausbreitung solcher Praktiken, die allerorts vom Gesetz mit schweren Strafen belegt werden, führt aber ganz gewiß zum Resultat einer Verminderung der unehelichen Geburten. So kann also unter gewissen Umständen umgekehrt die Vermehrung der unehelichen Geburten ein Anzeichen höherer Moral sein. In einem Vergleich zwischen dem Dirnenwesen in der Stadt und dem auf dem Lande in Deutschland heißt es: "Nur sind diese Prostituierten des Dorfes nicht so raffiniert wie ihre Schwestern in der Stadt. Der Irrigator ist bei ihnen nicht der regelmäßige Schmuck ihrer einfachen Wohnungen, und die Abtreibungskünste der Großstadt sind ihnen noch verhältnismäßig fremd. Infolgedessen ereignet es sich bei ihnen viel öfter, daß sie uneheliche Kinder zur Welt bringen. Da die Engelmacherinnen auf dem Lande noch nicht so regelmäßig ihr schändliches Gewerbe ausüben, so wachsen die Kinder mutig und frisch heran.“1) Wer demnach die Verminderung der unehelichen Natalität als einen Ausfluß vermehrter Sittlichkeit im Volke ansieht, wäre logisch gezwungen, die künstliche Abtreibung der Frucht unehelicher Liebesleute mit Freuden als „Fortschritt" zu begrüßen. Die Wissenschaft muB also jedes Inbeziehungsetzen von bei einem Volke vorhandener unehelicher Natalität und Sexualmoral und jedes Abschätzen des Grades dieser an der Höhe jener als eine Mystifikation zurückweisen, die dazu geeignet ist, die an sich schon nicht leichte Untersuchung vom Wesen des Fortschrittes durch unbefugte Seitensprünge zu stören.

I) Otto Mönkemöller, ,Korrektionsanstalt und Landarmenhaus". Leipzig I908. J. A. Barth. p. 26I ff. 
Unter die Gradmesser der Sittlichkeit in einem Volke hat man auch die Zahl der in ihm lebenden Prostituierten rechnen wollen. Gegen ein solches Vorhaben spricht in erster Linie schon die Untauglichkeit der Mittel: die Ungenauigkeit der offiziellen Unzuchtsstatistiken, ja die Unmöglichkeit eines statistisch verwendbaren Kriteriums der Prostitution. Aber auch innere Gründe lassen es für unnatürlich erscheinen, das Auf und Nieder der Prostitution mit einem Fortschritt oder Verfall der öffentlichen Sittlichkeit zu identifizieren. Ernste Männer haben die Behauptung verfochten, daß es gerade die allerbesten, warmblütigsten, hingebendsten, gläubigsten Elemente gewisser Frauenschichten seien, welche der Prostitution anheimfallen. ${ }^{1}$ ) Ohne so weit gehen zu wollen, läßt es sich doch nicht verkennen, daß die Verbreitung gewisser Formen der Ehe, wie die Kaufehe und die Ehe auf der Basis der Duldung gegenseitiger Sexualfreiheit, mindestens ebenso bedauerliche Indicien moralischer Dekadenz in einem Volke sind als die Ausbreitung der Bordelle oder des Straßendirnentums.

Ebenso kann die Zunahme beziehungsweise Abnahme der kecken und obszönen erotischen Kunst und Literatur nicht als Kriterium der Entsittlichung oder Versittlichung eines Volkes dienen. Fuchs bemerkt mit Recht, daB die erotische Karikatur ebenso Dokument des Niederganges als Dokument des gärenden Kraftüberschusses einer Gesellschaft sein kann.?

Endlich vermögen weder die Statistiken venerischer Erkrankungen, auf die sich die Naturwissenschaftler so gern berufen, noch die Beobachtung von dem Vorhandensein einer größeren oder geringeren Prolifizität bzw. von der Anwendung des Neomalthusianismus auf die Frage nach der

I) Vgl. z. B. Robert Hessen, ,Die Prostitution in Deutsch. land“. München 1910, Langen, p. 48, 57, I 23.

2) Eduard Fuchs, "Geschichte der erotischen Kunst". Berlin 1908, Hofmann, p. 284. 
geschlechtlichen Sittlichkeit einer bestimmten Bevölkerungsgruppe ausreichende Antwort zu geben.

Loria ist somit in vollem Recht, wenn er erklärt, jede Beschäftigung mit dem Problem des ethischen Fortschritts sei unnütze Zeitvergeudung. Fortschritt sei nur bei Dingen (Objekten) und nicht bei Menschen (Subjekten) feststellbar, und selbst die Vervollkommnung in jenen habe nicht die Fähigkeit, die Glücksmöglichkeiten für diese zu steigern. ${ }^{1}$ )

\section{Sechstes Kapitel. \\ Zum Problem der Koketterie.}

Das Mädchen hat nicht immer einen genauen Begriff davon, wie weit es mit seiner Koketterie in der Kleidung den Mann reizen kann und wie es infolgedessen von ihm gewertet wird. Häufig bedient sich das anständige Mädchen oder die ehrbare Frau mit Freuden neuer Moden, welche den Männern als in hohem Grade unschicklich und schamlos erscheinen, $\mathrm{ja}$, die sie für ausdrücklich auf Erweckung der männlichen Sinnenlust berechnet halten. Sie bedient sich ihrer, insofern sie kleiderlieb und ein fröhliches lebenslustiges Weltkind ist, wobei sie noch keineswegs leichtsinnig und flatterhaft in eroticis zu sein braucht, ohne Neben- und Hintergedanken, als Ding an sich. Im Manne spielt sich dann folgenderGedankengang ab: dieFrau (oder das Mädchen) zieht sich in einerWeise an, die die weiblichen Körperformen, ja die Formen ganz bestimmter weiblicher Körperteile, künstlich in scharfes Licht setzt. Das kann sie nur tun, weil sie den Zweck verfolgt, meine Blicke auf sich zu lenken und in mir Lustgefühle zu erwecken. Das Nachgeben der Mode gegenüber bedeutet also, daB das

I) Achille Loria, „Siamo noi migliori dei nostri Antenati?" in Loria: „Verso la Giustizia Sociale“. 2. Aufl. Milano I 908, Soc. Ed. Libr., p. 611. 
Weib sich dem Manne hinzugeben wünscht. Das Weib setzt dieser dickflüssigen und derben, primitiven Logik ein natürliches Schönheitsgefühl entgegen, über das sich nicht rechten läßt. Wenn sie sich nach der Mode kleidet, so gehorcht sie instinktiv dem Bedürfnis nach Eleganz, in der Art natürlich, wie sich dieser jährlich wandelbare Terminus gerade im Augenblick gibt. Das Bedürfnis nach Eleganz entspringt seinerseits wieder einer Regung weiblichen Ehrgefühls: nicht hintanzustehen unter den Geschlechtsgenossinnen aus der gleichen Gesellschaftslage: dem berechtigten Wunsch, am Wettlauf teilzunehmen. Dieser Wunsch aber wiederum hat seine Wurzel in der natürlichen Gefallsucht, in eben jenem Bedürfnis des Bewundertwerdens, das im innersten Sehnsuchtsschrein jedes normalen Menschen ruht, wenn anders traurige Entsagung es nicht unterdrückt oder gar weit häßlichere und weniger harmlose Lüste es nicht verdrängt haben. Das Bewundertwerden aber ist der eleganten Frau Selbstzweck. Es ist sinnlicher, aber deshalb noch längst nicht schlechterdings sexueller Natur.

Man hat die Koketterie in Rede und Gebärdenspiel die Mittlerin der Unzucht genannt. Es ist nicht zu verkennen, daß in diesem grausamen Urteilsspruch ein wahrer Kern steckt. Die Gefallsucht wird leicht zur Fallsucht, wenn sie nichts weiter sein soll als Werkzeug zur Eroberung des Mannes zum $Z$ wecke der Liebe; wenn sie sich darstellt als Liebesvorspiel. Aber sie kann auch nur heiteres Spiel sein. Spiel mit dem Feuer, wenn man will, aber doch Spiel: ein Spiel des Versteckens, des Gewährens, Hinhaltens und Zurückziehens, des scheinbar Gebens und Wiedernehmens, kurz, der erotischen Illusion. Diese Illusion spielt aber nun häufig eine die Ehe und die Moral schützende Rolle. Um den dem Menschen innewohnenden polygamischen Trieb in etwas zu zähmen, muß der Mensch das Bewußtsein seiner polygamen Kapazität besitzen. Das heißt, das Weib wie der Mann müssen das Bewußtsein haben, daß es nur an ihnen liege, wenn sie auf 
die Polygamie verzichten und der (dem) Auserwählten mono. gam treu bleiben, daß es ihnen aber stets möglich sei, im Kreise sympathischer Menschen der eigenen Gesellschaftsschicht geschlechtliche Eroberungen zu machen, sofern sie nur den Finger danach rühren. Dieses Bewußtsein nun verleiht die Koketterie. Durch sie erwirbt das Weib die Genugtuung, von den Schönsten und Besten des anderen Geschlechts bewundert und begehrt zu werden. Natürlich ist das nur möglich, wenn das Weib selbst in seinem Benehmen vorhandenes oder gut gespieltes Begehren durchblicken läßt und die Möglichkeit des Ehebruchs und der Eingehung eines ungesetzlichen Liebesverhältnisses nicht von der Hand zu weisen scheint. So entsteht jene Gesellschaft, in der auch die anständigste Frau nur selten auf den Luxus verzichtet, bisweilen den Schein der Unanständigkeit auf sich zu lenken. Sie setzt sich dadurch gegenüber dem kurzsichtigen und moralinsauren Beobachter, zumal wenn dieser aus der Kleinbourgeoisie stammt und das leichtgeschürzte Spiel gesellschaftlicher Erziehung, welches spielen zu können alterworbene Gewohnheit und intellektualistisch-ästhetische Qualitäten (Lebensart, schnelles Erfassen, geistige Biegsamkeit) voraussetzt, in seinem Unverständnis für blutigen Ernst hälh, sehr ungünstigen Urteilen aus. Aber sie ist doch meistens, ohne gut zu sein, weit besser als ihr Ruf, da die Koketterie in ihr nur der unschuldige Ausdruck eines starken Instinktes, ja vielleicht gar nur der letzte Schirm für ihre eheliche Treue ist. Man wäre versucht, die Koketterie, unter diesem Gesichtswinkel betrachtet, als einen, häufig unbewußten, Versuch zu bezeichnen, den polygamen Geschlechtstrieb ohne Begehung materiell grob-sinnlicher Akte zu befriedigen.

Es erübrigt sich zu sagen: das Mittel ist gefährlich. Auch von der Koketterie, die stets eine gewisse Herausforderung in sich schließt, kann es heißen: wer sich in Gefahr begibt, kommt darin um. Oft bedeutet die Koketterie nicht eine 
Ableitung vorhandener starker Sinnlichkeit, sondern eine unbewußte oder auch bewußte Hinlenkung zur Geschlechtlichkeit. Es ist, vor allem dem inexperten Auge - und viele Männer bleiben ihr Leben lang trotz aller Experimente in diesem Punkte inexpert - nicht leicht, die beiden Typen der Koketterie voneinander zu unterscheiden. Auch mögen dem Bestreben der Frau, sich Respekt zu verschaffen, nachdem sie längstens alle Wasser hat springen lassen, um den Mann den Respekt vor ihr verlieren zu lassen, unschöne Eigenschaften zugrunde liegen: Hochmut und Herrschsucht, die kein Mittel, auch das des stärksten sexuellen Reizes nicht, unversucht lassen, um eine möglichst große Anzahl von Männern möglichst dauernd liebestoll und anbetungstrunken vor sich auf die Kniee zu zwingen. Ein Verfahren, dessen Reiz für die Frau gerade dadurch ungemein erhöht wird, daß sie, die angebetete Göttin selbst, trotz aller von ihr geübten Vorspiegelung sexueller Gelüste als die unnahbar Reine aus den Gefahren siegend hervorgeht. Denn noch eine weitere Charaktereigenschaft bildet häufig die Basis zügelloser Koketterie: geschlechtliche Unlust und Bedürfnislosigkeit, die sich in ihrer Eiseskälte darin gefallen, warmblütige Nenschen wahnsinnig zu machen und durch geschlechtlichen Kitzel da gewagtes Spiel zu treiben, wo keinerlei eigene Gefahr vorliegt, da der eigene Frost vor jeder Eventualität, daß der Brand von der einen auf die andere Seite übergreifen könnte, von vornherein schützt.

Wie die meisten Äußerungen menschlicher Psyche, ja, in noch viel höherem Grade als die meisten unter ihnen, ist die Koketterie polyedrischer Natur. Sie kann urwüchsig sein und verfeinert und es bedarf, um Werturteile über sie fällen zu können, gründlicher Analyse im Einzelfalle. 
98 VII. Zum Problem der Behandlung des Proletariats usw.

\section{Siebentes Kapitel.}

\section{Zum Problem der Behandlung des Proletariats in der Wissenschaft.}

Es gab eine Epoche in der Geschichte, in der die Weltverbesserer und Philosophen kein wirksameres Heilmittel für die Schäden der Zeit wußten, als dem entarteten, verweichlichten und krankhaft-kränklichen Reichen das Urbild des armen Mannes, wie es sich in ihren Köpfen malte, entgegenzuhalten. Das heißt den urkräftigen und kerngesunden Armen, den Mann aus dem Volke mit den „doppelten“ Muskeln, den prallen Backen und den kirschroten Lippen, zu dessen physischer Kraftfülle und sittlicher Tugend es zu gelangen galt, eine Aufgabe, die mit unbedingter Sicherheit gelöst werden müßte, falls man sich nur des Rezeptes nicht entschlagen wollte, ihn in seiner Lebensweise nachzuahmen. Das war die Zeit, in der aus philosophischem Munde das Wort von der Notwendigkeit der Rückkehr zur Natur fiel, in der Grafen sich als Schäfer und Königinnen sich als Milchmädchen verkleideten und die Nachbildung proletarischer Lebensformen, teils als ehrlich gemeintes Gesundungsmittel, teils als ritterlicher Sport, die oberen Schichten der besitzenden und gebildeten Klassen mit gewaltigem Eifer erfüllte.

Dem folgte die Epoche der großen französischen Revolution. Da trat neben dem Kleinbürger der Proletarier selbst auf den Plan der Geschichte, und die Geschäfte, die er mit den wohlhabenden und hochmögenden Herren abzuwickeln hatte, waren so intimer Art, daB diese Gelegenheit erhielten, sich das vermeintliche Urbild körperlicher und geistiger Gesundheit einmal in nächster Nähe anzusehen. Bei diesem 
nicht immer freundlichen Kontakt mit der Plebs konnte es ihnen nicht entgehen, wie sehr sie sich, sowohl bezüglich der einen, wie bezüglich der anderen Auffassung geirrt hatten. Der Proletarier war in Wahrheit physisch elend und auch sittlich keineswegs so hochstehend, daB er den Besitzenden als Vorbild zu dienen imstande gewesen wäre.

Aber die Erkenntnis vom äußeren Wesen der unteren Klassen vermochte in den Köpfen der Reichen nicht die Überzeugung zu befestigen, daß es ihre Pflicht sei, Mittel und Wege ausfindig zu machen, um die ,ärmeren Brüder“ ökonomisch und moralisch zu heben. Als Louis Blanc einige Jahre bevor der vernachlässigte peuple zum zweitenmal dröhnenden Schrittes die Bühne der französischen Geschichte durchmaß - mit dem Ernste des Gelehrten und der Ausdauer des Fanatikers den herrschenden Klassen das Dogma von der in letzter Analyse bestehenden Interessengleichheit $z$ wischen Arm und Reich predigte und die Reichen aufforderte, sich dem Emanzipationskampf der Armen nicht nur nicht hindernd in den Weg zu stellen, sondern ihm sogar großmütig selbst die Bahn zu ebnen, wehte ihm teils der eisige Hauch der Apathie entgegen, teils antwortete ihm das schreiende Hohngelächter des wohlerwogenen Klassenegoismus. Es wurde klar, daB auch die neuen Privilegierten nicht mit ethischen Argumenten zu gewinnen waren, insofern diese ihren Interessen und Gewohnheiten zuwiderliefen.

Jede Klasse hat ihre besonderen Wert- und Gerechtigkeitsvorstellungen. Jede Klasse will „Gerechtigkeit", nicht durchweg nur mit Hintergedanken verbrämt oder aus Hypokrisie, sondern auch bona fide. Jean Jaurès hat so unrecht nicht, wennschon er diesen Gedanken in so einseitiger Weise entwickelt, daß wir ihn nicht als bindendes Gesetz für die Entwicklung der Gesellschaft anzuerkennen vermögen, wenn er sagt, daß die Menschheit seit vielen Jahrhunderten auf der Suche nach der Wahrheit und in der Entwicklung zur 
Gerechtigkeit begriffen sei. ${ }^{1}$ ) Nur daß diese Begriffe keine Norm haben. Sie sind nur die Reflexe der gesellschaftlichen Umgebungen, in denen sie entstanden sind. Sehr treffend bemerkt einmal Karl Kautsky, auch der eingefleischteste Aristokrat halte, sofern er ein persönlich anständig denkender Mann sei, zwar auf Gerechtigkeit im Sinne der Gleichstellung der Gleichen, aber er verstehe unter Gleichen allerdings lediglich Ebenbürtige und könne deshalb die Gleichstellung gesellschaftlich Ungleicher nicht als Gerechtigkeit, sondern umgekehrt nur als Gleichstellung von Ungleichen, also als Ungerechtigkeit empfinden. ${ }^{2}$ ) Vom bürgerlichen Standpunkt aus verstößt auch das Lohnverhältnis und - also - Abhängigkeitsverhältnis des Proletariers vom Besitzer der Produktionsmittel durchaus nicht gegen die Idee der Gerechtigkeit, da das Lohnverhältnis ihm lediglich als Tauschverhältnis gilt, in welchem gleiche Werte ausgetauscht werden.

Selbst der wissenschaftlichen Pflicht einer Erkundung der Grenzen und Tiefen des Massenelends gingen die Mächtigen geflissentlich aus dem Wege. Das Elend wurde als die normale Atmosphäre einer fortgeschrittenen Gesellschaft angesehen und, zumal seitens der nicht von ihm Betroffenen, mit echtem Fatalismus ertragen. Aus dieser Auffassung von der Gesetzlichkeit und Unabänderlichkeit eines solchen Zustandes floß das praktische Verhalten dem Pauperismus als Problem gegenüber. Die Stellung der Wissenschaft in den ersten Jahrzehnten des XIX. Jahrhunderts dem Elend des handwerkerlichen und des keimenden industriellen Proletariats sowie der unter nicht weniger jämmerlichen Lebens-

I) „La conception d'après laquelle l'humanité, dès son point de départ, a pour ainsi dire une idée obscure, un pressentiment premier de la destinée de son développement". (J ea n Jaurès, „Idéalisme et Matérialisme dans la Conception de l'Histoire“. Lille I90I, Impr. Ouvr. P. Lagrange, p. 5.)

2) Karl Kautsky, „Der Rückzug der Zehntausend“. Neue Zeit, XX. Jahrg., N. 25. 
formen dahinsiechenden Landarbeiterschaft gegenüber läBt sich wirklich, ohne ihr Unrecht zu tun, in den banalen Operettensatz zusammenfassen:

\author{
„Glücklich ist, \\ Wer vergißt, \\ Was doch nicht zu ändern ist!“
}

Aber das wissenschaftliche und das menschliche Gewissen erwachten allmählich. Zuerst in England, dann auch in Frankreich, dann überall mehrte sich die Zahl derer, welche auf die sittliche Pflicht und die ökonomische Notwendigkeit hinwiesen, die Grenzen des Elends ziffernmäBig festzustellen. Als erster erhob Simonde de Sismondi seine Stimme (1 8 I9), indem er in seinen Principes d'Economie die Behauptung aufstellte, die neueWirtschaftsordnung sei drauf und dran, die einen ungeheuer reich, die anderen über alle Begriffe arm zu machen. In England entwarf Edward Baines mit seiner berümten History of the Cotton Manufacture in Great Britain (London 1835) das erste Gemälde von der sozialen Lage einer der bedeutendsten modernen Arbeiterkategorien. Kurz darauf publizierte in Frankreich Eugène Buret einen eingehenden Vergleich zwischen der Arbeiterklasse in Frankreich und der in England und stellte, ähnlich wie Sismondi, dem Reichtum der Nationen das Elend der Nationen gegenüber. $\left.{ }^{1}\right)$ Fast gleichzeitig fertigte ein anderer Franzose, Villermé, mit seinem als Dissertation der Académie des Sciences Morales et Politiques in Paris erschienenen Tableau sur l'Etat Physique et Moral des Ouvriers en soie, en laine et en coton ein Gegenstück zu dem Werke von Baines an.

So erhielt man die Statistik des proletarischen Elends. Aber, wie schon Ludwig Börne bemerkte, das Schicksal in

r) Eugène Buret, „De la Misère des Classes Laborieuses en Angleterre et en France", in "Cours d'Economie Politique". Bruxelles 1843, Soc. Typ. Belge, p. 437. 
Zahlen hat etwas sehr Beruhigendes an sich. ${ }^{1}$ ) Zahlen sind so nackt und kahl. Den Jammer, den Gram, die Todesqual, die in ihnen stecken, drücken sie so diskret aus, daß man beinahe sagen könnte, daß sie sie verbergen. Auch für diesen Fall trifft der ewig wahre Spruch des alten Paracelsus zu, daß jede Imagination ihren Korpus haben müsse. Ziffern aber haben keinen Korpus. Es gehört schon eine ungeheuer große Dosis Imagination dazu, sich abstrakte Dinge sofort ins Konkrete übersetzen zu können. Der Philister, der beim Morgenkaffee aus seiner Zeitung erfährt, daß in der Mandschurei vierhunderttausend Menschen abgeschlachtet worden sind, verdaut diese Nachricht geistig (und seinen Kaffee körperlich) ohne jegliche störenden Erscheinungen; er würde es schwerer ertragen, wenn aus dem Nebenzimmer das Röcheln auch nur eines einzigen Sterbenden an sein $\mathrm{Ohr}$ schlüge.

Trotz der Ungefährlichkeit der Statistik, hinter der kein proletarischer Willen zur Macht stand, hat man in jenen Zeiten, als die Arbeiterfrage sozusagen noch in der Wiege lag, freilich versucht, die Bedeutung dieser Klasse auf das geringstmögliche $\mathrm{Maß}$ herabzumindern. Die berühmte Enquete über die Lage der arbeitenden Klassen in Frankreich, mit der die Regierung des Landes I 848 die Académie des Sciences Morales et Politiques, und diese wiederum den Nationalökonomen Adolphe Jérômemalanaui - den konservativen Bruder des großen Revolutionärs - beauftragte und die doch dazu bestimmt war, über das Elend der in rapidestem Wachstum begriffenen Klasse des industriellen Proletariats Licht zu schaffen, behauptete schlankweg, daß die classes ouvrières in der grande famille des travailleurs bloß einen sehr kleinen Prozentsatz (une faible portion) ausmachten, und erklärte das Elend der Arbeiterschaft kühn nur

I) Ludw. Börne, „Aus meinem Tagebuch“. Leipzig, Reclam, p. 62. 
aus dem Mißverhältnis ihrer maßlos gewachsenen Lebensbedingungen und ihrer noch unentwickelt gebliebenen moralischen Qualitäten. ${ }^{1}$ ) Dieser krampfhafte Versuch - und wir haben an dieser Stelle nur ein besonders typisches Beispiel davon nambaft gemacht - die numerische und ökonomische Gewaltigkeit des Proletariats gerade in einer Zeitepoche zu schmälern, in der sie sich selbst den Blinden und Tauben aus der Beobachtung der Tagesereignisse geradezu aufdrängen mußte, sticht merkwürdig ab von der fortgeschrittenen Erkenntnis, die sich erleuchteten Geistern schon im XVII. Jahrhundert erschlossen hatte, mit dem großen Vauban ${ }^{2}$, der gern bekannte, daß das ungelernte Proletariat — das er als les manœuvriers bezeichnete - nicht nur wenig verdiene, trotzdem es dieselben Qualitäten aufzuweisen habe wie die, die mehr verdienten, sondern auch, daß gerade diese Klasse ein unentbehrliches Element in der Gesellschaft bilde und ausgemacht sie die gröBte Arbeit in ihr verrichte. Aber was man am Hofe Ludwigs XIV., unter dessen Regierung das Proletariat als handelnder Faktor noch nicht in die Weltgeschichte eingetreten war, wenn auch nicht ungestraft seitens der Gewalthaber, so doch unter dem Beifall der Gelehrtenwelt jener Zeit sagen konnte ${ }^{3}$ ), das war nach dem Sturze der

I) Adolphe J. Blanqui, „Les Classes Ouvrières en France pendant l'Année 1848“. Paris 1849. Petits Traités publiés par l'Académie des Sciences Morales et Politiques. Firmin Didot, p. 10.

2) Sébastien Leprêtre de Vauban, „La Dîme Royale“. Paris 1874 . Librairie de la Bibliothèque Nationale, p. $76: 77$.

3) Es ist überhaupt eine bewundernswerte und beachtenswerte Tatsache und verdiente wohl zum Thema einer Spezialmonographie gemacht zu werden, daB gerade unter den Hofleuten des Roy Soleil, also des ausgesprochensten Alleinherrschers des XVII. Jahrhunderts, eine große Zahl von Männern anzutreffen ist, die durchaus "moderne" Gedankengänge zu entwickeln und, wenn auch nicht sozial zu empfinden vermochten, so doch soziale Gedanken furchtlos auszusprechen wagten. So finden wir z. B. bei dem Marquis de La Fare den marxistischen Satz ausgesprochen: "Je crois qu'il n'y ait personne qui n'ait senti par lui-même, qu'on pense et qu'on agit 
IO4 VII. Zum Problem der Behandlung des Proletariats usw.

feudalen Gesellschaftsordnung durch die Roture nicht mehr möglich. Die Herrschaft der Roture, die in der großen französischen Revolution ihren Anfang nahm, hatte den proletarischen und proletaroiden Volksschichten gegenüber, die sich nun vermittelst der Revolution in den Betriebsformen und dem damit verbundenen Untergang weitester Schichten des mageren Teiles der Bourgeoisie, insbesondere der Einzelselbständigen und der handarbeitenden Kleingewerbetreibenden rapide vermehrten, eine gewaltige Klärung des Verhältnisses zwischen den Klassen zur unmittelbaren Folge. Die feudalen Nebel des persönlichen, auf herrschaftlicher Willkür, herrschaftlichem Wohlwollen und herrschaftlicher Fürsorgepflicht gegründeten Abhängigkeitsverhältnisses waren, wenigstens bis an die Grenze der Elbe, geschwunden, und Besitzende und Besitzlose standen sich auf offenem Felde als soziale Gegner gegenüber. Die Ära des „freien“ Arbeitsvertrages und das Prinzip der "freien" Konkurrenz mußte, bei der gegebenen wirtschaftlichen Ungleichheit der Kontrahenten bzw. der Kontendenten, die soziale Kluft zwischen arm und reich noch weiter aufreißen und dadurch den Antagonismus zwischen den beiden Hauptklassen der modernen Gesellschaft verschärfen.

Es lag nun zweifellos im Lebensinteresse der jungen Bourgeoisie, zunächst jede wissenschaftliche Beschäftigung mit dem Proletariat hintanzuhalten. Nicht nur, um den schlafenden Leu nicht zu wecken, nicht nur, weil jede junge zur Herrschaft gelangte Klasse in stolzem Siegesgefühl zunächst stets die Tendenz hat, ihre Nachfolgerin auf dem

différemment dans la bonne et la mauvaise fortune, dans les richesses et dans la pauvreté", und die These von der Ideologie als Überbau zur Ökonomie aufgestellt, die er in die Worte kleidete: „Tout le monde prend l'esprit de son état“ (s. M. d. L. F.: „Mémoires et Réflexions sur les Principaux Evènements du Règne de Louis XIV et sur le Caractère de ceux qui $y$ ont eu la principale Part". Nouv. Ed., Amsterdam 1782, p. 6 ff.). 
Plan der Geschichte zu ignorieren, sondern auch aus Gründen sozusagen theoretischer Observanz. Jede Wissenschaft erwächst zuerst aus den Tatsachen heraus, sie ist deren ,ideologischer Überbau"; jede Wissenschaft beschäftigt sich vorzugsweise mit den Problemen, die von den besitzenden Klassen als die drängendsten, aktuellsten empfunden und ihr von ihnen als solche gewiesen werden. Die aus den Fesseln des Feudalstaates erlöste Bourgeoisie hat in den ersten fünfzig Jahren ihrer Herrschaft lediglich den starken Drang in sich gefühlt, die endlich gewährte Freiheit von Handel und Wandel auszunützen; daher der gellende Schrei des enrichissezvous, dem sie mit ebenso viel Scharfsinn als Tatkraft und Beständigkeit gefolgt ist. Dieser wirtschaftlichen Tendenz der Bourgeoisie entsprach die Tendenz der gelehrten Ökonomie der Zeit. Nicht das Wie der Produktion interessierte sie, sondern das Wieviel der Produktion, nicht die Genesis und Analysis der Gütererzeugung oder gar das Problem der Güterverteilung, das sie leicht auf ethische Kategorien geführt haben würde ${ }^{1}$ ), sondern das Problem der Gütervermehrung. Ihr mußte also jede Beschäftigung mit dem Wesen der großen Produzenten- und der großen Konsumentenmassen fernliegen. Diese Auffassung der Volkswirtschaft besaß noch keinerlei soziale Tendenzen. Die Völker wurden als große industrielle Unternehmungen empfunden, der Mensch als eine Maschine zur Gütererzeugung und Güterkonsumtion, das menschliche Leben als ein Kapital. Die Gedanken der Volkswirte waren völlig auf die Hervorbringung von Reichtum konzentriert. David Ricardo, der Prototyp der mit dem Problem des "Reichtums an sich" beschäftigten Nationalökonomen, meinte, es sei für den Reichtum einer Nation

I) Bekanntlich ging Jean Baptiste Say so weit, es als einen der Vorzüge dieser ökonomischen wissenschaftlichen Richtung zu rühmen, da $B$ sie unter keinerlei Umständen jemals irgendeiner Regierung lästig fallen könne. (J. B. Say, „Cours Complet d'Economie Politique“. Bruxelles 1842, Soc. Typ. Belge, p. 26.) 
sehr gleichgültig, wie groß die Zahl der an ihrem Reichtum teilhabenden Bürger sei. ${ }^{1}$ )

Aber diese Idylle wurde von Zeit zu Zeit immer wieder durch proletarische Unbotmäßigkeiten unterbrochen. Freilich, die Wissenschaft war nicht mehr in der Lage, sie unbefangen zu beurteilen. „Der Klassenkampf läutete die Totenglocke der wissenschaftlichen bürgerlichen Ökonomie; es handelte sich jetzt nicht mehr darum, ob dieses oder jenes Theorem wahr sei, sondern ob es dem Kapital nützlich oder schädlich, bequem oder unbequem, polizeiwidrig oder nicht sei."2) Die Glanzperiode des Aufsteigens der jungen Bourgeoisie in der Geschichte bedeutete gleichzeitig den Tiefpunkt in der Behandlung der arbeitenden Klassen durch die offizielle Wissenschaft.

Heute, wo der Prozeß der fortdauernden Bereicherung der oberen Klassen durch eine Anzahl bedrohlicher Krisen, die zum Nachdenken angeregt haben, zeitweise unterbrochen worden ist, und das lange vernachlässigte Proletariat mit kräftiger Pression in die Speichen der Geschichte eingegriffen hat und ein politischer Faktor geworden ist, haben die weitesten Kreise der Gelehrtenwelt anerkannt, daß ,l'objet de la science économique n'est pas la richesse, mais le travail "(Frédéric Passy)..$^{3}$ ) Aus diesem Grunde - neben den

1) ,To an individual with a capital of 20000 pounds, whose profits were L. 2000 per annum, it would be a matter quite indiffeent whether his capital would employ a hundred or a thousand nen, whether his commodity produced sold for 10000 pounds or ior 20000 pounds, provided, in all cases, his profits were not dimiaished below 2000 pounds. Is not the real interest of a nation sinilar? Provided its real net income, its rent and its profit be the ;ame, it is of no importance whether the nation consists of ten or of :welve millions of inhabitants."(David Ricardo, „Principles of Politial Economy and Taxation" [ed. Bell.]. London 1908, Gonner, p. 537.)

2) Karl Marx, „Das Kapital. Kritik der politischen Öko1omie". Bd. I, 2. Aufl. Hamburg I872, Meißner, p. 816 .

3) Frédéric Passy, „Leçons d'Economie Politique, faites à 'Université de Montpellier“. Discours d'Inauguration. I860/61, p. 8. 
zahlreichen Schulen sozialistischer Weltanschauung darf auch den Männern der praktischen und theoretischen Sozialreform, sowie den Führern der sogenannten historischen Schule der Nationalökonomie das Verdienst, an dieser Entwicklung mitgeholfen zu haben, nicht abgesprochen werden - ist sich heute die ernste Wissenschaft, neben der freilich eine operettenhaft leichtlebige Wissenschaft ad usum Delphinorum immer noch persistiert, darüber einig, daß gerade in der wissenschaftlichen Beschäftigung mit den ärmeren Volksklassen die wichtigste Aufgabe der Volkswirtschaft zu erblicken ist.

Und wie sollte sie es nicht sein? Es ist inzwischen unwiderleglich bewiesen worden, daß das Proletariat nicht eine Zugabe zum Begriff Volk, sondern daß es das Volk selbst ist. Für Deutschland hat Werner Sombart - in fast völliger Übereinstimmung mit Karl Kautsky - aus den Ziffern der Berufs- und Gewerbezählung von I 895 nachgewiesen, daB die proletarischen und proletaroiden Volkselemente (Einzelselbständige und Grundbesitzer von weniger als 2 ha) $67 \% \%$ der Bevölkerung ausmachen. $\left.{ }^{1}\right)$ Das wäre über zwei Drittel. Für England hat uns Chiozza Money die Bevölkerung nach ihrem jährlichen Einkommen in Klassen eingeteilt und folgendes Resultat dieser Einteilung überliefert: Reiche, d. $h$. Personen mit mindestens 700 Pfund Jahreseinkommen, die Familienmitglieder mit eingerechnet I 250000; Wohlhabende, d. h. Personen mit Jahreseinkommen zwischen 700 und 160 Pfund, immer die Familienangehörigen mitgerechnet 3750000 ; Arme, d. h. Personen mit weniger als r6o Pfund Jahreseinkommen $38000000 .^{2}$ ) In einer Bevölkerung von

1) Werner Sombart, „Die deutsche Volkswirtschaft im neunzehnten Jahrhundert“. Berlin 1903, Bondi, p. 53I; und Karl Kautsky, „Klasseninteresse, Sonderinteresse, Gemeininteresse“. Neue Zeit XXI, Nr. 224.

2) L. G. Chiozza Money, „Riches and Poverty“. $9^{\text {th }}$ edition. London 1909, Methuen and Co., p. 42. G. K. Holmes, „Ency- 
I o6 VII. Zum Problem der Behandlung des Proletariats usw.

sehr gleichgültig, wie groß die Zahl der an ihrem Reichtum teilhabenden Bürger sei. ${ }^{1}$ )

Aber diese Idylle wurde von Zeit zu Zeit immer wieder durch proletarische Unbotmäßigkeiten unterbrochen. Freilich, die Wissenschaft war nicht mehr in der Lage, sie unbefangen zu beurteilen. „Der Klassenkampf läutete die Totenglocke der wissenschaftlichen bürgerlichen Ökonomie; es handelte sich jetzt nicht mehr darum, ob dieses oder jenes Theorem wahr sei, sondern ob es dem Kapital nützlich oder schädlich, bequem oder unbequem, polizeiwidrig oder nicht sei." 2) Die Glanzperiode des Aufsteigens der jungen Bourgeoisie in der Geschichte bedeutete gleichzeitig den Tiefpunkt in der Behandlung der arbeitenden Klassen durch die offizielle Wissenschaft.

Heute, wo der Prozeß der fortdauernden Bereicherung der oberen Klassen durch eine Anzahl bedrohlicher Krisen, die zum Nachdenken angeregt haben, zeitweise unterbrochen worden ist, und das lange vernachlässigte Proletariat mit kräftiger Pression in die Speichen der Geschichte eingegriffen hat und ein politischer Faktor geworden ist, haben die weitesten Kreise der Gelehrtenwelt anerkannt, daß „l'objet de la science économique n'est pas la richesse, mais le travail "(Frédéric Passy). ${ }^{3}$ ) Aus diesem Grunde - neben den

I) ,To an individual with a capital of 20000 pounds, whose profits were L. 2000 per annum, it would be a matter quite indifferent whether his capital would employ a hundred or a thousand men, whether his commodity produced sold for 10000 pounds or for 20000 pounds, provided, in all cases, his profits were not diminished below 2000 pounds. Is not the real interest of a nation similar? Provided its real net income, its rent and its profit be the same, it is of no importance whether the nation consists of ten or of twelve millions of inhabitants." (David Ricardo, "Principles of Political Economy and Taxation" [ed. Bell.]. London 1908, Gonner, p. 537.)

2) Karl Marx, „Das Kapital. Kritik der politischen Ökonomie“. Bd. I, 2. Aufl. Hamburg 1872, Meißner, p. 8 I6.

3) Frédéric Passy, „Leçons d'Economie Politique, faites à l'Université de Montpellier". Discours d'Inauguration. I860/6I, p. 8. 
zahlreichen Schulen sozialistischer Weltanschauung darf auch den Männern der praktischen und theoretischen Sozialreform, sowie den Führern der sogenannten historischen Schule der Nationalökonomie das Verdienst, an dieser Entwicklung mitgeholfen zu haben, nicht abgesprochen werden - ist sich heute die ernste Wissenschaft, neben der freilich eine operettenhaft leichtlebige Wissenschaft ad usum Delphinorum immer noch persistiert, darüber einig, daß gerade in der wissenschaftlichen Beschäftigung mit den ärmeren Volksklassen die wichtigste Aufgabe der Volkswirtschaft zu erblicken ist.

Und wie sollte sie es nicht sein? Es ist inzwischen unwiderleglich bewiesen worden, daß das Proletariat nicht eine Zugabe zum Begriff Volk, sondern daß es das Volk selbst ist. Für Deutschland hat Werner Sombart - in fast völliger Übereinstimmung mit Karl Kautsky - aus den Ziffern der Berufs- und Gewerbezählung von I 895 nachgewiesen, daß die proletarischen und proletaroiden Volkselemente (Einzelselbständige und Grundbesitzer von weniger als 2 ha) $67 \%$ der Bevölkerung ausmachen. ${ }^{1}$ ) Das wäre über zwei Drittel. Für England hat uns Chiozza Money die Bevölkerung nach ihrem jährlichen Einkommen in Klassen eingeteilt und folgendes Resultat dieser Einteilung überliefert: Reiche, d. h. Personen mit mindestens 700 Pfund Jahreseinkommen, die Familienmitglieder mit eingerechnet I 250000; Wohlhabende, d. h. Personen mit Jahreseinkommen zwischen 700 und I 60 Pfund, immer die Familienangehörigen mitgerechnet $3750000 ;$ Arme, d. h. Personen mit weniger als 160 Pfund Jahreseinkommen $38000000 .^{2}$ ) In einer Bevölkerung von

I) Werner Sombart, „Die deutsche Volkswirtschaft im neunzehnten Jahrhundert". Berlin 1903, Bondi, p. 531; und Karl Kautsky, „Klasseninteresse, Sonderinteresse, Gemeininteresse“. Neue Zeit XXI, Nr. 224.

2) L. G. Chiozza Money, „Riches and Poverty". $9^{\text {th }}$ edition. London 1909, Methuen and Co., p. 42. G. K. Holmes, „Ency- 
I08 VII. Zum Problem der Behandlung des Proletariats usw.

43 Millionen gäbe es demzufolge 38 Millionen Arme, d.h. $88,4 \%$. Nicht weniger proletarisch scheint, wenn wir den dortigen Statistiken Glauben schenken dürfen, die Bevölkerung des Zauberlandes Amerika zu sein. Im Jahre I 890 hat man ausrechnen wollen, daß fast die Hälfte der in den Vereinigten Staaten von Nordamerika wohnenden Familien (5 500000 von I 2500 ooo estates) ein jährliches Einkommen von unter 500 Dollars hat. ${ }^{1}$ ) Genauer und vertrauenerweckender noch sind die Ziffern, die uns um die Jahrhundertwende J. Graham Brooks übermittelt: Poor $4762500=38,1 \%$; very poor $6250000=50 \%$; also "Proletariat" $=88,1 \% .{ }^{2}$ ) Eine ähnliche Sprache sprechen auch die Zahlen, welche ein Orthodoxer aus der amerikanischen Statistik I 900 mitteilt. Ihnen zufolge sind von den allen Berufsarten (außer der Agrarwirtschaft) angehörigen Männern 79,8\% in den großen Zentren und $78,1 \%$ in den Kleinstädten und auf dem Lande Proletarier. ${ }^{3}$ )

Hier drängt sich uns eine kurze Parenthese auf:

Gewiß, die Frage nach dem Begriff und der Begrenzung. der Klassen ist noch ungelöst, und auch Alfredo Niceforo unterläßt es in einer großen, kürzlich auch in deutscher Sprache erschienenen Arbeit, sich mit der Definition dieses Begriffes. des näheren auseinanderzusetzen. ${ }^{4}$ ) Darum scheidet er, den

clopedia of Social Reform“, edited by Funk and Wagnalls Co., I897 (zitiert bei Arturo Labriola, "Il Capitalismo. Lineamenti storici". Torino I9Io, Bocca, p. 347), rechnet freilich nur 51\% Arme aus.

I) Charles B. Spabr, „America's Working People. Distribution of Wealth in the United States". New York 1900, Longmans Green and Co., p. 56.

2) John Graham Brooks, „The Social Unrest. Studies in Labor and Socialist Movements". New York 1903, The Macmillan Co., p. 163 .

3) Isaac A. Hourwich, "The Social-Economic Classes of the Population of the United States, II", in der Zeitschrift The Journal of Political Economy, vol. I9, fasc. 4 (Chicago 1911).

4) Alfredo Niceforo, „Anthropologie der nichtbesitzenden Klassen“. Leipzig-Amsterdam I910, Maas u. Van Suchtelen, Kap.7. 
Spuren seiner Gewährsmänner folgend, nicht nur, trotz häufiger Ansätze zu einer gegenteiligen Auffassung, den keineswegs bereits abgestorbenen Mittelstand gelegentlich aus seinen Berechnungen aus ${ }^{1}$ ), sondern es bilden auch die „ärmeren Volksklassen", mit denen er sich vorzugsweise beschäftigt, nichts weniger als eine gleiche Größe und weisen an hundert verschiedenen Stellen des Werkes hundert verschiedene Nuancen auf. Das ist nun vielleicht insofern bedauerlich, als gerade der Begriff der Klasse dringend seiner wissenschaftlichen Erschließung harrt. Wir wissen, daß es nicht die Beschäftigungsart, die Profession ist, die das Kriterium für die Klassenbildung abgibt, so sehr sich auch eine interessierte, uns naseführen wollende Pseudowissenschaft, die sich besonders in einzelnen offiziellen Statistiken breitmacht, abmüht, die Menschheit in Berufsgruppen zu teilen - die berühmten "Landwirte“, die vom Zwergbauern unter 2 ha bis zum östlichen Latifundienbesitzer und zum in der Großstadt lebenden Absenteisten reichen und womöglich auch noch den Kossäten und den Landtagelöhner umfassen und uns dann diese Berufsgruppen als Klassen zu servieren, um damit möglichst alle sozialen Unterschiede zu verwischen und der wertvollen Arbeit der numerischen Absteckung der einzelnen Bevölkerungsteile voneinander, der Erkundung der sogenannten Stärkeverhältnisse der einzelnen Gesellschaftsklassen, Schwierigkeiten in den Weg zu legen. Wir wissen jetzt, daß die Scheidungslinien, welche die „Klassen“ bilden, nicht horizontal, sondern vertikal gezogen werden müssen. ${ }^{2}$ ) Darum ist es auch lächerlich, wie es bisweilen in der so-

1) In einer Reihe von Kapiteln (z. B. in Kap. 24) wird auch des Mittelstandes Erwähnung getan, während in anderen die Gesellschaft nur in zwei Rubriken, "Arme" und „Reiche", eingeteilt wird.

2) Raoul de La Grasserie, "Les Luttes Sociales", in den "Annales de l'Institut International de Sociologie“, publiées sous la direction de René Worms. Paris 1907, Giard et Brière, p. 187. 
zialistischen Tagesliteratur geschehen ist, das Lohnverhältnis und die Abhängigkeit vom Kapital (das den Direktor bei Krupp und den schlesischen Weber, die ja beide Lohnempfänger, „Arbeitnehmer“, sind, zu einer Klasse zusammenschweißen würde) als Grundlage der Klassenbildung anzunehmen. ${ }^{1}$ ) Die Zweiteilung der Bureaukratie in Großbeamte und Kleinbeamte wird in keiner Weise durch ihr Eigentumsverhältnis zu den Produktionsinstrumenten charakterisiert.') Es unterliegt keinem Zweifel, daß wir die Klasse nur als ökonomische Gruppe, besser als Aggregat von Individuen mit relativ gleicher ökonomischer Lebensführung - dieses Attribut ist vielleicht noch klarer im englischen standard of living sowie im italienischen tenor di vita ausgedrückt fassen können. K. Marx, der im III. Bande des Kapitals einen Ansatz zur Untersuchung des Klassenbegriffes gemacht hat, der leider Torso geblieben ist, spricht von der „Dieselbigkeit der Einkommen und Einkommenquellen“. Er unterscheidet dabei drei große gesellschaftliche Kategorien, „,deren Bestandteile, die sie bildenden Individuen, von Arbeitslohn, Profit und Grundrente, respektive von der Verwertung ihrer Arbeitskraft, ihres Kapitals und ihrer Grundrente leben". Aber die Einwände, die Karl Marx in den zwei auf diese Begriffsdefinition der Klassen folgenden

I) Vgl. p. 28 unserer Schrift.

2) So auch Gustav Schmoller (im "Jahrbuch für Gesetzgebung'“, usw. 1907, p. 322), dem wir, auch wenn wir uns mit seiner historisch-psychologischen Erklärungsart der gesellschaftlichen Klasse, nach welcher der Besitz als die Folge und nicht als die Ursache der Klassenbildung erscheint, nicht rundweg einverstanden erklären können, dankbar sein müssen, daß er zur Lösung dieser sozialhistorischen Grundfrage ganz bedeutendes Material herangetragen und hervorragende Gedankenarbeit produziert hat (vgl. die Aufsätze Schmollers in den Jahrgängen 1889 und I 890 des "Jahrbuch f. Gesetzgebung" und seinen „Grundrib zur allgemeinen Volkswirtschaftslehre“, Teil I, 7. bis I0. Tausend, Leipzig 1908, Duncker u. Humblot, pp. 580; Teil II, I. bis 6. Tausend, Leipzig I904, Duncker u. Humblot, pp. 719. 
Sätzen sofort selbst gegen sie erhebt, beweisen indizienmäßig die Schwierigkeit und Unfertigkeit des Problems selbst. Es kommt allerdings vielleicht in diesem Falle, wo es sich um das Bewegen so gewaltiger Figuren handelt wie der des Proletariats, nicht darauf an, wenn im einzelnen kleine Fehler mit unterlaufen. Wer mit Tausenden rechnet, läßt den Dezimalbruch unter den Tisch fallen.

Also: Heute ist es möglich, sich von den Existenzbedingungen des Proletariats ein Bild zu machen. Den offziellen und privaten statistischen Erhebungen sind psychologische und soziale Untersuchungen über das Wesen und die Lage des Proletariats zur Seite getreten. Die aufklärenden Arbeiten von Louis Blanc, insbesondere seine Schrift über die Organisation der Arbeit, die Durcharbeitung des vorhandenen älteren englischen statistischen Materials durch Karl Marx in seinem „Kapital“, dann, eingehender, eine lange Reihe von Monographien, von der vorwiegend von ökonomischen Gesichtspunkten geleiteten Schrift von Friedrich Engels über die arbeitenden Klassen in England an bis zu der synthetischen Abhandlung „Poverty“ des Amerikaners Robert Hunter und der feinen psychologischen Zeichnung, die Werner Sombart in seiner Arbeit „Das Proletariat" entworfen hat - wozu ferner noch eine Reihe wertvollster Lokalstudien, wie, um deren nur einige hervorzuheben, die Schilderungen des proletarischen Milieus von London durch Charles Booth, den bekannten Schöpfer der Heilsarmee, von Manchester durch B. Seebohm Rowntree, und von Rom durch Domenico Orano kommen - das sind die Bausteine, aus denen die moderne "Wissenschaft der unteren Volksklassen" ihr stolzes Gebäude aufgebaut hat. ${ }^{1}$ )

I) Louis Blanc, "Organisation du Travail", loco cit.; Karl Marx, „Das Kapital. Kritik der politischen Ökonomie“. I. Bd. 2. Auf. Hamburg 1872. Meißner; Friedrich Engels, „Die Lage der arbeitenden Klassen in England“, 1845; Robert Hunter, "Poverty", New York 1906, The MacMillan Company; Werner 
I 2 VII. Zum Problem der Behandlung des Proletariats usw.

Diesen Studien verdanken wir vor allem auch die Einsicht in die natürliche geistige Leere des Proletariats, jene Begleiterscheinung der großkapitalistischen Produktionsweise, die schon in den dreißiger Jahren des XIX. Jahrhunderts von Alexis de Tocqueville, dem die Vertrautheit mit den amerikanischen Verhältnissen Seheraugen verliehen hatte, konstatiert werden konnte, als er sagte, es müsse bei der peinlichen Arbeitsteilung des Kapitalismus dem modernen In. dustriearbeiter immer schwerer fallen, mit der von ihm verrichteten physischen Arbeit inneres sachliches Interesse zu verbinden; er werde gleichzeitig immer geschickter und immer weniger geistig regsam, und man könne sagen, dab in demselben Grade, in dem der Arbeiter in ihm sich vervollkommne, der Mensch in ihm verkümmere. ${ }^{1}$ )

„Reizlos, hoffnungslos“ — sagt auch ein Moderner "fließt das ewig gleiche Leben des Proletariers dahin. Ohne Rhythmus, ohne Schwung, ohne Inhalt. Einförmig. Eintönig. Grau. Wie ein kalter, regnerischer Novembertag. ... In läppischen Teilverrichtungen, die ein Affe gut genug wäre auszuführen, erschöpft sich vielleicht sein Tagewerk.“ Man kann nicht im Zweifel darüber sein, „daß der erste Zustand, in den die Massen infolge der kapitalistischen Entwicklung versetzt werden, ein Zustand der Öde ist, der Öde und derVerkümmerung aller Funktionen der Seele. ... Ein Wunder nur, daß die in voller Verwahrlosung aufwachsende Proletarierbrut nicht noch viel mehr verwildert, als es der Fall war oder ist, daB die Masse dieses armseligen Volkes nicht viel mehr verroht inmitten der menschenunwürdigen Lebensbedingungen, in

Sombart, „Das Proletariat", Bilder und Studien, Frankfurt a. M. 1906, Rütten u. Löning; B. Seebohm Rowntree, „Poverty, a study of Townlife“. London 1902, The MacMillan Co.; Charles Booth, "Life and Labour in London“. 2 Vol.; Domenico Orano, "Come vive il Popolo a Roma“. Pescara I9I2, Croce.

1) Alexis de Tocqueville, „De la Démocratie en Amérique". Paris 1840. Ch. Gosselin. Vol. II, p. 253. 
denen wir sie angetroffen haben." 1) Nur politische und geschichtsphilosophische Gedanken von großem Schwung und gewaltiger sittlicher Stoßkraft können, gemeinsam mit der wirtschaftlichen Notwendigkeit der diese Klassen verbindenden Solidarität, in dieses Grau in Grau einen Strahl hellen Lichtes werfen, den Geist der Massen über das stumpfe terre à terre ihrer wirtschaftlichen Funktionen erheben und ihr Herz für hohe Ideale schlagen lassen. Und doch, selbst in diesen Kämpfen bewahrheitet sich noch die These Louis Blancs von der Misere als einer großen, stets weitgeöffneten Schule der Verderbnis.")

Der notwendige, mehr als notwendige: als historische Tatsache existierende „Klassenkampf“ erzeugt nicht nur Idealismen; wir sehen, daß in diesem Prozeß des historischen Materialismus vielfach auch andere, regressive Kräfte tätig sind, die den Ethiker mit Besorgnis erfüllen und dem Sozialpädagogen zu denken geben. Das Lumpenproletariat und darunter möchten wir nicht nur das in Lumpen gehüllte Proletariat verstanden wissen - persistiert und wird persistieren, solange der Boden vorhanden ist, der es und die Effekte, die es im Gesellschaftsleben auslöst, im Keime birgt.

Aber während die Ökonomie sich immer mehr dem Verständnis vom Wesen des Proletariats erschloß und teils für die Dringlichkeit sozialer Reform, staatlicher Beihilfe oder autonomer Entwicklung, plädierte, teils die Waffen schmiedete, die zum Kollektivismus führen und dieses Wirtschaftsideal nicht mehr als dunstiges Hirngespinst ideologischer Träumer, sondern als das logische autochthone Ziel eines durch das privatrechtliche Eigentum an den Produktionsmitteln zum lebenslänglichen Diener eben des privatrecht$75,76$.

1) Werner Sombart, „Das Proletariat“, loco cit. p. 68, 69,

2) Louis Blanc, „Organisation du Travail“. 4. Auflage, loco cit., p. 38 .

Michols: Probleme der Sozialphilosophie 
lichen Eigentümers an den Produktionsmitteln gewordenen und diesen Zustand als ein Unrecht empfindenden und ihm deshalb dauernd entrinnen wollenden Proletariats erscheinen lieB ${ }^{1}$ ), mit anderen Worten, während sich alle Richtungen in der Volkswirtschaftslehre, soweit sie auch sonst immer auseinandergehen mochten, in dem Bestreben trafen, die Beschäftigung mit dem Proletariat zum Mittelpunkt ihres Studiums zu machen und dieser Klasse der Bevölkerung, sei es auch nur in Abschlagszahlungen, das Recht auf das Leben anzuerkennen, erwuchs den armen Bevölkerungsklassen ein erbitterter und erbarmungsloser neuer Feind in den Naturwissenschaften.

Die Naturwissenschaftler, auf all das Große pochend, was in ihrem Fache geschaffen, versuchten es, in die Sozialwissenschaften einzudringen. Ihre Exponenten standen, von wenigen Ausnahmen abgesehen, der Psychologie der Arbeiterschaft verständnislos und ihren Bestrebungen als Klasse gegnerisch gegenüber. Diese Stellungnahme war aber nur das äußere Symptom ihrer wissenschaftlichen Überzeugungen.

Die Naturwissenschaftler rechtfertigten die elende Lage des Proletariats durch das Gesetz der Auslese. Sie sagten: Die Armen haben ihre Armut verdient, weil sie geistig, seelisch, moralisch und physisch elend sind. Ihr Elend besteht demnach zu Recht und liegt im Interesse selbst der Menschheitskultur.

Der Stolz, mit dem die modernen Naturwissenschaftler von der Höhe der achtunggebietenden Ergebnisse ihrer Forschungen in den letzten fünfzig Jahren herab sich in die Brust werfen, ist sowohl menschlich vollauf erklärlich, als auch sachlich berechtigt. Aber wenn er in eine Art wissen-

I) Über die Beziehungen zwischen der privatkapitalistischen Gesellschaftsordnung als Sein und dem Kollektivismus als proletarisches Wollen bzw. Müssen hat Karl Kautsky einige ausgezeichnete Bemerkungen niedergeschrieben (s. Kautsky, „Klasseninteresse usw.", loco cit. p. 271). 
schaftlicher Hegemonie ausarten will, findet er seine Grenzen an den Grenzen der Naturwissenschaft selbst. Denn es ist ein unmögliches Beginnen, von der Warte der Naturwissenschaften aus den übrigen Wissenschaften ihr methodologisches Verhalten diktieren zu wollen. Es ist nicht wahr, daß, wie Ernst Häckel meint, uns die organischen Vorbilder für die sozialen Verhältnisse durch die vergleichende Zoologie und Entwicklungsgeschichte, die Zellentheorie und die Protistenkunde geliefert werden. ${ }^{1}$ ) So oft es versucht worden ist, die als krank dargestellte Ökonomie durch naturwissenschaftliche Behandlung zu kurieren und die Gesetze der Naturwissenschaft ohne weiteres auf die Ökonomie zu übertragen, oder gar die gesamte Ökonomie aus der Naturwissenschaft abzuleiten, so oft ist dieser Versuch gescheitert. Das lehrt uns das Wesen wie die Geschichte aller dieser Bestrebungen von Otto Ammon ${ }^{2}$ ) bis Eduard Sacher ${ }^{3}$ ) mit eindringlicher Deutlichkeit. Ammon zufolge müBten sich die Sozialwissenschaften nach den Naturwissenschaften richten. Da der Mensch die Grundzelle des sozialen Organismus ist und die Kenntnis eines Organismus nur durch eine peinliche Analyse der Zellen, aus denen er besteht, gewonnen werden kann, so muß - dieser Gesichtspunkt einmal akzeptiert - die physische Wesenheit des Menschen sichere Schlüsse auf die soziale Wesenheit der Gesellschaft gestatten. Einen derartigen Anachronismus hatte schon Fr. A. Lange vorgeahnt, als er, der doch ebenfalls erklärte, das Problem der Arbeiterfrage ,aus den von Darwin entwickelten Grundsätzen abzuleiten“, erläuternd hinzusetzte, immerhin müsse man bedenken, daß, während die Pflanze bewußtlos, das Tier in der Regel ganz vom Naturtriebe be-

I) Ernst Häckel, „Die Welträtsel“. Stuttgart I903, Strauß, p. 9.

2) Otto Ammon, „Die Gesellschaftsordnung und ibre natürlichen Grundlagen“. 1895 (3. Aufl. I900).

3) Ed. Sacher, "Gesellschaftskunde als Naturwissenschaft ". Dresden, E. Pierson. 
herrscht, den Naturgesetzen willenlos unterlägen, im Menschen, als letzter Stufe des natürlichen Vervollkommnungsprozesses, jedoch die Fähigkeit auftrete, sich über den grausamen und seelenlosen Mechanismus der Natur bis zu einem gewissen Grade zu erheben, so daß die Gesetze Darwins nicht als absolut notwendige Zugaben des menschlichen $\mathrm{Da}$ seins zu betrachten seien. ${ }^{1}$ ) Aber derartige Erwägungen liegen der eng-naturwissenschaftlichen Methode fern. Ammon z. B., dem im übrigen keineswegs alleVerdienste abgesprochen werden sollen, überträgt die Gesetze Darwins ziemlich leichten Herzens auf das Gebiet der volkswirtschaftlichen Tatsachen. Ihm gilt, mit Weißmann, die natürliche Selektion für allmächtig, und er überträgt ihre Folgerungen von den niedrigsten Tierarten auf den Menschen selbst. Wie im Tierreich der Kräftigere über den Schwächlicheren im Lebenskampfe den Triumph davonträgt, so vollzieht sich derselbe ProzeB auch in der menschlichen Gesellschaft. Da sich nun aber aus der Beobachtung der Vorgänge der sozialen Geschichte die klare Erkenntnis der Tatsachen ergibt, daß im sozialen Lebenskampfe die Reichen über die Armen Sieger bleiben, so folgert Ammon, nach Analogie des animalen Lebenskampfes, daß stark und reich, schwach und arm synonyme Begriffe, Tautologien, seien. Er klassifiziert die Menschen nach ihrem natürlichen Verstand und erhält auf diese Weise eine Binomialkurve. Anfang und Ende der Parabel - Hochbegabte und Ganzidioten - sind schwach, die Mitte dagegen - welche die Mittelintelligenten darstellt - ist hoch gewölbt. Und nun sucht er nach der Rentenkurve. Er findet, daß sie der Intelligenzkurve ähnlich sieht wie ein Haar dem anderen. Wenige nur sind Milliardäre. Je kleiner die Rente, desto höher steigt die Kurve, bis sie ihren Kulminationspunkt findet, der der größten

1) Friedrich Albert Lange, „Die Arbeiterfrage, ihre Bedeutung für Gegenwart und Zukunft". 3. Aufl. Winterthur I 875 . p. 30 . 
Zahl der Renten entspricht. Endlich, am anderen Ende der Kurve, befindet sich ein Tiefpunkt, auf etwa derselben Linie wie der Anfangstiefpunkt, der die Zahl der ganz Armen angibt: das Proletariat. Aus dem Vergleich der beiden Kurven nun leitet Ammon den Satz ab, daß der Reichtum das Korrelat der Intelligenz sei. Je reicher der Mensch, desto entwickelter seine Intelligenz. Aber dieser anscheinende Parallelismus der beiden Parabeln hält, wie uns Achille Loria gezeigt hat ${ }^{1}$ ), einer ernsten Nachprüfung nicht stand. Während die Zahl der unter dem Intelligenzdurchschnitt Begabten (geistig Armen) kleiner wird, steigt die Zahl der unter dem Rentendurchschnitt Begüterten (wirtschaftlich Armen, das Proletariat) gewaltig an. Die Zahl der ganz Armen kann also unmöglich der Zahl der ganz Reichen gleich sein; sie muß sie vielmehr hoch überragen.

Auch hätte Ammon, um uns von der Richtigkeit seiner Auffassung zu überzeugen, beweisen müssen, daß die beiden Kurven an jeder ihrer einzelnen Stellen auf demselben Material fußen. ${ }^{2}$ ) Anders ausgedrückt, daß die einzelnen Gruppen der Intelligenz und des Reichtums an allen Parallelstellen der beiden Kurven aus denselben Komponenten zusammengesetzt seien. Aber auch wenn Ammon es verstanden hätte oder verstehen würde, diese ernsten Einwände gegen die methodologische Beweisführung seiner These aus der Welt zu schaffen, die These selbst würde dadurch nicht einmal an Stärke gewinnen. Wenn er das große biologische Gesetz der natürlichen Selektion in der sozialen Geschichte der Menschheit bestimmend wirken sieht, so kann ihm schon der Logiker darauf antworten: optische Täuschung! In der

1) Achille Loria, "La Sociologia, il suo Compito, le sue Scuole, i suoi recenti Progressi“. Verona-Padova 1901, Frat. Drucker, p. 95 .

2) Achille Loria, „Verso la Giustizia Sociale (Idee, Battaglie ed Apostoli)". Milano 1904. Studi Economici-Sociali-Contemporanei No. 2. Soc. Ed. Libraria, p 497-513. 
I 8 VII. Zum Problem der Behandlung des Proletariats usw.

Tat kann dieses Gesetz schon deshalb in rebus socialibus nicht in Kraft treten, weil die Menschheit nicht in der Na. tur, sondern in der Wirtschaft lebt, die wirtschaftlichen Bedingungen, unter denen die einzelnen Menschen existieren, aber so einschneidend verschieden sind, daß sie das Gesetz der natürlichen Auslese, das die Natur beherrscht, bis auf einen kümmerlichen Rest aufheben. Sowohl der Reichtum als auch die Armut halten Wacht, daß dieses Gesetz die Schwelle der Menschengeschichte nicht überschreite. Während die Armut selbst die Starken tötet, erhält der Reichtum selbst die Schwachen am Leben. ${ }^{1}$ ) Das Gesetz von der natürlichen Selektion wird durch die heutige Ökonomie zu einem Gesetz von der unnatürlichen Repression. Man kann nicht so weit gehen, mit Adam Smith die Intelligenz ledig. lich aus dem Reichtum zu erklären ${ }^{2}$ ), aber es steht, allen Legenden auf diesem Gebiet zum Trotz, doch fest, daß die natürliche Intelligenz der unnatürlichen, d. h. künstlich geschaffenen Treibhaushitze eines gewissen Grades von Wohlhabenheit bedarf, um sich ausreifen und mannbar werden zu können.

Aber nicht nur nicht zur Basierung, nicht einmal zur Erklärung sozialen Geschehens kann die Biologie verwandt werden. Bekanntlich hat selbst ein so geistreicher Kopf wie Novikow - die Biologie scheint bisweilen ihre Jünger mit Blindheit zu schlagen — sich dazu verleiten lassen, zu den ökonomischen Phänomenen einen biologischen Kommentar zu schreiben. ${ }^{3}$ ) Er erklärt gelegentlich den ökono-

I) Man vergleiche darüber die großzügigen Auseinandersetzungen von Michel Angelo Vaccaro, "La Lotta per l'Esistenza e i suoi Effetti per l'Umanità“. 3. Aufl. Torino 1902, Bocca, p. $187-211$.

2) Adam Smith, „An Inquiry into the Nature and Causes of the Wealth of Nations" (Ausg. London I905, Routledge, p. $675 \mathrm{ff}$.).

3) J. Novikow, „Les Gaspillages des Sociétés Modernes. Contribution à la question sociale“. Paris I894, Félix Alcan, p. 271. 
mischen Prozeß der Kapitalisation für eine „biologische Tatsache" und meint, das Kapital erfülle dieselbe Funktion in der Wirtschaft wie das Fett im Körper des Menschen: es sei eine Reserve, die dazu diente, im Falle der Not die Gewebe zu ernähren. Bernstein traf den Nagel auf den Kopf, als er diesen Versuch einer biologischen Fundierung der Nationalökonomie mit den beißenden Sarkasmen ablehnte, daB zunächst Kapital und Vorrat zweierlei seien und daB es ferner auch eine Krankheit gebe, die man Fettsucht nenne, in der sich die Fettbildung auf Kosten der gehörigen Funktion der notwendigsten Organe des Körpers vollziehe. ${ }^{1}$ )

Wir taten der mißglückten Versuche einer Anwendung naturwissenschaftlicher Codices auf wirtschaftliches Geschehen nur deshalb Erwähnung, um an der Hand einiger typischen Stichproben auf die innere Unmöglichkeit einer naturwissenschaftlichen Penetration der Sozialwissenschaft hinzuweisen. Es ist eine contradictio in adjecto, volkswirtschaftliche Erscheinungen naturwissenschaftlich erklären zu wollen. Die inhärenten Tendenzen der Natur sind eben auf die Ökonomie nicht übertragbar. Die Natur ist, wie Eduard Bernstein, dem wir über die Zusammenhänge von Naturwissenschaft und Volkswirtschaft eine Reihe von klärenden Auseinandersetzungen verdanken, einmal bemerkt, die denkbar größte Verschwenderin. „Die bürgerliche Gesellschaft mit ihren maßlosen Vergeudungen ist nur eine armselige Stümperin im Vergleich mit der Natur. Von den Wärmestrahlen, die die Sonne aussendet, gelangt nicht der millionste Teil auf die Planeten, alle übrigen verflüchten sich ins Unendliche. Milliarden Keime von Lebewesen werden in jedem Augenblick auf der Erde erzeugt, die verkommen müssen, weil die Existenzbedingungen für sie nicht

I) Ed. Bernstein, ,Zur Geschichte und Theorie des Sozialismus". Berlin 1901, John ldelheim, p. I 7. 
vorhanden sind, beziehungsweise von anderen Wesen in Anspruch genommen werden. Leiten wir daher den Begriff natürlich von der Naturwelt $a b$, so ist die Verschwendung das Natürliche, die Ökonomie das Unnatürliche." 1) Die Volkswirtschaft aber hat in allen ihren Schattierungen, wenn das auch je nach den Schulen, in welche die Volkswirtschaftslehre eingeteilt ist, in beträchtlich verschiedenen Gradstärken hervorgehoben zu werden pflegt, die inhärente Tendenz zum Haushalt, zur wirtschaftlichen Sparsamkeit, zur Gütererhaltung. Ihre ganze Kunst besteht darin, die Bestie Natur nach Möglichkeit zu zähmen und zu zäumen. Sie ist die große Unterjocherin der Natur. Ihr Motto heißt: Größtmögliche Emanzipation der Menschen von den Naturkräften.

Die Naturwissenschaft interessiert sich für die Menschen schlechterdings nur als Einzellebewesen, in seltenen Fällen auch für die Menschheit als eine Gruppe von Lebewesen, gar nicht für die Menschen als Wesen von höheren Funktionen.

Man könnte vielleicht den Unterschied zwischen den Aufgaben der Nationalökonomie und denen der Anthropologie in folgende kürzeste Formel bringen: die Nationalökonomie ist die Lehre vom kollektiven Leben in der Bewegung, während die Anthropologie eine Lehre vom individuellen Leben in der Ruhe ist oder, mit einer Einschränkung gesagt, doch wenigstens von der Beobachtung des einzelnen statischen Menschen ausgehen muß.

Die Nationalökonomie sucht die sozialen Tatsachen in ihrer Komplexität zu ergründen, sie ist die Wissenschaft von der Produktion, Distribution und Konsumtion des Reichtums in ihrer Entwicklung, gefaßt in dem konstanten Zusammenhang ihrer Einzelerscheinungen. Es ist sicher nicht ganz gerecht, wenn die Anthropologen, und unter ihnen auch Niceforo, der

I) Idem p. II 5 . 
„Anthropologe der ärmeren Volksklassen“, der Nationalökonomie vorwerfen, sie habe ihre Untersuchungen sozusagen gleich beim Überbau begonnen und statt mit der Basis: dem Menschen, sogleich mit der nächst höheren Stufe: der Menschheit, angefangen. Statt des Konkretums: den Proletarier, meint Alfredo Niceforo, habe sie das Abstraktum: das Proletariat, sich zum Gegenstand ihrer Studien erkoren; sie habe sich mit dem Elend befaBt, den elenden Menschen von Fleisch und Blut aber in seinem Dunkel gelassen, kurz sie habe die menschlichen Handlungen vom Menschen losgelöst, gerade als ob jene nicht von diesem ausgingen. ${ }^{1}$ ) Wir möchten jedoch hier die These aufstellen, daß es gar nicht des Amtes der Nationalökonomie sein kann, sich mit dem Einzelmenschen zu befassen. Aufgabe dieser Wissenschaft ist lediglich die Beschäftigung mit Massenerscheinungen. Nicht der isolierte Mensch, sondern der summierte Mensch, die durch soziale und ökonomische Grenzen bestimmte menschliche Kategorie, das Aggregat von Menschen, interessiert sie. Die innerhalb dieses Aggregats auftretenden Massenerscheinungen untersucht sie und unternimmt es, ihnen die Geheimnisse ihres Bestehens und ihres Werdens abzulauschen, mit anderen Worten aus ihnen Schlußfolgerungen zu ziehen und „Gesetze“ für sie aufzustellen. Für Vergangenheit, Gegenwart und Zukunft. Deskriptive und normative Ökonomie. ${ }^{2}$ )

Die Suche nach Gesetzen erfüllt bekanntlich die moderne Wissenschaft nicht weniger als die antike. Alle Wissenschaften, etwa die Theologie, sofern man sie als Wissenschaft gelten lassen will, ausgenommen. Heftig tobt der Kampf insbesondere in der Geschichte. Karl Lamprecht

I) $\mathrm{Niceforo} \mathrm{l.} \mathrm{c.} \mathrm{p.} 32$.

2) Über die Berechtigung einer normativen Ökonomie s. die ausgezeichneten Ausführungen von Rudolf Goldscheid, „Entwicklungswerttheorie, Entwicklungstheorie, Menschenökonomie“, 1. c., p. $70 \mathrm{ff}$. 
122 VII. Zum Problem der Behandlung des Proletariats usw.

glaubt eine strenge Kausalität aller geschichtlichen Ereignisse, ein „Prinzip der Ordnung“, nachweisen zu können, das er vorzugsweise auf psychologischem Wege, nämlich durch eine stetige Entwicklung der Menschheit aus allgemeiner seelischer Gebundenheit zu immer größerer Differenzierung, erklärt wissen will. $\left.{ }^{1}\right)$ Theodor Lindner meint die dynamischen Gesetze der Weltgeschichte in den Kräften der Veränderung und der Beharrung gefunden zu haben ${ }^{2}$ ), womit, wie uns scheinen will, noch nicht allzuviel gewonnen wäre, weil uns die Kenntnis vom Rhythmus des Entwicklungsganges keinerlei Rückschlüsse auf die Richtungslinien - auf die allein es ankommt - gestattet. In der alten Geschichte beruft sich Ettore Ciccotti auf dieGesetze Marxens von der unbedingten Abhängigkeit der Formen des Rechtes von den Notwendigkeiten der Produktion und führt die Abschaffung der Sklavenarbeit auf die allmähliche wirtschaftliche Überlegenheit der freien Arbeit über die unfreie Arbeit im Produktionsprozeß zurück ${ }^{3}$ ), während Eduard Meyer die Gesetzlichkeit historischen Geschehens überhaupt leugnet und spottet, daß weder er selbst jemals ein historisches Gesetz entdeckt habe, noch bei einem anderen jemals einem solchen begegnet sei. ${ }^{4}$ )

Es mag zugegeben werden, wenn auch die metaphorische Form, in der Eduard Meyer diesen Gedanken geprägt hat, abzulehnen ist, daß man bei der Untersuchung der Geschichte auf die Existenz von geschichtsbildenden Gesetzen hin, wenigstens soweit man den äußeren Gang der geschichtlichen

I) Karl Lamprecht, „Was ist Kulturgeschichte?" Beitrag zu einer empirischen Historik. Deutsche Zeitschrift für Geschichtswissenschaft, neue Folge. Erster Jahrg. p. 75 ff. (1896/97).

2) Theodor Lindner: "Geschichtsphilosophie". 3. Auf. 1. c., p. II -34 .

3) Ettore Ciccotti, „Il Tramonto della Schiavitù“. Torino 1899, Frat. Bocca.

4) Eduard Meyer, "Zur Theorie und Methodik der Geschichte“" Halle a.d.S. 1902, Max Niemeyer. 
Ereignisse, die Aneinanderreihung der „vicende storiche“, betrachtet und sie nicht in Zusammenhang mit den übrigen Wissenschaften faBt, auf einige Schwierigkeiten stöBt. Wie entsteht, müssen wir uns fragen, ein wissenschaftliches $\mathrm{Ge}-$ setz? Die Methode der Gewinnung von Gesetzen zerfällt in drei Phasen: die Sammlung von Erfahrung, die Akkumulation von Erfahrung und die Generalisierung dieser angesammelten und akkumulierten Erfahrung. Es ist, wenn wir von den mathematischen Wissenschaften absehen, die Empirie, die zum Denkgesetz führt.

Das Material von Erfahrungen, über das die Geschichte verfügt, ist indes schwankend und ungewiß. In der Geschichte ist nicht nur bei der Interpretation der Genesis und Kausalität der Einzelgeschehnisse, sondern, was schwerer wiegt, auch bei der Konstatierung der bestimmten Tatsachenform der Einzelereignisse selbst den disparatesten Kommentaren Haus und Tür geöffnet. Schwankende und unklare Erfahrungen aber ergeben, summiert, eine ungenaue Größe. Die Summe geschichtlicher Beobachtungen braucht deshalb noch nicht ein geschichtsbestimmendes Gesetz zu ergeben.

Anders in der Nationalökonomie. Die Nationalökonomie unterscheidet sich neben anderen Merkmalen insbesondere dadurch von der Geschichte, daß sie ihre Erfahrungen aus festen Zahlenbeständen - der Statistik - herleiten kann. Die Statistik kann als die Wissenschaft bezeichnet werden, die die Aufgabe hat, den sozialen Tatsachen in Ziffern Ausdruck zu geben. Diese, die sozialen Tatsachen in Ziffern fassende Wissenschaft ist es, die der Nationalökonomie ihre philosophisch-exakte Kraft und Sicherheit verleiht und sie in gewissem Sinne hoch über die Geschichtswissenschaft, soweit sie nicht Wirtschaftsgeschichte ist, stellt; denn der Geschichtswissenschaft kommt keine Statistik zur Hilfe, da sich die historischen Tatsachen der Darstellung in Ziffern entziehen. Statistik und Nationalökonomie aber stehen in 
I 24 VII. Zum Problem der Behandlung des Proletariats usw.

Wechselwirkung. Aus der Statistik deduziert die National. ökonomie den größten Teil ihrer Sätze, während die Öko. nomie ihrerseits der Statistik die Aufgaben stellt, deren Lösung von wissenschaftlichem Wert ist.

Man könnte wohl die Nationalökonomie in höherem Sinne, nämlich in ihrer Eigenschaft als Klärerin und Erklärerin, auch als die Philosophie des sozialen Geschehens bezeichnen. Dadurch gerät die Nationalökonomie noch lange nicht in einen "Gegensatz" zur Naturwissenschaft als analytischer Grundwissenschaft. Ein derartiger Gegensatz wäre allerdings, darin hat Häckel ganz recht, in hohem Grade unnatürlich und verderblich. ${ }^{1}$ ) Mit unserem Versuch einer Grenzabteilung sind wir weit davon entfernt, die Notwendigkeit eines innerwissenschaftlichen Zusammenhanges zwischen beiden Wissenschaften leugnen zu wollen. Es wäre überhaupt ein durchaus verfehltes Beginnen, als Ziel der einzelnen Disziplinen die völlige Autonomie zu erstreben. Ohne Austausch ihrer Kenntnisse ist jeder Wissenschaftszweig Fragment. Das sind Wahrheiten, die schon der Vorschule der Erkenntniskritik angehören.

In diesem Sinne hängt auch die Nationalökonomie mit der Biologie auf das engste zusammen. Es soll nicht bestritten werden, daß, wie ja insbesondere auch die Philosophie - Aristoteles - bereits zu einer Zeit, in der von einer biologischen Wissenschaft noch nicht gut gesprochen werden konnte, „,biologisch" gedacht hat, die Nationalökonomie ganz besonders von den modernen Naturwissenschaften sowohl methodologisch als auch faktisch viel gelernt hat. Heute kann die Volkswirtschaftslehre ohne Anthropologie, ohne Soziologie in weitestem Sinne gar nicht mehr auskommen. Der Nationalökonom, der sich um die von jenen Wis-

I) Ernst Häckel, Vorwort zur ersten Auflage der „Welträtsel““. Stuttgart I 899 , E. Strauß. 
senschaften gewonnenen Resultate nicht kümmerte, wäre wie ein moderner Historiker, der die Erkenntnisse der Nationalökonomie nicht berücksichtigte, d. h. ein vielleicht brauchbarer Verwaltungsbeamter seines Duodezfaches, aber sicherlich kein Mann, dessen Schaffen auf wissenschaftliche Wertung Anspruch erheben kann.

Schon Karl Marx erkannte die Bedeutung der Naturwissenschaften für die Ökonomie vollauf an. Nach ihm entspringt der Antagonismus der sozialen Klassen - der ,Klassenkampf" - den "Naturgesetzen der kapitalistischen Produktion". Er rechtfertigt den Umstand, daß er gerade die englischen Verhältnisse zur Grundlage seiner Untersuchungen im „Kapital“ gemacht habe, durch einen Vergleich mit der Methode des Naturwissenschaftlers, der in der Physik die Naturprozesse entweder dort, wo sie in der prägnantesten Form und von störenden fremden Einflüssen mindest getrübt erscheinen, beobachtet, oder aber, noch besser, unter Bedingungen Experimente machen kann, welche den reinen Vorgang des Prozesses sichern. Ihm ist die Entwicklung der Gesellschaftsformation schlechterdings ein ,naturgeschichtlicher Prozeß", dessen Entwicklungsphasen, genau wie im Reiche der Natur, weder übersprungen noch einfach hinwegdebattiert zu werden vermögen. ${ }^{1}$ ) Die Nachfolger von Karl Marx haben diese naturwissenschaftliche Tendenz des Meisters in ihren Schriften noch stärker ausgeprägt und den Marxismus sogar als naturphilosophische Doktrin kat' exochèn ausgeschrien. Allerdings besitzt der größte Teil von ihnen von der Wirtschaftslehre des großen rheinischen Juden eine nur sehr blasse Vorstellung. Eine holländische Jüngerin glaubt den Berührungspunkt Marxens mit den Naturwissenschaften in dem Begriff der GesetzmäBigkeit oder Notwendigkeit jedes logischen Phänomens zu erblicken, ein gewiB magerer Anlaß,

I) K. Marx, „Das Kapital. Kritik der politischen Ökonomie“. I. Bd. 2. Auf. Hamburg I 872 , Meißner, p. $4-7$. 
I 26 VII. Zum Problem der Behandlung des Proletariats usw.

Marx den Naturwissenschaftlern zuzurechnen. ${ }^{1}$ ) Besonders phantastische Vergleiche stellte aber insbesondere Paul La. fargue, Marxens Schwiegersohn, der allerdings aus der Medizin hervorgegangen ist, an. Lafargue hat sich im Eifer seiner Befehdung der idealistischen Geschichtsauffassung des akademischen Philosophieprofessors und sozialistischen Po. litikers Jean Jaurès sogar zu der Behauptung verstiegen, eine Geschichtsauffassung, die nicht imstande sei, auch die Geschichte der Organismen der Zoologie und Botanik zu analysieren - eine Arbeit, die zu vollbringen er der materia. listischen zutraute! - , besitze keinen wissenschaftlichen Wert. ${ }^{2}$ )

Aber wenn Marx sich auch des inneren Zusammenhanges von Ökonomie und Naturwissenschaft sehr wohl bewußt war, so verkannte er doch keineswegs die technologis che Ver* schiedenheit ihrer Arbeitsmethoden. Er sprach es aus, was den Grundunterschied zwischen beiden Wissenschaften ausmacht, indem er darauf hinwies, daß zur Analyse der ökonomischen Gebilde weder das Mikroskop dienen könne, noch chemische Reagenzien: beides müsse ersetzt werden durch die Abstraktionskraft.

Neuerdings folgen beide Wissenschaften zweifellos derselben Grundtendenz. Ein begabter Neomarxist, Enrico Leone, hat sogar eine enge Blutsverwandtschaft zwischen ihnen feststellen wollen, da beide gleichmäßig "von dem dialektischen Prinzip des Widerspruchs" beherrscht werden. ${ }^{3}$ ) Die Periode des Immobilismus, in der die Phänomene so-

I) Vgl. Cornélie Huygens, „Darwin-Marx-Bernstein als Bestrijder van een natuurphilosophische Leer". Amsterdam 1901, Van Kampen, p. 107.

2) Paul Lafargue, "Idéalisme et Matérialisme dans la Conception de l'Histoire". Conférence en réponse à J. Jaurès. Lille IgOI, Lagrange, p. 24.

3) Siehe dic interessante Artikelserie von Enrico Leone, "Le Scienze naturali nel Marxismo“, in der Zeitschrift Il Divenire Sociale, Anno IV, No. 2 ff. 
wohl des natürlichen Seins als auch des sozialen Lebens als zeitlich und räumlich feststehend betrachtet wurden, hat der evolutionistischen Methode in diesen Wissenschaften Platz machen müssen. Der Dynamismus, die Veränderlichkeit der sozialen Formen, in denen die Menschheit lebt, ist zum Axiom geworden. Selbst in den Dunkelkammern historischer Seminare und theologischer Kränzchen mehrt sich die Zahl derer, die da einsehen, daß keine Wissenschaft sich den allgemeinen organischen Gesetzen der Differenzierung und Integrierung $z u$ entziehen vermag. Der Begriff der Dynamis, der im Gesetz von der ewigen Entwicklung seine Synthese fand und die Existenz aprioristischer Gesetze negiert, brachte die klare Einsicht von der Veränderlichkeit aller gesellschaftlichen Einrichtungen mit sich. Dieses wertvolle Leitmotiv alles menschlichen Geschehens nicht in genügendem Grade angewandt zu haben, bildet den ernstesten Vorwurf, der gegen die sog. Österreichische Schule erhoben werden kann, die in naturwissenschaftlichem Ehrgeiz sich vermißt, ökonomische Gesetze aus dem Gewicht des Newtonschen Fallgesetzes in der Physik herzuleiten und auf diesem Wege inviolable Satzungen von mathematischer Untrüglichkeit entdeckt zu haben sich einbildet.

Wenn aber die Ökonomie manches von den Naturwissenschaften lernen konnte, so schlug soziale Erkenntnis auch Bresche in manches Bollwerk naturwissenschaftlicher Begrenztheit. Zumal wurde die quantitativ und qualitativ gleich bedeutungsvolle Lombrososchule in Italien in ihrer Entwicklung durch sie beeinflußt. Zwar waren die anthropologischen Theorien Lombrosos und seiner Anhänger in ihren Konsequenzen „revolutionäre Taten“, da sie in allen Ländern eine Schule ins Leben riefen, die mit lauter Stimme eine gründliche, umwälzende Reform des Strafrechtes und des Gefängniswesens verlangte und innerhalb bestimmter Grenzen an manchen Orten auch durchzusetzen vermochte. Aber die rein anthropologische Basis dieser neuen Lehre war, zumal 
I 28 VII. Zum Problem der Behandlung des Proletariats usw.

in ihrem ursprünglichen Gewande, in hohem Grade antinationalökonomisch. Eine Lehre, die die Ursachen des Verbrechens ausschließlich in der anthropologischen Eigentümlichkeit und der anatomischen Anomalie des Verbrechers sah und sich so den Typus des geborenen Verbrechers schuf, an dem sie die Kräfte der Vererbung und des Atavismus nachzuweisen unternahm, mußte, wenigstens in der ausschließlichen Form, in der Cesare Lombroso sie zuerst konzipiert hatte und dozierte, durch die völlige Vernachlässigung des sozialen Faktors in der Genesis des Verbrechens in ihrem innersten Kern unsozial sein. Und in der Tat hat Cesare Lombroso jahrelang $\mathrm{zu}$ den hervorragendsten wissenschaftlichen Gegnern des Proletariats und seiner Bestrebungen gehört, wie er denn auch 1890 eines der bitterbösesten Bücher, mit dem der Sozialismus jemals erschlagen werden sollte, über Revolution und Verbrechen in ihrem Verhältnis zur Biologie und Pathologie veröffentlicht hat. Aber der Zahn der Zeit nagte an dieser unsozialen Theorie von der Alleinherr* schaft des degenerativen Charakters in der Kriminologie. Der bedeutendste Schüler Lombrosos, Enrico Ferri, ging mit fliegender Fahne in das Lager der Sozialdemokratie über und versucht sich seitdem in einem anthropologischen Sozialismus Darwin-Spencer-Marx. ${ }^{1}$ ) Lombroso selbst räumte in seinen Vorreden zu späteren Ausgaben des Uomo Delinquente dem sozialen Faktor seinen Platz ein und modifizierte seine Lehre vom geborenen Verbrecher dahin, daß der zum Verbrecher Bestimmte erst dann zum Verbrecher werde, wenn ungünstige ökonomische und soziale Verhältnisse seinem Hang zum Verbrechen Vorschub leisten. Er hat später mit der ihm eigenen, echt wissenschaftlichen Bescheidenheit und Selbstkritik eingestanden, seine naturwissenschaftlichen Gesichtspunkte im Anfang auf die Spitze getrieben und dadurch die

I) Siehe Enrico Ferri, „Socialismo e Scienza positiva“. Roma 1904. Casa Ed. Italiana. In viele Sprachen übersetzt. 
Ignoranten und Freunde der Ignoranz in der Politik mit seiner Unbedachtsamkeit gestützt $\mathrm{zu}$ haben, und hat die Einseitigkeit seines früheren Schaffens damit entschuldigt, daß er damals "noch nicht von der Nähe jenes Feuergeistes, der dem modernen Proletariat eigen ist und der einem hohen Ideal zustrebt und die geschichtlichen Umwälzungen hervorruft, inspiriert" gewesen sei. ${ }^{1}$ ) Der ehemalige Konservative lieb sich schlieblich sogar als Sozialist in den Stadtrat von Turin wählen. Einen ähnlichen Werdegang machte mit Lombroso eine große Schar von jüngeren und älteren Gelehrten durch, von denen an dieser Stelle nur noch des jugendlich-greisen Anthropologen an der Universität Rom, Giuseppe Sergi, der sogar zu antimilitaristisch-syndikalistischen Resultaten gelangt ist, gedacht sei.

Als eine Frucht dieser Entwicklung zur Synthese von Anthropologie und Nationalökonomie ist auch die wissenschaftliche Arbeit Alfredo Niceforos zu betrachten. Von der reinen Naturwissenschaft ausgehend, ist dieser junge Gelehrte, der, kaum dem Knabenalter entwachsen, durch seine bedeutungsvollen Schriften über oder, wie seine Gegner wollen, gegen Süd-Italien (er ist selber Sizilianer), in denen er mit großem Eifer die These von der absoluten Minderwerigkeit dieser Landesteile dem fortgeschrittenen Norden gezenüber verfocht, von sich reden machte, zu einer biologischen Wissenschaft gelangt, die man getrost unter die So:ialwissenschaften rechnen kann. Niceforo geht $z$ war auf len Menschen als Einzelindividuum zurück, aber nicht, um us ihm den hypothetischen, abstrakten Homo oeconomicus ler Österreicher zu konstruieren, sondern nur, um ihn als ür die Erkenntnis des Ganzen richtunggebenden Bestandeil zu benutzen. Man könnte seine Methode deshalb reser-

I) Cesare Lombroso, „Il Momento attuale“. Milano I904, iasa Ed. Moderna, p. 11, 65.

Michels: Probleme der Sozialphilosophie 
vatis reservandis der Absicht $\mathrm{Karl} \mathrm{Marlos}^{1}$ ) vergleichen, der gelegentlich einer norwegischen Reise den Gedanken faßte, aus der Kenntnis des Einzelmenschen in seinen wirtschaftlichen Schicksalen und aus ihrer Summierung die Ökonomie der Menschheit zu konstruieren, um so zu wertvollen Erkenntnissen zu gelangen.

Niceforo ist der Schöpfer eines neuen Wissenschaftszweiges, den er "Anthropologie der armen Volksklassen" getauft hat. Gerade dieser Wissenschaftszweig ist so recht eigentlich das, was man in Deutschland, dem Lande des wissenschaftlichen Fraktionnements, mit dem terminus technicus Grenzwissenschaft bezeichnet hat. Sie hat mit der Nationalökonomie das Ziel der Untersuchung, nicht die Rasse, wie die pure Anthropologie, sondern die wirtschaftliche Klasse, gerade mit Ausschluß der ethnographischen Elemente, gemein, während sie in der Anthropologie ihr Arsenal besitzt, aus dem sie sich ihre Waffen, d.h. ihre Methode und einen Teil ihres rein technisch-mechanischen Hilfsmaterials holt. Man macht sich vielleicht die wissenschaftliche Rolle dieses neuen Lehrgebietes am besten vermittelst eines der Mathematik entnommenen Bildes klar, indem man sich nämlich die Nationalökonomie und die Anthropologie in Gestalt zweier Kreise vorstellt, die sich schneiden: die zwischen beiden Schnittpunkten liegende, ellipsenförmige Schnittfäche ist die Anthropologie der armen Volksklassen, die somit keine der beiden Wissenschaften deckt, aber von beiden einen Teil umfaßt.

Niceforo, der mit dem ihm doch im Grunde recht wesensfremden Ammon zusammen von Lapouge als der bedeutendste Anthropo-Soziologe genannt worden ist ${ }^{2}$, steht in

I) Karl Marlo (Winkelblech), „Untersuchungen über die Or. ganisation der Arbeit oder die Weltökonomie“. Kassel 1850. Vol. I. p. 211 .

2) G. Vacher de Lapouge, „Die Entartung in den höheren und niederen Ständen". Pol. Anthropol. Revue, 5. Jahrg. Nr. 4. 
gewissem Sinne in Widerspruch zu den Schulen von Ottokar Lorenz in Deutschland und Vilfredo Pareto in Italien. Ohne die von jenen Schulen mit so vielem Eifer vertretene Theorie von der sozialen Kurzlebigkeit der jedesmal herrschenden Klasse ausdrücklich zu negieren, ist für Niceforo der „Reiche“ (l' uomo ricco) doch das Produkt einer langen Reihe reicher Vorfahren. Nur unter dieser Annahme ist sein anthropologischer Typus des Reichen überhaupt möglich.

Niceforos Theorien - das Resultat vorzugsweise anthropometrischer Untersuchungen - stützen auf das glänzendste die Doktrin des historischen Materialismus. Was Marx ökonomisch bewies, das hat Niceforo anthropologisch bewiesen: die Existenz zweier sozialer Welten. Hat Marx den Homo oeconomicus gezweiteilt und miteinander in Antithese gebracht, so zweiteilt nun Niceforo den Homo physicus. Marx hatte behauptet: zwischen dem Armen und dem Reichen gibt es keine Interessengemeinschaft. Nun ist Niceforo erstanden, der da verkündet: zwischen dem Armen und dem Reichen gibt es keine Typusgemenrsenant. Das Lebewesen Armer ist gruñveroctrieden vom Lebewesen Reicher. Sie differieren in ihren anthropologisch-biologischen Merkmalen. Aber auch Niceforo erklärt diese Differenz als im letzten Grunde durch die Wirtschaft entstanden. Gerade hier offenbart er sich uns mehr als Sozialwissenschaftler denn als Anthropologe, indem er die Tatsache zwar nicht ganz, aber doch zu sehr außer acht läßt, daß der anthropologische Typus des Reichen vom anthropologischen Typus des Armen nicht nur aus ökonomischen, sondern auch aus anthropologischen Gründen abweichen kann, wie denn z. B. der Adel in mehreren Ländern zum größten Teil aus Nachkommen von den Durchschnittsbewohnern des Landes ethnisch heterogenen Erobererhorden stammt.

Auch die zweite These Niceforos: der anthropologische Typus des Armen ist vom anthropologischen Typus des Reichen nicht nur verschieden, sondern ihm anthropologisch ge- 
I 32 VIII. Zum Problem der zeitlichen Widerstandsfähigkeit usw.

sprochen durchaus unebenbürtig, minderwertig, ist nichts als die anthropologisch-anthropometrische Nachprüfung eines sozialwissenschaftlich längst anerkannten Satzes, der sich noch dazu logisch direkt aus den Grundbegriffen des historischen Materialismus ableiten läßt.

Gerade unter volkswirtschaftlichem Gesichtswinkel betrachtet sind die Erkenntnisse der Anthropologie des Proletariats von gröBter, wirksamster, praktischer Bedeutung. Es liegt uns fern, an dieser Stelle die ganzen unübersehbaren Gefilde der die Fragen der politischen Spekulation und der sozialen Pädagogik berührenden Probleme näher erörtern oder auch nur skizzieren zu wollen. Nur auf einen Punkt möchten wir hindeuten, nur einen Fingerzeig geben, ohne auf die Sache selbst näher einzugehen. Die Frage drängt sich auf, eine schwerwiegende Doppelfrage: Ist dieses geistig und körperlich defekte Proletariat, wie es sich in den Studien der politisch-sozialen Anthropologie unserem Auge zeigt, reif für seine Emanzipation als Klasse, und, wenn wir diese Frage verneinen müssen, was haben wir $z u$ tun, um es reif $\mathrm{zu}$ machen?

\section{Achtes Kapitel. \\ Zum Problem der zeitlichen Widerstands- fähigkeit des Adels.}

Als eine der bedeutendsten geschichtsphilosophischen Theorien der neueren Zeit dürfen wir das Dogma von der Circulation des Élites betrachten, das den bedeutendenVolkswirtschaftslehrer Vilfredo Pareto zum Verfasser hat. Diese Theorie besagt kurz folgendes: Keine Gesellschaft vermag ohne herrschende Schicht auszukommen, aber alle herrschenden Schichten fallen schnellem Verfall anheim und machen in kurzer Zeit neuen, aus dem Volke kommenden Herrscher- 
schichten Platz. Das Volk wird sich nie demokratisch verwalten können, aber die Herrschenden selbst unterliegen beständigem Wechsel. ${ }^{1}$ )

Es lohnt sich, diese Theorie einmal kurz auf Herz und Nieren zu untersuchen. Sie basiert zunächst auf der inneren Unmöglichkeit einer Volksherrschaft. Dieser Frage haben wir bereits eine größere Untersuchung gewidmet.") Sie basiert aber fernerhin auch auf dem Prämiß von der Kurzlebigkeit und Dekadenz der Aristokratie. Aber es muß die Frage gestellt werden: Ist diese Erkenntnis richtig und inwieweit entspricht sie den Tatsachen, die wir kennen?

Das soziologische Problem des Adels als herrschender Klasse stellt sich uns in folgender Form: Existiert der alte Adel noch? Und, im Bejahungsfall, nimmt er 1. sozial, 2. ökonomisch und 3 . biologisch noch die gleiche Stellung wie vor etwa zweihundert Jahren ein?

Sicher ist, daß der Adel heute überall da, wo eine moderne Industrie aufgekommen ist, ökonomisch gemessen hinter der Oberschicht des gewerbetreibenden Bürgertums zurückgeblieben, an die zweite Stelle gerückt ist, wenngleich sich diese Konstatierung nur auf ganz besondere Gebiete bezieht. Richtig ist ferner, daB der Adel manchenorts eine nur geringe Nuptialität und eine erschreckend hohe Sterilität aufweist. Doch sind auch diese Beobachtungen bisher nur in engem Felde gemacht worden und lassen noch keineswegs eine Generalisierung ihrer Ergebnisse zu.

Immerhin dürfte sich zunächst eine kurze Analyse der beträchtlichsten auf diesem Gebiete geführten Untersuchungen lohnen.

1) Vilfredo Pareto, „Les Systèmes Socialistes". Paris I902, Giard et Brière. 2 Vols.

2) Robert Michels, „Zur Soziologie des Parteiwesens in der modernen Demokratie. Untersuchungen über die oligarchischen Ten. denzen des Gruppenlebens". Leipzig I9II, Klinkhardt, p. 40 I ff. 
In Schweden existiert ein sogenanntes Adelshaus, gegründet vom König Gustav Adolf im Jahre I626, in welches jeder Edelmann, welcher darauf Wert legte, als solcher gezählt und gerechnet zu werden, eingeführt werden mußte. Jede Adelsfamilie erhielt dort eine genealogische Tabelle angewiesen, auf welcher alle die Familie betreffenden Ereignisse und Veränderungen ihres Personenstandes (Geburten, Heiraten, Todesfälle usw.) gebucht wurden. Auf diese Weise wirkte das Adelshaus als eine Art Statistisches Bureau für die schwedische Aristokratie und vermag nun dem Demographen eine Fülle wertvollster Aufschlüsse zu geben. Es ist das Verdienst Fahlbecks, diese wertvolle Fundgrube ausfindig gemacht und nach Kräften ausgenutzt zu haben. ${ }^{1}$ )

Von I626-I 898 haben in Schweden insgesamt 3033 dem Adel angehörige Familien (I 42 gräfliche, 4 I 7 freiherrliche, 2474 titellose adlige Familien) bestanden; von diesen sind in dem angegebenen Zeitraum 2319, nämlich 82 gräfliche, 277 freiherrliche und I965 einfache Adelsfamilien ausgestorben. Mit anderen Worten - und darin besteht für uns das interessanteste Ergebnis der Fahlbeckschen Untersuchungen - in etwa zweihundertundsiebzig Jahren ist $76,6 \%$, über ein Drittel der der Geburtsaristokratie angehörigen Familien, offiziell, d. h. im Mannesstamme und also dem Namen nach, vom Erdboden verschwunden.

Ein weiteres interessantes Ergebnis der Fahlbeckschen Untersuchungen besteht darin, daß von 2319 seit 1626 ausgestorbenen Adelsfamilien nur 137 solchen Geschlechtern angehören, deren Adel über I 626 zurückreicht. Diese Konstatierung würde für eine These sprechen, nach welcher die alten Adelsfamilien eine größere Dauerhaftigkeit aufweisen als die

I) P. E. Fahlbeck, „Sveriges Adel“, I. „Aetternas Demographi“, Lund I 898 , sowie "La Noblesse de Suède, Etude Démographique“. Resümee von der Hand des Verf. selber im „Bulletin de l'Institut International de Statistique“, Vol. XI, I dre Livraison. Kristiania 1900, Steen, p. I $70 \mathrm{ff}$. 
neuen. Die schwedischen Untersuchungen scheinen in derTat zu beweisen, daß die Mortalităt der Familien, anstatt mit ihrem Alter zuzunehmen, mit ihrem Alter abnimmt. Junge Familien - das Wort jung hier immer im aristokratischen, nicht im biologischen Sinne gebraucht - sind demVerfall mehr ausgesetzt als alte. Für die Aristokratie ist das Jugendalter das kritischste. Von je 1000 ausgestorbenen Adelsfamilien sind 439 in den ersten 25 Jahren des Bestehens der Familie als Adelsfamilie, 206 nach einer Dauer von I 26-I 50 Jahren ausgestorben. ${ }^{1}$ ) Aus diesen Zahlen dürfen indes wohl nur mit einiger Vorsicht Schlüsse gezogen werden. Erfahrungsgemäß pflegt die Verleihung des Adels leichter zu erfolgen, wenn der zu adelnde pater familias kinderlos oder doch mit nicht allzuviel Kindern gesegnet ist: einmal um dem Adel nicht gar zu viel neues Blut auf einmal zuzuführen, dann auch, weil es sich bei kinderreichen Familien häufiger als bei kinderarmen ergibt, dab in ihnen Söhne vorkommen, deren moralisches oder auch politisches Verhalten es dem Landesfürsten nicht angezeigt erscheinen läßt, den Vater - und mit ihm den mibliebigen Sohn - in den Adelsstand aufzunehmen. Dieser Grund liefert bis zu einem gewissen Grade die Erklärung dafür, warum der Prozentsatz der junggeadelten Familien, die schon binnen kurzer Zeit wieder aussterben, so hoch ist. Immerhin dürfte aber freilich dieser Umstand doch nicht ausreichen, um das starke Dem-Erlöschen-Ausgesetztsein der jungen Aristokratien restlos ursächlich zu erhellen.

Welches sind aber die Gründe der geringen physiologischen Widerstandsfähigkeit des schwedischen Adels überhaupt? Fahlbeck schlieBt jeden Erklärungsversuch auf Grund moralischer Degeneration von vornherein aus. Der schwedische Adel ist als Klasse genommen nicht verlottert und verlumpt. Dagegen liegt bei ihm physiologische Degenera-

I) P. $173 / 174$. 
I 36 VIII. Zum Problem der zeitlichen Widerstandsfähigkeit usw.

tion in aller Form vor. ${ }^{1}$ ) Diese Degeneration bezieht sich vorzüglich auf die bei ihm feststellbare hohe Sterilität der Ehen, die geringe Kinderzahl der fruchtbaren unter ihnen sowie die hohe Mortalität der männlichen Nachkommen. Ferner ist unter den Ursachen des Aussterbens der schwedischen Adelsfamilien aber auch die niedrige Nuptialität, das starke Hagestolzentum zu erwähnen. Von je I 00 männlichen Mitgliedern der aussterbenden Generationen haben sich nur knapp 30 verheiratet.

\section{Anzahl der sterilen Ehen (auf roo Ehen) im schwe- dischen Adel.}

\begin{tabular}{|c|c|c|c|c|c|c|}
\hline \multirow{2}{*}{$\begin{array}{c}\begin{array}{c}\text { Adelsfamilien } \\
\text { von }\end{array} \\
2 \text { Generationen }\end{array}$} & $\begin{array}{c}\text { I. Gene- } \\
\text { ration }\end{array}$ & \multicolumn{4}{|c|}{$\begin{array}{c}\text { Sterile } E \text { he } n \\
\text { in der }\end{array}$} & $\begin{array}{l}6 . \text { Gene } \\
\text { ration }\end{array}$ \\
\hline & 13,72 & 63,68 & - & - & - & - \\
\hline 3 & 8,76 & I 9,64 & 64,15 & - & - & - \\
\hline 4 & 10,75 & 17,09 & 20,79 & 62,07 & - & - \\
\hline 5 & I 8,31 & I 7,29 & 23,08 & 21,36 & 75,00 & - \\
\hline 6 & 10,26 & 10,00 & 19,35 & 14,29 & 17,07 & 70,00 \\
\hline
\end{tabular}

Wie aus obiger Tabelle ersichtlich, blieben von je 100 Ehen männlicher Mitglieder der jeweils aussterbenden Generation $62-75 \%$ ohne Nachkommen. Wie stark die geringe Fruchtbarkeit zum Verschwinden der Familien beigetragen hat, beweist die Tatsache, daß in der aussterbenden Generation unter den fruchtbaren Ehen der Durchschnitt der Kinderzahl nur $1,00-2,67$ betrug. Die Mortalität der männlichen Nachkommen unter I 9 Jahren betrug in der letzten Generation $40-50 \%$. Endlich überwogen die weiblichen Geburten über die männlichen im Verhältnis von IOO zu 79,08 (Familien von vier Generationen) und roo zu 69, i 2 (Familien

I) p. 180 . 
von sechs Generationen). Über die Nachkommenschaft dieser Töchter aber, welche bei ihrer Verheiratung des Namens verlustig gingen und infolgedessen statistisch nicht mehr als mit zur Familie gehörig betrachtet wurden, schweigt die Statistik. ${ }^{1}$ )

Das hier angeschnittene Problem ist für die Frage nach dem Fortbestand des Blutes überaus wichtig. Eine jahrhundertelang zur Aristokratie gehörende blühende Familie kann, obgleich womöglich mit zehn Töchtern behaftet, im Mannesstamm plötzlich aussterben. Gesetzt den Fall, die zehn Töchter heiraten sämtlich und diese Ehen sind sämtlich mit Kindern gesegnet, so erhalten wir zwar wohl ein ganz besonders starkes Renouveau des Blutes; die Familie aber ist erloschen. Hier steht also der biologische Familienbegriff mit dem juridisch-statistischen in unlöslichem Widerspruch. Die bei dem Stand der heutigen Statistik fast unbeantwortbare Frage, ob der abgestorbene Teil der alten herrschenden Klasse wenigstens in ihrem weiblichen Stamm in der gegenwärtigen herrschenden Klasse noch fortlebe, ist indes von höchster Wichtigkeit für die Beantwortung der Frage, ob die alte Aristokratie wirklich der physischen Dekadenz anheimgefallen ist oder nicht; es sei denn, man wolle die Frage ohne weiteres bejahen, weil weibliche Nachkommenschaft ein greifbares Zeichen von Dekadenz sei, was indes doch wohl eine gewagte maskuline Behauptung sein dürte. Im übrigen ist daran zu erinnern, daß die Kontinuität der die herrschenden Klassen ausmachenden Familien vielfach gerade durch die Töchter der alten Geschlechter, welche in die neuen Familien hineinheiraten, gewahrt wird. Die im Mannesstamm erlöschenden Familien verheiraten ihre Töchter natürlich innerhalb des Kreises gleichgestellter oder, wenn diese kapitalkräftiger und angesehener sind, der sich gleichstellenden Familien. Das alte Herrscherblut geht auf

I) p. $177-179$. 
I $3^{8}$ VIII. Zum Problem der zeitlichen Widerstandsfähigkeit usw.

diese Weise keineswegs verloren, während den neuen Herrscherschichten altes Blut zugeführt wird.

In Frankreich hat schon vor langer Zeit ein Mitglied des höheren Adels, der Marquis Bénoiston de Châteauneuf, nachzuweisen versucht, daß die durchschnittliche Dauer der adli. gen Familien nicht dreihundert Jahre übersteigt. Die Gründe, die er für diese Erscheinung angibt, sind: das Recht der Erstgeburt und die dadurch für die Kadetten entstehenden Verelendungstendenzen, die Verwandtschaftsehe mit ihren Folgen der Sterilität, hauptsächlich aber der den französischen Adel als einen Soldatenadel dezimierende Krieg und endlich die Duellwut. ${ }^{1}$ ) Gewiß ist es zutreffend, daß der Krieg den französischen Adel wohl in äußerstem Grade geschwächt hat. Der weitaus größte Teil des französischen Adels ne choisit point d'autre profession que celle des armes, wie der Marquis de Feuquières, der erste französische Kriegswissenschaftler, schon 17 I 7 gesagt hat. $\left.{ }^{2}\right)$ Indes müssen aber doch noch generellere Ursachen mit den Ausschlag für die relativ geringe mittlere Lebensdauer der französischen Adelsfamilien gegeben haben, sintemalen Bénoiston de Châteauneuf selbst angibt, daß er bei seinen Untersuchungen über die Lebensdauer bürgerlicher und kleinbürgerlicher Familien zu ähnlichen Resultaten wie beim Adel gelangt ist. ${ }^{3}$ )

In Mannheim hat Schott nach der Zahl der alten Familien geforscht. Von den knapp 1000 Familien, die Mannheim im Jahre I 79 aufwies, sind im Jahre I900, also nach einem Zeitraume von I 8 I Jahren, noch 99, also etwa

I) Bénoiston de Châteauneuf, „Mémoire Statistique sur la Durée des Familles Nobles en France“. Paris, Journal d'Hygiène, 1845 .

2) „Mémoires de M. le Marquis de Feuquières, contenant ses Maximes sur la Guerre et l'Application des Exemples aux Ma. ximes." Nouv. Éd. Londres et Paris 1750, Rollin, Vol. I, p. I.

3) Bénoiston de Châteauneuf, 1. c. 
ein Zehntel, vorhanden ${ }^{1}$, d. h. noch in Mannheim wohnhaft. Neun Zehntel gingen im Laufe der Jahre verloren. Von den I807/18I I ermittelten 146I Familien sind I900, also nach einem Zeitraume von 89 Jahren, noch $5^{6} 3$ übriggeblieben ${ }^{2}$ ), d. h. etwas über ein Drittel. Da sich die Stammfamilien von 1807 aber häufig 1900 in etliche Einzelfamilien (,Zweige") zerteilt wiederfinden, kann man für heute ein Vorhandensein von rund I 300 echten Alt-Mannheimer Familien ausrechnen. ${ }^{\text {? }}$ )

Auf die Frage, die uns hier besonders interessiert, die der Kontinuität der politischen Klasse, gibt die Schottsche Untersuchung allerdings hiermit noch keine große Ausbeute. Die Schottsche Analyse bezieht sich auf ,alte Mannheimer Familien". DasWort alt ist hier aber lediglich in chronologischem, nicht in sozialem Sinne gebraucht. Alt sind infolgedessen auch die Tagelöhnerfamilien, insofern sie sich nur bis 1807 zurückführen lassen. Wie groß die Zahl der den herrschenden Klassen angehörigen Geschlechter unter den 563 ermittelten überlebenden Familien ist, läßt sich nicht leicht ersehen. Doch geht aus der Betrachtung der Listen überzeugend hervor, daß die untersuchten Familien ganz überwiegend dem Arbeiterstande und dem Kleinbürgertum angehören. Unter den 543 von 1807 bis 1900 in Mannheim sebhaften Familien finden wir gar nur eine einzige von Adel (von Fischer) angegeben. ${ }^{4}$ ) Vorausgesetzt, daB die Angabe wirklich zutrifft, würde sie zum mindesten auf eine äußerst geringe Wurzelfestigkeit des Mannheimer Adels schließen lassen. Allerdings muß da der Tatsache Erwähnung getan werden, dab zu Beginn der untersuchten Periode die Stadt

1) Sigmund Schott, „Alte Mannheimer Familien. Ein Beitrag zur Familienstatistik des XIX. Jahrhunderts“. Mannheim und Leipzig I910, Bensheimer, p. 33 .

2) p. 21,23 .

3) p. 32 .

4) p. 26. 
Mannheim von einem Ereignis betroffen wurde, das nicht nur die äußere Charakteristik der Stadt stark beeinflussen, sondern auch sehr beträchtliche demographische Folgen nach sich ziehen mußte, nämlich die Verlegung der Residenz nach Karlsruhe. Es unterliegt wohl keinem Zweifel, und auch Schott ist dieser Ansicht ${ }^{1}$ ), daß damals die Abwanderung eines groBen Teiles des Adels erfolgte und überhaupt die herrschenden Schichten der Stadt stark in ihrer sozialen Zusammensetzung modifiziert worden sind.

Bei Studien wie der Schottschen liegt also wohl der Hauptwert nicht so sehr in ihren Ergebnissen zur Beleuchtung des Problems der Dauerhaftigkeit der Familien als vielmehr in denen zur Feststellung des Grades der Bevölkerungsbewegung oder, positiver ausgedrückt, der Seßhaftigkeit der einzelnen Bevölkerungsteile. Schott gibt uns keinen Aufschluß über die Frage, was aus den I 900 nicht mehr vorhandenen Alt-Mannheimer Familien geworden ist. Wieviel von ihnen sind ausgestorben, wie viele hingegen bloB verzogen? Daß die Zahl der letzteren groß sein muß, gibt Schott implizite selber $z u$, wenn er zu berichten weiß, daß in Mannheim die überwiegende Zahl aller erloschenen Stammfamilien, nämlich $73,6 \%$, gar nicht in die zweite Generation gekommen sind, es also in Mannheim zu keiner Familienbildung im Mannesstamm mehr gebracht haben. ${ }^{2}$ ) Inmitten der Lebensperiode der ersten der gemessenen Generationen, im Jahre I 801, erfolgte eben, wie erwähnt, die Verlegung der Hauptstadt von Mannheim nach Karlsruhe.

Dagegen kann man sich aus den Listen, die den Beruf des Stammvaters I 809 und die Berufe der Urenkel 1900 enthalten ${ }^{3}$ ), ein leidlich sicheres Urteil darüber bilden, dab die soziale Stellung der Familie in der Regel in jenem
I) p. 66 .
2) p. 40.
3) p. $47 \mathrm{ff}$. 
Zeitlauf keine sonderliche Schwankung durchgemacht hat, und hierin ist auch eine Anzahl den höheren Ständen angehöriger Familien einbegriffen, deren Oberhäupter drei oder mehr Generationen hindurch genau denselben Beruf ausgeübt haben. Schott gewann den Eindruck, daß Senkung und Hebung die Ausnahme von der Regel der Beibehaltung des sozialen Standard bilden und daB weitaus die meisten Generationsfamilien sich das ganze Jahrhundert hindurch auf dem gleichen Stockwerk bewegen, während ,nur wenige in das Paternosterwerk steigen, das sie hinauf oder hinunter befördert“.1) Überdies muß bei derartigen Untersuchungen stets darauf achtgegeben werden, sich nicht durch die oft irügerischen, in der neuen Zeit weit großartiger als ehemals klingenden Berufsangaben irreleiten zu lassen. So, wenn der Vater als Handwerksmeister angegeben ist, der Sohn hingegen als Fabrikant figuriert, braucht die Familie noch längst nicht eine soziale Steigerung erfahren zu haben. Der Handwerksmeister von I 860 entspricht eben in vielen Fällen seiner ökonomischen Lage und seiner gesellschaftlichen Geltung nach dem Kleinfabrikanten oder auch „Fabrikbesitzer“ von I goo. Häufig sind beide Berufsarten nur Stufen einer rein technischen Entwicklung; mit anderen Worten der Fabrikant von heute steht zum Handwerksmeister von gestern wie der Schmetterling zur Puppe.

Man hat beobachten wollen, daß die natürlichen Kinder, die sogenannten Bastarde, überaus häufig wertvolle Menschen waren und physisch und psychisch weit über ihren im Bett der offiziellen Ehe gezeugten Brüdern standen. In der Tat kargt die Geschichte nicht mit Beispielen: Don Juan de Austria, Vendôme, Gaston d'Orléans, Dunois, Prinz Eugen von Savoyen, der Connétable de Bourbon, Marschall Moritz von Sachsen, alle Söhne oder Enkel freier Liebe,
1) p. 55 . 
142 VII. Zum Problem der zeitlichen Widerstandsfähigkeit usw.

ebenso wie auch die Pompadour und die Zarin Anna von RuBland. $\left.{ }^{1}\right)$ Die hohe Intelligenz, welche die Bastarde auszeichnet, gilt vielfach als Beweis für dieVorzüglichkeit, die der gesetzlich ungeregelten Zeugung an sich innewohne. Vielleicht bis zu einem bestimmten Grade mit Recht. Die „Kinder der Liebe“ sind Früchte natürlicher Wahlverwandtschaft, konzipiert in einem starken sinnlichen Rausch zweier junger Menschen; die legitimen Kinder der kirchlich gesegneten und staatlich gebuchten Ehe, unter deren Entstehungsursachen die Liebe zumeist an letzter Stelle zu stehen pflegt, wenn nicht gar überhaupt fehlt, werden dagegen nur $z u$ oft von einem alternden Manne und einer unfreudigen Frau zwischen zwei Gähnkrämpfen erzeugt. Kein Wunder also, wenn das Kind aus der ersteren Verbindung dem aus der zweiten an Schönheit und Entwicklungsmöglichkeiten überlegen ist. Aber die häufige Überlegenheit der illegitimen Sprossen über die legitimen beweist nichts für die These der Dekadenz des Adels. Zunächst ist in Erwägung zu ziehen, daß die illegitimen Kinder nur dann zu tüchtigen Männern heranreifen, wenn ihnen seitens der Väter eine sorgsame Erziehung zuteil wird. Das Gros der unehelichen Kinder geht bekanntlich in Elend und Verbrechen jämmerlich zugrunde. Fernerhin aber darf auch die Tatsache nicht vergessen werden, daß die unehelichen Mütter jener ihre Halbbrüder von der hohen Aristokratie und aus den Königshäusern in den Schatten stellenden Bastarde fast ausschließlich selber dem Adel angehörten. Der Hinweis auf die Überlegenheit der Bastarde besagt also gar nichts in bezug auf die vermeintliche Dekadenz des Adels, sondern höchstens auf die der königlichen Geschlechter. Auch mag Colajanni recht haben, wenn er den wesentlichsten Grund der Überlegenheit der Bastarde in der im Vergleich mit der Erziehung der legi-

I) Théodore Ribot, „L'Hérédité Psychologique“. $7^{\circ}$ édition. Paris 1902. Alcan, p. 175 . 
timen Seigneurs einerseits strengeren und in anderer Richtung wieder freieren Erziehung, die ihnen zuteil wird, erblickt. Durch sie werden gewisse gute Keime in ihnen leichter entwickelt und gewisse schlechte Keime eher unterdrückt als bei den legitimen Kindern. ${ }^{1}$ ) Jedenfalls ist festzuhalten: die Bastarde vermögen ihre ehelichen Brüder nur dann an Leistungsfähigkeit zu übertreffen, wenn ihnen der uneheliche Vater in der Erziehung zur Seite steht.

Häufig wird der These von der Dekadenz des Adels eine wesentlich intellektuelle Fassung gegeben. Vom deutschen Adel meint Sombart einmal, man dürfe wohl sagen, „ohne jemandem etwas Übles anzutun, daß von dem, was wir heute unter Bildung und Kultur im guten wie im schlechten Sinn verstehen, in diesen Schichten außerordentlich wenig zu finden ist". Er ist der Ansicht, daß,,im wesentlichen alle neueren Strömungen auf dem Gebiete der Wissenschaften, namentlich aber der Kunst und Literatur an jenen Kreisen vorübergerauscht sind, ohne sie eigentlich zu berühren". Zum Beweis dafür, meint er, brauche man sich nur einmal in der Wohnung eines preuBischen Ministers umzusehen, oder aufzupassen, welchen Geschmack die Herren von der Regierung und ihre Frauen im Theater, bei der Auswahl ihrer Lektüre, in der Beurteilung von Bildern usw. betätigen, um sofort zu empfinden, daß sich zwischen ihnen und dem, was die moderne Bildung in Deutschland repräsentiert, eine tiefe Kluft auftue. ${ }^{2}$ ) Diese Bemerkungen sind im wesentlichen zutreffend. Das Kontingent, das der alte Adel in Deutschland dem Lehrpersonal der Hochschulen stellt, auf denen er doch bei seinen nahen Beziehungen zu den maßgebenden Regierungsinstanzen gewiß glänzende Fortkommensmöglichkeiten hätte, ist an Zahl und in der Regel _ viel-

I) Nap sleone Colajanni, ,Socialismo e Sociologia Criminale". Catania 1884. Tropea, Vol. I, p. 207.

2) Werner Sombart, „Die Elemente des politischen Lebens in Deutschland".. Morgen I, 9. 
144 VIII. Zum Problem der zeitlichen Widerstandsfähigkeit usw.

leicht je zwei Volkswirtschafter und Historiker ausgenommen - auch an Wert sehr gering. In Frankreich ebenso wie in Italien und England liegen die Verhältnisse besser. Im allgemeinen kann man beobachten, daß es dem Durchschnittsaristokraten überall, aber zumal in Deutschland, an jedem inneren Interesse für die Wissenschaft mangelt. $\left.{ }^{1}\right)$ Mehr noch: der Adel, zumal der angesessene Adel, steht ihr mit tiefem, nicht leicht überwindlichem Mißtrauen gegenüber. Er wittert in der Wissenschaft die Schrittmacherin der Revolution, die Todfeindin des Restbestandes seiner gesellschaftlichen Privilegien.

Indes das geringe Vorhandensein von wissenschaftlichintellektuellen Qualitäten, dem man im Adel begegnet, bedeutet keineswegs Unfähigkeit dieses Bevölkerungsteiles zur Ausübung der Herrschaft. Zumal in der Politik besitzt der alte Adel ein ihm durch generationenlange Zucht immanent gewordenes Verständnis und Feingefühl, das bis auf den heutigen Tag hin noch nicht versagt hat. Daß die Parteien der Rechten unter ihren Führern eine große Zahl bedeutender Adliger zählen, ist bei dem konservativen Charakter des Adels nicht verwunderlich. Bemerkenswerter ist die Tatsache, daß auch die Parteien der äußersten Linken häufig Adlige an der Spitze haben. In der parlamentarischen Vertretung der radikalen Partei Italiens hat der mittlere und hohe Adel die Hegemonie. Die sozialdemokratische Fraktion des bayrischen Landtages wurde eine Zeitlang von zwei Geburtsaristokraten, den einzigen im Landtag, geführt. Der Adel verleugnet auch heute seine politische Tüchtigkeit und sein altes Herrscherblut nicht. Demokraten haben spotten wollen, daß das Persönlichkeitsniveau des deutschen Adels ständig sinke; daß ,in den adligen Brutanstalten, die den Bedarf der Regierung an hohen Beamten decken sollen,

1) Auch im Pariser Lateinviertel fällt die Spärlichkeit des Adels auf, vgl. René Vallery-Rad ot, "L'Étudiant d'aujourd'hui““. Paris 1878, Hetzel, p. $3^{8}$. 
nur noch eine Gesellschaft von mageren Piepshühnern aufgezüchtet wird"; daß zwar Ausnahmen wohl vorkommen, dem Mittelprodukt aber „jeder vorsichtige Bankdirektor kaum eine Markenkleberstelle anvertrauen" würde. Auch hat man zornig den Fortbestand jenes Vorurteils konstatieren wollen, daß, ,während die übrige weiße Menschheit sich mit dem abscheulichen Vorurteil begnügt, daß die weiße Hautfarbe höher als die schwarze zu schätzen sei, man in Preußen noch unter die Haut blicke und dort noch farbige Unterschiede herausfinde". $\left.{ }^{1}\right)$ Man hat, allen Leugnungsversuchen der adelsfreundlichen Presse zum Trotz, feststellen können, daß 8o Prozent der deutschen Korpskommandeure dem alten Feudaladel angehören, und Gädke hat ausgerechnet, daß bei der Kavallerie von den Leutnants zwei Drittel, von den Rittmeistern drei Viertel, von den Majors vier Fünftel, von den Obersten und Generalmajors sechs Siebentel, von den Generalleutnants sieben Achtel und von den Generalen der Kavallerie alle dem Adel entstammen. ${ }^{2}$ ) Ähnlich liegen die Verhältnisse auch bei der Diplomatie. Zugegeben, daB hier behördlicherseits eine übermäßig starke Bevorzugung des Adels stattfindet. Zugegeben ebenfalls, daß ein wenn auch nicht übermäBig hoher Bruchteil dieser Nobili dem neuen Geldadel sowie dem Chargenadel angehört. Die These von der Dekadenz des Adels hingegen könnte nur dann mit Erfolg verfochten werden, wenn es gelänge, diesen Offizieren und Beamten Unfähigkeit im Beruf nachzuweisen.

- Die Annahme von der Dekadenz des Adels hat manche empirischen Ursachen. Der Reisende, der in den alten vornehmen Städten Italiens an den herrlichen Palästen bewunderungstrunken vorbeigeht, ist aufs äußerste erstaunt, ja peinlich berührt, wenn er erfährt, daß fast alle diese großartigen Bauten,

I) T. W., „Briefe eines Negerdiplomaten“. Berliner Tageblatt XLII, Nr. 21 .

2) Berliner Tageblatt XXXVIII, Nr. 4 I.

Michels: Probleme der Sozialphilosophie 
I 46 VIII. Zum Problem der zeitlichen Widerstandsfähigkeit usw.

von denen mehrere für sich allein eine größere Geschichte aufweisen als manche Großstadt des Nordens, nicht mehr in den Händen der Familie befindlich seien, sondern der eine einem jüdischen Bankier, der andere einemRentner aus Amerika, der dritte einer Bank oder einer Aktiengesellschaft gehört. Aus dieser an und für sich richtigen Tatsache ist in hellem Eifer die Folgerung von der völligen Dekadenz und Verarmung des Adels gezogen worden. Es ist unbestreitbar, daß selbige in vielen Einzelfällen zutrifft. Vielfach haben in der Tat die Söhne die herrlichen Besitztümer derVäter nicht zu halten vermocht und es vorgezogen, den Palast der Ahnen günstig zu verkaufen und sich eine bescheidenere Wohnstätte auszusuchen. Aber Verarmung war nicht die einzige Quelle für die richtig konstatierte Erscheinung. Um das zu verstehen, genügt es, die Entwicklung der modernen Städte zu beob. achten. Durch die baulichen Veränderungen und die Ausdehnungstendenzen, denen sie unterliegen, ist häufig ihr Zentrum verschoben: die, welche ehemals die elegantesten und vornehmsten Viertel waren, sind heute Kaufmannsviertel (Paris: le Marais!) oder gar Armenviertel geworden. Auch die Hygiene hat ein Wort mitgeredet, und nicht zuletzt die Mode und der Snobismus. Alle diese Elemente haben dahin zusammengewirkt, daß der patrizische Adel seine alten, ungesunden, oder doch nicht mehr komfortablen Stadthäuser verlassen und sich, dem Zuge der Zeit folgend, an der Peripherie, im Villenviertel neue Häuser gebaut hat. Man mag das in vielen Fällen pietätlos und geschmacklos schelten und guten Rechtes behaupten, daß die neuen Behausungen an innerer patriarchalischer Sicherheit und Vornehmheit zumeist weit hinter den alten Palazzi zurückstehen. ${ }^{\text {) }}$ Ein

I) Einen typischen Beweis für diese Behauptung liefern die sogenannten Patrizier in Köln, die heute fast bis auf den letzten Rest die alten, ruhigen und vornehmen Häuser im Stadtinnern verkauft und sich am "Ring" oder gar auf dem flachen Lande neu angekauft haben. 
Zeichen von Armut aber ist der Wechsel nicht. Die neuen Villen geben den alten Häusern an Glanz und Reichtum nichts nach; sie übertreffen sie sogar an solchem bisweilen bei weitem.

Wenn wir die Namen der Offiziere der preuBischen Garderegimenter in der "Rangliste" nachlesen, können wir mühelos konstatieren, daß die großen Familien des preußischen Grundbesitzes und der preußischen Beamtenschaft, die zu Zeiten Friedrichs des Großen und der Befreiungskriege an der Spitze des preuBischen Volkes standen, noch nahezu vollzählig zur Stelle sind. Und zwar ohne daß sie an politischer oder ökonomischer Schwerkraft Einbuße erlitten hätten. Letzteres mag aus derTatsache, daß sie ihre Söhne in die vornehmsten und teuersten Regimenter senden, ersteres aus der Tatsache, daß aus diesen Familien sich vorzugsweise die hohe Generalität des deutschen Heeres ergänzt, ersehen werden. Ähnliches läßt sich, mutatis mutandis, für Italien, Spanien, Dänemark, Rußland, England, Ungarn konstatieren. Noch heute liegt dieVertretung vieler der bedeutendsten Länder und Städte in den Händen von alten, zum Teil ältesten Geschlechtern entstammenden Männern. In Venedig ist ein Grimani Oberbürgermeister, in Florenz ein Corsini, ein Wahlkreis von Rom ist im Parlament von einem Caetani, ein anderer war bis vor kurzem von einem Borghese vertreten. Die deutsche Diplomatie wird fast durchweg von Männern ältesten Adels geleitet, in der englischen Regierung sitzt zurzeit ein Churchill. Neben den Herren vom Feudaladel treffen wir in den höchsten Stellen der Regierung freilich bereits Männer aus dem Neuadel und aus dem Bürgerstande an. Immerhin scheint mir die These unbeweisbar, die auch kürzlich wieder, mit geschickten Beispielen verteidigt, von Hans Kurella aufgestellt worden ist, daß nämlich ,die Nachkommen der im Mittelaiter zur Herrschaft gelangten Geschlechter zu Zeiten schneller politischer oder wirtschaftlicher Umgestaltung nicht in leitende Stellungen gelangen, wenn ihnen nicht aus der Sphäre der 
I 48 VIII. Zum Problem der zeitlichen Widerstandsfähigkeit usw.

kaufmännischen oder verwaltenden Begabung neues Blut zuflieBt". 1 )

Indes, das noch gegenwärtige Vorhandensein des alten, wenn auch nicht des ältesten Adels bedeutet mehr die Konservierung alter Familien denn die Konservierung alter Aristokratie. Denn alte Familien können sehr wohl im Laufe der Jahrhunderte bestehen bleiben und an Glanz, Reichtum und sozialem Einfluß sogar zunehmen, aber durch ständige heterogene Heiraten so sehr ihr Blut geändert haben, daß sie als Gesamtheit betrachtet nicht mehr den gleichen anthropologischen wie mentalen Typus bilden wie vor hundert Jahren. Ein Beispiel möge das Gesagte illustrieren: Wenn ein Graf Isenplitz nach der Emanzipation der Juden in PreuBen im Jahre 1820 ein Fräulein Salomon heiratete, der aus dieser Ehe geborene Sohn I 846 die Tochter des Rostocker Universitätsprofessors Dr. Emmanuel Kurz ehelichte, der Sprößling dieser Ehe sich 1873 mit der süddeutschen Verlagsbuchhändlerstochter Fräulein Müller vermählte, und deren SpröBling I 897 sich wieder ein Fräulein Cohn oder Cohen zur Gattin auserwählte, so wird deren Sohn, der I 9 I 3 als Avantageur bei den Gardekürassieren eintritt, zwar äuberlich, also bezüglich des Namens und Titels, dem uradligen Urgroßvater gleichen und an finanzieller Potentialität ihn wahrscheinlich noch übertreffen; es ist aber unleugbar, dab der Graf Isenplitz von I9I 3 nur den sechzehnten Teil des adligen Geblütes seines Vorfahren aus dem Jahre 1820 besitzt. Die übrigen Abstammungsteile $\left({ }^{15} / 16\right)$ sind unaristokratischer, ja zum Teil unarischer Herkunft. Mit anderen Worten: Die Adelsfamilie hat sich zwar dem Namen und der Stellung nach hundert Jahre erhalten, aber es ist doch anthropologisch ein völlig anders gearteter, ganz anderen Kreisen angehöriger Mann, der I9I3 die Familie

I) H. Kurella, „Die Intellektuellen und die Gesellschaft. Beitrag zur Naturgeschichte begabter Familien". Wiesbaden 1913. Berg. mann, p. 22/23. 
vertritt. Le nom est resté le même, la chose a changé à fonds.

Nun wird man sich aber vor der Tatsache nicht verschließen können, daß Tausende und aber Tausende altadliger Familien in allen Ländern Mittel- und Westeuropas einen ähnlichen Entwicklungsgang durchgemacht haben. Die Vermischung des Adels mit Familien der Bourgeoisie, insbesondere der Plutokratie und des Judentums, ist in vielen Ländern bereits Tatsache geworden; so, Kennern zufolge, in großem Umfang in Frankreich. ${ }^{1}$ ) Um große Bestandteile des deutschen und des ungarischen Adels steht es ähnlich. Mit anderen Worten: Wenn einstens gelten konnte, daß der Adel durch lang fortgesetzte Zuchtehe und die Zugehörigkeit zu den stets gleichen Berufssphären auch im Äußeren, in der geistigen wie leiblichen Beschaffenheit, gewisse anthropologische Charakteristiken aufwies, die manchenorts noch durch seinen von den übrigen Volksgenossen ethnisch verschiedenen Ursprung als einer Schicht von Eroberern verstärkt wurden, so ist das heute nur noch in geringem Umfange der Fall. Der Adel existiert zwar noch in den gleichen Familien, aber die Mütter eines großen Teiles derselben entstammen seit mehreren Generationen nicht mehr der aristokratischen, sondern der demokratischen Gesellschaftssphäre. Das Endresultat dieser genealogischen Tatsache ist, daß einem großen Teil des heutigen Adels der ihm ehemals angeborene Typ abhanden gekommen ist: der Graf Isenplitz weist heute eine Körperstruktur, eine Nasenlänge, eine Physiognomik und ein Gebärdenspiel auf, die sich von denen - je nachdem - des Herrn Müller oder des Herrn Cohn nicht mehr wesentlich unterscheiden.

Die Theorie von dem Wechsel der oberen Klassen, der Circulation des Élites, muß demnach nach zwei Richtungen

I) G. De Contenson, „L'Avenir du Patriotisme“. Paris I9ıo. Bibl. des Saints-Pères, p. I 7 I. 
I 50 VIII. Zum Problem der zeitlichen Widerstandsfähigkeit usw.

hin korrigiert werden: die alte Aristokratie verschwindet nicht, taucht nicht unter, wird nicht proletarisch, verarmt nicht einmal (wenigstens nicht absolut genommen), macht nicht neuen Herrschergruppen „Platz“, sondern bleibt an der Spitze der Nationen, die sie jahrhundertelang leitete, stehen. Aber sie wird erstens in sich selbst geändert, verliert, ganz oder zum Teil, ihr durch in der gleichen Kaste betriebene Inzucht erworbenes und lange Zeit durch Sitte und Gesetz intakt erhaltenes Sonderblut, ihre Pureté de sang, und unterscheidet sich nunmehr von den sozial niedriger Stehenden nur noch durch den höheren Einfluß auf Staat und Gesellschaft. Kurz, der Adel ist nicht mehr eine juridisch und anthropologisch differenzierte Klasse, sondern nur noch eine gesellschaftlich differenzierte Klasse. Zweitens aber übt die alte, und selbst die verjüngte Aristokratie die Herrschaft nicht mehr allein aus, sondern ist genötigt, sie mit allerhand neuen Herrscherschichten zu teilen: frischem Beamtenadel, geadelten oder ungeadelten Plutokraten, getauften oder ungetauften Kleiderjuden, ja bisweilen selbst mit gekämmten oder ungekämmten Gelehrten. Kurz, heute gesellt sich zu der in sich bereits in hohem Grade alterierten Geburtsaristokratie eine mehr oder weniger anpassungsfähige Geldaristokratie, Rangaristokratie und Geistesaristokratie. Sie alle zusammen machen die Aristokratie im Sinne der herrschenden Klasse aus. Immer neue Elemente dringen in die ehemals feudale Aristokratie ein, drängen sich ihr auf, einen Platz neben ihr an der Sonne beanspruchend.

Aber wenn er auch nicht mit der Aristokratie zusammenfällt, sondern nur einen Teil von ihr ausmacht, bemächtigt sich der Adel doch allmählich ihrer, durchdringt sie, erobert sie, drückt ihr den Stempel seiner moralischen und intellektuellen Wesenheit auf. Schon zu Zeiten des großen Ludwig kannte nicht nur die neugebackene Bourgeoisie, sondern selbst die Noblesse de robe keinen höheren Ehrgeiz, als durch intimen Umgang mit der Noblesse d'épée sozial zu ge- 
innen. In welchen Formen sich dieser Prozeß abspielte, ist in umoristischer Form in Molières unsterblichem Lustspiel „Le ourgeois-Gentilhomme", in ernsterer Form in den ausgesichneten Memoiren des Abbé de Choisy nachzulesen. ${ }^{1}$ ) Im eutigen Deutschland können wir die gleiche Beobachtung lachen: es gibt keine gesellschaftlich selbständige, auf sich olze Bourgeoisie. Die deutsche Bourgeoisie ist in ihren pitzen nur eine Vorstufe zum Adel. Ihre höchste Aspiraon geht dahin, erst vom Adel aufgenommen zu werden, $m$ dann in ihm aufzugehen. ${ }^{2}$ ) Das betrifft zumal die sogeannt patrizischen Familien, die auf eine, wenn auch überwieend kaufmännische, ältere Vergangenheit zurückblicken und ch auf bedeuten de finanzielle Mittel stützen können. AmRhein at der Veradeligungsprozeß bereits mächtig eingesetzt.

Der Adel, überschwemmt durch zumeist finanziellen Ursrung verratenden Neuadel ohne adlige Vergangenheit und, um Teil, ohne aristokratische Manieren und Lebensformen nd seiner alten Vorrechte bis auf den Rest der Majoratsnd Fideikommikgesetzgebung und das ungeschriebene Vorzcht der fast exklusiven Besetzung der Stellen der Diplotatie und der obersten Ränge in Heer und Verwaltung bezubt, ist heute sozusagen entklassiert. Mit anderen Worten, r macht heute keinen Stand mehr aus, weil er keine allemein gültige gesetzliche Sonderstellung mehr besitzt, und eine Klasse mehr aus, weil er noch weniger irgendwelche irtschaftliche Konturen aufzuweisen vermag. Daher muß enn die Schaffung einer allgemeinen wirtschaftlichen Basis ls erster, notwendiger Schritt empfunden werden, den durch ie Demokratie differenzierten, ja volatilisierten Adel wieder u einigen und zu konsolidieren.

I) Abbé de Choisy, „Mémoires pour servir à l'histoire de ouis XIV“. Utrecht 1727. Van de Water, p. 23.

2) Über die Amalgamierung alter und neuer Herrscherschichten isführlicher in meiner Soziologie des Parteiwesens, 1. c., p. I $5 \mathrm{ff}$. $183 \mathrm{ff}$. 
Der alte Adel hat es an Absonderungsversuchen dem neuen Adel gegenüber nicht fehlen lassen. Es ist ihm zum klaren BewuBtsein gekommen, daß, seitdem die Reinheit seines Blutes nicht mehr gesetzlich geschützt ist, der Adel als Rasse Gefahr läuft, unterzugehen. Es ist ihm zugleich auch nicht entgangen, daß die seit der Französischen Revolution bis auf den letzten, freilich noch beträchtlichen, aber schon nicht mehr in allen Ländern vorhandenen Rest der Majorats- und Fideikommißgesetzgebung erfolgte Abschaffung der Sonderrechte der Primogenitur seine finanzielle Kraft arg parzelliert hat. Er empfand es schmerzlich, dab der Einzug von Beamtenadel, Gelehrtenadel und Geldadel mit dem tönenden, wenn auch tönernen Geräusch der ihm verliehenen Titel und den Namen, die sich von den seinigen häufig nicht unterscheiden ließen, ihn in das Heer des Neuadels, der Roture von gestern, einrangierte und ihm die einzige Prärogative, die aus dem Namen mit untrüglicher Sicherheit hervorgehende adlige Vergangenheit, verschleierte. Es sind deshalb im Schoße des alten Adels häufig Stimmen laut geworden, die einer Regenerierung der Aristokratie das Wort reden. So meint z. B. in Italien der einem reichsunmittelbaren Uradelsgeschlechte angehörige Francesco Guasco in seinem Vorwort zu einem vielbändigen Lexikon des piemontesischen Feudaladels ${ }^{1}$ ): Es müsse bereits im Namen zum Ausdruck kommen, ob die Familie jemals ein Feudum besessen habe oder nicht; ob der Familienname mit dem Feudum zusammenfalle, ein Umstand, der auf dieWahrscheinlichkeit alten, ehemals mit Jurisdiktionsrechten behafteten Adels schließen lasse, oder ob der ursprünglich bürgerlichen Familie nur das Recht auf einen Adelstitel und einen dem beibehaltenen bürgerlichen Namen hinzugefügten, aber rein dekorati-

1) Francesco Guasco (Marchese Francesco Guasco di Bisio), „Dizionario Feudale degli Antichi Stati Sardi e della Lombardia dall' Epoca Carolingica ai nostri tempi"“. Vol. I. Pinerolo I9I I. Chiantore e Mascarelli. 
ven Feudalnamen (Ortsnamen) verliehen wurde, was auf neuen, nach I 8 I 5 erworbenen Adel schließen lasse. Kurz, es solle schon in der Namensführung zum Ausdruck kommen, ob der Adel Stand oder lediglich Prädikat bedeute. So z. B. sei es geboten, daß der Marchese Luigi Medici del Vascello, dessen Vorfahren einfach Medici geheißen und später den Titel Marchese und das Anhängsel del Vascello, aber ohne Besitz und Feudalrecht, erhielten, im Namen das Wort Medici stets als Erkennungszeichen mitführe. Dieser habe somit nicht die geringste Befugnis, sich Marchese Luigi del Vascello, was ein wirklich feudaler alter Adelsname sein würde, zu nennen. Ja, er dürfe sich nicht einmal als Marchese Luigi Medici bezeichnen, sondern er müsse die Worte Medici del Vascello, bürgerlichen Namen und verliehenes Anhängsel, stets unzertrennlich im Namen führen, da nur dadurch die Herkunft der Familie ersichtlich sei. Der Name würde dabei folgendermaßen zu analysieren sein. Titel: Marchese, Vorname: Luigi; Name: Medici; Prädikat: del Vascello. ${ }^{1}$ ) Altadlig, feudaladlig dagegen sei nur der, bei welchem Name (Familienname) und Prädikat von Rechts wegen zusammenfalle, z. B. Marchese Vittorio Saluzzo, d. h. Vittorio, mit dem Titel Marchese, aus der Familie der alten Herren des Ortes Saluzzo. Es erhellt, daß die kürzeren Namen demnach was zu begreifen den Profanen unter den Bürgerlichen, in deren Augen die Vornehmheit eines adligen Namens mit dessen Länge zunimmt, schwer fallen mag — vielfach die besten und ältesten in der Aristokratie wären. Guasco sagt: nur die Familien, welche ehemals das Recht der Jurisdiktion ausübten, dürfen den Namen der von ihnen innegehabten Feuden unmittelbar hinter ihrem Adelstitel oder dem Taufnamen oder auch, je nach Belieben, allen beiden, führen. Dieses Vorrecht sei als fügliches Andenken an den Besitz

I) Die Analogie mit deutschen Namen wie z. B. Heyl von Herrnsheim ist ohne weiteres klar. 
I 54 VIII. Zum Problem der zeitlichen Widerstandsfähigkeit usw.

der Herrenrechte, mit denen einst ihre Familien belehnt waren, aufzufassen. ${ }^{1}$ ) Solchen Forderungen liegt die Zurückführung des Adels auf den Feudalbegriff zugrunde. ${ }^{2}$ )

Aus diesem Feudalbegriff des Adels ergibt sich noch eine weitere Reihe von Forderungen.

I. Die desVerbotes der ausschließlichen Benennung nach dem Feudum auch für die Brüder und Söhne des Familienoberhauptes. Das wird ohne weiteres klar, wenn wir uns in die Zeiten der feudalen Jurisdiktion zurückversetzen. Der Adelsname, der den Besitz eines bestimmten Ortes usw. angibt, steht weder den Brüdern noch den Söhnen des noch lebenden - souveränen, herrschenden - Caput familiae zu, sondern ausschließlich dem Belehnten.

2. Den Töchtern des Adelshauses kommt lediglich der Familienname, aber nicht der Titel zu. Sie erheiraten dann allerdings Titel und Würden des Ehemanns, verlieren diese aber als Witwe wieder. ${ }^{3}$ )

Derartige Bestrebungen sind zugleich aristokratisch und demokratisch, je nach der Art der Betrachtungsweise. Aristokratisch, weil sie aus durchaus aristokratischem Geiste geboren sind. Schon die Beschäftigung mit derlei Problemen setzt bereits das Vorhandensein aristokratischen Standesbewußtseins voraus. Aber nicht nur der Geist, auch der Wille, nicht nur der Ausgangspunkt, auch der Endpunkt ist aristokratisch, gilt es doch die Erzielung der Erhaltung bzw. Neuentfaltung auf alter Grundlage, des alten Herrenstandes. Der Franzose würde sagen: le renouveau de la classe sei-

I) Guasco, 1. c., p. X.

2) Die Verachtung des neuen Adels kommt bei Guasco auch dadurch zum Ausdruck, daß er im V. Bd. auf p. 23 I 5 ff. die neuen, seit I8I 5 betitelten Adelsgeschlechter aufzählt, indem er, boshaft genug, den Beruf des Betitelten (Händler in Knöpfen, Kammerdiener), oft auch die Rasse ("Jude“, merkwürdigerweise nur vier Geschlechter [Levi dei Veali, zwei Ottolenghi und Weill-Weiss] unter 400), angibt.

3) Guasco, p. XIII. 
gneuriale. Und zwar durch Anknüpfung an die alte Geburtsstätte des Feudaladels: an den feudalen Landbesitz und den aus ihm abgeleiteten Namen und Titel. Kein Zweifel, das Beschreiten des von Guasco angegebenen Weges würde zur Wiederherstellung der Peerage führen, wie sie heute nur England noch besitzt.

Jedoch die aristokratische Auslese, die, wenn auch nach rein äußerlichen Gesichtspunkten betrieben, sich als Folge der Reformvorschläge einstellen würde, müßte doch wieder auch demokratische Rückwirkungen hervorrufen. Der Adel würde durch sie dezimiert werden. Die große Mehrzahl der Adligen würde des Adels als solchen verlustig gehen, entadligt werden: ein grausames Schicksal, wie es radikaler kaum ein achtundvierziger Volksmann hätte ausdenken können. Was vom Adel übrigbliebe, würde in zwei schon dem $\mathrm{Na-}$ men nach erkenntliche Klassen geteilt werden: den alten Adel aus der Zeit, in welcher der Adel noch ein Stand war, den neuen Adel, dessen Adel nur Prädikat ist.

Gleichzeitig erscheint es vom Feudalstandpunkt aus auch als gegeben, der englischen Sitte der Primogenitur, wenn auch nicht mehr auf wirtschaftlichem, so doch in Ermangelung besserer Mittel zur Erreichung des Zweckes auf einem revisionistischen Wege wieder zu ihrem ehemaligen Glanze zu verhelfen. Es wird gefordert, daß, wo nicht alte verbriefte Rechte den Söhnen einer fürstlichen, gräflichen usw. Familie unterschiedslos den Titel des Vaters als Familienerbteil gewährleisten oder vermachen, oder doch nach der Geuitur abgestufte, unterschiedene Adelsprädikate üblich sind, nach dem Tode des Vaters der Titel lediglich in den Besitz des ältesten Sohnes übergehen soll. Zu Lebzeiten des Vaters aber soll überhaupt keiner der Söhne Recht auf dessen Titel besitzen. Eine logische Folgerung für wen immer, der den Adel als im, wenn auch duodezimal geschwächten, Besitz souveräner Rechte befindlich betrachtet. Ebenso wie nicht alle Söhne des Königs von Preußen nach dem Ableben desselben 
I 56 VIII. Zum Problem der zeitlichen Widerstandsfähigkeit usw.

König von Preußen werden können, so ist es dieser Logik zur Folge absurd, wenn sich die Söhne des Grafen Kielmannsegg nach dem Tode des Familienoberhauptes alle Grafen Kielmannsegg nennen. Was dem einen recht ist, ist dem anderen billig. Denn beide, Adel und Königtum müssen, da ihr Ursprung der gleiche, durch das gleiche Prinzip bestimmt werden. ${ }^{1}$ ) Reformversuche wie die des Marchese Guasco sind natürlich trotz ihrer inneren Logik von vornherein dazu bestimmt, auf die Verwirklichung zu verzichten. Die heutige Zeit, und der übergroße Teil des heutigen Adels selbst, wertet im Adel die Titulatur, nicht das ursprüngliche feudale Element. Die Reformen Guascos setzen zudem eine Art politischer Restauration voraus, wie sie selbst die Mächte der Heiligen Allianz nicht einzuführen gewagt haben. Die heutigen Zeiten, die im Zeichen der Arbeiterbewegung stehen, sind solchen Problemen besonders abgeneigt. Der moderne Adel selbst aber findet zu solchen, seine eigenen Scharen schwer schädigenden Experimenten keine Kräfte mehr.

Indes bedeutet die Metamorphose des Adels durchaus nicht dessen gesellschaftliche Unwirksamkeit. In den Salons ist der Adel immer noch richtunggebend, wo immer es überhaupt Adel gibt. Der alte Adel erweist seine ihm immanente Anziehungskraft, deren Ätiologie wir hier nicht auseinandersetzen können, selbst dann noch, wenn er von den Regierungsgeschäften verdrängt ist. Nirgends ist die politische Macht des Adels als politische Kaste so zusammengebrochen als in Frankreich. Von dem Blutbad, in das der erste französische Stand in der großen Revolution getaucht wurde, hat

I) Noch unmöglicher sind dementsprechend natürlich die Titulaturen diminutiven Charakters, wie sie in den Familien z. B. des italienischen Adels den Kindern gegenüber gang und gäbe sind: contino, contessina, marchesino, marchesina. Sie sind rein willkürlichen Charakters und logisch unzulässig. 
er sich noch heute nicht erholt. Tausende der alten Familien sind damals ausgerottet worden. Was übrigblieb, sah sich, trotz der von den rückgekehrten Bourbonen ausgezahlten Emigrantenentschädigung, ökonomisch geschwächt und sozial vom Staate preisgegeben. Offiziell ist gegenwärtig der Adel in Frankreich abgeschafft; er genießt keinerlei Schutzes. Wer unbefugt ein Adelsprädikat annimmt, geht straflos aus. Trotz dieser staatlichen Entwertung des Adels sehen wir in Frankreich unter den guten und reichen Familien des Bürgertums, insbesondere in den Provinzen, eine Tendenz zur Nobilitation, die natürlich mangels einer zuständigen Instanz durch die Interessierten selbst erfolgt, auf kommen. Mit andernWorten, es entsteht in Frankreich selbsttätig ein neuer Adel selbsternannter Grafen und Marquis. Man sollte nun meinen, diese Karikatur des Adels bedeute den Todesstoß für den alten Adel. Das Gegenteil trifft zu. Wie uns der Vicomte d'Avenel in einem geistreichen Büchlein zu erzählen weiß und wie jeder Kenner französischen Gesellschaftslebens bezeugen kann, drängt dieser neue selbstgeschaffene Adel nach Anerkennung seitens des alten authentischen Adels. Indes diese Anerkennung wird ihm nur dann zuteil, wenn er sich Sitten und Manieren, Lebensgang und Anschauung des alten Feudaladels angeeignet hat, ihm ähnlich geworden ist, wie ein Ei dem andern. ${ }^{1}$ ) Auf diese Weise besteht also eine Art von Selbstverteidigung des alten Adels: er prägt, kraft seines alten, ewig jungen Prestiges und der Eleganz und Sicherheit seiner Lebensformen, den neuen Schichten der Aristokratie seinen Stempel auf und läßt sich von ihnen neues Geld und neues Blut zuführén.

Das Resultat dieser Entwicklung könnte man folgendermaßen zusammenfassen: die neuen Mächte, die aus dem sozialen Hexenkessel emporsteigen, nehmen, kaum an

1) Vicomte Georges d'Avenel, „Les Français de mon Temps". Paris 1904. Nelson, p. I08 ff. 
die Oberfläche gelangt, die Färbung der oberen Schicht an, die sie dort vorfinden. Die Anziehungskraft der alten Herrscherkaste ist so groß, daß sie sich alle jungen Mitteilhaber an der Macht in kurzer Zeitspanne assimiliert. Das adlige Noviziat aber hat, wie alle Noviziate, den inneren Drang, seine Zugehörigkeit zur alten Aristokratie durch das mit doppeltem Eifer betriebene Bestreben zu beweisen, den traditionellen Ideengehalt der alten Herrscherschicht sich $z u$ eigen $\mathrm{zu}$ machen, intakt $\mathrm{zu}$ erhalten und eifersüchtig vor jeder Infiltration neuer geistiger Elemente zu bewahren. So sorgt das Eindringen physisch heterogener Elemente in den Adel für die psychische Integrität der Adelsmentalität.

Adel und Aristokratie fallen nicht völlig zusammen. Gewiß gehört der Adel fast insgesamt zur Aristokratie, aber er deckt sich nicht mit ihr. Er macht von ihr nur einen Teil aus. Der Adel hält sich „am Ruder", es fällt ihm nirgends ein, vom Schauplatz der Geschichte zu verschwinden. Aber er kann das nur, indem er seine Reinheit preisgibt und ständig neue Elemente in sich aufnimmt. Er geht bei diesem Anpassungsprozeß aller physischen Charakteristiken verlustig. Indes gelingt es ihm, aus der Fusion psychisch als Sieger hervorzugehen und sein Wesen auf die heterogenen Elemente zu übertragen. Wir wissen nicht, ob es ein historisches Gesetz ist. Aber wir wissen, daB heute der Adel die Aristokratie bestimmt, sich ihrer bemächtigt und sie nach seinem Geiste formt.

\section{Neuntes Kapitel.}

\section{Zum Problem der internationalen Bourgeoisie.}

Wir sind uns sehr wohl bewußt, daß wir uns in diesem Kapitel eine unmögliche Aufgabe stellen. Wir werden in ihm nicht mehr geben können als einzelne Schlaglichter, einzelne Bilder, indem wir aus dem unentwirrbaren Gewirr 
der nationalen Sonderheiten der internationalen Bourgeoisie einige besonders charakteristische Züge vorsichtig herausheben und beleuchten.

Das Kapitel soll die Psychologie der Bourgeoisie in den verschiedenen nationalen Verbänden behandeln. Es enthält demnach sozusagen von vornherein zwei Unbekannte: Nation und Klasse. Heinrich Heine, der ewig grobe Dichter, hat einmal in seinen Reisebriefen über Polen gesagt, es sei ungemein schwer, ein Volk zu charakterisieren, denn, setzte er hinzu, es gehöre mehr als ein ganzes Menschenalter dazu, um auch nur einen einzigen Menschen, auch nur die Psychologie eines einzigen Individuums, genau kennen zu lernen. Diese Bemerkung trifft überall $\mathrm{zu}$, besonders aber dort, wo es sich darum handeln muß, große Massen, seien es ethnische Aggregate oder wirtschaftliche Gruppen, willkürlich zusammenzufassen, unter Sammelbegriffe zu bringen, und sie dann kollektiv zu beurteilen. Über alle Maßen schwierig wird diese Charakterisierung aber in unserem Falle, wo es sich um zwei Massenbezeichnungen handelt.

Was ist Bourgeoisie? Was ist das Kriterium, vermittelst dessen wir feststellen können, ob diese oder jene Gesellschaftsschicht zur Bourgeoisie gehöre? Wir leben heute in einer Zeit, in welcher der Übergang vom kleinen und vom mittleren Betrieb zum Großbetrieb sich, im Gewerbe wenigstens, mit immer wachsender Schnelligkeit vollzieht, in einer Zeit, wo die Agrarverhältnisse, wenn wir Europa in seiner Gesamtheit betrachten, an Schwergewicht für das Volksganze immer mehr zurückstehen und die Industrie immer mehr in den Vordergrund tritt. Industrie, und zwar zentralisierte, akkumulierte Industrie. Mit anderen Worten, wir leben in einer Epoche, in der die Arbeitermassen stärker und stärker anwachsen. Auch die Bourgeoisie wächst an Zahl ihrer Angehörigen. Aber die Statistik zeigt, daß das Anwachsen der handarbeitenden Bestandteile eines jeden Volkes in einem beträchtlich schnelleren Tempo erfolgt als das An- 
I60 IX. Zum Problem der internationalen Bourgeoisie

wachsen der oberen Schichten desselben Volkes. In einer derartigen Übergangszeit, wo die Lohnfrage, die Arbeiterfrage, immer mehr die politische Tagesordnung beherrscht, in einer Zeit, wo die arbeitenden Klassen in immer größeren Gegensatz, und zwar einen vorzugsweise wirtschaftlichen Gegensatz, zu den oberen Klassen geraten, ist es sehr verständlich, wenn viele sagen, der Gradmesser für die Bildung der wirtschaftlichen Klassen sei ihr Verhältnis zur Produktion oder vielmehr ihre Stellung in der Produktion, ihr Verhältnis zu den Produktionsmitteln. ${ }^{1}$ ) Schon längst ist ein Karl Marx erstanden, gefolgt von einer Reihe von Jüngern, die erklärt haben, alle diejenigen Teile des Volkes, die die Produktionswerkzeuge und damit die politische und wirtschaftliche Macht in Händen haben, gehörten zur Bourgeoisie, während anderseits die übrigen Volksteile, welche am Besitz der Produktionsmittel keinen Teil haben, dagegen aber, wie es die heutige Produktionstechnik verlangt, gezwungen sind, sich dieser Mittel, die einem anderen gehören, zu bedienen, und die infolgedessen in eine Art Leibeigenschaft und Botmäßigkeit diesem letzteren gegenüber geraten, zum Proletariat gehören. Es ist ohne weiteres zuzugeben, daß eine derartige Auffassung, ein derartiges Kriterium zur Scheidung der wirtschaftlichen Klassen in der Mehrzahl der Fälle zutreffend sein wird. Aber wir haben im Wirtschaftsleben doch eine Unmenge von Nuancen, von $Z$ wischengliedern, und es ist deshalb vollständig unmöglich, wissenschaftlich mit diesem Kriterium allein überall auszukommen. Der Direktor einer großen Fabrik ist ein Angestellter, ein Beamter der Fabrik, kein Arbeitgeber, sondern ein Arbeitnehmer. Er ist ein Lohnempfänger. Er empfängt unter Umständen allerdings einen Lohn von 40000 Mark, und es schlagen sich um solche Posten bekanntlich selbst Minister, die, um eine derartige Lohnarbeiterstelle

1) Vgl. p. 12-13 dieses Buches. 
einnehmen zu können, sogar um ihren Abschied aus dem Staatsdienste einkommen und auf die damit verbundenen hohen und höchsten Ehrungen Verzicht leisten. Ein solcher Mann wäre nun nach der gegebenen Definition kein Bourgeois, sondern ein Proletarier. Er gehörte nicht in die Kategorie der Besitzer der Arbeitsmittel, sondern in die Kategorie der Besitzlosen, der Abhängigen, der Lohnarbeiter. Andererseits wissen wir, wie viele unserer kleinen Bauern, die ein kleines Äckerchen besitzen, das nur einen minimalen Ertrag, geringer als der Durchschnittserwerb eines Lohnarbeiters, abwirft, sehr häufig sich einbilden, kraft dieses Besitzes, also kraft ihres Eigentums an einem Produktionsmittel, an Land, nicht zum Proletariat, sondern zur Bourgeoise zu gehören und denen der industriellen Arbeiterschaft entgegengesetzte Interessen zu haben. Wir sehen hier: Bourgeoisie?, Proletariat?, die Grenzlinien sind schwer festzulegen, vielmehr in jedem Falle, bei jedem einzelnen wirtschaftlichen Individuum besonders zu bestimmen. Darum wäre es natürlich eine unendliche Arbeit, wollten wir hier auch nur über das Problem der sozialen Klassen reden. Wir müssen uns deshalb darauf beschränken, auf die diesem Problem zugrunde liegenden Schwierigkeiten hinzuweisen, ohne den Versuch zu wagen, sie zu beseitigen. ${ }^{1}$ )

Auch über das zweite Problem, das der Nation, können wir hier nur leise Andeutungen machen, um so mehr, als wir es an anderer Stelle ausführlich zu behandeln gedenken.') Die herrschende Schicht jeden Landes, jeden Volkes, jeder Nation weist ökonomisch ähnliche Züge auf. Wir wissen alle, - und die Wissenschaft ist durchdrungen von der Wahrheit dieser Marxschen These, — daB das wirtschaftlicheVerhalten der Bourgeoisie gegenüber dem Proletariat nur

I) Vgl. unsere Ausführungen auf p. 29-30 dieses Buches.

2) Über den Begriff der Nation und die Bildung des Vaterlandsgedankens verweise ich auf mein Werk: „Das Vaterland" (Siebeck, Tübingen 1914). 
eines sein kann: Behauptung der leitenden Stellung im Wirtschaftsleben und daher äuBerster Widerstand gegen die Versuche derArbeiter, in den Prozeß der Erzeugung und Verteilung der Güter Einspruchsrecht zu gewinnen. Und auch das wissen wir, daß dieses Verhalten nicht von der Rassenmischung, nicht von ideologischen Momenten, sondern einzig und allein von ökonomischen Bedingungen und ökonomischen Notwendigkeiten abhängt. Aber andererseits trägt doch die herrschende Schicht in jedem einzelnen Lande sozusagen ihre besondere Physiognomie. Wenn wir näher beobachten, wenn wir nicht die Augen, die Haarfarbe, die Nase allein, sondern die Schädelbildung, die Gesichtsmuskeln, den Grad der physischen Beweglichkeit, die Gesten, das Auftreten, die Art des Anzugs usw. beschauen und das Gespräch in der Muttersprache belauschen, dann werden wir durch den Vergleich der einzelnen Beobachtungsobjekte untereinander ohne weiteres gewahr, daß trotz aller Gleichheit in ihrer Stellung zu den unteren Schichten ihres Volkes zwischen den Bourgeoisien der einzelnen Länder große Unterschiede obwalten. Die Weltauffassung, das persönliche Benehmen, die gesamten geistigen Beziehungen und die physische Charakteristik, alles das ist in der Bourgeoisie der einzelnen Länder verschieden. So kommen wir denn zur Morphologie der Bourgeoisklassen in den einzelnen Ländern. Wir legen uns die Frage vor: worin bestehen die Hauptunterschiede im geistigen und wirtschaftlichen Verhalten der oberen Schichten — um das Wort Bourgeoisie möglichst $\mathrm{zu}$ vermeiden - in den einzelnen Ländern? Wir möchten gleich hinzusetzen, daß wir hier natürlich vorzugsweise von den Nationen sprechen, die wir persönlich kennen, die wir zu studieren Gelegenheit hatten, wie die italienische, die deutsche, die englische, die französische, die amerikanische, und auch von diesen nur insofern ihrWesen der Sphäre unserer Beobachtungen angehört, so daß also alle übrigen Länder aus der Betrachtung ausgeschaltet sind. 
Die nationalen Bourgeoisien sind verschieden in der Art, sich zu geben. Ihre einzelnen Schichten weisen in den einzelnen Ländern sogar eine andere Schichtenlage auf. Ein Beispiel wird das erläutern. In Amerika, wird behauptet, existiere keine Tradition. Die amerikanische Bourgeoisie besitze keine Geschichte und keine Konvention. Diese Ansicht ist nur von bedingter Richtigkeit. Für alle jene Länder und Staaten alter Schöpfung, die Gebiete, welche die europäischen Einwanderer zu einer Zeit betreten haben, in der in Europa noch die feudalen Ansichten stark die Psychologie der herrschenden Schichten belasteten, für die Staaten, in denen sich bereits eine Aristokratie zu entwickeln vermochte, für die Staaten ferner, in denen die europäischen Ureinwanderer nicht aus obdachlosen Proletariern, also nicht aus Elementen, die nach Amerika gekommen waren, um sich ein höheres soziales Piedestal zu schaffen, bestanden, sondern den oberen Schichten der Nationen, aus denen sie stammten, angehörten, trifft jene Behauptung nicht zu. Auch in Amerika besitzt die Tradition ein Gewicht, mit dem gerechnet werden muß. Genau wie in Europa, so besteht auch in Amerika ein sozialer Geltungsunterschied zwischen den Reichen und den Reichgewordenen. Insbesondere in den alten Staaten wird die Aristokratie nicht allein mit der Goldwage gewogen, sondern sie wird auch mit dem, wennschon bürgerlichen, Stammbaum gemessen. Man denke hier besonders an Staaten wie Virginia und Carolina, welche zum Teil von Mitgliedern der englischen Gentry, vom englischen Landadel, einer Schicht, die ihre alte Geschichte in die neue Heimat mitgebracht hat, besiedelt worden sind; ich denke an Louisiana, wo Franzosen, ich denke an Massachusetts, wo englische Puritaner, und zwar eine relativ gebildete Masse, an Kanada, wo im I 7. Jahrhundert französischer Kleinadel hinkam, kurz an alle jene Teile, wo ältere, überwiegend sozial höherstehende Schichten der europäischen Nationen hingekommen sind, - und wir könnten noch ferner auf das besonders wert- 
I64 IX. Zum Problem der internationalen Bourgeoisie

volle Beispiel der holländischen Kolonie Nieuwe-Amsterdam, später New York, verweisen, in dem die alten niederländischen Familien noch heute eine bevorzugte Stellung einnehmen. In allen diesen Staaten herrschen feudale Ansichten, feudale Vorurteile, besteht ein Patriziat. Aber in den Staaten neuerer oder ganz neuer Konstruktion - und diese sind in der Union heute überwiegend - ist allerdings keine Tradition vorhanden. Wohnt doch in allen historisch jungen Ländern dem Gelde im ganzen die größte soziale Durchschlagskraft inne. In Ländèrn jüngster Kultur ist das Geld sogar der einzige Gradmesser sozialer Schätzung. Es ist das einzige Moment, welches in der Wertung der Menschen starkes Gewicht besitzt. Das Geld allein hat soziale Geltung in den neuen Staaten der Union. Der Millionär von drei Millionen Dollar ist als solcher schon ein sozial höher bewerteter Mensch als der Millionär mit nur zweiundeinhalb Millionen, der mit vier Millionen gilt mehr als der mit drei Millionen und beide sind dem zweiundeinhalbfachen Millionär überlegen. Alles ist der Herrschaft des Geldsacks untergeordnet. Selbst in Arbeiterkreisen, ja gerade in ihnen, genießen die Millionäre eine Achtung, in der sich Staunen und Verehrung mischen. Zeitungswesen und vielfach selbst die Justiz sind dem Meistbietenden zugänglich. Die Presse ist angefüllt mit Nachrichten aus dem Privatleben der Finanzkönige, deren tollsten Prassereien und sinnlosesten Verschwendungen mit ehrfurchtsvoller Scheu geschildert werden. Im sozialen Leben Nordamerikas ist im ganzen die Schwerkraft des Geldes entscheidend. Dementsprechend hat die amerikanische Bourgeoisie in ihrer Weltauffassung und in ihrem Auftreten etwas Hartes, Prosaisches, Unpersönliches, Metallisches. Ihre Vitalität ist auf Erwerbssinn, Geldverdienst gestellt. Bildung, Familie, Manieren sind ihr als Elemente zur Einschätzung der Mitmenschen bloß sekundäre Momente.

Wenn wir nunmehr unseren Blick von Amerika abwenden 
und ihn über jene langgestreckte Halbinsel im Mittelländischen Meer, die wir Italien nennen, schweifen lassen, so gewahren wir mühelos, daß dort die Bourgeoisie in ganz anderen Formen auftritt und daB in ihr ganz andere Faktoren Geltungswert besitzen. Wenn in Amerika dem Gelde die vornehmste soziale Durchschlagskraft innewohnt, so sehen wir in Italien Kunst und Bildung im Vordergrund des öffentlichen Lebens stehen. Erst in zweiter Linie kommt das Geld, auch dann nur in gewissen Formen, stark verquickt mit ästhetischen Momenten, daneben zur Geltung. Denn der Reiche ist zwar auch in Italien angesehen, aber mehr als Künstler, vom ästhetischen Standpunkt aus, als ein Mann, der es versteht, in feiner Weise frisches Geld zu erwerben oder ererbtes Geld zu erhalten, oder in feiner Weise Geld auszugeben zu gemeinnützigen $Z$ wecken oder doch zur Kultivierung seines Geistes. Der uomo ricco, der Reiche nach amerikanischem Muster, ohne Bildung, ohne Familientradition, ohne Schliff - ich spreche natürlich immer nur vom Durchschnitt - spielt als solcher in Italien weder eine direkte politische Rolle noch besitzt er irgendwie besonderes soziales Ansehen. Dagegen sehen wir dort das politische Leben beherrscht von Advokaten, Ärzten, Literaten, Universitätsprofessoren, kurzum von den Bestandteilen der Bourgeoisie, welche in sich eine gewisse Bildung, eine gewisse Kultur verkörpern. In Toskana wurde I 904 unter dem Beifall der organisierten Sozialdemokratie der Dichter Gabriele D'Annunzio als Kandidat zu den Wahlen aufgestellt. Das Zentralorgan der Partei bemerkte dazu, daß, obschon er keinerlei politisches Programm aufzuweisen vermöchte, sich für die Sozialdemokratie die Wahl doch rechtfertige, da der Dichter eine ,illustrazione di nostra Terra“ sei $^{1}$ ). Mit anderen Worten: Ästhetik und literarischer Ruhm gehen über Kompetenz. Der Adel als solcher spielt im sozialen Leben Ita-

1) Avanti, XII, 42 . 
I 66 IX. Zum Problem der internationalen Bourgeoisie

liens keine beträchtliche Rolle, besonders wenn man von einzelnen römischen, genuesischen, piemontesischen und venezianischen Verhältnissen absieht. Der Adel hat in Italien als solcher politisch ausgespielt und sieht das Feld seiner Tätigkeit auf einige Spezialgebiete - Hof, Diplomatie, Pferderennen, bonne société — beschränkt. Weder der riccone, noch der nobile zieht in Italien die Angen der Öffentlichkeit auf sich.

Ein treffliches Beispiel für die psychologische Eigenheit der italienischen Bourgeoisie bot das Erdbeben von Messina, das, wie alle Katastrophen, die die Natur erzeugt, das menschliche Sein in seinen tiefsten Tiefen aufwühlte und sämtliche sozialen Verhältnisse durchrührte. Bei dieser Gelegenheit konnte man sehr gute Beweise für die Richtigkeit unserer These finden. Die Mutter Natur, in diesem Falle eine Stiefmutter, hatte keine Klasse, keine soziale Schicht geschont. So haben in Messina etwa 30 Fürsten und Fürstinnen des süditalienischen Hochadels neben einer ganzen Reihe von Millionären und einem Milliardär unter den Trümmern ihrer Paläste ihr Grab gefunden. Die italienische Presse, auch die konservative, hat die Namen dieser Leute nur in den allgemeinen Verlustlisten aufgezählt. Da stand der Name eines Prinzen neben dem eines Signore, der Lastträger im Hafen war. Dagegen regte sich die italienische Presse aller Parteischattierungen darüber auf, ob der bekannte Gaetano Salvèmini, Professor der neueren Geschichte an der Universität, in parteipolitischem Sinne sogar ein als Sozialist tätiger Mann, am Leben geblieben sei. Gleich hinter dem Interesse der öffentlichen Meinung für diesen Hochintellektuellen aber kam die Frage, wie es wohl den Sängern ergangen sei, die in der großen Oper gesungen hatten. Das Interesse der öffentlichen Meinung konzentrierte sich also nicht auf die Bourgeoisie des Geldes oder der Tradition, den Adel, sondern auf die Bourgeoisie der Bildung und der Kunst.

Es sei uns gestattet, zur Psychologie der nationalen Bour- 
geoisien noch ein drittes Beispiel heranzuziehen. Wenn wi nämlich Deutschland betrachten, dann sehen wir, daß, trotz. dem dort unzweifelhaft viel Geld und viel Bildung vorhan. den, trotzdem in der deutschen Bourgeoisie eine ungemeir große Summe von echtem Reichtum und wirklichem Könner anzutreffen ist, im politischen und sozialen Leben der $\mathrm{Na}$. tion weder Bildung noch Geld die größte Durchschlags. kraft besitzen. In Deutschland herrscht noch ganz beson. ders die Tradition vor. Der politischen Konstitution des Landes entsprechend sind es Schichten, die eine Tradition eine Familiengeschichte aufweisen und damit verbunder einen Titel, also der Adel, die Feudalkreise und daneber einige Generationen alte bürgerliche Bureaukratenfamilien welche in Deutschland noch immer das soziale Überge. wicht haben. Gewiß, in England spielt der Adel ebenfalls eine sehr große Rolle. Aber der englische Adel ist mit den deutschen Adel nicht vergleichbar. Die ökonomischen Funk. tionen, die er im Leben der Nation erfüllt, sind von dener des deutschen Adels dem Grad und zum Teil selbst de1 Wesenheit nach verschieden, ja ihnen entgegengesetzt. Ir England hat sich der Adel zweifellos eine soziale Elastizi. tät bewahrt, die ihm seine Privilegien garantiert. Der eng. lische Adel hat sich teils dadurch, daß er sich das Rech der Primogenitur, das Recht der Vermögensvermachung au den Ältesten sicherte, teils aber durch eine ungeheuer ge. schickte Anpassung an die Anforderungen des modernen in. dustriellen Lebens, indem er nämlich spekulierte und in Ge schäften machte wie eine Rotte von Börsenmännern, also ersten؛ auf dem Wege des Erbrechts und zweitens auf dem des mo. dernen Gelderwerbs, selbst in der kapitalistisch-demokrati. schen Entwicklung des Staats- und des politischen Leben: seine Sonderstellung, ja seinen ökonomischen Vorsprung er halten. So gilt im Munde des Volkes in England der noble man gleichzeitig als rich man. Der Adel in England genieß somit die allgemeine Wertschätzung seiner britischen Mitbür 
ger nicht allein wegen der Tradition, die er vertritt, sondern weil er außerdem auch in die kapitalistische Sphäre mit hineingehört. Auch in Italien ist der Adel noch vielfach an. gesehen, indes auch hier nicht wegen der Tradition allein, sondern weil er es verstanden hat, in sich eine Summe von Bildung und von Kunstsinn zu vereinigen, die ihn den Krejsen der intellektuellen Bourgeoisie nähert. Wenn der Adel heute noch in Italien geschätzt wird, so nicht so sehr ob derjenigen seiner Attribute, die ihn von der Bourgeoisie entfernen, nicht ob seiner Ahnen und seiner Geschichte, sondern gerade umgekehrt wegen der Eigenschaften, die er mit der Bourgeoisie gemeinsam hat, nämlich ob seiner Kultur. In der Tat ist in den Städten ein beträchtlicher Bestandteil des italienischen Adels bestrebt, auf den Gebieten der Literatur, der Wissenschaft und der Pflege der Musik hinter dem gebildeten Bürgertum nicht zurückzubleiben. Dagegen liegen in Deutschland die Dinge sehr verschieden. Auch in Deutschland besitzt ein Teil des Adels, besonders auf dem Lande, wo es ihm wirtschaftlich noch gut geht, sicherlich Anteil an den Bildungsgütern seines Volkes. Auch in Deutschland ist die Selbstverständlichkeit eines gewissen Besitzstandes Attribut der Aristokratie. Aber bei alledem ist es doch unbestreitbar, daß der ungebildete und verhungerte Edelmann, àlso einer, der in England wegen seines Hungers und in Italien wegen seiner Unbildung zum Gegenstand des öffentlichen und privaten Hohnes werden würde, und nur so geringe soziale Geltung besäße, daß er aus dem Kurs verschwinden würde, in Deutschland immerhin noch eine gesellschaftliche Rolle spielt. In Italien und England geht der verarmte Edelmann häufig so weit, seinen Adelstitel abzulegen oder doch keinen Gebrauch mehr von ihm zu machen. Dieselbe Schicht Adeliger indes, die es dort vorzieht, bescheiden im Kleinbürgertum unterzutauchen, besitzt in Deutschland immer noch eine gewaltige soziale Stellung und unter allen Schichten der Nation die größte politische Macht und die 
Die drei Grundelemente der Herrschaft der Bourgeoisie 169

meiste soziale Durchschlagskraft. In Wien gehört nur der Hochadel zur Hofgesellschaft, in Berlin auch der kleine und kleinste. $\left.{ }^{1}\right)$ Es ist das innerhalb der besitzenden Klassen in Deutschland noch überaus lebendige Gefühl für die Werte der Tradition, welches diesen Bevölkerungsteilen ein soziales und politisches Leben garantiert, ja sogar noch eine soziale Zukunft sichert.

Wenn wir nunmehr die drei Länder, Amerika, Italien und Deutschland miteinander vergleichen, sehen wir Amerika beherrscht von der Bourgeoisie des money, vom Gelde. Reines System der Plutokratie. Am meisten herrschberechtigt ist der, der das meiste Geld hat. Dagegen wird Italien dominiert von einer großen Schar von Advokaten und Universitätsprofessoren. Diese Behauptung kann wohl nicht treffender bewiesen werden als durch den Hinweis auf eben die Tatsache, daß die alleinige, $28 \mathrm{Mitglieder}$ zählende sozialistische Fraktion der italienischen Kammer I904 neun Hochschullehrer aufwies, während zu derselben Zeit der 397 Mann starke deutsche Reichstag insgesamt nur zwei Männer dieses Berufes besaß. Deutschland endlich wird regiert nicht von der Klasse der Bildung oder der ölronomischen Potenz, sondern von $\mathrm{Hu}$ saren- und Ulanenoffizieren adligen Geblüts, Assessoren und Diplomaten, welche die Grafenkrone besitzen. Wir können das Ergebnis dieses Vergleichs auch in folgender Weise zusammenfassen: Jede herrschende Schicht besitzt drei Grundelemente, die sie befähigen, die Zügel der politischen Herrschaft über die weiten Massen des demokratischen Volkes in der Hand zu behalten: Die Bildung, das Geld und die Geschichte. Oder, anders ausgedrückt: die Macht der Wirtschatt, die Macht der Kultur und die Macht der Ge-

I) Darüber können sich die Österreicher nicht genug wundern : "Geheimräte und Stabsoffiziere von ganz kleinem Adel mit Frauen bürgerlicher Herkunft, ohne großes Vermögen, sind (in Berlin) berechtigt, mit Kind und Kegel bei Hof zu erscheinen!"“ (von Ballwitz: Berliner Hofgesellschaft, Die Zeit (Wien) I, Nr. 38). 
wohnheit. Diese drei verschiedenen Machtelemente sind in jeder herrschenden Schicht vorhanden. Indes sie gruppieren sich in den einzelnen Nationen der drei genannten Länder in verschiedenartiger Weise. In Deutschland steht die Bourgeoisie der Gewohnheit, in Italien die Bourgeoisie der Kultur und in Amerika die Bourgeoisie des Geldes obenan. Wir haben also, um es noch anders auszudrücken, in Amerika ein Hervortreten des rein quantitativen Elementes in der Bourgeoisie, in Italien ein Hervortreten des mehr qualitativ gefärbten Elementes in der Bourgeoisie und in Deutschland ein Hervortreten der überwiegend traditionellen Elemente in der Bourgeoisie - dieses letztere Wort hier im Marxschen Sinne verstanden - vor uns.

Wir haben zu unserer soziologischen Untersuchung gerade die Deutschen, die Italiener und die Amerikaner ausgewählt, weil bei ihnen die drei Grundelemente, die Bourgeoisie des money, die der Intelligenz und die der Geschichte, am schärfsten zum Ausdruck gelangen. Die französische Bourgeoisie z. B. stellt eine Synthese fast gleicher Teile aller drei Elemente dar. Wenn wir die Analyse der Abgeordneten des Palais Bourbon vornehmen, finden wir eine ungleich größere Zahl von Industriellen als im Parlament Italiens, eine beträchtlich größere Zahl von Adligen als in Ländern ganz moderner Struktur, wie in Amerika, wo der Adel offiziell nicht das Adelsprädikat tragen darf, zugleich aber auch eine weit größere Anzahl von Gelehrten als im deutschen Reichstag vor. Wir sehen die Bourgeoisie in Frankreich die Züge, die sie in Deutschland, Italien, Amerika aufweist, zugleich tragen, nur in weit weniger prägnanter Form. Die modernen politischen Kämpfe innerhalb der französischen Bourgeoisie selbst, die Affären Dreyfus, Syveton und wie sie alle heißen, bis auf die Geschichte von heute herab sind nichts anderes als der äußere Ausdruck der inneren sozialen Kontraste zwischen den drei verschiedenen Elementen unter den herrschenden Klassen Frankreichs. Es gibt in Frankreich einen 
mächtigen Adel sowie einen mächtigen Klerus, eine mächtige Geldbourgeoisie und eine mächtige Schicht der Advokaten und Professoren, deren je zweiseitiger Kampf noch nicht zugunsten des einen von ihnen definitiv entschieden ist.

Wenden wir uns nun der Psychologie des industriell-kommerziellen Elementes in der Bourgeoisie allein, und zwar seinem Verhalten außerhalb des eigenen Landes zu. Wenn wir das wirtschaftliche Auftreten der einzelnen Nationen auf dem Weltmarkt betrachten und die Art und Weise, wie die deutsche Bourgeoisie auf dem Weltmarkt Geschäfte macht, mit den entsprechenden Methoden der französischen und englischen Bourgeoisie vergleichen, gewahren wir, daß die deutsche Bourgeoisie ganz besonders durch eine Qualität ausgezeichnet ist: ihre ungeheure Anpassungsfähigkeit. Dieser Anpassungsfähigkeit verdanken der deutsche Handel und die deutsche GroBindustrie in allererster Linie ihre Erfolge auf dem Gebiete der Weltwirtschaft. Einige Beispiele werden das leicht klar machen können. In Brasilien lieben es die Eingeborenen nicht, irgendwelche Gegenstände, Waren, zu kaufen, die in schwarzes Papier eingewickelt sind. Die schwarze Farbe ist für sie die Farbe der Trauer, und da die Sonne in Brasilien so schön heiß brennt und alle Gegenstände in weiße Farbe badet, wollen sie nicht an Trauer erinnert sein. Nun war Brasilien beherrscht vom englischen Import, und speziell die dort gangbaren Metallindustriewaren, ganz besonders Nähnadeln und Stecknadeln, waren englisches Fabrikat. Aber die Engländer wickelten diese Nähnadeln und Stecknadeln in schwarzes Papier ein. Die Brasilianer beklagten sich darüber. Das war jedoch den Engländern ganz gleichgültig. Sie waren die alleinigen Herren des Imports in Brasilien und verkauften die Nähnadeln in schwarzem Papier ruhig weiter. Da erhielten deutsche Fabrikanten - es waren übrigens helle Sachsen von dieser Angelegenheit, diesem merkwürdigen Vorurteil der Brasilianer einerseits und der ebenso merkwürdigen Hals- 
I72 IX. Zum Problem der internationalen Bourgeoisie

starrigkeit der Engländer andererseits, Kenntnis. Gleich fingen sie an, große Quantitäten Nähnadeln und Stecknadeln nach Amerika zu schiffen und dort zu verkaufen. Diese waren aber in rosarotes Papier eingewickelt. Das Ende vom Liede ist klar: Innerhalb dreier Jahre hatten die Deutschen die Engländer aus dem Felde geschlagen und beherrschten nun ihrerseits den brasilianischen Markt. Nebenbei bemerkt, waren die deutschen Nähnadeln schlechter. Ein anderes Beispiel: In Trinidad haben die Eingeborenen das physiologische MiBgeschick, Plattfüße zu besitzen. Auch dorthin fand englischer Import statt. Aber die englischen Schuhe und Strümpfe waren natürlich "London fashion" und nahmen auf die Plattfüße keine Rücksicht. Auch da erhielten die Deutschen Kenntnis von dieser Sonderheit und verfertigten Schuhe für Plattfüße, die reißenden Absatz fanden. Kurz, das Resultat war in Trinidad dasselbe wie in Brasilien: der deutsche Handel nistete sich ein. ${ }^{1}$ ) Auch aus Indien werden für das Assimilationsvermögen des deutschen Handels und der deutschen Industrie drastische Beispiele erbracht. Wie der indische Schriftsteller Mitra berichtet, traf er am heiligen Fluß Godawari einen deutschen Händler, der allerhand billigen Kram verkaufte, dabei aber jede Verpackung in Leder (das die Inder in den Bädern nicht gern brauchen) peinlich vermied. Zumal seine billigen Schnupftabaksdosen aus Zinn gingen glänzend ab, trotzdem die Mehrzahl der Inder gar nicht schnupft. DieUrsache für die Beliebtheit der Dosen war, daß der Deutsche auf dem Deckel das Bild des Gottes Ganescha hatte abdrucken lassen. Bei seinem Vergleich zwischen englischer und deutscher Weise im Handel und Wandel behauptet unser Gewährsmann, daß es in Großbritannien nicht einen einzigen Ort gäbe, wo ein Industrieller oder Exporteur den indischen Markt, seine

I) Diese beiden Vorgänge, die dem Werke Werner Sombarts, „Die deutsche Volkswirtschaft im 19. Jahrhundert“ (1. c. p. 128), entnommen sind, wurden mir von einem brasilianischen Gelehrten bestätigt und ergänzt. 
Anpassungsvermögen d. deutsch., Starrheit d. engl. Industrie I 73

Bedürfnisse und seine Psychologie kenne und verstehe. Er sagt, der Engländer wisse gar nicht, daß der Erfolg Deutschlands z. B. in der Scherenindustrie dem Umstande $z u$ verdanken sei, daß der indische Dorfschneider seinen Daumen zu schützen wünscht und darum eine Schere bevorzugt, die eine größere Öffnung für den Daumen als für den Zeigefinger hat. Der am Hergebrachten hängende Fabrikant in Birmingham gibt sich indes nicht die Mühe, sich über das, was dem indischen Dorfbewohner angenehm ist, unterrichten zu lassen. Seine Unkenntnis oder Nichtbeachtung der ihm verächtlich erscheinenden Vorurteile wird von seinem deutschen Nebenbuhler zu eigenem Vorteil ausgenützt. „Der Schlüssel zu den Erfolgen der deutschen Handeltreibenden liegt darin, daß es ihnen niemals in den Sinn kommt, ihren indischen Kunden ihr eigenes Urteil aufdrängen zu wollen. Sie begreifen, daß die Gewohnheiten von Tausenden von Jahren sich nicht in einem Tage ändern lassen."1) Aus Norwegen wies ein englischer Konsularbericht 1908 erschrocken auf die Erfolge hin, welche der deutsche Exporthandel durch die eifrige Bereisung des dortigen Absatzgebietes zu erzielen gewußt habe. Obgleich von Deutschland und von England aus eine etwa gleich lange Seereise nötig ist, um Norwegen zu erreichen, waren, zumal im wichtigen Handelszentrum Bergen, überwiegend deutsche Reisende anzutreffen. In den größeren Gasthäusern der Stadt waren die besten Zimmer meist von Deutschen besetzt, die die verschiedensten Branchen vertraten. In den Jahren I 9o6-igo8 stieg die Anzahl der auf dem Polizeiamt in Bergen genommenen, für Reisende ausgestellten Lizenzen von 478 (i. J. 1 906) auf 570 (i. J. I 908). Davon waren 1907 nicht weniger als 285 , also genau die Hälfte, Deutsche, und nur 69 Engländer. Der Rest verteilte sich auf andere Länder. $\left.{ }^{2}\right)$ p. 367 .

I) S. M. Mitra, „Indian Problems“. London 1908. Murray,

2) Zeitschrift für Sozialwiss., XI. Jahrg., p. 7 I1. 
Wir sehen also, die deutsche Bourgeoisie, der deutsche Exporthandel verfügt über eine seltene Rührigkeit sowie einen ungemein scharfen Blick für Eigenheiten und Launen der Kundschaft auf dem Weltmarkt sowie eine seltene Geschicklichkeit in der Anpassung und Ausnützung der verschiedenartigen Eigentümlichkeiten der anderen Nationen. Freilich beschreitet diese Anpassungsfähigkeit der deutschen Exportbourgeoisie vielfach Bahnen, die sie bis hart an die Grenze der Unsolidität führen und ihr den $\mathrm{HaB}$ und Neid der Bourgeoisie Englands und Frankreichs in viel höherem Maße zuziehen, als es der wirtschaftliche Konkurrenzkampf an sich allein rechtfertigen und erklären würde. $\left.{ }^{1}\right)$ Vor einem spanischen Kaufladen gewahrte ich einmal im Ladenfenster eine hübsche Schachtel Schreibfedern, die mir echt spanisch schien: auf dem Deckel war ein spanischer Soldat abgemalt und die Schachtel selbst war rot und gelb gepinselt. Ich kaufte sie, um sie meinen Kindern mitzubringen. Als ich sie aber meinen Kindern aushändigte, zeigte es sich, daß auf der Innenseite des Deckels etwas auf Deutsch geschrieben stand. Es war Nürnberger Fabrikat. Weiter: Als ich kürzlich zwischen Pisa und Livorno reiste, wurde ich mit einem italienischen Matrosen bekannt, der aus Griechenland kam und im Piräus große Mengen von echt griechischen Zigaretten in Schachteln eingekauft hatte. Als Aufschrift trugen sie in griechischen Lettern „Hellas" und „authentisch hellenische Zigaretten" und alles mögliche weiter in griechischer Sprache. Nachher merkte ich, daß innen im Deckel ganz klein gedruckt "Dresden“ stand. Als ich zum zweitenmal in Frankreich war, es war zu Zeiten des

I) Man vergleiche das Urteil eines Franzosen: "Que de fois, au cours de mes voyages, j'ai été frappé de l'ardeur avec laquelle il (le commis voyageur allemand) cherche d recueillir des renseignements, de l'habilité avec laquelle il se faufile, s'insinue, revient à la charge, sans se laisser rebuter par le mauvais vouloir dont il est souvent l'objet." (Georges Blondel, "Les Embarras de l'Allemagne". Paris 19I2, 5. Aufl, p. 3II). 
Dreyfußprozesses, kaufte ich mir eine Photographie, eine Ansichtskarte des alten nationalistischen Deutschenfeindes General Mercier. Der General war abgebildet und darunter stand die Marseillaise mit einem Marschtext, der zur Revanche gegen Deutschland aufforderte. Ganz, ganz klein aber, auf der anderen Seite, man mußte die Lupe nehmen, um es zu erkennen - stand eine Berliner Firma.

Genug der Beispiele. Wir fragen uns: Wie kommt es, daß der deutsche Exporthandel, also das Menschenmaterial, das ihn leitet, der deutsche Bourgeois, diese besondere, bisweilen selbst bis zur Schmutzkonkurrenz gehende Anpassungsfähigkeit, die wir an einigen beliebig zu vermehrenden Beispielen kennen gelernt haben, aufweist? Welches sind die kausalen Zusammenhänge zwischen dem Gepräge der deutschen Bourgeoisie im Inland und diesen besonderen Eigenschaften, die sie bei dem Vertrieb ihrer Waren im Auslande kennzeichnen? Es ist gesagt worden, und nicht von antisemitischer Seite, sondern von rein volkswirtschaftlicher, die besondere Anpassungsfähigkeit der deutschen Bourgeoisie läge darin, daß sie große Bestandteile des Judentums in (sich aufgesogen habe. ${ }^{1}$ ) Es wäre also dies eigentlich nicht pine deutsche, arische, germanische Eigenschaft, sondern eine jüdische. GewiB, zweifellos besitzen die Juden im Handel eine ungeheuer starke Anpassungsfähigkeit. Der Jude versteht es, die Klienten zu beobachten, günstige Gelegenheiten wahrzunehmen, er ist wirklich psychisch aufmerksam. Er knüpft Fäden, intellektuelle und psychologische, zwischen sich und dem Käufer. Ferner kommt auch dazu, daß durch die besondere politische Gestaltung und politische Geschichte des deutschen Volkes das Judentum förmlich dazu gedrängt wurde, die große Bedeutung in Handel und Industrie zu erlangen, die es heute einnimmt. In Deutschland ist der Jude noch nicht emanzipiert, zwar wohl auf dem

I) Sombart, „Deutsche Volkswirtschaft“, 1. c., p. 129. 
I 76 IX. Zum Problem der internationalen Bourgeoisie

Papier, aber doch noch nicht in der Tat. Während die begabteren Elemente unter den Juden in anderen Ländern, wie in Frankreich, Italien, England, vielfach in die Verwaltung gehen, ja einzelne von ihnen sogar Staatsminister werden - ich erinnere an den italienischen Kriegsminister Ottolenghi, an Disraeli, später Lord Beaconsfield in England, an Crémieux, Gambetta und andere in Frankreich, während also die intellektuellsten und intelligentesten Elemente aus dem Judentum in den fortschrittlicheren demokratischen Ländern, wie in den westeuropäischen Staaten, vom Verwaltungsapparat und dem politischen Leben der Nation absorbiert werden, sehen sich die Juden in Deutschland von diesen Existenzmöglichkeiten vollständig ausgeschlossen; sie können nicht einmal Richter, nicht Offiziere werden, von hohen Regierungsbeamten gar nicht zu reden. Selbst ins Parlament gelangen sie nur schwer hinein, nur auf dem Wege der sozialdemokratischen Agitation. So kommt es, daß in Deutschland die besten Elemente des Judentums dem Handel, den kaufmännischen und den industriellen Kreisen bewahrt bleiben. Also die Elite, die Intelligentesten unter den Juden, widmen sich außer den studierten freien Berufen dem Geld- und Warenvertrieb und verbleiben so innerhalb der gewerbetätigen Bourgeoisie. Es läge also, da ein besonders starker, qualitativ hochstehender Einschlag jüdischer Intelligenz und ein noch stärkerer quantitativer Einschlag des Judentums tatsächlich im Handel und in der Industrie Deutschlands vorhanden ist - bekanntlich ist ein großer Teil der Industriellen, speziell in der Seidenund in der Textilindustrie jüdisch - im Bereich der Wahrscheinlichkeit, daß die Anpassungsfähigkeit der deutschen Bourgeoisie zum Teil wirklich den begabten jüdischen Bestandteilen in ihr zu verdanken wäre. So wäre es also erklärlich, daß die spezifischen Eigenschaften der staatsdeutschen Bourgeoisie bis zu einem gewissen Grade mit den spezifischen Eigenschaften des Judentums zusammenfallen. Aber 
wir glauben, daß dieses Moment, wenn es auch zweifellos zur Entstehung des erwähnten Charakteristikums des deutschen Handels mitgespielt hat, doch nicht von ausschlaggebender Bedeutung ist. Wir sind mit dem Hinweis auf den jüdischen Einschlag der von uns gestellten Frage nicht auf den Grund gekommen; wir haben die eigentlichen Grundmotive noch nicht gefunden, aus welchen die besondere Anpassungsfähigkeit der deutschen Bourgeosie abzuleiten ist.

Wir deuteten es vorhin schon an: Wenn wir die Deutschen vergleichen mit den Engländern und Franzosen, dann sehen wir, wie ungemein verschiedenartig - häufig - ihre Handelsauffassung, ihr kommerzielles Auftreten ist. Kulant, anpassungsfähig, ja anpassungswillig sind, immer vom Durchschnitt gesprochen, die Franzosen und Engländer in keiner Weise; sie sind nichts weniger als zuvorkommend oder unternehmenslustig. Der Güte ihrer Ware gewib, bemühen sie sich nicht sehr um die Gunst ihrer Kundschaft, ja sie sind sogar leicht geneigt, dieser gerade ihren besonderen Geschmack aufzudrängen. Der deutsche Handel trägt den Stempel mutigen, draufgeherischen Spekulantentums, während die Engländer und Franzosen solide, alte Geschäfte mit honetten Prinzipien betreiben, aber ohne dabei im ganzen großen Fortschrittsgelüsten zu huldigen. Man wird diese Grundzüge an allen Orten internationalen Konkurrenzwettstreites, möge er sich nun in Konstantinopel, in den marokkanischen Häfen oder in China abspielen, bestätigt finden. Úberall ein Unterschied: der Deutsche der geschäftige Parvenü, der Franzose und Engländer der Geschäfte treibende Rentier.

Dagegen gewahren wir in anderen Ländern wie Italien, und zwar besonders in den Provinzen der Poebene, ganz ähnliche psychologische Voraussetzungen zum Handel wie in Deutschland. Wir beobachten dort ebenfalls eine ungemein mutige Inangriffnahme industrieller Probleme, ebenfalls ein wirtschafts-psychologisches Expansionsbedürfnis 
I 78 IX. Zum Problem der internationalen Bourgeoisie

großen Stiles. Vor einigen Jahren hat sich die Baumwollund Wollindustrie Piemonts eine Zeitlang nicht erfolglos an die Eroberung des argentinischen und brasilianischen Marktes gemacht. Schon I 894 klagten deutsche Fabrikanten über die ernsthafte Konkurrenz, welche ihnen die Italiener auf dem südamerikanischen Markte machten. ${ }^{1}$ ) Wir sahen in Italien „fürstliche Kaufleute“, Selfmademen, aufkommen und sich jenseits des Ozeans großeVermögen erwerben. ${ }^{2}$ ) Wirgewahren, daß die Italiener, die freilich in anderen Dingen, wie in der Pünktlichkeit und Akkuratesse der internationalen Kundenbedienung noch gar viel von den Deutschen zu lernen haben ${ }^{3}$ ), ebenso scharf aufpassen, mit ebenso gewundenem Rückgrat sich, wo es nur irgend Platz gibt, in fremde Verhältnisse hineinschlängeln wie die Deutschen. Es existieren also verwandte Momente zwischen dem italienischen und dem deutschen Handel, zwischen dem Auftreten der italienischen und dem der deutschen Bourgeoisie. Vielleicht ist es diese Koinzidenz, welche uns auf die richtige Spur zur Beantwortung unserer Frage bringt. In der Tat ist die Anpassungsfähigkeit der Deutschen und Italiener vor allen Dingen aus zwei Momenten zu erklären. Erstens aus der historischen Jugend ihrer Staatswesen und zweitens aus der physiologischen Kraft ihres Menschenmaterials.

Aus der historischen Jugend. Der deutsche wie der italienische Kaufmann standen, gerade in der Zeit des reifenden Kapitalismus, an die hundert Jahre auf dem Weltmarkt ohne Rückhalt da. Sie gehörten Nationen an, die in kleine Staaten zerspalten und zerklüftet waren. Der römische Kauf-

I) Werner Sombart, "Italienische Briefe", Nr. 2. Sozialpolitisches Zentralblatt, Vol. III, Nr. 30.

2) Vgl. hierïber u. a. Luigi Einaudi, „Un Principe Mercante". Torino I900, Bocca.

3) Vgl. darüber meinen Aufsatz: „Tendenzen des italienischen Handels im östlichen Mittelmeer", im Weltwirtschaftlichen Archiv, Bd. II, Heft I (Juli I9I3). 
mann war ein Untertan seiner Heiligkeit des Papstes, der sich nicht allzusehr um Anknüpfung von Handelsbeziehungen mit Amerika bemüht hat. Die Einwohner von Venetien und der Lombardei waren Untertanen der kaiserlich österreichischen Hofburg, und auch dort konnte sich der Sinn für weitschauende Handelstätigkeit natürlich nicht entfalten. Es fehlte sowohl in Deutschland als in Italien der nationale Zusammenhang, die nationale Einheit und zumal die wirtschaftliche Geschlossenheit, die der Nation erst die Grundlage zu industriellem Vorwärtskommen bieten. $\mathrm{Zu}$ einer gesunden wirtschaftlichen Entwicklung ist, realpolitisch genommen, ein gewisses Quantum nationaler Einheit notwendig. Jene deutschen und italienischen Kaufleute, die sich vor 1860-70 am Weltmarkt in Amerika und sonstwo beteiligten, wußten sich als Angehörige ihres Volkes nicht recht Geltung zu verschaffen. Sie mußten sich, wollten sie etwas erreichen, anschmiegen, wo sie konnten. Sie mußten es, weil sie als der Überschuß numerisch großer aber politisch schwacher, ja, zerstückelter und z. T. sogar unter Fremdherrschaft lebender Nationen kein anderes Mittel besaßen, um zu etwas zu gelangen. Die kapitalistischen Exportindustrien Deutschlands und Italiens sind überdies auch im wirtschaftlichen Sinne noch sehr jung. Beide haben sehr spät begonnen, auf dem Weltmarkt zu erscheinen: Deutschland war vor dem Jahre 1870 eine ökonomische Null, Italien vor 186I sozusagen ein ökonomisches Minus. Dagegen hatten es die Franzosen und Engländer, diese beiden alten Kaufmannsnatiouen mit festem Besitz, mit historisch gewordenen Herrschaftsrechten, mit bestimmten Geschäftsverbindungen, Handelsprivilegien usw. nicht notwendig sich zu beugen und traten dementsprechend auf dem Weltmarkt mit großer Sicherheit und stolzem Selbstbewußtsein auf. Die Deutschen und Italiener aber waren genötigt, sich denVerhältnissen anzupassen, und haben sich bis auf den heutigen Tag diese Anpassungsfähigkeit mit all ihren Vorzügen und Nachteilen bewahrt. 
I 80 1X. Zum Problem der intermationalen Bourgeoisie

Das zweite Motiv für die Anpassungsfähigkeit besteht in der physiologischen Frische dieser politisch jungen Nationen. Frankreich hat im Jahre $1846 \quad 34 \%$ Millionen Einwohner gehabt. Deutschland in demselben Jahre fast genau eben. soviel. Frankreich und Deutschland waren also numerisch, der Zahl der Bevölkerung nach, gleichwertige Elemente. Heute, im Jahre I9I3, ist Deutschland Frankreich um über 2 I Millionen Menschen über den Kopf gewachsen. Italien hat im Jahre 180 I eine Bevölkerung von I 7 Millionen besessen. Jetzt, d. h. vor einigen Jahren, bei Gelegenheit der letzten statistischen Aufnahme im Jahre 19 I 1, besitzt Italien eine Bevölkerung von $34 \%$ Millionen. Also die Bevölkerung Italiens hat sich innerhalb von I Io Jahren verdoppelt. Wir brauchen die Zahlen nur zu betrachten, so springt uns schon eine ganze Reihe von Schlüssen in die Augen. Bei derartig starken Volksvermehrungen, die eine ungeheuer starke physiologische Frische voraussetzen, wird die Fxpansion, die Wanderlust und der Wanderzwang des Volkes, die Betätigung auf dem Weltmarkt, zur Selbstverständlichkeit und Notwendigkeit.

Seit geraumer Zeit stehen die Fragen der Volksvermehrung bzw. Verminderung im Mittelpunkt des öffentlichen und des wissenschaftlichen Interesses. In Wien hörten wir einmal den Vortrag eines sehr begabten Reichsratsabgeordneten, der seine Zuhörer fast zwei Stunden lang darüber unterhielt, ob die Tschechen oder die Deutschen mehr Kinder erzeugen, und nach der Lösung dieses Problems das Anrecht der Deutschen bzw. Tschechen auf Böhmen entschieden wissen wollte. Der betreffende Redner vertrat die Auffassung, daß die Macht einer Nation zumal an der Zahl ihrer Angehörigen gemessen wird. Je zahlreicher eine $\mathrm{Na-}$ tion an Köpfen ist, desto größer ist ihre politische, ja wie er hinzufügte, sogar ihre wirtschaftliche Macht. Ich halte diese Meinung nicht für richtig. Sie ist nur richtig unter militärischen Gesichtspunkten. Unter diesen betrachtet ist 
natürlich diejenige Nation die mächtigste, welche über die größte Anzahl von Gewehrläufen verfügt, und da zum Tragen eines Gewehrlaufes ein Mensch gehört, diejenige, welche über die größte $Z$ ahl erwachsener Männer verfügt. ${ }^{1}$ ) Nun stehen wir allerdings in bezug auf die Kinderzahl vor der Tatsache, daß Frankreich zurückgeht. Infolgedessen haben die Nationalisten ganz recht, wenn sie immer von neuem den Appell an die Frauen richten: „Ihr allein könnt uns helfen! Bringt uns Kinder auf die Welt, denn wir brauchen Soldaten!“ Im übrigen, glaube ich, ist indes - vorausgesetzt natürlich, daß es sich nicht um gar zu disparate Größen handelt - die Frage nach der Macht einer Nation vorzugsweise wirtschaftlich zu stellen. Demnach würde es sich nur darum handeln, ob diejenige Nation die mächtigste ist, auf welche die größte Summe der Wirtschaftsgüter entfällt, oder vielmehr diejenige, welche den höchsten Individualsatz an solchen aufzuweisen hat. Also, wenn wir das Gesagte auf das Verhältnis von Frankreich zu Deutschland zur Anwendung bringen, wäre Deutschland, immer natürlich abgesehen von rein politischen und militärischen Gesichtspunkten, nur dann mächtiger, falls - was übrigens, und zwar teilweise gerade wegen des in Frankreich üblichen Zweikindersystems

I) Über die Überlegenheit an Zahl äußert sich aber Generalleutnant 2. D. v. Zwehl in den Jahrbüchern für die deutsche Armee and Marine wie folgt: „Läßt sich auch nicht sagen, daß die Vorbedingung für den Angriff Überlegenheit an Zahl sein müßte, so ist doch bei dem heutigen Stande der Wehrfassungen der Großmächte, bei der Gleichartigkeit der Bewaffnung, der Ausbildung und aller technischen Hilfsmittel für den Krieg auf glänzende Erfolge einer Minderheit gegen eine Mehrheit kaum zu rechnen. Mit je größerem Nachdruck das Prinzip der Vernichtung des Gegners durch Umfassung bei nachdrücklichen Angriffen auf allen anderen Teilen des Schlachtfeldes betont werden muß, um so bedeutungsvoller ist neben innerer Tüchtigkeit die Überlegenheit an Zahl geworden. Es ist ein ganz vergebliches Bemühen, die folie des nombres zu verspotten. Gesunde strategische Grundsätze bauen sich am sichersten auf der Überlegenheit an Zahl auf." (Dic Wehr, I, Nr. 4, p. 17). 
nicht zutrifft - das Durchschnittsvermögen der Einwohner Deutschlands größer wäre als das der Einwohner Frankreichs oder das Gesamtvermögen der deutschen Nation sich höher beliefe als das der französischen.

Die von uns konstatierte physiologische Stärke der politisch jungen Nationen, wie der italienischen und der deutschen, hängt aber ursächlich nicht so sehr etwa mit militärischen Präventivmaßregeln als mit der ganzen wirtschaftlichen Auffassung dieser Nationen zusammen. Woher kommt es, daß diese Völker so viele Kinder erzeugen? Woher kommt es, daß die Polen, die ebenfalls eine aufstrebende Nation sind, sich, wie der preußische Ministerpräsident Fürst Bülow sagte, vermehren „wie die Kaninchen"? Das kommt daher, daß die genannten Völker spekulativ sind. Spekulativ im Sinne der Unternehmungslust. Der Franzose oder Engländer setzt nicht eher Kinder in die Welt, bevor er sich nicht einen rechnerischen Anschlag gemacht und dieser ihm nicht die Sicherheit gegeben hat, daß er diesen Kindern auch ein gewisses Quantum von wirtschaftlichen Gütern und sozialer Entwicklungsmöglichkeit garantieren kann. Dagegen tun die Deutschen, Polen und Italiener nicht ein gleiches. Auf "Teufelholmich" produzieren sie Kinder. Es wird auf dieses demographische Phänomen hin dann, und das ist sehr lehrreich, die ethische Rechtsgrundlage für weitgehende politische Forderungen konstruiert. Dies geschieht sowohl in Italien wie in Deutschland. In Deutschland durch den ehemaligen Pfarrer Friedrich Naumann. "Schafft nur Kinder herbei!" sagen die Theoretiker der Volksvermehrung, „das ist von militärischem und volkswirtschaftlichem Standpunkt ein Gut. Ihr erhaltet ja mit ihnen auch ein Recht auf Land. Denn das Volk, das viele Kinder hat, mehr Kinder, als es ernähren kann, braucht Land, und infolgedessen hat ein Volk von 80 Millionen einen göttlichen Anspruch darauf, ein Nachbarvolk von 30 Millionen, das einen Länderkomplex von ähnlichem Umfang besitzt, zu ver- 
drängen oder ihm wenigstens unter Wahrung seiner Nationalität seinen Überschuß aufzudrängen." Diese Tendenz wird auch von einem Teil der deutschen Volkswirtschaft geteilt. Jetzt geht es noch, sagt man sich, aber in roo Jahren müssen wir mit Frankreich Krieg führen, um das reichsländische Territorium zu erweitern oder mindestens das Plus der deutschen Bevölkerung dem volksarmen Frạkreich aufzuzwingen.

Das sind alles sehr bedeutsame Gedankengänge, die mit unserer Aufgabe, die Erscheinung der Anpassungsfähigkeit der deutschen Bourgeoisie im Welthandel zu analysieren, in um so engerem Zusammenhange stehen, als sie auch auf die anscheinend gegensätzliche Begleiterscheinung der Geschmeidigkeit, nämlich der brutalen Energie des Auftretens in allen den Fällen, in denen erstere nicht ausreicht, ein scharfes Licht werfen. Vorderhand freilich haben die jungen Nationen mit der Notwendigkeit zu rechnen, daß sie quantitativ oder doch qualitativ beträchtliche Teile des Bevölkerungsganzen in die politisch selbständige Fremde schicken müssen. Diese finden dort notwendigerweise nur dann ihr Brot, wenn sie sich anpassen und lernen, den fremden Charakter genau zu kennen und einzuschätzen. Denn worin besteht der Export und die Expansion der kinderarmen - französischen und englischen Bourgeoisie? Ganz überwiegend in Kapital. Dagegen der Export der kinderreichen - Deutschen und vor allem der Italiener? Neben einem nicht geringen, aber doch relativ geringeren Export von Kapital in einem Export von Menschenmaterial. Dieses Menschenmaterial heißt bei den Italienern: Maurer, Gipsarbeiter, Landtagelöhner, bei den Deutschen, seit dem Aufhören der großen Auswanderungsperiode, Handlungsreisende und in Artikulo Wissenschaft reisende Professoren.

Zum Schluß sei noch eines Charakterzuges gedacht, der die nationalen Bourgeoisien in den einzelnen Ländern voneinander scheidet und der sich mit dem oben geschilderten 
auf das engste berührt. Wenn wir den deutschen Staat in seinem wirtschaftlichen und politischen Wesen betrachten, dann fällt uns auf den ersten Moment auf, daß ein Widerspruch besteht zwischen dem Wert der Funktionen, welche die einzelnen Schichten der deutschen Bourgeoisie erfüllen, und dem Schwergewicht, das sie im öffentlichen Leben besitzen. Deutschland ist nicht mehr ein Agrarland. Die Zahlen bestätigen es zur Genüge. Aus den letzten Berufszählungen in Bayern geht klar hervor, daß auch dieses Land, das lange das Hauptbollwerk der Landwirtschaft war, nunmehr überwiegend industriell geworden ist. Also Deutschland ist ein Industrieland, und wenn die Marxsche Theorie unretouchiert annehmbar wäre, müßte Deutschland deshalb politisch beherrscht werden und das intellektuelle Gepräge tragen von der dieses Wirtschaftssystem repräsentierenden Menschenschicht, also von der industriellen Bourgeoisie. Hingegen sehen wir in der Wirklichkeit Deutschland nicht ökonomisch, aber politisch und sozial geleitet werden von einer alten Herrenschicht, die ein Wirtschaftssystem, das noch der präkapitalistischen Zeit angehört, also ein überwundenes Wirtschaftssystem repräsentiert, nämlich von der agrarischen "Junkerschaft". Deutschland steht unter der politischen Herrschaft der Vorbourgeoisie, des Adels. In Deutschland ist die Bourgeoisie in der Tat weit entfernt davon, die politische Macht in ihren Händen zu konzentrieren. Es ist vielfach gesagt worden, der Grund hierfür sei darin zu erblicken, daß in Deutschland der Bourgeoisie das gefehlt habe, was sie in England und Frankreich besessen habe und wodurch sie dort stark geworden sei, nämlich die Bundesgenossenschaft der Arbeiterschaft, des Proletariats. In Deutschland, heißt es, ist die Arbeiterschaft der Bourgeoisie in den Rücken gefallen, wodurch die Bourgeoisie vor der Zeit schwach geworden und schwach geblieben ist. Aber dieser Einwand hat nur einen bedingten Wert. Eine nur bedingte Bedeutung deshalb, weil er sich ledig- 
lich auf einige kurze und vorübergehende Episoden in der Arbeiterbewegung stützen kann, auf die Zeit, als Lassalle auftrat und zu dem Behufe, die Arbeiterschaft aus der politischen Gefolgschaft des bürgerlichen Freisinns herauszureißen, das Hauptaugenmerk seines Angriffes auf die Mittelklasse, die Bourgeoisie, richtete und sich deshalb unter Umständen gar nicht scheute, Bündnisse mit dem Adel gegen das Bürgertum abzuschlieBen. Aber das waren nur wenige Jahre des Kampfes. Seitdem hat die Arbeiterschaft Deutschlands - wenn auch in der ihr eigenen groben Form sich heiß darum bemüht, die Bourgeoisie zum Kampf gegen den Adel aufzupeitschen und ist nicht müde geworden, sie zur Bundesgenossenschaft gegen das absolute Königtum aufzufordern. Aber eben diese Bourgeoisie hat die Bundesgenossenschaft der Arbeiter, die sie nie ernst gewollt hat, beständig zurückgewiesen. Gewiß, das Proletariat hat nicht sorgfältig die Entfaltung der Bourgeoisie abgewartet, es hat in sie eingegriffen mit wirtschaftlichen Forderungen und Streiks veranstaltet, als die deutsche Bourgeoisie noch nicht kernfest war und sich noch nicht organisiert hatte, kurz, als dem Arbeiterbund noch kein Unternehmerbund entgegenstand. Möglich, daß es auf die Fabrikherren psychologisch erbitternd wirkte, daß das Proletariat mit der autokratischen Staatsmacht liebäugelte, während das Bürgertum erst die Einrichtungen im Staate nach seinem Sinne noch umschaffen wollte und sich in seiner Behaglichkeit von einer Riesenschar von Arbeitern, die die Lohnfrage aufrollten, gestört sah. Aber andererseits ist dieses Phänomen nicht auf Deutschland beschränkt geblieben. In anderen Ländern, wie z. B. in England und Frankreich, ist die Arbeiterschaft gleich zu Beginn ihrer Emanzipationsbewegung in ungleich schärferer und energischerer Weise aufgetreten und hat den BereicherungsprozeB der Bourgeoisie mit weit größerer Rücksichtslosigkeit zu unterbinden versucht wie in Deutschland. Die politische Machtlosigkeit und Rückgratlosigkeit, die das deutsche Bürgertum 
durchaus kennzeichnet, rühren in ihren ursächlichen $\mathrm{Zu-}$ sammenhängen nicht so sehr von dem besonderen Verhalten der Arbeiterschaft in Deutschland her - denn in den anderen Ländern ist die Arbeiterschaft wahrlich sehr viel weniger friedlich und gemütlich aufgetreten als dort -, sondern vielmehr von dem Kompromis, den die einzelnen Schichten der herrschenden Klassen selbst in Deutschland untereinander eingegangen sind. Das Bürgertum hat die Privilegien des persönlichen Regiments und des alten Grundbesitzes auf politischem und sozialem Gebiete anerkannt, sich aber als Entschädigung dafür auf wirtschaftlichem Gebiete der Hilfe des staatlichen Apparates gegenüber der Arbeiterschaft und der ausländischen Konkurrenz versichert. Es hat auf die eigene Emanzipation verzichtet, um die Emanzipation der Arbeiterklasse aufhalten zu können und sich auf dem Weltmarkt zu bereichern.

So hat denn in Deutschland eine reinliche Arbeitsteilung stattgefunden: die Bourgeoisie im engeren Sinne organisiert die Weltwirtschaft und der Grundbesitz die Politik. Wir erblicken dort auf der einen Seite eine ausgezeichnete Organisation des feudal, d. h. vorkapitalistisch gebliebenen Staates, in der Mitte eine ausgezeichnete Organisation des Produktionsmechanismus und auf der anderen Seite eine ausgezeichnete Organisation der Arbeiterschaft auf allen Gebieten. Die straffe Organisation aller sozialen Formen ist also nicht nur das hervorstechendste Kennzeichen der deutschen Bourgeoisie, sondern geradezu des ganzen deutschen Volkes. Dieselbe Pflichttreue, dieselbe Fähigkeit der Unterordnung, dasselbe Teilmenschentum, dieselbe glänzende Bureaukratie, die wir im Staatswesen finden, finden wir mit allen ihren guten und schlechten Seiten in der Sozialdemokratie, und einzelne Züge davon selbst in jedem deutschen Kegelklub, kurz, überall, wo deutsche Männer deutsche Verbände gründen, wieder. Überall herrscht Pflichtbewußtsein, überall praktische Auffassung des Lebens, überall Unter- 
Das deutsche Charakteristikum der Organisationsfähigkeit $\quad$ I 87

ordnung, aber auch überall ein greifbarer Widerspruch zwischen äußerer Organisationsfähigkeit und innerer - psychischer - Desorganisation. Wenn wir das Seelenleben des mittleren Deutschen betrachten, kann es uns nicht entgehen, $\mathrm{daB}$ sich in ihm zwischen Theorie und Praxis, zwischen Denken und Tun ein ungeheurer Spalt auftut. Die Kluft zwischen der intellektuellen Revolution in Theorie und Wissenschaft und der oft kläglichen und fast stets kleinbürgerlichen Haltung des deutschen Normalbürgertums im Bereiche der Wirklichkeit macht sich überall auf dem Gebiete der Politik und des sozialen wie des persönlichen Lebens geltend.

Das formale Organisationstalent ist der hervorragendste Charakterzug der Deutschen. Aus ihm erklären sich ihre wirtschaftlichen und politischen Erfolge. Indes Organisation setzt Herdenqualitäten voraus und Mangel an Individualität. Je höher der Individualismus und das Gefühl für persönliche Freiheit in einem Volk entwickelt ist, desto geringer die Fähigkeit und die Tugenden der Organisation, wie z. B. die Italiener $z$ war die größten Individualisten und prächtigsten und intelligentesten Einzelmenschen, aber auch die schlechtesten Organisatoren sind. In Italien existiert - außer der Arbeiterpartei und den Republikanern - keine politische Partei, die irgendeine Struktur aufwiese oder ein Programm besäße. Aber auch die altberühmte französische Bureaukratie ist weniger gut staatsbureaukratisch, die altberühmten englischen Parteien sind weniger gut parteibureaukratisch organisiert als die entsprechenden Einrichtungen in Deutschland. Das macht sich auch im gemeinsamen internationalen Leben bemerklich. In der Gewerk. schaftsbewegung z. B. liegen fast alle internationalen Sekre. tariate heute in den Händen der Deutschen, weil sich gezeigt hat, daß die Engländer kein Sekretariat zur allgemeiner Befriedigung führen können. Ihrerseits sind die Franzoser außerstande, auch nur einen Kongreß gemütlich zu gestal. ten, während die Deutschen die geborenen Kongreßveran. 
stalter sind und die Kunst verstehen, zu leiten, zu führen wie zu folgen.

Die von uns im Laufe dieses Kapitels angedeuteten Tendenzen sind Momente, die mit dem guten Willen allein nicht verändert werden können. Wir haben es hier also mit „Natur"gesetzen, d. h. mit ursächlich bedingten, notwendigen Eigenschaften zu tun, die jenseits von Gut und Böse stehen. Infolgedessen vermögen wir in diesen Zusammenhängen zunächst keine Ziele aufzustellen. Unsere wissenschaftliche Aufgabe, die Aufgabe der Sozialphilosophie oder wenn man will der Soziologie, ist nicht in erster Linie eine teleologische, nicht mit dem Wunschvermögen zu bemeistern, sondern vorderhand lediglich eine klärende. Erst nach stattgehabter Klärung, nachdem im Völkerleben bestimmte Züge festgestellt sind, dann vielleicht - vielleicht - können aus diesen festgestellten Tatsachen Summen gezogen, und unser Wunschleben in dieser oder jener Form in den Tempel der Musen hineingetragen werden. Unsere erste Aufgabe ist aber eine rein wissenschaftliche, nicht politische. Sie besteht nicht darin, zu bestimmen, was gut und was schlecht angeordnet ist, sondern darin, festzustellen, wie die tatsächlichen Verhältnisse liegen und wohin die Tendenzen der Entwicklung führen.

\section{Zehntes Kapitel.}

\section{Zum Problem: Wirtschaft und Politik.}

Die ökonomische Betrachtungsweise der Geschichte ist im Zeitalter der großen technischen Erfindungen entstanden, welche die Herstellungsmittel im Produktionsprozeß jäh revolutionierten und jene quantitativ gewaltige Ära einleiteten, die wir als das Zeitalter der Maschinen oder, wenn sich beide Ausdrücke auch keineswegs decken, als das Zeitalter des Kapitalismus kennen. Es war ein italienischer National- 
ökonom zu Beginn des I 9. Jahrhunderts, der als politischer Flüchtling und Patriot sein Leben in England zugebracht hatte, Giuseppe Pecchio, welcher in einer kleinen Schrift, die er später auch als Anhang zu einem interessanten Bändchen über die Geschichte der Finanzen und der Volkswirtschaft im Königreich Italien ( $1802-1814$ ) herausgab und die er als Dissertazione sino a qual punto le Produzioni Scientifiche e Letterarie seguano le Leggi Economiche delle Produzioni in generale, zu deutsch: Abhandlung über die Frage, inwieweit die Erzeugnisse der Kunst und Wissenschaft den wirtschaftlichen Gesetzen der Produktion im allgemeinen folgen, betitelte, die Behauptung verfocht, daß insbesondere die geistige Produktion nicht von der Staatsform abhängig sei, sondern in Quantität wie in Qualität lediglich von den Gesetzen des Angebotes und der Nachfrage bestimmt werde. ${ }^{1}$ ) In der Geschichtschreibung selbst ist die systematische Bezugnahme auf die Wirtschaft zuerst von einem deutschen Historiker, Carl Wilhelm Nitzsch, in seiner Geschichte der Gracchen 1847 mit Glück und Konsequenz unternommen worden.')

Es ist aber erst das unbestreitbare Verdienst Marxens und Engels', die Sonderrolle der Produktivkräfte unter den geschichtsbildenden Faktoren nicht nur in ein System gebracht, sondern ihr auch durch die Schöpfung einer neuen Philosophie der Geschichte den gebührenden Platz angewiesen zu haben; zuerst in schroffer und unhaltbarer Form, derzufolge alle Erscheinungen, auf welchen Gebieten menschlicher Tätigkeit sie liegen, als direkte Folgeerscheinungen der Wirtschaft, „als Überbau“ eines Unterbaues von notwendigerweise wirtschaftlicher Beschaffenheit, aufgefaßt wurden;

I) Giuseppe Pecchio, „Dissertazione“, 1. c., p. I33; vgl. auch Paolo Orano, „Il Precursore Italiano di Carlo Marx“. Roma 1899, Voghera.

2) Vgl. C. Jastrow, „Carl Wilhelm Nitzsch und die deutsche Wirtschaftsgeschichte", im Jahrbuch für Gesetzgebung, Verwaltung usw. Jahrg. VIII (188I), p. $873-897$. 
später in einer wesentlich gemäBigteren Fassung, in der, laut Briefen Engels' aus den Jahren I 890 und 1894, zugegeben wird, daß Rechtsformen, politische, juristische, philosophische Theorien, religiöse Anschauungen bzw. Dogmen auf den Gang der Geschichte Einflüsse ausüben, die stark auf sie wirken und in vielen Fällen sogar vorwiegend ihre Form bestimmen. „Es sind also unzählige, einander durchkreuzende Kräfte, eine unendliche Gruppe von Kräfteparallelogrammen, daraus eine Resultante, das geschichtliche Ereignis, hervorgeht." Und weiter, in einem Briefe von I 895: „Die politische, rechtliche, philosophische, literarische, religiöse usw. Entwicklung beruht auf der ökonomischen. Aber sie alle reagieren aufeinander und auf die ökonomische Basis.“ "1)

Eine Vorbemerkung: Die soziale Gruppe unterliegt der ökonomischen Triebfeder in hohem Grade, wenn auch längst nicht absolut, schon weil ihr häufig die Erkenntnis der ökonomischen Notwendigkeit und Nützlichkeit fehlt, und sie deshalb, während sie glaubt, im Einklang mit dem ihr eigenen wirtschaftlichen Stimulus zu handeln, den ihrem wirtschaftlichen Vorteil entgegengesetzten Weg einschlägt. Der Einzelmensch hingegen kann sich sogar, sei es, daß er sich vom Fanatismus packen läßt oder daß er im Besitz hoher Charaktereigenschaften ist, von seinen ökonomischen Banden bewußt befreien, d. h. im persönlichen wie im politischen Leben ein Verhalten befolgen, das mit seinen ökonomischen Interessen in unversöhnlichem Widerspruch steht. In der Bewegung des Sozialismus haben wir, zumal in den Erstlingszeiten und in bestimmten Ländern, wie Rußland und Italien, aber auch in Frankreich, Perioden gehabt, in denen die Arbeiter von Enthusiasten und Idealisten aus den oberen Klassen angeführt wurden, die kein Opfer scheuten, wenn

1) Eduard Bernstein, „Die Voraussetzungen des Sozialismus und die Aufgaben der Sozialdemokratie". Stuttgart 1904, Dietz, p. 7 . 
es ihnen nur für die Sache, der sie sich weihten, Erfolg versprach, Männern wie der Fürst Krapotkin und der Marchese Carlo Cafiero, Großgrundbesitzern, die auf ihr Erbe verzichteten oder es bis auf den letzten roten Heller für die Zwecke ihres Ideals ausgaben, sich für ihre eigene Person mit kümmerlichster Lebensführung begnügend. ${ }^{1}$ ) Von dem individuellen Faktor wäre also bei der Betrachtung der uns hier interessierenden Frage überhaupt grundsätzlich abzusehen.

Die politische Verfassung und selbst das politische Leben einer Nation sind in der Regel weit davon entfernt, der entsprechende Ausdruck für die vorherrschende Form des Wirtschaftslebens zu sein, die wir in ihr vorfinden. Das überzeugendste Beispiel dafür ist die merkwürdige Antinomie, welche das Leben des modernen Deutschlands beherrscht. Ökonomisch betrachtet längst ein überwiegend industriellkapitalistisches Land - die in Handel und Gewerbe beschäftigte Zahl seiner Einwohner ist nicht nur nicht unbeträchtlich größer als der Prozentsatz des ackerbautreibenden Teiles seiner Bevölkerung, sondern das Verhältnis ändert sich noch jedes Jahr weiter zugunsten des ersteren - ein Land, das in vieler Hinsicht den Vergleich mit den am meisten typisch industriell-kapitalistischen Staaten derWelt, England, Belgien und Amerika, nicht zu fürchten braucht, trägt Deutschland, was Regierungsform, Regierungsgeist, Sitten und Gebräuche des Volkes anbetrifft, noch in hohem Grade feudalistisch-aristokratischen Stempel. ${ }^{2}$ ) In Preußen wird die "politische Klasse" noch aus Landjunkern und Staatsbeamten gebildet. Selbst den Söhnen der größten Industrieherren bleiben die als vornehmste geltenden Regimenter und Ämter verschlossen. Weiteres Symptom der von uns angezeigten Erscheinung: die Rechtsstellung der Landarbeiter unterscheidet sich in wesentlichen Punkten, und zwar zu ihren

1) Vgl. meine „Soziologie des Parteiwesens“" usw., l. c., p. $320 \mathrm{ff}$.

2) Vgl. hierzu unsere Ausführungen auf p. I 85 dieses Buches. 
Ungunsten, von der Rechtsstellung der Industriearbeiter. Mit anderen Worten: die ökonomisch in die zweite Linie gedrängten Landbesitzer haben sich als politisch widerstandsfähiger gegen den Ansturm der Arbeiterbewegung und ihren Einfluß auf den Staat erwiesen als die ökonomisch stärkeren "Bourgeois" in den Städten. Treffend bemerkt ein gelehrter ungarischer Bibliothekar und Marxist, Ervin Szabó, die gleichm wirtschaftliche Basis erzeuge in den einzelnen Ländern, je nach den in ihnen vorhandenen Stärkeverhältnissen der wirtschaftlichen Untergründe der Vergangenheit und der alten Traditionen, voneinander stark abweichende soziale Strukturen. ${ }^{1}$ )

Ähnliche Beobachtungen wie die hinsichtlich der Beziehungen zwischen Wirtschaft und Präponderanz bestimmter Klassen im politischen Leben lassen sich auf fast allen an. deren Gebieten machen. So auch, trotzdem man nicht immer ohne Glück den Protestantismus als die Konfession der Reichen hat darstellen wollen, auf dem Gebiete der Religion. Max Weber hat recht, wenn er vor dem Versuche warnt, die religiösen Bewegungen schlechterdings zu Reflex- oder Folgeerscheinungen wirtschaftlicher Vorgänge $\mathrm{zu}$ degradieren. Sehr zupaß macht er darauf aufmerksam, daß die religiöse Spaltung im sechzehnten Jahrhundert senkrecht durch die von ihr betroffenen Volksgesamtheiten durchgegangen sei; erst später habe sich, allerdings teilweise durch Motive wirtschaftlicher Art, manchenorts eine ständische Scheidung auf konfessionellem Gebiete vollzogen. ${ }^{2}$ ) Auch im Staatsrecht läßt sich nicht ohne weiteres eine bestimmte Herrschaftsform als notwendiger Überbau bestimmter Wirtschaftsund Produktionsverhältnisse mit historisch gültigen Argu-

1) Ervin Szabó, „Politique et Syndicats“. Mouvement So. cialiste, Année XI, p. III.

2) Auf dem I. deutschen Soziologentag in Frankfurt, Oktober 1910. Protokoll der Verhandlungen, Tübingen 1911, Mohr, p. 198. 
menten nachweisen. Den Despotismus finden wir in der Tyrannis vieler Stadtgebiete der Magna Graecia, im römischen Imperium, in manchen mittelalterlichen Feudalstaatswesen, im Kaiserreich Frankreich und bei dem Hirtenvolk der Kaffern, also auf der verschiedenartigsten ökonomischen Basis in Blüte. ${ }^{1}$ )

Die Genesis derStaaten ist nie allein auf ökonomische Notwendigkeiten zurückzuführen, häufig steht sie zu ihnen in absolutem Widerspruch. Zur ersten These: in der Bewegung, die zurEinheitDeutschlands und der parallelen Bewegung, die zur Einheit Italiens führte, haben wirtschaftliche Wünsche, insbesondere die Sehnsucht nach einem zur Entwicklung eines groBen Handels und einer mächtigen Industrie nötigen einheitlichen weiten Zollgebiet, das Bedürfnis, alle dem Aufblühen von Handel und Wandel im Lande imWege stehenden Schranken der Kleinstaaterei niederzureißen, teils bewußt, teils unbewuBt mitgespielt. ${ }^{2}$ ) Kein Historiker von Fach, welcher Partei er immer angehören möge, wird aber leugnen können, daß das auf vorzugsweise linguistischer Grundlage entstandene Vaterlandsgefühl und die nur sehr lose mit wirtschaftlichen Motiven zusammenhängende Aktion des Nationalitätenprinzips ebenfalls in stärkster Weise zur Entstehung der beiden Reiche beigetragen haben. Auch bei der Loslösung Belgiens von Holland I 830 war die wirtschaftliche Triebkraft besonders spürbar. Immerhin hätte sie allein vielleicht nicht genügt, wäre ihr nicht der Umstand zu Hilfe gekommen, daß das

1) Vgl. Adolfo Asturaro, „Il Materialismo Storico e la Sociologia Generale". Genova 1904, Libr. Moderna, p. 293.

2) Man lese für Italien die allerdings sehr skizzenhaften Artikel von Giuseppe Prezzolini, „Fattori Economici nel Risorgimento Italiano", in der Voce, Anno III, Nr. I; und von Arnaldo Agnelli, "Il Materialismo Storico e il Risorgimento Italiano", in der Vita Internazionale, XVI, Nr. 7-9; sowie von demselben, „Il Materialismo Storico e il Risorgimento Italiano. Posizione del Problema", in den Rendiconti del Reale Istituto Lombardo di Scienze e Lettere, Vol. XLVI, fasc. 5 (Pavia 1913).

Michels: Probleme der Sozialphilosophie 
französische oder französierte Bürgertum der belgischen Provinzen durch sprachlichen und persönlichen Kontakt mit dem nahen Frankreich einen Teil der liberalen Grundideen der französischen Revolution und der Ära Napoleon in sich aufgenommen hatte, während das abgeschlossen lebende Holland noch ganz überwiegend konservativen Gedankenrichtungen zugetan war, so daß zwischen den beiden Völkern außer dem wirtschaftlichen Gegensatz ein solcher mentaler Art, und zwar nicht aus der Wirtschaft, sondern aus der Geographie sowie der politischen Geschichte geborener, obwaltete.

Zur zweiten These: es gehört zu den elementarsten Erkenntnissen der Geschichtsforschung, daß sich insbesondere vom vierzehnten bis zum Beginne des neunzehnten Jahrhunderts die Staatenbildung, ganz unabhängig von den wirtschaftlichen Bedingungen der Länder, auf Grund von dynastischen Familienbeziehungen vollzogen hat. Österreich hat, nur wirtschaftlich betrachtet, niemals eine Existenzberechtigung besessen, ebensowenig das aus Katalonien und Kastilien durch eine Königsheirat zusammengeschweißte Spanien, ein zwar geographischer, aber so wenig ökonomischer Begriff, daß die Intelligenteren unter den Katalanen (die sog. Separatisten) schon seit dem 17. Jahrhundert eine reinliche Scheidung von den ethnisch wie ökonomisch gleich wesensfremden westlichen Gebietsteilen der Pyrenäenhalbinsel erstreben.

Dagegen kann das Dazwischentreten starker politischer Maßregeln je nachdem die Wirtschaft gewaltig heben oder in Grund und Boden ruinieren. Es ist wirtschaftshistorisch nicht unstatthaft, den wirtschaftlichen Niedergang Spaniens mit derVertreibung der dortigen Juden und den fast gleichzeitig eintretenden Beginn des Aufschwungs der nördlichen Niederlande, insbesondere Amsterdams, mit der Tatsache, daß sich der größte Teil dieser Juden gerade jenen Landesstrichen zuwandte (1492, 1609/1 1 ), in nahe Verbindung 
zu bringen. In der Tat datiert die Entwicklung Amsterdams außer vom Ruin Antwerpens durch die Spanier und von der Einwanderung der Vlamen (I 579- I 586) von der Immigration von 5000 Juden aus der Pyrenäenhalbinsel her. Ebenso hat die Rückgängigmachung des Edikts von Nantes oder, wie man will, von Nîmes durch Ludwig XIV. im Jahre I 685 und die darauf innerhalb der nächsten drei Jahre erfolgte Auswanderung von über 50000 Familien - man hat später den Exodus sogar auf 400000 Menschen und mehr veranschlagen wollen - Frankreich in demselben MaBe verarmt, als sie seinen Grenznachbarn außer Spanien kommerziellen und industriellen Nutzen gebracht hat. Voltaire sagt von diesen Refugiés sehr treffend, daß sie allèrent porter chez les étrangers les arts, les manufactures, la richesse. Presque tout le Nord de l'Allemagne, pays encore agreste et dénué d'industrie, reçut une nouvelle face de ces multitudes transplantées. Elles peuplèrent des villes entières. Les étoffes, les galons, les chapeaux, les bas, qu'on achetait auparavant de la France, furent fabriqués par eux. Un faubourg entier de Londres fut peuplé d'ouvriers français en soie ; d'autres y portèrent l'art de donner la perfection aux cristaux, qui fut alors perdue en France. ${ }^{1}$ ) Die unglückliche französische Politik hatte die Errungenschaften der französischen Industrie nach dem Ausland verpflanzen helfen.

Die beiden von uns hier herangezogenen Fälle, der spanisch-jüdische wie der französisch-hugenottische, sind typische Fälle historischer Begebenheiten von höchstar Ber deutung, welche obgleich politischer Quellementsprungen, mächtige Umwälzungen auf wirtschaftlichem Gebiete nach stch gezogen haben. Wirtschaftlicher Uberbau auf psychologischer - Ideologischer, ja, ausgesprochen religiöser Basis. Religiöse Unduldsamkeit wurde da zum Anlaß, daß der ge-

I) Voltaire, „Siecle de Louis XIV". (Ausg. Paris I864, Didot, p. 419.) 
werblich oder kaufmännisch brauchbarste Teil der Einwohnerschaft das Land verließ und seine Emsigkeit, seinen Gewerbefleiß exportierte. Im habsburgischen Spanien die Juden und Judenstämmlinge (Marranos), d. h. die Angehörigen einer Rasse, die, um mit Sombart zu sprechen, als die „Inkarnation kapitalistisch-kaufmännischen Geistes" angesehen werden $k_{a n n}{ }^{1}$ ) und die in den Peregrinationen, die zu unternehmen sie in der Geschichte gezwungen war, wo immer sie auftauchte, sofern man ihr nur irgendwie Bewegungsfreiheit gestattete, Handel und Wandel zur Blüte gebracht, und, umgekehrt, wo immer man sie vertrieb, wirtschaftliche Stagnation oder Zerfall als Fluch hinterlassen hat. ${ }^{2}$ ) Im bourbonischen Frankreich die Bewohner der industriell am höchsten entwickelten Provinzen, insbesondere des Südens. Es ist klar, daß ohne diese politis chen Erscheinungen die wirtschaftliche Entwicklung, hier Hollands, dort zumal des protestantischen Deutschlands, nicht oder doch erst sehr viel später und langsamer eingetreten wäre. Die Ätiologie der Verpflanzungen der Industrie von einem Land in ein anderes mittels starker, durch politische Unterdrückung hervorgerufener Wanderungen, weist in Begebenheiten, wie den vorliegenden, keineswegs auf verborgen liegende Triebkräfte wirtschaftlicher Natur. Meines Wissens hat denn auch zurzeit kein

I) Vgl. u. a. Werner Sombart, „Der moderne Kapitalismus". Leipzig 1902. Vol. II, p. 349, auch I, p. $266 \mathrm{ff}$.

2) $\mathrm{DaB}$ die Juden selbst trotz aller unfreiwilligen Wanderungen auf ihre Kosten kamen, liegt auf der Hand. Teils arm, zum großen Teil verarmt, waren die Juden in der ersten Hälfte des 17. Jahrhunderts aus Portugal und Deutschland nach Amsterdam gekommen. Schon 1672 konnten sie, als der französische General Prinz von Condé auf holländischem Gebiet stand, ihm ohne Not (die Franzosen waren eben erst in die Betuwe eingebrochen) 2 Millionen Gulden bieten, um einer eventuellen Plünderung bei der Eroberung von Amsterdam zu entgehen (s. "Mémoires de Monsieur de Gourville concernant les affaires aux quelles il a été employé par la cour depuis 1642 , jusqu'en 1698." Paris 1724. Tome II, p. 159). 
noch so intransigenter Anhänger des historischen Materialismus das Wagnis ernsthaft unternommen, die Judenauswanderung aus Spanien oder den Hugenottenzug aus Frankreich als Glieder in die Kette der materialistisch-historischen Phänomene im Marxschen Wortsinne einzureihen. Dem Stande der heutigen Forschung zufolge stehen wir also in beiden Fällen immer noch vor der Tatsache, daß durch politisch-religiöse Momente bedingte Metamorphosen der Wirtschaft möglich sind. Grundsätzlich ist freilich die Frage nicht außer acht zu lassen, ob die politische Maßregel, welcher es gelang, wirtschaftliche Ringe umzuformen, nicht am Ende selbst ihrerseits von ökonomischen Ursachen hervorgerufen sei. Aber die Antwort auf die Frage wird nicht immer in affirmativem Sinne ausfallen.

Diese Erkenntnis ließe sich in einigen Bänden voller Beweise aus dem historischen Leben aller Zeiten und aller Völker illustrieren. Es sei uns gestattet, aus der Fülle des Beweismaterials, das uns zur Verfügung steht, wenigstens einige Beispiele herauszugreifen.

Die Kontinentalsperre hat trotz ihrer kurzen Dauer und ihrer unvollständigen Durchführung auf Handel und Industrie des Festlandes wie Englands selbst eine geradezu revolutionäre Wirkung ausgeübt. Sie hat die alten Beziehungen zwischen Import und Export über den Haufen geworfen und andere an ihre Stelle gesetzt, sowie endlich in fast allen Ländern, es wäre wissenschaftlich nicht einmal anfechtbar, wollten wir die Worte hinzufügen: mit einem Schlage, neue Industriezweige ins Leben gerufen. In Italien, das im I 8. Jahrhundert von England her mit Töpferwaren überschwemmt gewesen war, entstanden nach dem Einfuhrverbot dieser Artikel durch den König Napoleon allerorten nationale Töpfereien und Fabriken - so in Como, Mailand, Treviso, Pavia, Vicenza und Bologna. Andererseits ging durch die politische Aktion die zumal in Bologna blühende Industrie der Kreppstoff- und Kreppschleierfabrikation (veli crespi), deren Be- 
deutung besonders auf der Höhe des Exportes nach Eng. land beruht hatte, zugrunde, während die Engländer das Ausbleiben der Bologneser Einfuhr an dieser Ware durch Gründung eigener Fabriken zur Herstellung der Schleier ausglichen. Der Einfluß der Kontinentalsperre auf die Gestaltung von Handel und Gewerbe in Italien läßt sich, wie der bereits erwähnte zeitgenössische Nationalökonom Giuseppe Pecchio sich ausdrückt, geradezu in den Satz zusammenfassen, daß alle Industrien, die auf den inneren Markt angewiesen waren, einen ungemeinen Aufschwung zu verzeichnen hatten, während hingegen diejenigen Industrien, die für die Ausfuhr gearbeitet hatten, stark zurückgingen. ${ }^{1}$ ) Nicht anders stand es in anderen Teilen des europäischen Kontinents, wie z. B. in den Rheinlanden. Der Handel, insbesondere der Transithandel, zumal der Handel in den den englischen Kolonien entstammenden Kolonialwaren, litt schwer. Daran vermochte selbst der auf ziemlich breiter Basis betriebene Schmuggel, an welchem sich gelegentlich selbst Kölner Patrizier beteiligten, auf die Dauer nichts zu ändern, insbesondere als die napoleonische Energie schlieblich zu dem Gewaltmittel der Verbrennung aller auf dem Kontinent angetroffenen englischen Waren ihre Zuflucht nahm. Andererseits entstanden auf dem linken Rheinufer, unter der eifrigen Protektion der französischen Regierung, wichtigste neue Industriezweige wie, zum Ersatz des Rohrzuckers, mächtige Rübenzuckerfabriken ${ }^{2}$ ) - wie denn die heute blühende Zuckerindustrie auf dem Kontinent überall der politischen Maßregel der Bekämpfung Englands durch das Em-

I) Giuseppe Pecchio, „Saggio Storico sulla Amministrazione Finanziera dell' Ex-Regno d'Italia dal 1802 al 1814 ". Torino 1852. Ausg. der Biblioteca dei Comuni Italiani, p. I I8/1 19.

2) Mathieu Sch wa nn, ,Geschichte der Kölner Handelskammer“. Köln a. Rh. 1906. Neubner, p. 289; desgl. für Italien G. Camillo Borgnino, „Cenni Storico-Critici dell' Industria dello Zucchero in Italia." Bologna I9ı. Zanichelli, p. 64. 
pire ihre Entstehung verdankt - sowie bedeutende Flachsand Leinwandspinnereibetriebe, dazu bestimmt, die englischen Baumwollwaren entbehrlich zu machen ${ }^{1}$ ) - in Köln allein sollen I 8 I 3 nicht weniger als 23 Baumwollmanufakturen bestanden haben ${ }^{2}$ ) - ferner, ebenso wie in Italien, Steingutfabriken. Die französische Herrschaft hatte Köln als niedergehende Handelsstadt vorgefunden; die napoleonische Politik gab dem Kölner Handel den TodesstoB, bewirkte aber, dab die Stadt sich binnen fünfzehn Jahren in eine blühende Industriestadt verwandelte.

Nicht nur das Zollsystem, auch das Schlachtenglück kreiert oder, je nachdem, vernichtet letzten Endes ganze Industrien. Der Übergang einer Provinz von einer Hand in die andere bedeutet häufig eine völlige Umwälzung der in ihr obwaltenden industriellen und kommerziellen Verhältnisse. Diese Umwälzung erklärt sich durch den Wechsel des Absatzmarktes, seinerseits hervorgerufen durch die mit jedem Besitzwechsel verbundene Verschiebung der Zollgrenzen. Das wird deutlich z. B. durch eine Betrachtung der handelspolitischen Folgen der Loslösung des linken Rheinufers von Frankreich (1815). Sie bedeutete für die rheinische Industrie zunächst den Verlust des französischen Marktes, den sofortigen Neuausbruch eines über alle Maßen erbitterten Zollkrieges mit den Holländern, die mit ihren Zöllen die Schiffahrt fast völlig lahm legten - mußten die Kölner im Jahre I 822 doch eine Ladung von 300 Tonnen Heringen, die sie aus Schweden hatten kommen lassen, vor der Einfahrt in holländische Gewässer ins Meer senken, da der Durchgangszoll, den die Holländer auf sie erheben wollten, von solcher Höhe war, daß die Fische in Köln unverkaufbar geworden wären. ${ }^{3}$ ) Am schlimmsten aber wirkte die mit der

I) Schwann, p. 289 .

2) idem p. 315 .

3) idem p. 40I. Über den heftigen Gegensatz der Rheinlande 2u Holland siehe auch Karl Kumpmann, ,Entstehung der Rheinischen Eisenbahn-Gesellschaft". Essen a. Ruhr I910, p. $j$ I. 
Annexion der Rheinlande durch Preußen verknüpfte Aufhebung der zum Schutz der dortigen jungen Industrie errichteten französischen Prohibitivzölle. Wie eine Verheerung brach mit der Etablierung des free trade die englische Konkurrenz herein und bereitete in kurzer Zeit der neuen Baumwollfabrikation, selbst der Zuckerfabrikation im Kölnischen ein jähes Ende; ähnlich der Seidenindustrie. ${ }^{1}$ ) Erst spätere Ereignisse, insbesondere die direkte Verbindung Kölns mit dem Meere durch Bau der Eisenbahnstrecke nach Antwerpen, welche die Stadt endlich von der Rheinschiffahrt und den holländischen Besitzern der Flußmündung unabhängig machte, brachten Handel und Industrie wieder zu erneuter, ja unerhörter Blüte. Aber ein Teil der von Napoleon geschaffenen Industriezweige blieb auch dann tot. Ein weiteres Beispiel für den häufigen Fall, daß ein Land durch den durch politische Ereignisse hervorgerufenenWechsel seiner Staatszugehörigkeit in schwere wirtschaftliche Krisen gestürzt wird, bietet die Geschichte Elsaß-Lothringens vor und nach I 870 . Durch die Eroberung und Besitzergreifung durch Deutschland verlor die elsässische Textilindustrie den französischen Markt und mußte sich erst in schwerem Ringen im Reiche ein Äquivalent suchen. Dabei ging diese Umschaltung nicht ohne Spuren vorüber, sondern brachte wichtige Veränderungen in diesem Gewerbezweig hervor. So hat die elsässische Baumwollindustrie seit der Annexion im ganzen eine Einbuße erlitten, während die Wollindustrie sich nach einer kurzen Pause glänzend entwickelte.

Auch indirekt vermögen, auf dem Mittelswege psychischer Suggestion und Autosuggestion, politische Ereignisse richtunggebend auf die Wirtschaft einzuwirken. Ein so gut wie unbekanntes, aber wie uns scheinen will, belangreiches Beispiel ist folgendes: Im Jahre 1576 starb König Sebastian von Portugal, fünfundzwanzigjährig, in der Schlacht bei Al-

I) Schwann, p. 393 . 
kassar gegen die Mauren. Dieser Tod bezeichnete den Beginn einer langen für Portugal unheilvollen Ära. Es geriet unter spanische Fremdherrschaft, und seine wirtschaftlichen Interessen wurden dauernd geschädigt. Das Volk aber schenkte der Tatsache des Todes seines Fürsten keinen Glauben, sondern fuhr fort, der Rückkehr Sebastians in sein Vaterland, welche das alte Glück und die Blüte des portugiesischen Handels und Wandels wieder erneuern sollte, zu harren. Diese Hoffnung, welche auf die Dauer die Form des Aberglaubens annahm, ergriff bald auch das einheimische Wirtschaftsleben. Noch anfangs der sechziger Jahre des siebzehnten Jahrhunderts, also über hundert Jahre nach der Geburt des gefallenen Königs, war die Sitte in Portugal verbreitet, daß Waren oder auch Geld auf Kredit gegen die Verpflichtung des Schuldners, dem Gläubiger bei der Rückkehr des Königs Sebastian das Doppelte vom Wert des Geliehenen zurückzuerstatten, ausgeliehen wurden. ${ }^{1}$ ) Es ist begreiflich, daß diese merkwürdige Sitte gewaltige Verschiebungen in der Vermögensverteilung unter der Bevölkerung verursachen und nicht unerhebliche wirtschaftliche Krisen in der Geschäftswelt hervorrufen mußte.

Die Erkenntnis der politischen und ideologischen Kräfte, welche die Wirtschaft bisweilen bestimmend durchkreuzen, hat einzelne Wirtschaftshistoriker, merkwürdigerweise besonders in England, dazu verleitet, die Wirtschaftsgeschichte überhaupt als ein Anhängsel der politischen Geschichte zu betrachten und, die These Marxens in ihr Gegenteil umkehrend, sich für eine Geschichtsauffassung auszusprechen, gemäß deren die erstere nur als Überbau der letzteren erscheint. Nach W. Cunningham zum Beispiel ist die gesamte Geschichte des Handels und der Industrie Großbritanniens durch

I) "Mémoires de Monsieur d'Ablancourt, envoyé de Sa Majesté Très-Chrétienne Louis XIV en Portugal, contenant l'Histoire de Portugal depuis le Traité des Pyrénées de 1657 , jusqu'à I $6,68^{\circ}$. A la Haye 170 I. Ellinckhuysen, p. I 8. 
Vorgänge der politischen Geschichte, wie die Heirat Edwards III. mit Philippine, die Grausamkeit des Herzogs von Alba gegen die Niederländer, die Sinnesart der Stuarts usw. bestimmt. Er führt wörtlich aus, die Politik Englands sei nie ein direkter Ausfluß der Wirtschaft dieses Landes gewesen, während man wohl sagen könne, daß das wirtschaftliche Leben Englands direkt und unausgesetzt von den Geschehnissen in der Politik beeinflußt worden sei. Die wirtschaftliche Entwicklung Großbritanniens habe sich nach und nach den vorausgegangenen politischen Ereignissen anpassen müssen. Die englische Geschichte werde überhaupt erst dann verständlich, wenn man sich daran gewöhnt habe, das wirtschaftliche Geschehen in ihr dem rein politischen unterzuordnen. Selbst die englische Weltwirtschaft und das Kolonialsystem verdankten ihre Entstehung letzten Endes nicht wirtschaftlichen Bedürfnissen, sondern politischem und individuellem Ehrgeiz. Die Form der industriellen Institutionen sei in der Hauptsache schlechterdings lediglich als eine Folgeerscheinung der Politik zu fassen. ${ }^{1}$ ) Kürzlich ist auch in Deutschland ein beredter und genialer Gelehrter mit der Behauptung aufgetreten, daß nicht die Wirtschaft den Krieg, sondern umgekehrt der Krieg die Wirtschaft gebäre. $\left.{ }^{2}\right)$ Indes eine solche Auffassung ist ebenso einseitig wie jene, welche die Menschheitsgeschichte nur als eine Geschichte von Mandataren vermeintlicher ökonomischer Grundgesetze betrachtet. ${ }^{3}$ ) In Wirklichkeit übt keiner der Faktoren, welche das geschichtliche Werden bestimmen, alleinige Wirkung aus. Die endgültige Gestaltung der Dinge resultiert aus dem Walten vieler und ihrem Wesen nach verschiedener

1) W. Cunningham, „The Growth of english Industry and Commerce in modern Times". Cambridge 1905, p. 9.

2) Werner Sombart, „Krieg und Kapitalismus“. München 19r3. Duncker u. Humblot.

3) Vgl. Arturo Labriola, „Il Capitalismo“. Torino IgIo. Bor, p. $12 \mathrm{ff}$. 
Feststellg.d.Quantiläten als bestimmt vorauszusetz. Qualitätswerte 203

Kräfte. Die schwierige Aufgabe des Geschichtsphilosophen liegt darin, den historischen Einzelfall, den er zu untersuchen unternimmt, ätiologisch zu prüfen, das heiBt seine Entstehungsursache in ihre Koeffizienten zu zerlegen, deren Vielheit festzustellen und Zusammenhänge zu analysieren. Er wird dann in der Mehrzahl der Fälle feststellen müssen, daB kaum je der Ausbruch eines Krieges ernster wirtschaftlicher Triebkräfte entbehrt hat; selbst die sogenannten Kabinettskriege, Raubkriege und Launenkriege nicht. So hat der berühmte Einfall Ludwig XIV. von Frankreich in Holland im Jahre 1672 zwar längste Zeit als Muster eines geschichtlichen Ereignisses, das nur aus dem Tel est mon bon plaisir eines über alle Begriffe eitlen Monarchen zu erklären sei, gegolten und hat man sich lange als Erklärungsursache mit dem angeblichen Ärger des Bourbonen darüber, daß ihn die Gazetiers in den Generalstaaten in ihren Gazetten schlecht behandelten, begnügt. ${ }^{1}$ ) Heute indes wissen wir, daß der Krieg außer dem Wunsche, die spanischen Niederlande dem Gebiet der französischen Monarchie einzuverleiben, der in den Industriekreisen des Königreiches vorherrschenden Meinung von der Notwendigkeit entsprungen war, dem zwischen Holland und Frankreich wütenden Tarifkriege durch die Vernichtung des holländischen Handels ein für den jungen französischen Konkurrenten günstiges Ende zu bereiten. ${ }^{2}$ ) Andererseits sehen wir aber in den modernen Kriegen, in

I) So heißt es typisch: „Il pousse le mépris des hommes jusqu’à faire la guerre pour une médaille", selbst in der sonst so lichtvollen Abhandlung von Pierre-Edouard Lémontey, „Essai sur l'Etablissement Monarchique de Louis XIV“. Paris I8I8. Déterville, p. 376.

2) Der Generalkontrolleur der Finanzen, Staatssekretär Marquis de Lyone, fragte 1670 einen seiner Vertrauensmänner: "Qu'imaginezvous qu'on pourroit faire pour ôter le commerce aux Hollandois?"“. Dieser antwortete prompt: "Il n'y a point d'autre moyen pour cela que de prendre la Hollande“. Der bei dem Gespräch anwesende Prinz von Condé bekannte sich zu ganz der gleichen Meinung. (Vgl. Mémoires de Gourville, 1. c., II, p. 65.) 
denen die ökonomischen Beweggründe anerkanntermaßen sichtbar hervortreten, stets auch eine Reihe heterogener Faktoren tätig; fast stets spielen zu ihrer Entstehung neben den Triebfedern wirtschaftlicher Substanz auch andere Motive, wie z. B. das erweckte nationale Bewußtsein moderner Massen mit; so selbst in dem typischen Börsen- und Diamantfelderkrieg der Engländer in Transvaal, der in dem seit Jahrhunderten genährten $\mathrm{HaB}$ der alteingesessenen Hollanders gegen die englischen Parvenus und überhaupt in dem Kampf zwischen zwei verschiedenen, wenn auch beide dem sogenannten germanischen Stamme angehörigen Völkern, eine zweite, der rein wirtschaftlichen an Schwerkraft durchaus ebenbürtige Ursache aufwies.

So wird sich denn die Methode wirtschaftshistorischer und historischer Untersuchungen im ganzen in die Warnung zusammenfassen lassen, die jedem Wissenschaftler auf seinen Wegen mitzugeben wäre: Wehe dem, der nicht in jedem Einzelfall, von allen ideologischen Motivierungen abstrahierend, sich die Frage vorlegt nach den wirtschaftlichen Wurzeln des zu analysierenden Phänomens. Aber auch wehe dem, der sich nicht bewuBt bleibt, daß fast jede Erscheinung auf dem Gebiet kollektiver Tätigkeit ihre Entstehung auch noch weiteren Koeffizienten verdankt. Letzten Endes muß die Analyse aller geschichtlichen Ereignisse auf einer Feststellung der verschiedenen Quantitäten als bekannt vorauszusetzender Qualitäten (Wirtschaft, Rasse, Pläne, Tradition usw.) beruhen. 


\section{NAMENVERZEICHNIS}

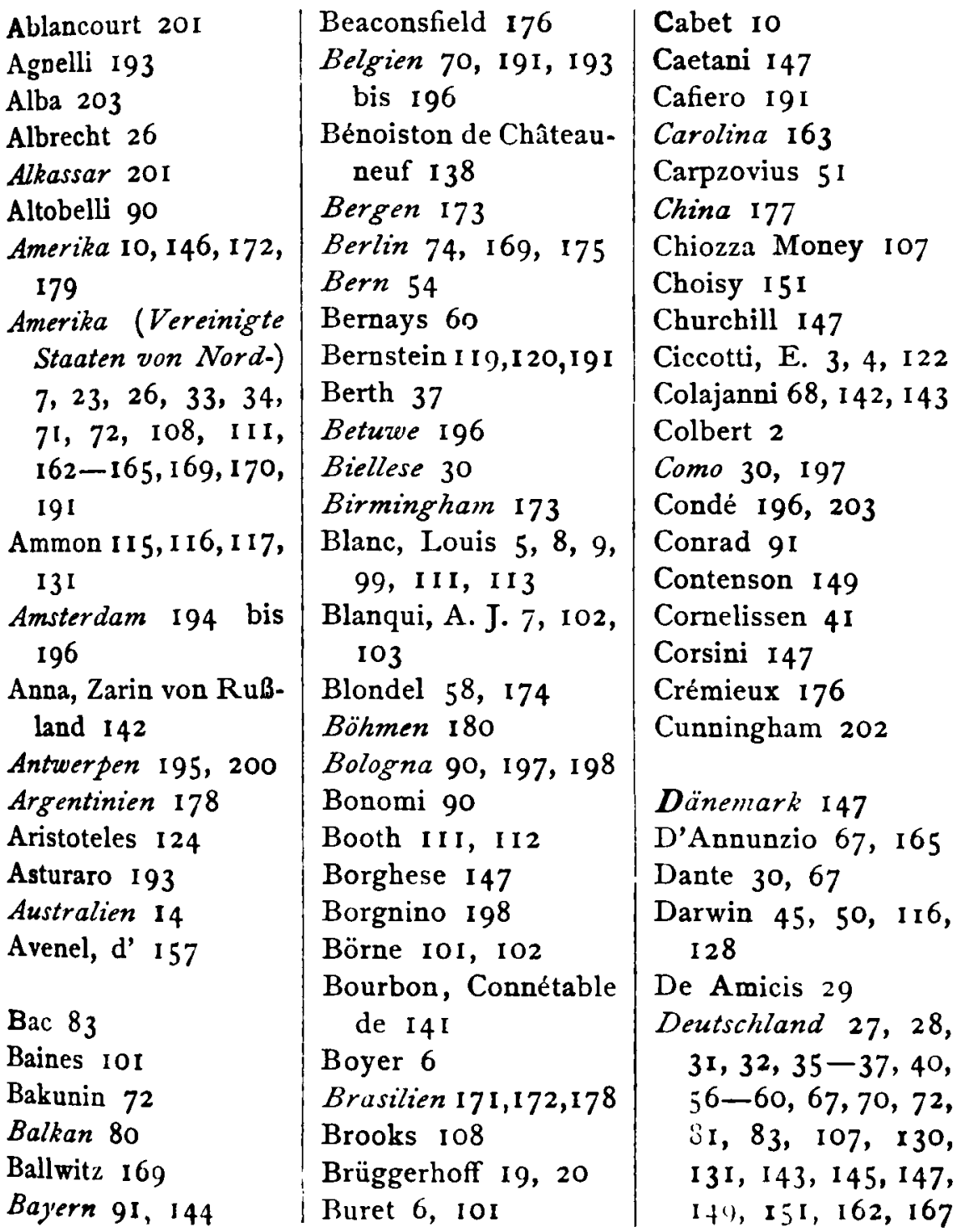


bis 187, I91, 193, Friedrich der Große I95, 196, 200, 202 Dresden 174

Dreyfus, A. I70, 174 Dreyfus, F. 3

Dufau 7

Dunois I 4 I

Edward III. 202

Einaudi 178

Elsa $\beta$-Lothringen 200 Emilia 30

Engels 6, 10, I I 1, I89, 190

England 6, 9, 10, 59, $67,79-8 \mathrm{I}$, IоI, 107, I I I, I 44, I 47, I 62, I63, I67, I68, $171-173,176,177$, $179,182,184,185$, I 87, I 89 , I 9 I, I 97 , I $98,202,204$

Eugen von Savoyen I 41

Europa 10, 72, 76, 149, 163, 198

Fahlbeck 134-137

Ferri 128

Feuquières 138

Florenz 147

Fourier 6, 7, 13,80 Frankreich 6-9, I1, $23,34,67,72,80$, $83,98,99$, IOI bis $104,138,144,149$ bis $152,156,157$, I62, I63, I70, I7 I, 1 74- 177, 179, I 80 bis $185,187,190$, I 93-200, 203

Fried 7 I

\section{47}

Fuchs, Ed. 93

Gädke 145

Gambetta 176

Garofalo 55

Gaston d'Orléans I 41

Genua I66

Georgi 15

Gide 14

Godawari 172

Goethe 67

Goldscheid $48-50$, I 2 I

Gourville 196, 203

Griechenland 174

Grimani 147

Guasco I 52-I 56

Gustav Adolf 134

Häckel I I 5, I 24

Halen, Don Juan van 70

Harbutt Dawson 58

Haulleville 86

Heine, H. 159

Herkner 23

Hervé $7 \mathrm{I}$

Hessen 93

Heyl von Herrnsheim 153

Hitze 36

Holland I65, 193 bis I96, I 99, 200, 203

Holmes 107,108

Holyoake 10

Hourwich 108

Hugenotten 195, 197

Hunter 7, I I I

Huygens I 25, 126

Hyndman 6
Ibsen 67

Indien 59, 64, 172, 173

Irland 70

Italien I6, I 7, 29, 30, $36,40,43,56,57$, $60,62,66,67,70$, $72,73,88-90,127$, 1 29, I 3 I, I 44-I 47, $152--156,162,165$, 166, 168-170, 174, $176-180,182$ bis I 85, I 87-I9I, I 93, 197-I99

Jastrow I 89

Jaurès 99, I00, I 26 Juan de Austria I4 I Fuden $61,62,63,148$, I 49, I 54, I 75-I 77, 195-197

\section{Kaffern 193}

Kalifornien 14

Kanada 3, 163

Karlsruhe 140

Kastilien 194

Katalonien 80, 194

Kautsky 17, 21, 100, 107, I 14

Ketteler 36

Köln 146, 198-200

Konstantinopel 177

Krapotkin 19I

Kroaten 36

Krupp 28

Kumpmann 199

Kurella 65 , 147, 148

Labriola, Art. 2 I, 26, $38,108,202$

La Fare 103, 104

Lafargue 25, 126 
La Grasserie 109

Lamennais 7-9

Lamprecht 121, 122

Lange, F. A. 59, I I 5, 116

Lapouge 130

Lassalle 185

Ledru-Rollin 6, 80

Lémontey 203

Leone 126

Lerda-Olberg 69

Levi dei Veali 154

Lewis 7, 25

Linck 28

Lindner 70,122

Linné 14

Livorno 174

Lombardei 179

Lombroso, C. 65, 127 bis 129

Lombroso, G. 68, 69

London 44, 80, II I, 195

Lorenz 131

Lorenzoni 30

Loria 44, 94, 117

Louisiana 163

Ludwig XIV. 3, 103, 104, 150, I 5I, 195, 203

Lyone 203

Mailand 197

Malkewitz 27

Manchester II I

Mannheim I38-I4I

Mantova 89, 90

Maria Theresia 88

Marlo I 30

Marokko 177

Marranos 196

Marx, Marxismus 6 , I0, $12,13,28,50$,
$72,79,106$, I10, I I I, I 22, I25, 126, I 28, I3I, 160, 16I, I 70, 184, 189, 192, 197,201

Massachusetts 163

Mauren 201

Medici del Vascello

153

Mercier 175

Merlino 38

Messina 166

Meyer, Ed. 122

Mitra 172, 173

Mittermaier 88

Molière 67, I 5 I

Mönkemöller 92

Moritz von Sachsen

I4I

Mosca 20

Nantes 195

Napoleon I. 38, 70, 194, 197-200

Napoleon III. 83

Naumann 36, 182

Neger 7 I

Véu' York I 64

Niceforo I08, I09, 120, I 21, 129 bis I 31

Niederlande 202, 203

Nietzsche 50, 53

Nimes 195

Nitzsch 189

Norwegen 67, 70, 173

Novarese 30

Novikow I 8, II 9

Nürnberg 174

Oldenberg I9, 8 I

Orano, D. I I I, I I 2

Orano, P. 184
Österreich 27, 36, 52, $60,87,88,127,169$,

I 79, 194

Ottolenghi 154,176

Owen 9

Pantaleoni 78

Paoletti 16

Pareto 131-I33

Paris 26, 74, 146

Passy 106

Pavia 197

Pecchio 66, 67, 189, 198

Piemont 166, I77

Piräus 174

Pisa 174

Po 30, 177

Polen 70, 182

Pompadour 142

Portugal 196,200,20 I

Prato 73

Preußen 33, 62, 63, I43, I45, I47, 148,

I 55, I56, I 9 I, 200

Prévost 83

Prezzolini 193

Proudhon II

Pullè 30

Rade 83

Ranke 67

Reggio Emilia 17

Rheinland 151, 198

bis 200

Ribot 142

Ricardo 105, 106

Rieseberg 27

Rochdale (Equitable

Pioneers) 9, 10

Roland Holst - van

der Schalk 14,15

Rom 74, 111, 147, 166 
Rom (Antike) 193

Rossi (Cardias) 10

Rostand 67

Rupland 62, 67, I47, 190, 191

Sacher II 5

Saint-Simon 8

Saluzzo I 53

Salvèmini 166

Say 105

Schmoller 81, I IO

Schott I38-I I

Schücking 83

Schulz, A. 32

Schwann I98-200

Schweden 134-137, I99

Schweiz 60

Sebastian von Portugal 200, $20 \mathrm{I}$

Seebohm Rowntree

I I I, II 2

Sergi 129

Shakespeare 67

Shaw 67

Simonde de Sismondi

$6,79,80$, IOI

Sizilien 129
Slavien 72

Smith 118

Sombart 7, 21, 25, 59, 107, I I I-I I 3, I 43, 172, 175, 178, 196, 202

Spahr 108

Spanien 36, 70, 80, 147, 174, 194-196, 201

Spencer 128

Squillace 54,55

Staudinger 16

Sudermann 67

Supino 8, 26

Syveton 170

Szabó 192

Tallon 6

Tanaro 29

Thwaite 58, 59

Tocqueville 112

Tolstoj 67

Toskana 165

Transon 8

Transvadal 204

Treviso 197

Trinidad 172

Troeltsch 19
Tschechen 180

Turin 43, 44, 129

T. W. 145

Ungarn 147, 149

Vaccaro 118

Vallery-Radot 144

Vauban 3, 103

Vendôme $14 \mathrm{I}$

Venedig 147

Venetien 88, 166, 179

Vezzani 90

Vicenza 197

Vico 84

Villermé 6, IOI

Villiaumé 6

Virginia 163

Vlamen 195

Voltaire 195

Weber, Max 192

Weill-Weiß I 54

Weißmann I 6

Wibout 26

Wien 70, 74, 169, 180

Zwehl I8I

Zwiedineck - Südenhorst 18 
Verlag von B. G. Teubner in Leipzig und Berlin

\section{Die Kultur der Gegenwart Ihre Entwicklung und ihre Ziele} Herausgegeben von Prof. Paul Hinneberg

\section{Teil I, Abt. VI \\ Systematische Philosophie}

2., durchgesehene Auflage. [X u. 435 S.] Lex.-8. 1908. Geh. M. I0.-, in Leinwand geb. M. 12.-, in Halbfranz geb. M. I 4.-

Inhalt: Allgemeines. Das Wesen der Philosophie: W. Dil the y. Die einzelnen Teilgebiete. I. Logik und Erkenntnistheorie: A.R i e bl. II. Metaphysik: W.Wundt. III. Naturphilosophie: W. Ost wal d. IV. Psychologie: H. Eb bing a u s.V.Philosophie der Geschichte: R. Eucke n. VI. Ethik: Fr. Pa uls en. VII. Pädagogik: W. Mü n ch. VIII. Ästhetik: Th. Lipps. - Die Zukunftsaufgaben der Philosophie: Fr. Paulsen.

\section{Teil I, Abt. V}

\section{Allgemeine Geschichte der Philosophie}

2., vermehrte und verbesserte Auflage. [X u. $620 \mathrm{~S}$.] Lex.-8 i9 I3. Geh. M. 14.-, in Leinwand geb. M. 16.-, in Halbfranz geb. M. 18.-

Inhalt: Einleitung. Die Anfänge der Philosophie und die Pbilosophie der primitiven Völker: W. Wundt. A. Die orientalische (ostasiatische) Philosophie. 1. Die indische Philosophie: H. Oldenberg. II. Die chinesische Philosophie: W. Grube. III. Die japanische Philosophie: T. I n ou y e. B. Die europäische Philosophie (u. die islam.-jüd. Philosophie des Mittelalters. I. Die europäische Philosophie des Altertums: H.v. A rni m. II. Die patristische Philosophie: Cl. B a e umker. III. Die islamische und die jüdische Philosophic: I. G ol d z i b e r. IV. Die christliche Philosophie des Mittelalters: Cl. Baeumker. V. Die neuere Philosophie: W. Windelband.

\section{Allgemeine Volkswirtschaftslehre}

Von Wilhelm Lexis. 2., verb. Aufl. [VII u. 256 S.] Lex.-8. 1913. Geh. M. 7.-, in Leinw. geb. M. 9.-, in Halbfranz geb. M. 11.-

lnhalt: A. Einleitung. I. Die Entwicklung der Volkswirtschaft. II. Die Methode der Volkswirtschaftslehre. - B. Der Kreislauf der Volkswirtschaft. I. Der Wert. II. Die Nachfrage. III. Die Produktion. IV. Kapitalvermögen und Unternehmung. V. Das Angebot. VI. Die Preisbildung. VII. Handel und Preise. VIII. Das Geld. IX. Kredit- und Bankwesen. X. Der Wert der Geldeinheit. XI. Das Einkommen. XII. Näheres über Arbeitseinkommen und Kapitalgewinn. XIII. Die Grundreate. XIV. Produktion und Einkommen. XV. Krisen. XVI. Die Konsumtion. XVII. Produktion und Verteilung. XVIII. Zukunftsaussichten. Literatur und Register.

Zur näheren Orientierung über das Gesamtwerk stehen auf Wunsch Sonder-Prospekto der erschienenen Bände sowie ein Probeheft gratis zur Verfugung, enthaltend Autoren-Verzeichnis, Probestücke mit Illustrationsproben (auch aus in Vorbereitung befindlichen Bänden). Resümees, Inhaltsverzeichnisse u. Beurteilungen d. bereits erschienenen Bände. 


\section{Verlag von B. G. Teubner in Leipzig und Berlin}

\section{Politik und Massenmoral. Von Dr. Arthur Christensen. Geh.}

\section{Politik und Massenmoral. M. 3-, in Leinwand geb. M. 3.60.}

Das Buch, das den ganzen Umfang der politischen Probleme der Gegenwart be. handelt (so u. a. die der ötfentlichen Meinung, der Parteityrannei und Berufspolitik, des Weltfriedens), dürfte von Interesse für jeden polit is ch interessierten Gebil. det en sein, darüber hinaus aber auch dem $\mathrm{H}$ is $\mathrm{t}$ or $\mathrm{ik}$ er wertvolle Anregungen bieten, wie als Beitrag zu der Frage der sta atsbürgerlichen Erziehung gelten können.

„Die Arbeit ist die eines überlegenen scharfen Geistes, der rücksichtslos den Dingen auf den Grund gebt, der ohne Furcht und Scheu die Wahrbeit, wie er sie zu erkennen meint, sagt, und der eine grobe Summe positiven Wissens in Vorrat hat. Fügt man hinzu, daB Christensens Begabung augenscheinlich eine kritische ist, und $\mathrm{daB}$ er einen "unaufdringlichen" und dabei doch meistervollen Stil schreibt, so ist zus diesen Prämissen der Schluß von selbst zu ziehen, daB Anregung, Belehrung und ästhetisches Wohlgefallen gleichmäBig aus der Lektüre der Arbeit dem Leser erwachsen.

Arbeit und Rhythmus. Von Geh. Hofrat Prof. Dr. Ka rl B iicher.

gr. 8. M. 7.-, geb. 8.-

Es werden die Beziehungen zwischen „Arbeit" und „Rhythmus", Poesie und Musik aufgedeckt, die ebenso überraschend wie einleuchtend sind. Das Buch bietet nicht nur volkswirtschaftliches, sozialwissenschaftliches, völkerkundliches und volkskundiges, sondern ebenso psychologisches, und physiologisches, wie literarisches und vor allem musikalisches Interesse.

„Büchers ,Arbeit und Rhythmus" ist ein Buch, das mit jeder Auflage in seinen Absichten und seinem Gehalt gewachsen ist. ... Auch der jetzt erschienenen vierten Auflage ist eine ausgiebige Durcharbeitung vorangegangen. Der Zauber, den der Stoff, wie Bücher im Vorwort erzählt, bei dieser Bearbeitung wieder auf ihn ausgeübt hat, wird auch den Leser des Buches gefangen nehmen. ... (Frankfurter Zeitung.) Sozialpolitik Von Professor Dr. Otto von $Z$ wiedineck-Südenborst. Sozialpolitik. Geh. M. 9,20, in Leinwand geb. M. ro.-

v. Zwiedineck-Südenhorst bat zunächst einen allgemeinen Teil vorangeschickt, in dem er in drei großen Abschnitten Gesellschaft und soziale Klassen, die Sozialpolitik und ihre Erscheinungsform und das Arbeitsgebiet sowie Ziele, Wege und Möglichkeiten behandelt. Erst dann folgen die einzelnen Probleme. Hier gibt der Verfasser stets außerordentlich objektive Darlegungen der einzelnen Fragen. Er läßt jedes Problem aus den gegebenen Tatsachen entstehen und berücksichtigt die Argumente aller Interessengruppen. So hat der Leser nie den Eindruck eines auf das Gefühl begründeten Plaidoyers, sondern sieht stets nur eine sorgfältig abwägeude wissenschaftliche Untersuchung. Das Buch scheint daher gerade für Praktiker, die sich über die Grundlagen einzelner Fragen unterrichten wollen, geeignet. Aber auch dem Studenten wird es wertvolle Dienste leisten. Ein gutes Register erhöht die Brauchbarkeit.

Soziale Pädagogik. Auf erfahrungswissenschaftl. Grundlage u. mit Hilfe Soziale Pädagogik. Auf induktiven Methode als universalistische oder Kultur-Pädagogik. Von Dr.Pa u 1 Berge ma nn. Geb.M. 10.-, in Halbfrz.geb.M. Ir.6o. „Bergemann schreibt seine Erziehungslehre für entschlossene, vorurteilslose Erzieher, die den Blick auf das Künftige richten, die Ernst damit machen, über all den Schutt und Moder, der sich aufgehäuft, kühn hinwegzuschreitẹn, alles alt und morsch gewordene ruhig dem Verfalle anheim zu geben, und die Überlebtes nicht immer wieder künstlich wiederbeleben wollen..." (Freie Bayr. Schulzeitung.)

Ethik als Kulturphilosophie. Von Dr. Paul Bergemann.

„... A.ls eine besonders liebenswürdige Eigentümlichkeit dieser dem Andenken der Mutter speziell pietätvoll gewidmeten Ethik will es mir dabei erscheinen, daB die Darstellung sich mit deutlicher Vorliebe dem Nächsten und Vertrautesten zuwendet. Der Verfasser will als Deutscher zu seinen Landsleuten sprechen, und so dient dem Typischen, das er schildert, die deutsche Vergangenheit in erster Linie als Vorbild ... Heimat- und Naturfreude und die edle Genugtuung am sittlichen Wirken der großen Kulturgewalten, die still und unablässig sich rühren, geben dem Ganzen einen milden, versöhnlichen Glanz .... Es ist ein gutdurchdachtes Buch, leicht faBlich, populär geschrieben, das den Leser mit Achtung und Vertrauen dem kenntnisreicben, wohlwollenden Verfasser gegenüber erfült." (Dische. Literaturztg.) 
Geschichte der Psychologie Von Dr. Otto Klemm, Privatdoz. Geschichte der Psychologie. für Philosophie an der Universität Leipzig. 8. Igrr. In Leinwand geb. M. 8.-

Eine Darstellung der Psychologie in ihrer geschichtlichen Entwicklung, die 2ugleich den Wert der Probleme der modernen Psychologie aufzeigt, und so ein sachliches Eindringen in diese Probleme vorbereitet.

„Eine Fülle von Tatsachen und Namen baben in dem Buch ibre Stelle gefunden: os kann daher geradezu als Nachschlagewerk dienen und ein ausführliches Verzeichnis der Namen erleichtert diese Benutzung. Trotzdem zerfällt die Darstellang niemals in Einzelheiten, sondern weiB in straffer und klarer Gliederung jedem Detail seine Stelle anzuweisen. Dadurch verliert der Leser niemals den Faden der Entwicklung, und die Lektüre des Buches ist leicht und angenehm. So kann die Bewältigung des vielfach verzweigten Stoffes als eine musterhafte bezeichnet werden; aus so vielon Einzelsteinen er zusammengearbeitet ist, es ist doch ein einheitlicher und klar gegliederter Bau entstanden."

(Archiv für Psychologie.)

\section{Einleitung in die Psychologie der Gegenwart.}

Von Guido Villa. Nach einer Neubearbeitung der ursprünglichen Ausgabe aus dem Italienischen übers. v. Chr. D.Pfla u m. gr. 8. I902. Geh. M. ro.-, in Leinw. geb. M. I2.-

„Das Buch wird im ganzen seiner Aufgabe, eine historisch-kritischo Einleitung in die Psychologie der Gegenwart zu geben, gerecht. In der Behandlung der Streitfragen versteht es der Verfasser, die verschiedenen Richtungen in sachlicher Beurteilung zu würdigen. In einem Buche, das in die Gegenwart einführt, mub es besonders schwer halten, immer objektiv zu bleiben. Der leidenschaftlose, sachliche Standpunkt, den Villa einnimmt, ist erfreulich. Der Stil und die Übersetzung des Buches sind derart, daB sich das Werk leicht und angenehm liest."

(Literarisches Zentralblatt für Deutschland.)

Psychologie als Erfahrungswissenschaft. $\underset{\text { Pofossor }}{\text { Von }}$ Dr. Hans Cornelius-Frankfurt a. M. gr. 8. I897. Geh. M. 1o.-

„Zu den an erster Stelle stehenden Leistungen der psychologischen Wissenschaft gehört auch das vorliegende Werk. ... Es sucht überall die prinzipiellen Fragen der Psychologie zu beantworten und weiB, bei strikter Wahrnehmung der empirischen Methode, den Mechanismus der BewuBtseinsvorgänge in überzeugender Klarheit von den elementarsten bis zu den kompliziertesten Prozessen auf Grund einer Reihe wesentlich neuer Gesichtspunkte und Betrachtungsweisen vor uns zu entwickeln."

(Allgemeine Zeitung, München.)

\section{Fortschritte der Psychologie und ihrer Anwen-} dungen Unter Mitwirkung von Privatdozent Dr. Wilhelm Peters herausdungen. gegeben von Dr. Karl Marbe, o. ö. Professor und Vorstand des Psychologischen Instituts der Universität Würzburg. 6 zwanglos erscheinende Hefte bilden oinen Band im Umfang von 24 Bogen. Preis für den Band 22 Mark. Einzelne Hefte 3 Mark. Erscheint seit 19r2.

Diese Zeitschrift will der Wissenschaft und der Praxis in gleichem Maße dienen, sie wendet sich nicht nur an Fachpsychologen, sondern auch an alle diejenigen Praktiker und Gelehrten, die sich von seiten der Psychologie eine Förderung ihrer Disziplinen versprechen müssen. Sie wird psychologische Untersuchungen aus den verschiedensten Gebieten bringen und nur solche Arbeiten zufnehmen, die nicht auf Methoden beruhen, deren Unbrauchbarkoit durch die Geschichte der Psychologie bewiosen ist. Da es sich gezeigt hat, daB die Psychologie bis heute nur auf Grund des Fxperiments und der Statistik wissenschaftliche Tatsachen und fruchtbare Theorien zutage gefördert hat, so werden auch die "Fortschritte" zunächst und vielleicht immer nur Untersuchungen und theoretische Erörterungen bringen können, die experimentell oder statistisch fundiert sind. 
Verlag von B.G. Teubner in Leipzig und Berlin

\section{Aus Natur und Geisteswelt}

Sammlung wissenschafitl.-gemeinverständl. Darstellungen aus allen Gebieten des Wissens.

Jeder Band geheftet M. I.-, in Leinwand gebunden M. I.25

Einführung in die Philosophie. Von Prof. Dr. R. Richter. 3, Aufl. von Dr. M. Brahn. (Bd. 155.)

Die Philosophie. Einführung in die Wissenschaft, ihr Wesen und ihre Probleme. Von Realschuldir. H. Rich ert. 2. Aufl. (Bd. 186.)

Führende Denker. Geschichtliche Einleitung in die Philosophie. Von Prof. Dr. J. Cohn. 2. Aufl. Mit 6 Bildn. (Bd. 176.)

Die Philosophie der Gegenwart in Deutschland. Eine Charakteristik ihrer Hauptrichtungen. Von Prof. Dr. O. Külpe. 5. Aufl. (Bd. 41.)

Die Seele des Menschen. Von Prof.Dr.J oh.Reh mk e. 4.Aufl.(Bd. 36.) Die Mechanik des Geisteslebens. Von Geh. Medizinalrat Prof. Dr. M. Verworn. 2. Aufl. Mit 18 Fig. (Bd. 200.)

Aufgaben und Ziele des Menschenlebens. Von Dr. J. Unold. 3. Aufl. (Bd. I2.)

Sittliche Lebensanschauungen der Gegenwart. Von weil. Prof. Dr. O. Kirn. 2. Aufl. (Bd. I77.)

Allgemeine Pädagogik. Von Prof. Dr.Th.Zi egler. 3. Aufl. (Bd. 33.) Großstadtpädagogik. Von J. Tews. (Bd. 327.)

ModerneErziehung inHaus u.Schule. VonJ. T e ws. 2. Auf.(Bd.159.) Hypnotismus u. Suggestion. Von Dr.E. Tröm n er. 2. Aufl. (Bd. 199.)

Der Aberglaube in der Medizin und seine Gefahr für Gesundheit und Leben. Von Prof. Dr. D. v. Hansemann. (Bd. 83).

Moderne Rechtsprobleme. Von Prof.Dr.J.K obler. 3.Aufl.(Bd. 128.) Die Psychologie des Verbrechers. Von Dr. P. Pollitz. Mit 5 Diagrammen. (Bd. 248.)

Verbrechen und Aberglaube. Skizzen aus der volkskundlichen Kriminalistik. Von Dr. A. Hellwig. (Bd. 212.)

Soziale Kämpfe im alten Rom. Von Privatdoz. Dr. L. Bloch. 3. Aufl. (Bd. 22.)

Soziale Bewegungen und Theorien bis zur modernen Arbeiterbewegung. Von G. Maier. 4. Aufl. (Bd. 2.)

Geschichte der sozialistischen Ideen im 19. Jahrh. Von Privatdoz.

Dr. Fr. Muckle. 2 Bde. (Bd. 269, 270, auch in I Bd. geb.)

Band I: Der rationale Sozialismus. (Bd. 269.)

Band II: Proudhon u. d. entwicklungsgeschichtliche Sozialismus. (Bd. 270.)

Die wirtschaftlichen Organisationen. Von Privatdozent Dr.

E. Lederer. Bd. 428.)

Statistik. Von Prof. Dr. S. Schott. (Bd. 442.)

Bevölkerungslehre. Von Prof. Dr. M. Haushofer. (Bd. 50.)

Die moderne Frauenbewegung. Ein geschichtlicher Überblick.

Von Dr. K. Schirmacher. 2. Aufl. (Bd.67.) 

